\title{
BIOLOGY AND MEDICINE DIVISION ANNUAL REPORT 1987
}

\section{Lawrence Berkeley Laboratory \\ University of California Berkeley, California 94720}

\section{April 1988}

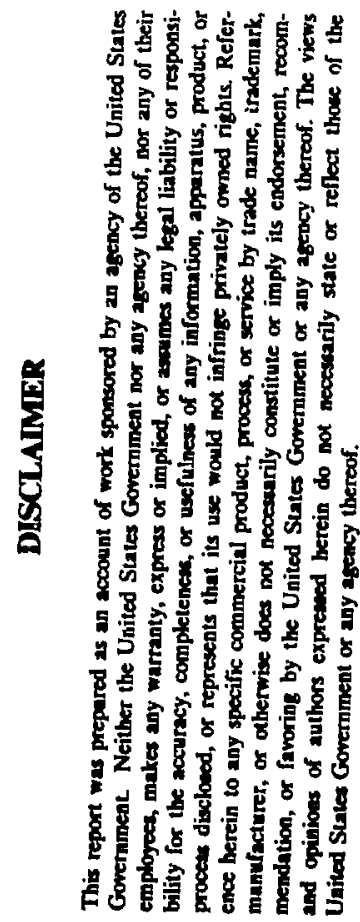

This work was supported by the Office of Health \& Environmental Research of the United States Department of Enercy under Contract DE-AC0376SF00098. Portions of this wort wore also supported by the National Institutes of Health, Department of Health and Human Services, the Armed Forces Radiobiology Research Institute, the National Aeronautics and Space Adminiutration, the Nuclear Regulatory Commisuion, the Office of Naval Research, Ljposome Technologies Inc., and Monsanto. The DOE projects, the contracts and grants with the above, and the subcontracts with the University of California San Francisco, the University of Southern California Medical Center, the University of Coïorado, and Stanford University are listed in Appendix A. 


\section{Preface}

This year an atterist has been made to develop a Biology and Medicine Division annual report that presents a coherent, integrated, and balanced portrayal of the research activities of the Division.

The decisions on the program emphasis for this new format were made by an editorial committee made up of Group Leaders and Deputy Group Leaders. As a result a much heavier burden fell on them as the contact points between the contributors and the Associate Laboratory Director's Office. In this capacity Eleanor Blakely, Mina Bissell,
Thomas Budinger, Aloke Chatterjee, Michael Esposito, Trudy Forte, and Bing Jap deserve special mention.

Credit for the coordination of the overall effort and much of the fine editing goes to Jan DeMoor, as it has in previous years. The efforts and interest of R.G. Barton and the staff of the Technical Information Department contributed in many ways to make this a more readable document than it might otherwise have been. 


\section{CONTENTS}

Introduction 1

Section 1. Structural and Macromolecular Biology ............................................................5

Electron Microscopy and Electron Crystallography .........................................................6

Chemical Element Localization in the Microenvironment of Epithelial Cells ............6

Analytic Electron Microscopy ..............................................................................6

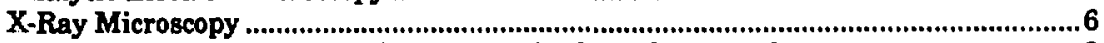

Development of Freezing Techniques for Biological Material .....................................8

Electron Crystallography of Membrane Proteins ...................................................................8

Spectroscopy of Nucleic Acids and Protoins ..........................................................................11

Fluorescence Detected Circular Dichroitm ...............................................................11

Differential Polarization Microscopy of Changes in Structure

of Spermatocyto Nuclei .................................................................................11

The Effect of Speed of Deoxygenation on the Percentage of Aligned

Hemoglobin in Sickle Cells: Application of Differential

Polarization Microscopy ..............................................................................13

Lipoprotein and Menibrane Protein Biochemistry .........................................................13

Lipoprotein Structure and Metabolism ...........................................................13

Genetics and Gene lisxpression of Lipoproteins .............................................................16

Genetic Factors that Influence LDL Subelaws Pattern ..........................................16

Expression of Lipoprotein Genes by Liver Cells ........................................................17

Atherosclerotic Plaque Protein ..........................................................................19

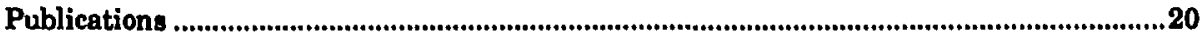

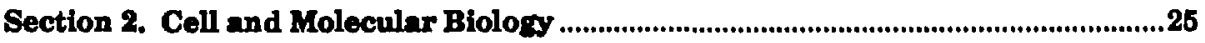

Molecular and Genetic Studies of DNA Damage and Repair ...............................................27

Molecular Mechanisms of DNA Damage by Carcinogens .........................................27

Processing of Letions in the Vicinity of Replication Forks ......................................28

Efficiency of Repair and Transcriptional Activity ................................................28

Oxidntive Damage and Direct Adduct Formation in Carcinogenesis ........................29

DNA Replication and Recombination ..............................................................................30

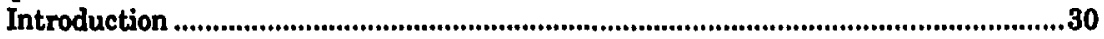

Postreplication Recombinational Repair ............................................................30

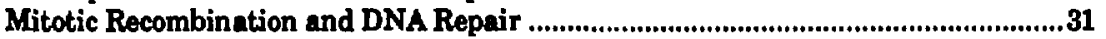

Recombinational Repair Medinted by RAD Genes .............................................. 32

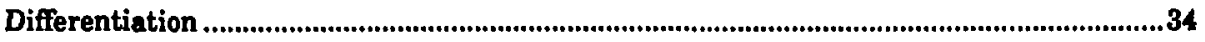

Mammary Cells as a Model for Studies of Gene Expression

and Polarized Secretion ..................................................................................34

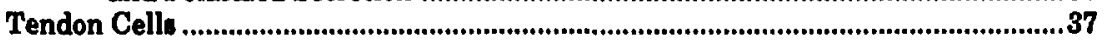

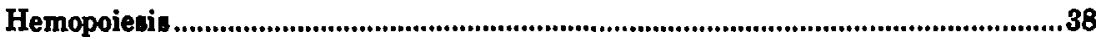

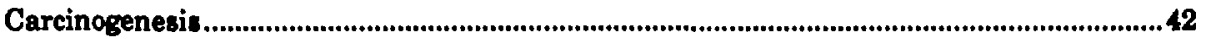

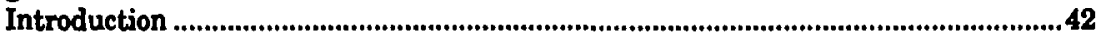

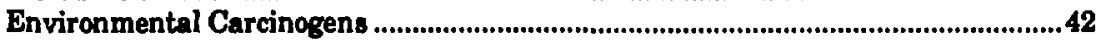

Human Mammary Cancer ........................................................................................4 43

Novel Approaches to Viral Carcinogenesis: Host-Virus

Interactions in Differentiation and Malignancy ........................................43

Publications 


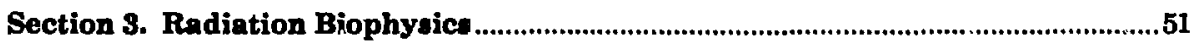

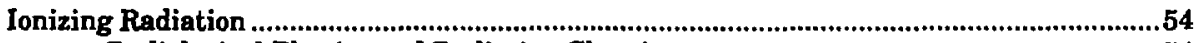

Radiological Physics and Radiation Chemistry ......................................................54

Molecular and Cellular Studies............................................................................59

Theoretical Modeling of Cellular and Molecular Effects .........................................63

Cell Transformation and Somatic Mutation Studies .............................................64

Oxygen-Glucose Deprivation as the Cause of Necrosis in a Tumor Analog ..............65

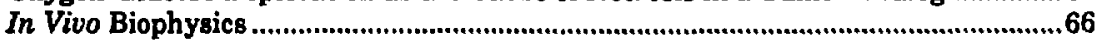

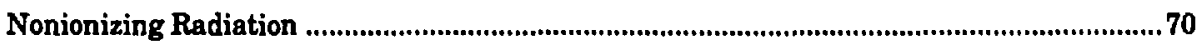

Field-Induced Changes in Membrane Permeability ..............................................70

Structural Changes in Eukaryotic Cell Membranes ............................................70

Cardiovascular Effects .....................................................................................70

Applications of Electromagnetic Fields in Spectroscopy and Chromatography ........ 71

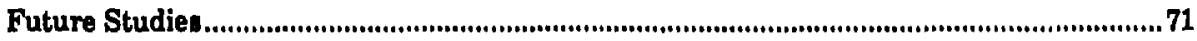

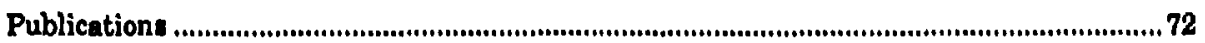

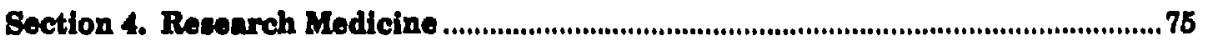

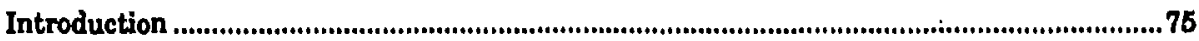

Brain Function and Divease Studies.................................................................................77

Schizophrenia and Affective Disorders ................................................................. 77

Clinical and Metabolic Significance of Cerebral White Matter Lesions Seen on NMR Imaging.......................................... 78

Quantitative NMR Measurements of Brain Atrophy in Normal Aging and Alzheimer's Disease....................................................... 78

Investigation of Cerebral Serotonin Receptor Sites with Radiolabeled Amphetamine Analogt .........................................................80

Differentiation of Actively Growing Tumor from Inactive Tumor In Vivo Using Positron Emistion Tomography .................................82

Quantitation of Hypoxia with Misonidazole Derivatives ............................................82

Heart and Atherosclerosis Studies ....................................................................................84

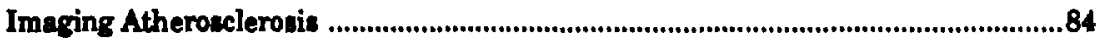

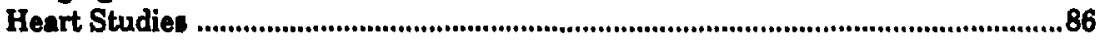

Therapy with Charged Particle Beams ............................................................................88

Review of Heavy Charged Particle Research Trial for FY $1987 \ldots \ldots \ldots \ldots \ldots \ldots \ldots \ldots \ldots \ldots \ldots \ldots . . . .88$

Treatment Planning Developments in Radiotherapy ............................................88

Stereatactic Heavy Charged Particle Radiosurgery ...............................................99

Neurobiological Effects of Heavy Particle Irradiation ...........................................92

Imaging, Instrumentation, and Methods ....................................................................93

New Positron Emiasion Tomograph Instrumentation ..............................................93

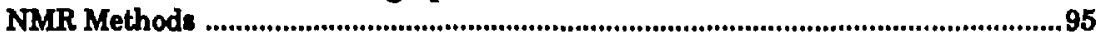

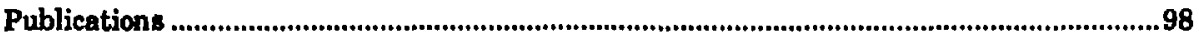

Appendiz A. Project, Contract, and Grant Suppport.........................................103

Appondix B. Biolony and Medicine Division Staff...............................................108 


\section{Introduction}

The continuity and tradition of research in biology and medicine at LBL-devoted to "advancing the application of physics, chemistry, and the natural sciences to biolosy and medicine* (as inscribed on the 1941 dedication plaque of the Donner Laboratory)-was emphasized this past year by the celebration of our 50th Anniveriary. The current research in life seiences at LBL remains compatible with this mision. There is a continuing commitment to basic utudies of biological and molecular function, particularly as they relate to carcinogenesis, mutagenesis, and athero. genesil, to the development and application of advanced nuclear medical tochniques, and to tudies basic to radiation damage and therapy utilizing the unique selection of particle radiation. available at LBL. These efrortis entail application of utate-of-the-art techniques derived from immunology, cell biology, molecular genetics and the traditional disciplines basic to medicine such as biochemistry, biophysics, physiology, and hematology.

\section{Planning}

During the past year, two unusual panels dealt with new and ongoing research at LBL. LBL Director Shirley received recommendations on research in life uciences from the Panel to Explore New Directions (PEND) and from the multicampus Life Sciences Task Force. These reports have recognized the potential importance of life sciences in the future of LBL.

The PEND Subcommittee for Life Sciences evaluated several potential new programs in the context of the LBL/DOE mistion. Their recommendations designated two initiatives as being appropriate for development at LBL at this time. The first was a biotechnology initiative that would utilize strength in 1) molecular and cellular biology at LBL/UCB to explore means for optimization of hout/vector systems for bioprocessing and 2) instrumentation and bicengineering to develop a pilot plant to facilitate scale-up of the optimized systems and to develop noninvasive means of monitoring cellular activity and productivity. The second initiative was a plan to bring to bear the combined activities of several divisions on the question of the extent and biological significance of free radical generation in the environment during energy conversion. The first of these initiatives has received funding from the Director's Program Fund and the UC Biotechnology Research and Education Program for bioprocess engineering. A pilot program in biotechnology will be initiated in FY 1988 that will include components from the Cell and Molecular Biology, Applied Sciences, and Engineering Divisions.

\section{Roorcanization}

The Life Sciencen Tank Force was charged with assessing current stren ths and future opportunities for the LBL life sciences program and to recommend an appropriate organizational structure. The recommendation included retaining and nurturing existing wtrength in chemical biodynamics and in research medicine and to promote cell and molecular biology. A new orgenizational itructure, implemented at the beginning of 1988, escentially embraces the organizational anpects of the Taak Force's recommendations. This new organization bring together, under the leadership of Paul Silverman as Associate Laboratory Director for Life Sciences, those divitions in which the major research effort is in life science. Concurrent with these organizational changes, Life Science was added to Eneray Science and General Science in the LBL milsion statement to reflect the recognized importance of this research area.

Paul Silverman remained head of the Biology and Modicine Division until January 4, 1988 when it was divided into two major research components: the Research Medicine Division, under the leadership of Thoma Budinger, and the Cell and Molecular Biology Division under the direction of Mina Bissell. This organizational structure meets the recommendation of the Takk Force to provide a more prominent role for the research program in cell and molecular biology.

Internal and extemal reviews have recognized the strength in the research effort at LBL and affirmed the appropriateness of its emphasis on research medicine, cell and molecular biology, and structural biology. The opportunity to combine these efforts with research in life sciences in other divisions was explored at a retreat late in the fiscal year. The potential of this integration to develop an even stronger program in life sciences is being realized and will be reflected in next year's report. 


\section{New Initiatives}

Any quality research program requires infusion of new concepts, innovative approaches to ongoing programs, and addition of complementary new initiatives if it is to maintain its scientific stature. In an effort to confront this necessity, several new projects were initiated last year and significant new directions were added to several ongoing programs. The new initiatives include development of a multidisciplinary program to examine the biophysical, cellular, and molecular anpects of radon exposure; the use of molecular epidemiology based on restriction length polymorphism to provide a molecular link to the incidence of familial diceases, particularly atherogenesis and breast cancer, and the addition of the hemopoietic system to the studies of the relationship between perturbations in gene expression and carcinogenesis.

The Human Genome Center became the major new initiative developed in life sciences at LBL during the past year. As a result of this effort, LBL was designated by the Secretary of Enercy as one of the two DOE-sponcored centers for the national Human Genome Project. The Center at LBL is designed to focus strengths in cell and molecular biology, instrumentation, data management and analysis, and structural biology on the formidable and challenging task of physically mapping and sequencing large portions of the human genome. This project exemplifies the new emphasis on the importance of research in life sciences to the total research effort at LBL. The Human Genome Center has the potential of becoming one of the largest single biomedical initiatives attempted at LBL.

In addition to the the two major programs initiated during FY 1987-the Human Genome Center and Cell Transformation by Radon Progeny-several ongoing programs are being significantly expanded. The goal is to encourage the revearch effort in nuclear medicine and in the cellular and molecular aspects of radiobiology, mutagenesis and carcinogenesil, and gene expression.

Specific programs targeted for expansion include advancing our understanding of the mechanisms for repairing damaged DNA, the cellular and molecular consequences of radiation-induced DNA damage, the role in carcinogenesis of perturbations in differentiation, and diagnoatic and therapeutic applications of radiation and related instrumentation developed in research medicine.

\section{Accomplishments}

The research effort in DNA repair was mounted at LBL several years ago with major emphasis in bacterial and yeast systems. This work has progressed and coalesced to produce four new projects on DNA repair, three of which involve human cells. These projects use concepts and techniques refined in simpler systems to increase our understanding of DNA repair in human cells. This is complemented by the expanding effort of radiobiologist at LBL to characterize chemically the damage induced in DNA by various types of radiation, the biological conequences of this damage, and how this damage is recognized and repaired in the cell. The research effort at LBL in gene expression, particularly in mammary epithelial cells, has achieved international recognition. Continued growth of this program is expected, and the emphatis will remain on modulation of the differentiated itate by cytokines, tissue subutrata and other cells, and the role of aberrations in these modulation in carcinogenic processen.

Rewearch in nuclear medicine continues to advance investigations of physiology and disease processes, the development of special instruments to aid in these investigations, and the development of treatment regimens using the variety of radiation sources available at LBL. The use of nuclear magnetic resonance (NMR) for imaging tissues and blood flow was pioneered at $L B L$, and a new positron emission tomograph (The Donner-600) that provides 2.5 times finer spatial resolution than previously ponsible was designed and developed here. A significant expansion of the medicine propram will include the research and development necessary to transfer this instrumentation to the clinic. Construction of a biomedical jeotope facility has been proposed in support of the PET-imaging effort. LBL has the staff necessary to develop radiolabeled imaging agents, but productivity is hampered by the lack of facilities for producing short-lived tracers and inadequate facilities for meeting the demand for synthesis of new and improved PET-imaging agents.

The research on biomedical applications of heavy-ions is at the forefront in testing and refining 
effectiveness as a treatment modality for certain inoperable tumors and for arteriovenous malformations (AVMs) in the brain. The proposed upgrade of the Bevalac, the source of the unique spectrum of charged-particle beams available at LBL, will facilitate the anticipated expansion of this program. One goal of the recent reorganization is to foster a highly integrated program involving heavy-ion therapy in conjunction with imaging by PET and NMR.

There are two major parts to the research effort in atherogenesis. The firnt is to underntand the metabolism of specific lipoprotein subclasses and subspecies and the role of variations in this metabolism, and the underlying molecular and biological cause of these variations, as factors protecting againat or related to the onset of premature atheroaclerosis. The second part is related to this goal. Preliminary evidence indicates that a predominance of small dense subclasses of low density lipoproteins (LDL) in the circulating plasma is related to the risk of cardiovasuclar disease. The objective of this research to test the hypothesis that the patterns of subclasses of LDL are in large measure determined genetically. This hypothesis is being tested by screening for the prewence of various LDL subclasses in carefully defined families and performing both complex regregation analysis in pedigrees and linkage analysis restriction fragment length polymorphisms (RFLP) in DNA.

\section{Technology Transfer}

Another goal of the research effort in life sciences at LBL is to transfer new findings to the medical community and to industry for application in the private sector. Recent examples of this activity in nuclear medicine are the discovery of metabolic aberrations in Alzheimer's disease and the newly defined phenomenon of heart muscle flow rebound in coronary artery disease.

\section{Summary}

Modern biology is characterized by rapid change. The development of new tools and the resulte derived from their application to various biological mystems require significant shift in our concepts and the strateries that are adopted to analyze and elucidate mechanioms. In parallel with exciting new scientific developments our organizational structure and programmatic emphases have altered. These changes and developments have enabled the life sciences at LBL to be better positioned to create and respond to new opportunities. The work summarized in this annual report reflects a vital multifaceted research progrsm that is in the vanguard of the areas reprecented. We are committed to juatifying the confidence expressed by LBL through the now mission atatement and reorganizational changes devigned to give greater prominence to the life sciences. 


\section{$4 / 5$}

\section{Section: 1. Structural and Macromolecular Biology}

The Structural and Macromolecular Biology Group comprises multidisciplinary investigators whose major objective is to understand the structural-functional relationships of biologically important molecules. The breadth of the program ranges from protein structure studies at the level of atomic detail using highly sophisticated electron crystallography techniques to optical opectroscopy methods utilized to study the orientation and structure of proteins and nucleic acids in intact cells. And because protein structure and synthesis in biclogical systems are under the regulation of specific genes, the program examines genetic regulation in the formation and metabolism of specific biologica? structures.

The different research components of our proup and the research affinities of its members are indicated below.

\section{ACTIVITES OF 'THE BTRUCTURAL AND MACROMOLECULAR BIOLOGY GROUP}

Electron Microscopy and Electron Cryatallocraphy

Spectroscopy of Nucleic Acida and Proteins:

Lipoprotein and Membrane Protein Biochemiatry

\section{Scientiats}
J. Bastacky
F. Burkhard
K. Downing
R. Glueser
T. Hayes
B. Jap

S. Bickneso

R. Glaewer

B. Jap

F. Livolant

M. Maestre

A. Nichols

D. Berry

S. Bicknere

T. Forte

B. Jap

R. Kraun:

M. LaBelle

F. Lind gren

T. Musliner

A. Nichols

J. Owicki

M. Robineon

P. Williams
Technical and Staff Craduate Students

J. Barr

G. Gutman

S-H. Kong

C. Lee

G. Perkins

P. Walian

J. Corbett

S.Goolsby
J. Adamson
P. Blanche
R. Celli
D. Chin
G. Giotas
L. Glines
E. Golder
E. Gong
R. Harvey-Turner
S-H. Kong
B. Nordhausen
V. Obie
J. Orr
J. Selmek-Halsey
J. Slack
M. Austin
T. Forte
R. Krauss
M. Labelle
M. McCall

L. Abe
A. Cavanaugh
L. Glines 


\section{Electron Microscopy and Electron Crystallography}

\section{CHEMICAL ELEMENT LOCALIZATION IN THE MICROENVIRONMENT OF EPITHELLAL CELLS}

The chemical elements of the cell's microenvironment are often found to be localized in small particles or microcompartments surrounding the cell. Such localization and compartmentalization can result in individual cell exposure to concentrations of chemical element (or molecules containing such elements) that are quite difierent from the exposure calculated from data obiained by bulk chemical analysis of the extracellular Auids. If certain microcompartments or particles tend to concentrate the element, the individual cell exposure can be strikingly difforent from that ontimated froni macroenvironmental measurements.

The analysis of the elemental compotition of small volumes (on the order of the size of individual cells) has been carried out during the past year using the analytic electron microscope at the National Center for Electron Microncopy (NCEM) at LBL. Both elemental mapping and estimates of concentrations based on characterintic $x$-ray analysis by a thin-film program at NCEM were carried out. The elements $P$ and $\mathrm{Fe}$, as distributed in red blood cells and lung type II epithelial cells, were used as test specimens. Elemental concentrations and distribution can also be determined by using synchrotron radiation ( $x$ rays) to excite characteristic $x$-ray fluorescence or by measuring the absorption edge structure in scanning transmission $x$-ray microscopy. An alternative method of x-ray microscopy imaging uses a contact radiograph (lithograph) to record the information and an electron microscope to read the information from the $x$-ray lithograph. During the past year, investigators in our group provided biological specimens for' synchrotron radiation experiments in collaboration with the LBL Center for X-ray Optics. Progress on both $x$-ray mcanning and $x$-ray lithography methods during the past year are described below.

\section{ANALYTIC ELECTRON MICROSCOPY}

The analytic electron microscope (AEM) is a scanning transmission electron microscope (STEM), JEOL $200 C X$, fitted with both high-angle and ultrathin window $x$-ray detectors and a Kevex 8000 series spectrom. Ler. The beam is capable of penetrating whole cells.
Figure $1.1 \mathrm{a}$ shows the wall from a single lung alveolus in the STEM. The lung had been inflated and maintained under controlled physiologic conditions, then frozen in situ. This sample was frozen relatively slowly by pouring liquid nitrogen over the lung; however, techniques are presently being developed for rapid freezing using a metal probe. Sections of frozen lung tissue were transferred to the opecimen chamber of the low-temperature ecanning electron microscope (LTSEM) in a special vacuum trannfer device currently being designed and developed in conjunction with the AMRay and EMScope corporations. After examination under the electron beam of the LTSEM, final freese-drying was carried out on the stage of the scanning microscope. A single alveolar wall from the lung (approximately $10 \mu \mathrm{m}$ thick and $100 \mu \mathrm{m}$ long) was removed uning microdisuection techniques and mounted between two beryllium grids. Increased magnification of the image [Fig. 1.1(b)] allows selection of individual cells for enalysis by beam spot or raster modes [Fig. 1.1(c)]. Characterintic x-ray peaks were measured to determine the concentration of apecific elements in individual cells.

Figure 1.2 shows two superimponed spectre; one spectrum was sbtained from the red blood cell marked "RBC" in Fig. 1.1(c) and the other spectrum from the type II epithelial cell marked " $T_{n}{ }^{*}$ in Fig.1.1(c). The iron peak $(\mathrm{Pe})$ is present only in the rod blood cell and the phosphorous peak $(P)$ is higher in the epithelial type II cell. The type II cell produces phospholipid surfactant, which is critical in preventing alveolar collapse.

The pattem of $\mathrm{P}$ and $\mathrm{Pe}$ distribution can be recognized more exsily by elemental mapping of the alveolar wall. In Fig. 1.3 the microscope generates a spectrum at each point in $125 \times 64$ raster then each pixel is displayed with an intensity of red proportional to the concentration of iron and an intensity of green proportional to the concentration of phosphorus.

\section{X-RAY MICROSCOPY}

In the past year pilot studies were conducted to assess specimen preparation and mounting for the first trials of $x$-ray microscopy on lung tissue. Sequential correlative microscopy before and after $x$-ray imaging was conducted using the analytic electron microscope and high voltage electron 

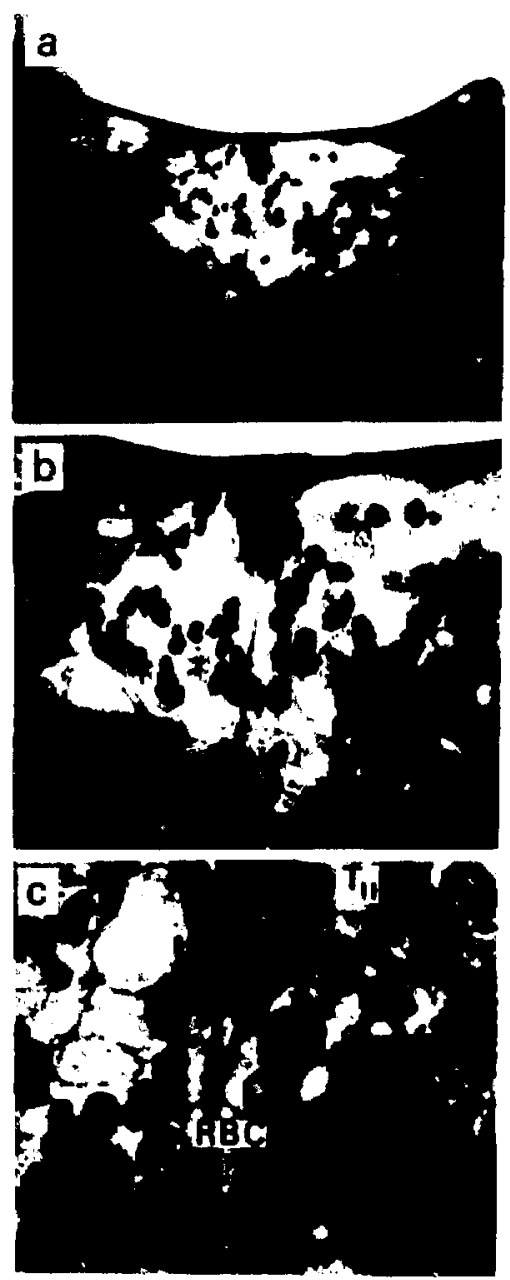

Fis. I.I The scannin trantmiscion electron microwcope transilluminates the wall of a cingle air sac or alvolus from the lung. Red blood alle line up within the thin shet of copillaries that make up this sas exhany membrane. This sample of dos lung was frocen while inflated then frece-dried. No chemical fixatives, stains nor metal coals suere uevd. Digures 1.16 and $1.1 \mathrm{c}$ are increasing marnifications of the center of the field in Fig. 1.1a. Red celle are approximately $5 \mathrm{\mu m}$ in diamuter. The

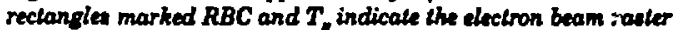
arean during the collection of the spectra in $\mathrm{Ni}, 1.2 . R B C$ is the red blood cell, $T$. the alvedar epilhelial Type II cell. QABB 882. 866)

microscope at the National Center for Electron Microscopy. Freeze-dried alveolar wall preparations similar to those described above were photographed in the transmission light microscope and examined
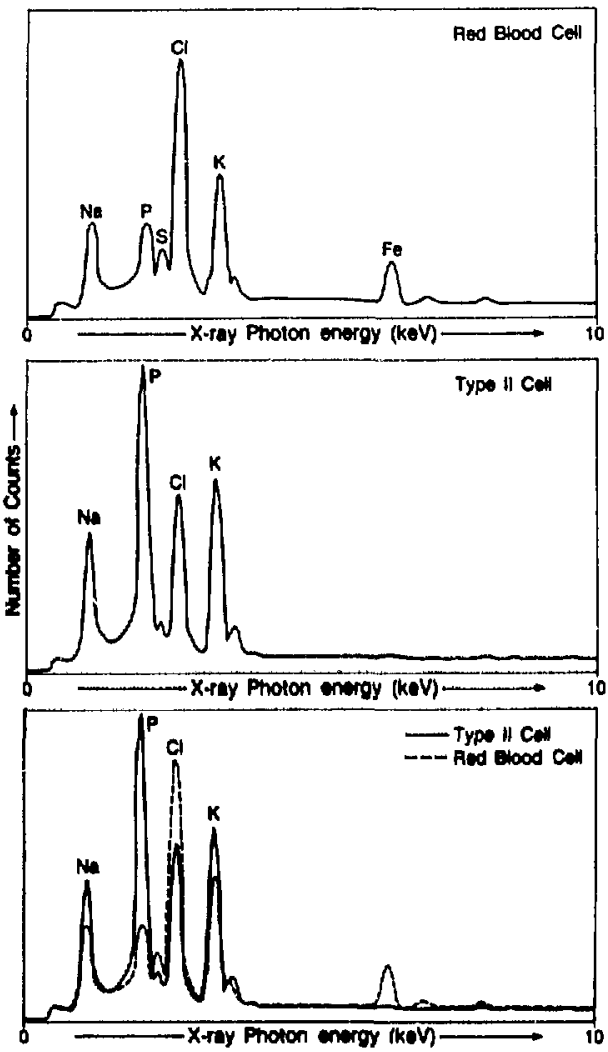

Fi. I. Characleristic x-roy fworecence spectra from red blnod coll and aluelar epilhelial type II cell in Fig. 1.1. OCBL 881-7940)

with the LBL prototype scenning $x$-ray mieroscope system operated by the LBL X-Ray Optics Group at the National Synchrotron Light Source at Brookhaven National Laboratisy. This instrument was able to focus monochromatic $x$ rays to an elliptical spot of $10 \times 5 \mathrm{\mu m}$ and to scan this spot in a line across the alveolar wall, taking a characteristic $x$-ray opectrum at each of 12 to 14 points aiong the line. The specimens were returned to LBL, the lung was mounted on Be grids, and the same area was analyzed with the AEM. X-ray spectra excited by the AEM electron beam were compared with those excited by the $x$-ray beam. STEM images were compared with the original transmission light images. The sample was also transilluminated by the $1.5-\mathrm{MeV}$ electron beam of the high voltage electron microscope to obtain fine structural detail as a first step in the evaluation of beam damage with the scanning $x$-ray microscope. 
(a)

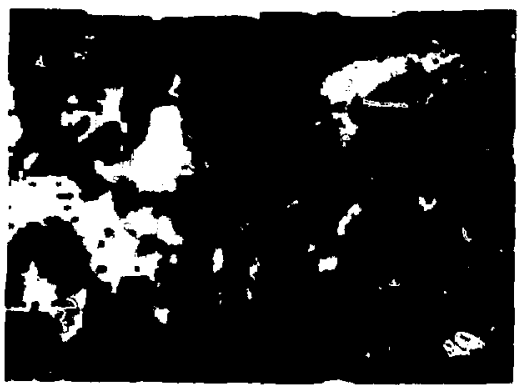

(b)

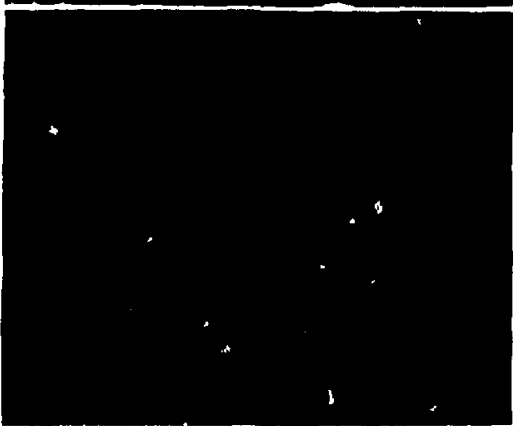

N5. 1.t. (a) Digitaliend inage of the come alwoler wall in Nip. 1.1(c). The aralytic doctron micromeope collects a charocteristic $x$-ray epectrum at mach point in the $195: 561$ pixel feld then in

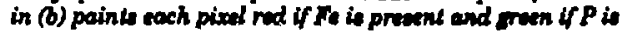
present. In this x-ray map of the alvelar wall, the intendity of color at each point is proportional to the amount of the element present. In the above block and white print of thio map the distribution of the derments is still dicesmithe but the pattem in much lose evident than in the oryinal. (C.9ll 800.1346 )

\section{DEVELOPMENT OF FREEZING TECHNIQUES FOR BIOLOGICAL MATERIAL}

A joint study with Dr. Patrick Echlin at the Botany School, Cambridge University was directed toward a better understanding of the cellular changes that take place in specimens held at subzero temperatures during microscopic examination and analysis. Relatively unaltered biological material can be cryofixed at temperatures from -20 to $-2^{\circ} \mathrm{C}$, held at the fixation temperature until cellular electrolyte equilibrium is estrablished and then snap-frozen for analysis by SEM-characteristic x-ray techniques. The experiments were carried out uning primordial tisnue found in the low-tem. perature-resistant turion or bud of the aquatic plant Lemina (Duckweed), which had been the opecimen used in previous studies of frozen hy. drated material examined at linuid-nitrogen temperatures. Viability atudies were carried out in the upper ice-temperatura range and the transition from liquid to solid phase was monitored on individual turions by mierocalorimetry and thermal analyais of the exotherm that accomnanies the freezing of the supercooled tiesue. Preliminary results indicate that the furion of Lemna is an excellent tout apecimen for experiment that would develop tochniques fo: the eximination of unaltered biological upecimens by nof $x$-ray mimroncopy.

T. Hayes and J. Bastachy. Affliate Members: $J$. Goerke (UCSF) J. Underwood, \&. Thompsoi, $R$. Giacue,Y. Wu., and $\mathbf{X}$. Howells (Center for X-ray Optice, LBL), C. Echer (NCEM, LBL).

\section{Electron Cryotallotraphy of Membrane Proteins}

Electron crytallography has boen used widely in structural studies of biological molecuies at a resolution of $20 A$, and in a fow crees to somewhat better then $10 \mathrm{~K}$. Information obtained at that resolution is useful in identifying major structural domains. However, the full underntanding of functional mechanimm of protein molecules requires a knowledge of molecular structure in atomic detail. Electron crytallography has great potential to become a powerful technique for determining the atomic structures of membrane proteins. The best resolution that is currently attainable by the electron crystallography technique is about $6-7 \mathrm{~A}$, which is somewhat short of that needed to discern the atorsile structure of the proteins. Until recently, weveral problems havi: limited the attainable resolution.

In the past year, technical breakthrougtis haye been made in elostroin cryatallography for determination of atomic structures of mombrane protein. The first is a technique that improves the aignal-tonoise ratio of the high revolution details in the images of biological samples, thus allowing high resolution images $t w$ be routinaly ohtuined; the 
other is the crystallization of membrane protein: for nolecular structure determination. These breakthroughs have contributed major ateps toward making electron crystallography become a routine technique for molecular structure determination of proteins.

Specimen movement that occurs in response to incident electron radiation has been a major problem in obtaining high resolution images of biological sumples. It has long been known that rudiation damage limits the resolution of images of organic specimens. This damage result ir kreakage of covalent bonds and puts atress on the specimen. These effocts produce movement in tho upecimen during electron radiation that results in umearing of the imsere and a resulting loss of contrast of the high resolution details. To overcome this problem, a small-spot illumination technique was roveloped that produces a dramatic increase in the contrast of high resolution details of imseges. This is demonstrated by the quality of images of a monolamellar parafin crystal obtained in thit way (Fig. 1.4). The crystalline lattice spacing of $3.7 \mathrm{~A}$ is clearly visible in these images. In contrast, wuch a lattice spacing is not visible or appears with much lower contrant when images of parafin crystals are obtained saing conventional methods. The umallspot technique has recently been applied to obtain high resolution images of bacteriorhodoprin, a light-driven proton pump, and of outor membrane

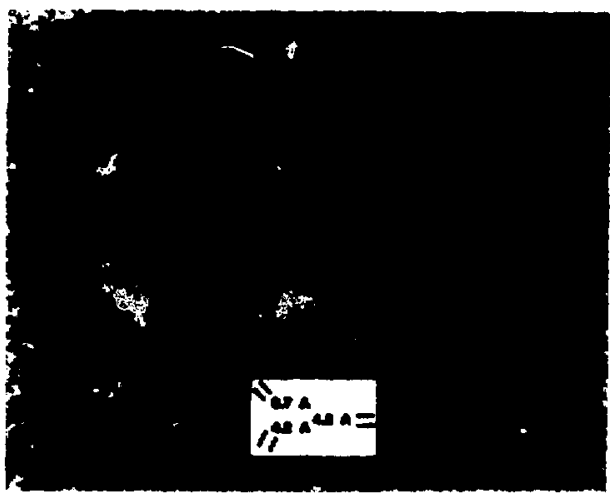

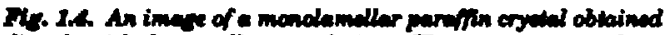
dincetly with the encll pot technique. The imese is comewhor:

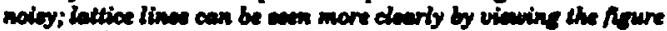

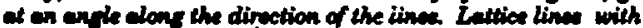
epweins of 3,7 and 49 A as indionded ere vivible. The dark coots at the internctions of lines correupond to the inace of the parefin chains wen end-on. (XBB 876-699) channels from $E$. coli. The small-spot technique therefore provides a major step in developing electron crystallographic technique for routine three-dimensional structure determination at the atomic level. This technique can be similarly applied to improve the contrast of high resolution details for crystalline fibers, such as actin filaments and microtubules. Images of these samples have been limited in the past to give low resolution details as a result of specimen movement and of radiation damage. The small spot technique opens a new dimenoion to electron crystallographers for structural determination of biological macromolecules.

Specimen flatness and/or the interaction of biological samples with tho support film have reduced the success rats of obtnining high vesolution images and the diffraction pattern of bacteriorhodpsin in purple membrane at high tilt angles. Images at various tilt angles are needed in order to obtain the three-dimensional molecular structure. The successe rate of obtaining high resolution images diminishes at increasingly high tilt angles. This is now the only known limiting factor in obtaining the high resolution structure of bacteriorhodopsin by electron crystallographic methodm. A recent study focuses on ways to change the surface properties of the support film to ensure thet the ample remains flat. The use of support films with holes and the frowen hydrated opecimen technique have provided some encouraging reaults, but further work is needed.

Cryatallization of membrane proteins forming two-dimentional cryatals is a necesuary step in obtaining the three-dimentional molecular structure of a protein by electron cryatallography. Cryatallographic averaging provides a way to enhance the signal-to-noise ratio of high resolution dotails with a minimum dose of electron radiation, damege from which limits the dose allowed to obtain hich resolution structural details of biological ramples. In the past, purple membrane, which naturally forms highly ordered arrays, was the only epecimen from which one could successfully obtain a high resolution structure to $6 \mathrm{~s} \mathrm{~A}$ by electron cryatallography. There was an urgent need to show that membrane proteins that are not naturally cryntalline can be reconstituted to form twodimensional crystals that diffract to high resolution. Such reconstitution has now been successfully done for a membrane protein, PhoE porin, and the crystals diffract to at least $3.4 A$ (Fig 1.5).

The specimen flatness problem, which clearly hindered progress in obtaining high resolution data 


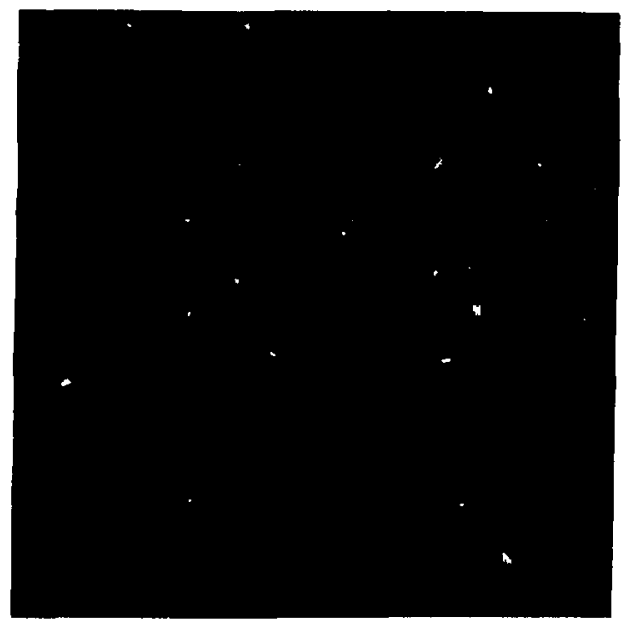

Fy. 1.t. A high revolution dection diffrection pattern of Phos porin embeddad in glucow. The peltern has been procened by compuler to raduce the both round intencity, The diffraction paltem was obloined at a temperature of $-120 \mathrm{C}$. The patlerm thowe reflection extending to at lea $3.4 A$. (ABB 870-10681)

at high tilt angles for bacteriorhodopsin, appears to be less severe for PhoE porin. It was possible to obtain high resolution diffraction of PhoE porin at 45 degrees tilt without significantly degrading its quality. The interaction of the PhoE membrane with the support film as compared to that of bacteriorhodopxin may be the main difference: bacteriorhodopsin cryatals diffract only when the support film is hydrophobic while PhoE porin crystals diffract even when the support film is highly hydrophillic. It is currently believed that the surface properties of the support film and of the sample susponsion determine the degree of stress on the support film, rewulting in varying degrees of bencing of the support film. The bending of the support film, in turn, rewult in the fading of the diffraction pattern as the sample is tilted.

Significant progress has been made in obtaining a high resolution three-dimensional structure of PhoE porin. A projection map of PhoE porin (Fig. 1.6) with a resolution better than $10 \mathrm{~A}$ has been obtained. The projected map shows that the structure of porin convists of a hollow cylinder with outer diameter of about $40 \mathrm{~A}$. The diffraction pattern of PhoE porin shows strong reflections at approximately 4 and $10 \AA$ sugesesting that the $\beta$ sheets, which are known to make up its secondary structure, are oriented approximately normal to the membrane plane. Assuming that the cylindrical

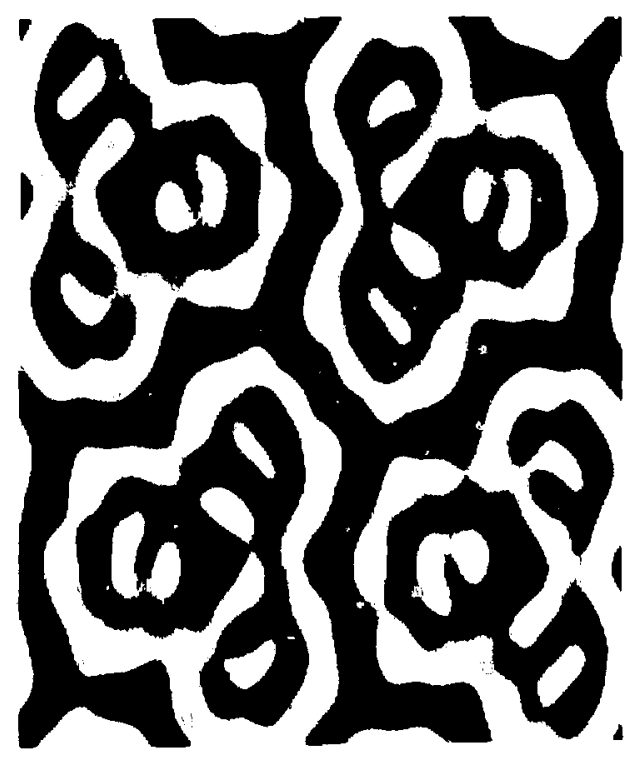

Hy.I.C A projocted map of Phos porin embeddad in glucave. The map is oblained from an imare by computer proceseing that anhances the contrat. The efruciural information is limited to a recolution of about $10 A$. There are four trimers in a unit cell. Each trimer eppeare as thre cylindrical atructume (dark ringo) of $B$ shet, where the central dark region of each cylinder repre. cente a glucoen-filled chaned. (XBB 881-8)

structure extends across the membrane, about $40 \mathrm{~A}$ thick, the number of $\beta$ strands needed to form such a hollow cylinder is about 19 , each strand being 12 residues long. The total number of residues needed to form such a channel is about 230. Since PhoE porin consiats of 330 residues, there are about 100 remaining residues for linker peptides and for forming a possible gating structure. This type of model is consistent with our three-dimensional map of negatively stained $\mathrm{PhoE}$ porin at a resolution of better than $20 \mathrm{~A}$. Our three-dimensional map hows trimeric channels, each of which is about 35 $A$ long and $20 \mathrm{~A}$ wide. The trimeric channels traverie the membrane, but they do not merge. Each channel probably has an extended narrower segment that may play an important role in both its molecular selectivity and possible gating mechanism. Currently, the three-dimensional structure of $\mathrm{PhoE}$ porin at high resolution is being determined in order to provide more detailed information about the molecular design of the channel.

Great effort has been given to crystallize halorhodopsin (hR), a light-driven chloride pump. Reconstituted hR with lipids, extracted from purple 
membrane, forms two-dimensional patches, indicating that our crystallization condition is not too far from the ideal one. The reconstituted patches have not yet shown any ordered arrays. Work is currently underway to refine the crystallization protocol in order to obtain well-ordered crystals.

A new project has been initiated to purify mitochondrial transport enzymes, the adenine and phosphate transporters, for subeequent cryatallization into two-dimensional cryatals suitable for electron crystallographic atudies. When these proteins have been purified to homogeneity, attempts will be made to crystallize them following the same technique that has been used successfully in the reconstitution of $\mathrm{PhoE}$ porin into crystals. The natural abundance of the two transporters in mitochondria from beef heart and their stability when purified are certainly positive factors for successful two-dimensional crystallization.

Rabert M. Glaeser, Bing K. Jap, Kenneth Downing, and Edward Berry. Affiliated Members: Paula Flicker, Peter Walian, and Seok-Hwan Kong.

\section{Spectroncopy of Nucleic Acide and Protein.}

\section{FLUORESCENCE DETECTED CIRCULAR DICHROISM}

Fluorescence-detected circular dichroism (FDCD) is a pewerful tool for atudying the structure of proteins that possess fluorophores wuch as the amino acid tryptophan. In normal FDCD measurements, a large part of the fluorescent signal is lost by the phenomenon of photoselection. This latter spectroscopic artifact arices when fluorophores are excited by linearly polarized light and emit anisotropically due to lone rotational times and transition dipoles that are closely aligned with the plane of polarization. Residual linearly polarized light occurs in most FDCD instruments, thus decreaning senvitivity. $A$ technical breakthrough has been made in the part yoar by membere of our epectroscopy proup in developing an ellipsoidal mirror syutem that virtually eliminates the signal from photoselection. The design of the elliptical mirror aystem that is placed incide the sample chamber of the Jasco spectropolarimeter is schematically shown in Fig. 1.7. Fluorescent emission reaching the photomultiplier tube is increased by a factor of 18 . By increasing the signal-to-noise ratio, the mirror assembly will be extremely useful for other forms of spectroscopy, and will be important for resolving the structure of complex biological macromolecules. Experiments are presently underway to study the tructure of apolipoproteins and changes induced in the structure of the protein molecule during interaction with specific lipids.

\section{DIFFERENTLAL POLARIZATION MICRCSCOPY OF CHANGES IN STRUCTURE OF SPERMATO- CYTE NUCLEI}

Phase-dependent forms of microscopy (phase contrast, interference, polarization, and so forth) have been used for many years; they use the amount of phase retardation to measure the isotropic or anisotropic index of refraction. Investigators in our group have developed a microscope that forms images dependent on small differences in extinction for different forms of incident polarized light. By modulating the polarization of incident light on the sample and digitally recording the

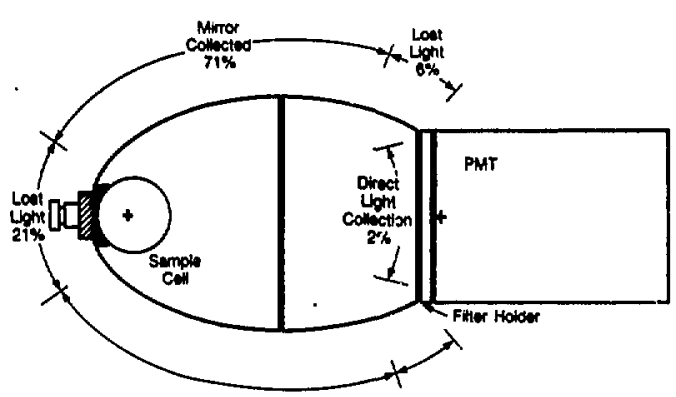

Pr. 1.7. The basic ellipaidal mirror configuration showing the eample all with its collar, the modification of one mirmor, and the position of the photomultiplier tube $(P M T)$ ( + indicates the ellipwidal foci). The positions and pencentages of light collection and lose are aleo indicated. (XBL 875-7731) 
difference in intensities of transmitted light, images have been obtained that reveal epecifically either linear or chirally ordered structures. Linear polarized light, incident alternately with two perpendicular direction of polarization, forms images of structures that have linear order or linear orientation. Right and left circular polarized light incident alternately on a sample forms imuges of chiral structure. Structures with neither linear order nor chirality are essentially invisible. Thus, linear dichroism, circular dichroism, and linear and circular differential scattering imagec can be used to detect specific types of structures that may be obecure by conventional methode. The structure of the nucleolus (the site of RNA synthenis) in live primary spermatocytes of Drocophile when they are tranecriptionally active and inactive has boen elucidated by linear and circular difforential

(a)

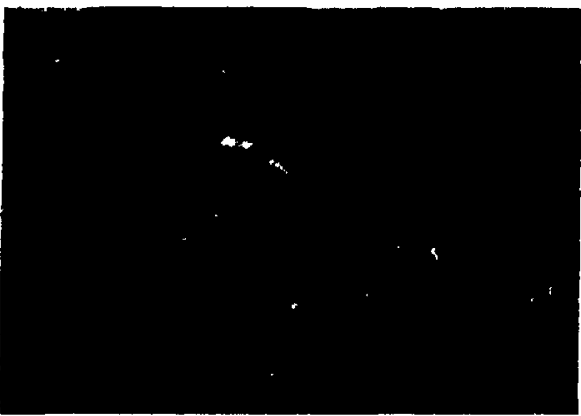

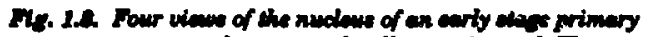
spermatocyte: more than ten axch celle ware ingend. The

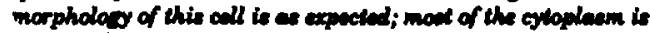
containad in a small rayion etll atbehad to part of the grot above. The nucieus (with its prominent nudiolue) bahse up the remainder of the call. The nudeolus ( $n$ ) and the premimed $Y$ chromovome $(Y)$ are labelad. (W) The tranomionion imare of a primary epormatocyte. The field of view in the differmitial imares is $7 \mathrm{~mm}$ on wech side; the wevelength wod to imere is $150 \mathrm{~nm}$. The while bar with the diffirential image is $2 \mathrm{~mm}$ lons. A squere outtinas the area of this coll thet was imaged in the differential polerisation imagen. Both linear and circular difforential extinction are color codid with blue (WL) repromentins +0.008 10 0.0; yellow (ol) reprewents 0.0 io 0.008 . (b) A circular differential imags ehowing the nucleolus and pert of the $Y$ chromovome. (c) A linear differential imase of the cane arna in (b) showing the inde domain nucleolus (center, yollow) and part of the la mpobruat chromosoine (upper right, blue). (d) The imare of the amownt of lnowarly aligned material. The imare is obtaind from two linear dichroism imean [one is shown in (c)] with the principal anes of polarisation differing by 15 de snw. The norm of these two images sives the amount of oriented maverial independent of the dincetion of orientetion. The nucisolus and part of the lempbrueh chromosome are readily viable in (a) through (d). Note that the cirallar and linear differential imase show different etructures at this stage in development. [( $a) X B B$ 860-8866, (b,c,d)XBC-869-7926] imaging techniques. The active nucleolus is separated into regions of differing amount of linear and chirally scattering material while the inactive nucleolus and the heterochromatic region of the $\mathbf{Y}$ chromosome show the same uniformity of linearly and chirally scattering material (Fig. 1.8). Thus polarization-dependent images reveal structures that correlate with the transcriptional activity of colls.

(b)

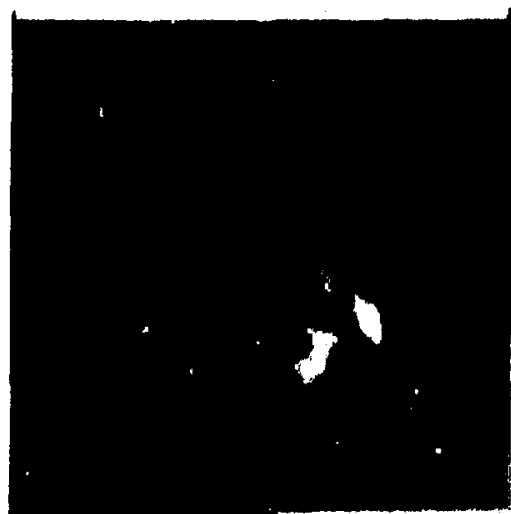

(c)

(d)

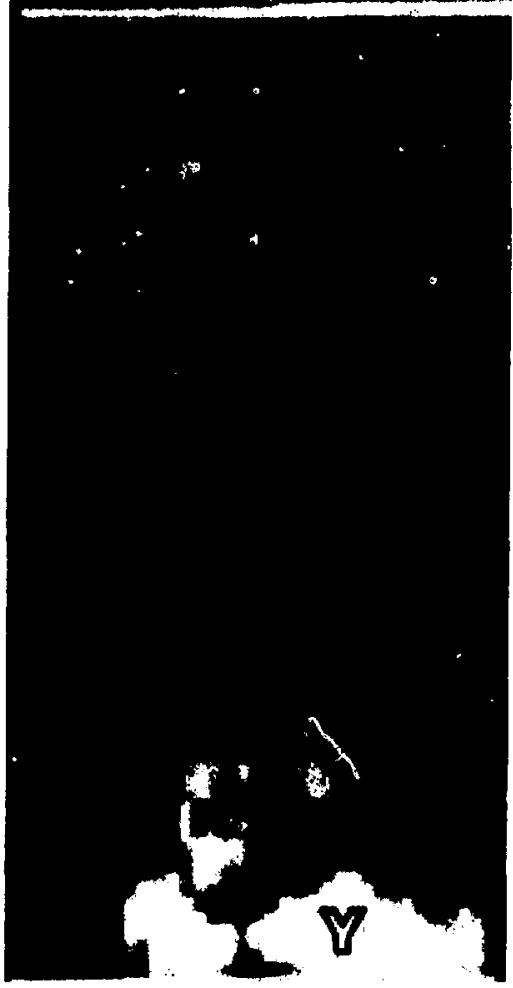


THE EFFECT OF SPEED OF DEOXYGENATION ON THE PERCENTAGE OF ALIGNED HEMOGLOBIN IN SICKLE CELLS: APPLICATION OF DIFFERENTIAL POLARIZATION MICROSCOPY

Differential polarization microwcopy (linear dichroism) has boen used to moasure the percentage of aligned hemogtobin $(\mathrm{Hb})$ in 1086 deoxygenated red blood cells from subjects with sickle cell anemia. The percentage was found to be only alightly dependent on the apeed of deoxycrenation, thus whowing that the percentage of aligned $\mathrm{Hb}$ was thermodynamically controlled (at has boen found previounly for the percentage of polymerized $\mathrm{Hb}$ ). The alight docrease in the percentage of aligned $\mathrm{Hb}$ due to increasing speed of deoxygenation is primar- ily due to the increase in number of cells containing no detectable aligned $\mathrm{Hb}$. This class of cells was also the most variable between the different subjects atudied. Two other groups of cells were identified that contain different numbers of domains of aligned $\mathrm{Hb}$, and theme groups contain statistically different percentagen of aligned $\mathrm{Hb}$. The differences between these clasues of cells were shown to be primarily due to different numbers of initial nucleation sites within each cell. It appears that the presence of preformed nucleation sites within cells at room oxygen tention results in the thermody. namic control of aligned $\mathrm{Hb}$ polymer.

Marcas Maestre, William Michols, Stephen Bicknex, and Alex Nichols. Affiliated Member: Ignacio Tinoco (Chemical Biodynamics, LBL).

\section{Ifpoprotein and Membrano Proteln Blochemistry}

\section{LIPOPROTEIN STRUCTURE AND METABO- LISM}

Lipoproteins are macromolecules that tranuport triglycerides and cholenterol in the planma. Normally these lipids are important as nources of energy for cells, and they are required for cell growth and repair. However, it is well known that exaggerated levels of plesma lipids, particularly cholesterol, increase riak to atherosclerosic. Lipoproteins do not represent a single population of particles but rather are best described as distinct families or claseses that are distinguished by the protein(s) called apolipoproteins (apo), ascociated with the lipid. The protein associated with the lipoprotein ultimately determines the metabolic fate of the particle:

The metaboliom of various lipoproteins and the interactions between classes of lipoproteins are extremely complex. Abnormalities in lipoprotein metaboliam or procensing can lead to the onset of atheromeleronin. The complexity of lipoproteins and their role in atherogenenis is schematically repre. mented in Fig. 1.9.

The goal of investigations in the lipoprotein subgroup is to underatand the origin and fate of specific lipoprotein subclasses and subupecies, and their contribution as possible riak factors in atheromclerosis or their capacity to protest against premature atherosclerosis. To this end, membern of our group are carrying out extontiye in vitro modeling tudies in order to delineate how lipoprotein macromolecules are anuembled and subeequently modified by specific ensymes.

Plasma HDLt are asmociated with decreased risk to premature stherseclerosis; this property of HDL has led to atudies aimed at understanding the structural-functional aspect of their molecules. Extennive progress has been made in understanding the origin of epecific high density lipoprotein cubclances. HDL are composed of at least five different components and are ascociated with three major apolipoproteins, apo AI, AII, and E. Specific details on conversion of apo AI (or AII or E) precursors to representative plarma components have boen delineated with protein-lipid models interactod with the enzyme lecithin:cholenterol acyltranuferase (LCAT). Model complexes formed with three apo AI molecules, phospholipid, and cholenterol are discoidal atructures, of 13.5-nm diameter. Following incubation with LCAT, apheres of 9.2-nm diameter that contain three apo A molecules are generated (Fig. 1.10). Starting with discoidal complexes containing two apo AI 
MAVOR LIPOPROTEIM PATHWAYS INYOL VED IN ATHEROSCLEROSIS

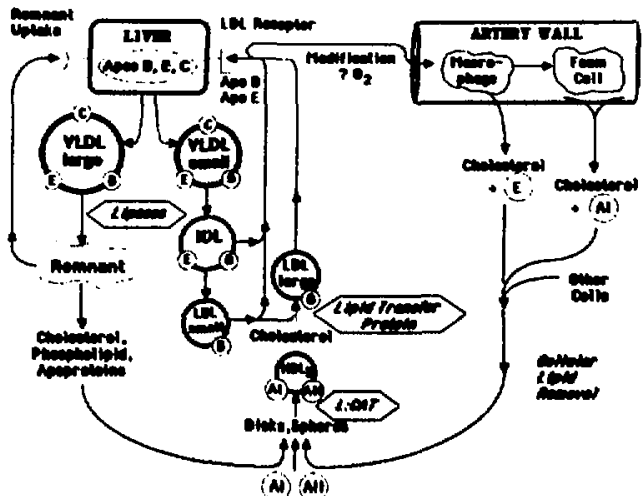

Dy. 1.D. Schamatic of major llpoprokin pathuags involued in atheroclerate. The liver is the mator counce of apolipoprotein (apo)B, $E$, and $C$. The major particlen coeneled bs the liver are trislyceride-rich atruchure, VIDL. VLDLthislyceride in hydrolyad, thus forming omaller pertides, includisy IDL and $L D L$, that traneport mont of the binod't cholecterd. $L D L$ that are abnormally modified in the blood ars thought to be talmen up by arterial macrophers that then give rive to foam calle that are

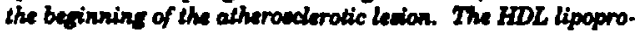
teine areacialed with apaAl and apadI are believed to ramove excess cholcterd from callo with the help of apoll, which is gntheaied by many calle and is belleved to tranport cell cholesteral into the blood. The HDL are of ten termed "rood" lipoproteins becenee of their ability to reverse choleoterol transport, i.e., remove it from alle. The precureor HDL asaciated with cholesteral is diecoidal in thepe but is rapidly sonverted to the mature epherioul HDL by the mome ixcithinscholevterol acyltrarsferase (ICAT). The cholesteral cccumulating in large HDL is tranefermed to $L D L$ and is ultimately derraded in the liver. (BBC 8710-8578)

molecules, LCAT produces a wherical product 8.5 $\mathrm{nm}$ in diameter that contains three apo $\mathrm{AI}$ molecules per particle. During transformation, fusion occurs with the formation of a particle containing three apo AI molecules and the liberation of one apo AI. The properties of the core-containing particles (opheren) with three apo AI molecules clonely resemble those of the major plasma apo AI without apo AII HDL subpopulation, which also contains three apo AIs and is between $8.2-8.8 \mathrm{~nm}$ in diameter. This apo AI HDL model atrongly suggests that three apo $\mathrm{AI}$ proteins are required to stabilize an HDL core containing 13-22 cholenteryl ester molocules. Model complexes employing apo AII were developed to study the molecular dynamics of HDL particles containing this protein. Normally, plasma apo AII is found in asuociation with
A O hr $0.544(13.5 \times 4.4 \mathrm{~nm})$

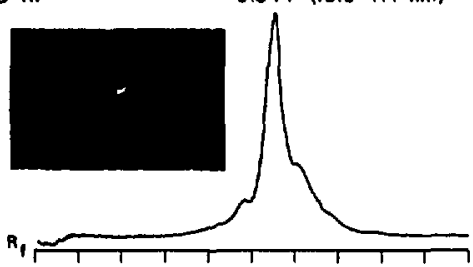

B $6 \mathrm{hr}$

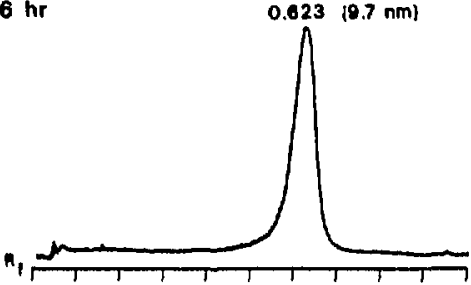

C $24 \mathrm{hr}$ $0.605(9.2 \mathrm{~nm})$

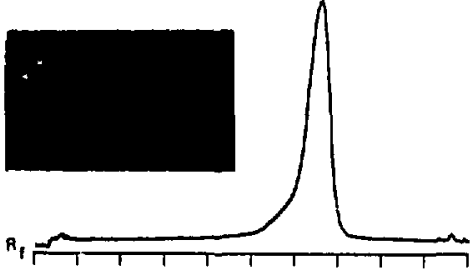

D $24 \mathrm{hr}+\mathrm{LDL}$

$0.722(8.6 \mathrm{~nm})$

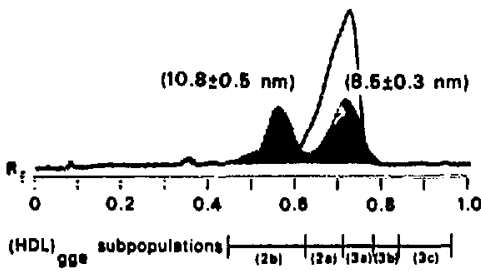

Fy. 2.20. Gradient gel elsetropharesin patterne of tranformaticn products from fractions ioclated from incubation mirtures compriand of three apadl-uneterified cholenterol complexes, partially purified LCAT, human werum albumin, and $16-\mathrm{mM} b$. mercaptoethenol. Pattern correspond to the following incubation (37 C) pertode: $(A) \mathrm{O} \mathrm{hr}$; $B$ ) $6 \mathrm{hr}$; and (C) $24 \mathrm{hr}$. Electron micrographs (Formuar erids) of material in froctions from $0 . h r$ and 24hr misturw are shown with corresponding electro. phoretic patterns. Pattern (D) is of 24-hr transformation product isolated from mirtures with wame composition as in (A)-CC) above, but containing LDL as cource of additional cholesterol. The shaded pattem in (D) is a schematic representotion of the $R$, dittribution of the two major subpopulations observed in the human plasma HDL population containing apaA-I without apaA-II (LP(A-I without A-II)). For reference, the particle sire intervals of the major subpopulations of total HDL are indicated below pattern (D). (XBL 866-1890) 
apo $\mathrm{AI}$, except for the genetic abnormality in which apo AI is not synthesized. Using cholate dialysis for association of apo AII and phospholipid, several discrete complexes are generated. These complexes, which probably mimic nascent apo AIIcontaining HDL, are separated by gel filtration into subfractions that have specific numbers of apo AlI molecules and electron-microscopic size. The minimum number of apo AIIs required to stabilize the discoidal HDL is three; with increasing disc diameter the number of apo AII molecules per particle increases. The well-defined apo AII model complexes are currently being uned to underntand the role of this protein by itself and in association with apo AI to participate in formation of plasma. HDL ubpopulations.

Apo $\mathrm{E}$, which is known to play a role in reverse cholesterol transport is al so currently under investigation. Model complexes are boing generated that promise to be extremely usoful in understanding formation and procesting of apo E-rich HDL. In addition, collaborative atudies on the physicalchemical properties of apo $\mathbf{E}$ have been carried out with investigators at the Gladatone Foundation, San Francisco. This 34,000-dalton protein is readily fragmented into two proteolytic fragments of $10 \mathrm{kDa}$ and $22 \mathrm{kDa}$. The $10-\mathrm{kDa}$ fragment aggregates into tetramers while the 22-kDa portion remains monomeric and has a globular conformation. This important work indicates that the protein has two independently folded domains that muy mediate its lipid and receptor-binding functions

Unlike HDL, the lower density lipoprotein classes contain subpopulations that are positive risk factors for coronary artery disease. Important breakthroughs have been made in the past year in understanding the intricate interrelationships between subpopulations of very low density lipoproteins (VLDL), intermediate density lipoprotein: (IDL), and low density lipoproteins (LDL). LDL consist of a spectrum of several subpopulations on nondenaturing gradient gels as outlined in Fig. 1.11, where peaks I and II are large less dense particles and LDL-III and IV are small denser particles. As indicated in Fig. 1.11, IDLs appear in the region before LDLs and are precursors of LDL subspecies. A novel experimental approuch was developed in order to determine which VLDL or IDL subclass was the precurwor of specific LDL subpopulations. Human plasma lipoproteins of known density (VLDL or IDL) were icolated, isotopically labeled with $\mathrm{W}$, and injected into rats, which possess an active lipolytic pathway but no

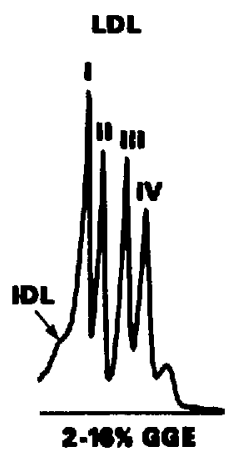

Ny. 1.LI. Demitometric ecan of IDL and LDL subpopulations uparated by electrophormis 8 to $16 \%$ nondenaturine polyacrylamidn cals. (XBL 851-8948)

lipid-transfer activity. In vivo transformations of VLDL $\rightarrow$ IDL $\rightarrow$ LDL were charted by electrophoretic blotting of the radiolabeled products. This unique method of following in vivo metabolism of human triglyceride-rich VLDL particles revealed that normal small-sized VLDL can give rise to IDL-1s and ultimately cholesterol-rich LDL-IIs. Somewhat smaller sized IDL-2s were found to zenerate larger LDL-I species. VLDLs from patients with familial type 3 hyperlipoproteinemia produce cholesterol-rich particles intermediate in size between IDL-1 and IDL-2. These unususal species are also found in patients with familial hypercholesterolemia and may represent atherogenic particles responsible for increased risk of cardiovascular disease in these disorders.

Recent work with LDI-I enriched in vitro with triglyceride indicates that lipolysis of triglyceride in such particles generates the smaller denser LDL. III particle associated with increased atherosclerosis risk. This suggests that LDL-I and LDL-III are metabolically related, which is consistent with previously reported inverse correlations between these two subclasses of LDL.

Lipoprotein lipase is a key remodeler of triglyceride-containing lipoproteins along with lipid transfer proteins. Pursuing this aspect of triglyceride-rich lipoproteins, members of the Lipoprotein Research Group have recently shown that VLDL and LDL form an association complex during lipolysis, which suggests a mechanism whereby lipids can be transferred from one lipoprotein class 
to another. Current atudies are underway that are specifically addressing the role of HDL during lipolysis. Preliminary studies suggest that HDLs are able to inhibit VLDL-LDL complex formation. Moreover, during lipolywis, lipids can be tron aferred to HDL apolipoproteins, thus indicating a metabolic interaction between triglyceride-rich particles and anti-atherogenic HDL.
Alex V. Nichols, Trudy M. Forte, Ronald M. Krauss, Frank T. Lindgren, and Thomas A. Musliner. Affiliated Members: Michael La Belle, Miguel Robinson (LBL), Virgie G. Shore, (Lawrence Livermore National Laboratory), and Lon Aggerbeck, Karl Weisgraber, John Wetterau, and David Chappell (all of Gladstone Foundation, San Francisco).

\section{Genetics and Gene Expresion of Lipoproteins}

\section{GENETIC FACTORS THAT INELUENCE LDL SUBCLASS PATTERNS}

Based on nondenaturing gradient gel electrophoresis, investigators in this Group have provided data on more than $\mathbf{4 0 0}$ individuals that reveal the existence of two distinct LDL subclass patterns, donoted $A$ and $B$ in Fig. 1.12. In these examples of pattorns $A$ and $B$ the three component curves correspond to LDL subclasses I, II, III, and IV. Pattorn A is characterized by a major peak of large, buoyant LDL subclansen I and II, and a minor peak representing omaller LDL-III. In contrast, pattern $B$ has a major peak of smaller denser LDL-III or
Pattem A

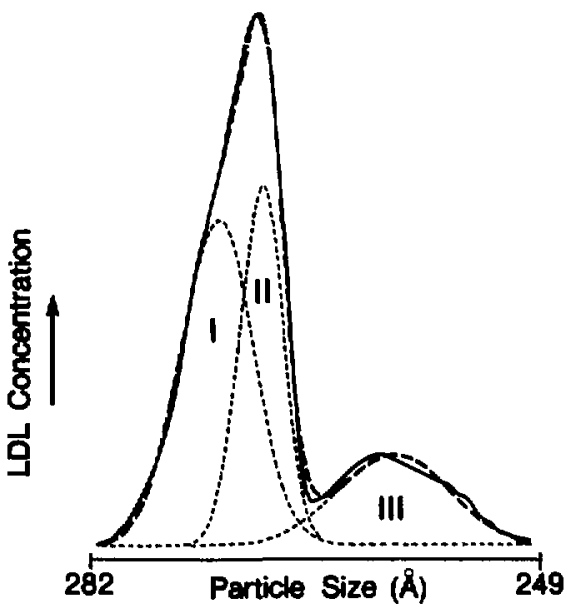

Pattem B

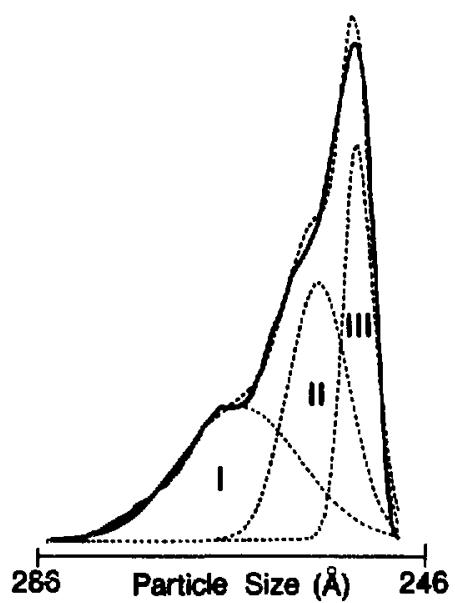

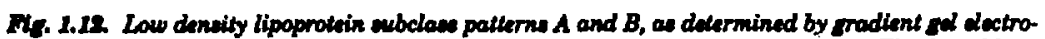
phoreats. The solid lines repnent densilometric tracinge of the rodient ad bands. The dotced lines were determined by mathemation modeling to facilitate identification of the $2 D L$ sublasese. Pattem $A$ is charackerised by a major peat of lare LDL ambdases (LDL-I and $I J$ and a minor peah of omaller LDL. In contrast, pattern $B$ is characterized by a major peak of small $L D L$ (LDLIII or IV), often with shewing of the curve to the Lef. (XBL 853-8233E) 
LDL IV particles, with skewing of the curve toward the larger particle diameter.. LDL subclass pattern $A$ is, in general, defined as an LDL subclass pattern with the major gradient gel peak at a particle diameter of $255 \mathrm{~A}$ or greater, and skewing of the minor components of the curve to the right. Pattern $B$ has the major peak at a particle diameter less than $255 \mathrm{~A}$, with akewing of the minor components of the curve to the left.

To teut the hypothesis of penetic control of LDL subclasses in a healthy population, 200 healthy Mormon families are currently being recruited and screened for LDL subclass distribution. To date 29 large kindreds, including 61 nuclear families and 300 members, have been screened among the relacives in these families.

The distribution of pattern $A$ and pattern $B$ shows apparent cox, age, and hormonal offects. That is, only 17\% of males under are 40 domonstrate LDL subclass pattorn $B$, while more than $40 \%$ of the males over that age have pattorn $B$. Among fomales, the higheat prevalonce of pattern B, $\mathbf{6 0 \%}$, was seen amone postmenopaunal women. Subjects with LDL aubclase pattorn $B$ have higher mean triglyceride levels, Jower HDL cholestorol levels, and higher apo B levels. These trends are seen despite the fact that these families are healthy and lipid values are generally within normal ranges.

Segregation analysis has been performed on these families uxing a mixed model incorporating both a major gene effect and a polygenic component. The best-fitting model included a major gene effect influencing LDL subclass pattern $B$ with a dominant mode of inheritance, an allele frequency of 0.28 for the allele leading to LDL subclan pattern $B$, and a small but significant polygenic component. The observed segregation ratios for the 49 families with both parents screened and the expected ratios based on the above model are summarized in Table 1.1. Based on this anmple, the allele leading to LDL subclants pattern $B$ is present in a large proportion of the healthy population. If 10 , this trait may be a marker for genetic predisposition to lipid disorders, and possibly increased coronary heart disease risk.

A collaboration was conducted with the Boston Area Health Study that supgests that there is indeed a correlation between LDL pattern types and cardiovascular disease. In this case-control study, it was found that $54 \%$ of male subjects with myocardial infarction had pattern B. Subjects with pattern B also had elevated plasma triglyceride and apo $B$ levels. LDL subclass pattern $B$ is associated
Table 1.1 Segregation ratios by parental mating type and age of offopring.

\begin{tabular}{|c|c|c|c|c|}
\hline \multirow{2}{*}{\multicolumn{2}{|c|}{ Parental mating }} & \multirow{3}{*}{$\begin{array}{c}\begin{array}{c}\text { Number of } \\
\text { matings }\end{array} \\
14\end{array}$} & \multicolumn{2}{|c|}{$\begin{array}{l}\text { Number of } \\
\text { offspring Age } \\
<40 \text { pattern }\end{array}$} \\
\hline & & & $\mathbf{A}$ & $\mathbf{B}$ \\
\hline$A \times A$ & $\begin{array}{l}\text { Observed } \\
\text { Expected }\end{array}$ & & $\begin{array}{l}41 \\
41.0\end{array}$ & $\begin{array}{l}0 \\
0\end{array}$ \\
\hline$A \times B$ & $\begin{array}{l}\text { Observed } \\
\text { Expected }\end{array}$ & 27 & $\begin{array}{l}66 \\
66.1\end{array}$ & $\begin{array}{l}28 \\
27.9\end{array}$ \\
\hline $\mathbf{B} \times \mathbf{B}$ & $\begin{array}{l}\text { Obierved } \\
\text { Expected }\end{array}$ & 8 & $\begin{array}{l}13 \\
10.9\end{array}$ & $\begin{array}{l}7 \\
9.1\end{array}$ \\
\hline
\end{tabular}

with a high-risk lipoprotein profile, i.e., higher triglycerides and apo B levels and lower HDL cholesterol. Future studies will probe the molecular ivais for LDL patterns $A$ and $B$. It is possible that genes coding for apo B structure include DNA polymorphisms that are ansociated with a given LDL pattern. Specific DNA restriction enzymes will be used to determine whether there are differences in restriction fragment length polymorphisms (RFLP) in DNA coding for apo B, and whether such RFLP 8 correlate wtih either pattern $A$ or pattern B.

Melised A. Austin and Ronald M. Krauss. Afiliate Member: Karen Vranizan.

\section{EXPRESSION OF LIPOPROTEIN GENES BY LIVER CELIS}

The human hepatoma line Hep G2 has been extensively used to study synthesis of HDL and LDL precursors; a major drawback with this line is its inability to secrete very low density lipoproteins (VLDL) under basal conditions. A major breakthrough in the past year was the jdentification of two other human hepatoma-derived cell lines that secrete precursor or nascent lipoproteins. One, Hep $3 B$, is able to produce VLDL in basal medium. The three lines presently under investigation are phenotypically distinct in their expression of apolipoproteins in defined medium as noted in Table 1.2. 
Table 1.2 Expression of apolipoprotein in defined medium.

\begin{tabular}{ll}
\hline Cell line & Major apolipoprotein \\
\hline Hep G2 & B and AI \\
Hep 3B & B and AII \\
NPLC & E \\
\hline
\end{tabular}

An important observation in the past year is that Hep G2 apo AI is secreted primurily as a lipid. free form. This led to the hypothesis that HDL may be assembled extracellularly. Extracellular ansembly was demonstrated by model incubations using Hep G2 lipid-free apo A and phospholipid. Such products were discoidal in thape and represent in vitro analog for nascent HDL harveated from the culture medium. Nondenaturing gradient gel scans and complementary views of the electron microscopic structure of HDL-like complexes formed by incubation of Hep G2 lipid-free protein fraction with the phospholipid, dimyristoylphosphatidylcholine, are shown in Fig. 1.13. At a molar ratio of phospholipid to apo AI of 100:1, a complex $9.7 \mathrm{~nm}$ in size is formed that is similar to the intact lipoprotein isolated from the medium. A higher molar ratio, 300:1, results in the formation of even largersized complexes. The inference from such stucies is that HDL may not necessarily be pre-assembled in the liver; rather some may be assembled extracellularly through interaction of lipid-free apo AI with membranes and/or other lipoproteins. This premise remains to be tested experimentally.

Another important observation made in the pant year is that newly synthesized LDLs, i.e., thors secreted by Hep G2 and Hep 3B cells, differ electrophoretically from plasma counterparts. Several poistible factors contributing to the increased negative charge are that the carbohydrate moiety of the protein is different in newly secreted particles and/or that the apo B protein conformation may be different on naccent LDL. Altered properties of the LDL surface may guarantee that the newly ayntheized particles are not taken up by the cells that secrete them. The liver has numerous receptor that recognize LDL (the LDL receptor or apo B-E receptor) eubsequently leading to the
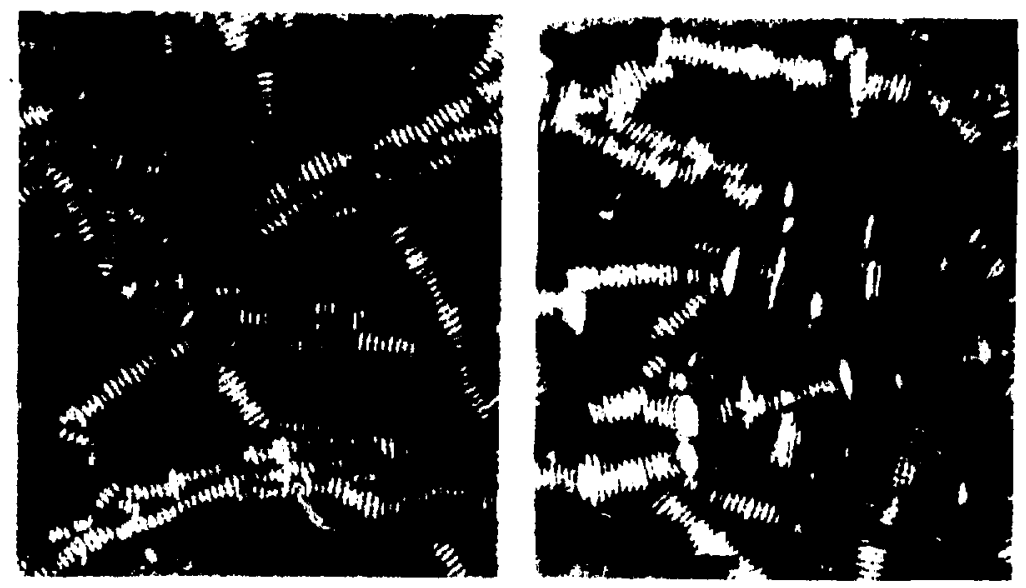

Bty. 1.13. Electron micro raphe of nepatively tained complexes formed by incubation of Hep G2 lipid-free apall with the phosphalized, dimyristoylphosphatidylchaline. (A) Phospholipid: protein molar ratio 100:1; (B) ratio $300: 1$. Bar repreunts $100 \mathrm{~mm}$. (XBL 871-438) 
intemalization and degradation of LDL. (Fig. 1.14). Newly synthesized LDL may not be recognized by the receptor by reason of altered conformation of the ligand. Clearly, two aspect of nascent LDLs are yet to be explored: 1) that the apa B protein is structurally different from circulating plasma LDLs that have probably undergone modification in the plasma, and 2) that nascent LDLs do not recognize normal LDL receptors. To assess apo B protein structure, future studies will utilize monoclonal antibodies that recognize specific apo B epitopes to determine whether there are differences between nascent and plasma apo $B$ which could account for

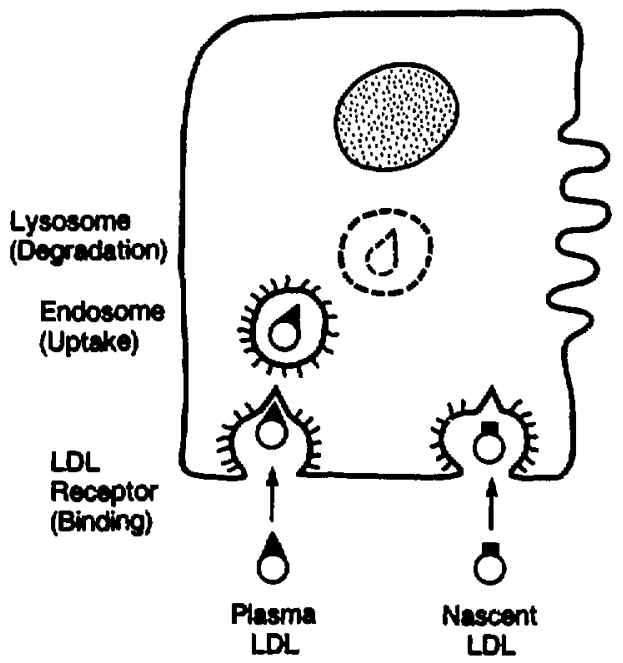

Fir. 1.14 Schematic showing interaction of normal plasma $L D L$ with the $L D L$ receptor on cell eurfaces. A poselble ecenario for novant $L D L$ is alvo shoun; sublle changes on the surfoce of the particle may prevent its neconition of and binding to the LDL receptor, (XBL $8711.8007 \mathrm{~A})$ the observed difference in electrophoretic behavior. Ligand blotting techniques will be used to assess to what extent nascent LDLs bind to normal LDL receptors.

Melissa A Austin, Ronald M. Krauss, Trudy M. Forte, and Michael La Belle. Affiliated Members: Alex Nichols, Mark R. McCall, Miguel Robinson, Karen Vranizan, and Virgie G. Shore (Lawrence Livermore Laboratory).

\section{ATHEROSCLEROTIC PLAQUE PROTEINS}

The objective this study was to use anion . exchange and reverse-phase HPLC to provide new knowledge about the properties of plaque protein. and to determine whether different protein species are present in plaque harvented from two anatomical sites: the coronary artery and thoracic norta. Protein extracts wero charactorized by anion exchange and reverwe-phase HPLC and the integrated chromatograph revealed significant differences in both peak retention times and areas for protein species from coronary artery compared to thoracic aorta artery plaque. Coronary artery plaque proteins possessed a high degree of cationic charge and polarity compared to those present in thoracic aorte plaque and normal mammary artery. This suggests that specific protein makers may be expressed in plaque of different anatomical origin, and that the procesuing of protein may be diatinct to plaque sites. In constrast, characterization of molecular weight by gel electrophoresis resolved no major differences between plaque types. These findings indicate that proteins in human plaque lesions of different anatomical origin can be resolved by HPLC methodology and that they exhibit different charge and polarity. Such an HPLC approach may prove useful in the quantitative identification and ultimate isolation of specific protein markers present in plaque during atherogenesis, and in the study of mechanisms of protein involvement in plaque formation.

Robert Liburdy. 


\section{PUBLICATIONS: Lipoprotein and Structural Biology}

\section{CONTRIBUTIONS TO JOURNAIS}

Abney, J.R., Braun, J., and Owicki, J.C. Lateral interactions among membrane proteins: implications for the organization of gap junctions. Biophys. J. 62, 41-154 (1987).

Austin, M.A., King, M.C., Bawol, R.D., Hulley, S., Friedman, and G.D. Risk factors for coronary heart disease in adult fomale twins: genetic heritability and environmental influences. Amer. J. Epidemial. 125, 308-318 (1987).

Bastacky, J., Hook, G.R., Finch, G.L., Goerke, J., and Hayes, T.L. Low-temperature ccanning electron microscopy of frozen hydrated mouse lung. Scanning 9, 67-70 (1987).

Braun, J., Abney, J.R., and Owicki, J.C. Latoral interaction among membrane proteins: valid estimates based on freese-fracture electron wicroscopy. Biophys. J. 62, 427-439 (1987).

Bustamante, C., Maestre, M.F., and Wells, K.S. Recent advances in polarization spectroscopy: perspective of the extension to soft $x$-ray techriques. Radiation Biophysics 44,331-341 (1986).

Carr, K.E., Hayes, T.L., Indran, M., Bantacky, S.J., Madlinden, G., Ellit, S., and Ainwworth, E.J. Morphological critoria for comparing effects of $x$-rays and neon ions on moure umall intentine. Scanning Electron Microscopy 1, 799-809 (1987).

Carr, K.E., Hayes, T.L., Watt, A, Bastacky, S.J., Klein, S., find Fife, M. Specimen handling and data interpretation in $\mathrm{x}$-ray microanalyuis of frozen hydrated etched gastrointentinal tract. J. Electron Microscopy Technique 4, 371-381 (1986).
Carr, K.E., Heyes, T.L., Watt, A., Klein, S., McKoon, M., Bastacky, S.J., and Ellis, S. Biological variation in cryomicroanalytic data from mouse small intestinal villi. J. Elect. Microscopy Tech. 5, 65-69 (1987).

Chiu, W., Downing, K.H., Dubochet, J., Glaeser, R.M., Heide, H.G., Knapek, E., Kopf, D.A., Lamvik, M.K., Lepault, J., Robertson, J.D., Zeitler, E., and Zemlin, E. Cryoprotection in electron microscopy. J. Microscopy 141, 385-391 (1986).

Downing, H. and Glaeser, R.M. Improvement in high resolution image quality of radiation. censitive upecimen achieved with reduced spot ize of the electron beam. Ultramicroscopy 20, 269-278 (1986).

Finch, G.L., Bastacky, S.J., Hayes, T.L., and Fisher, G.L. Low-temperature scanning electron microscopy of particle-exposed mouse lung. J. Microscopy 147, 193-203 (1987).

Finch, G.L., Fisher, G.L., and Hayes, T.L. The pulmonary effects and clearance of intratracheally instilled $\mathrm{Ni}_{2} \mathrm{~S}$, and $\mathrm{TiO}$, in mice. Environmental Research 42, 83-93 (1987).

Forte, T.M., Nichols, A.V., Selmek-Halsey, J., Caylor, L, and Shore, V.G. Lipid-poor apolipoprotein A-I in Hep G2 cells: formation of lipidrich particles by incubation with dimyrintoylphouphatidylcholine. Biochimica et Biophysice Acta 920, 185-194 (1987).

Franceschini, G., Calabresi, L., Tosi, C., Sirtori, C.R., Fragiacomo, C., Noseda, G., Gong, E., Blanche, P., and Nichols, A.V. Apolipoprotein A-I $I_{\text {man }}$ correlation between high density lipoprotein subclass distribution and triglyceridemia. Arteriosclerosis 7, 426-435 (1987). 
Goldberg, I.J., Le, N.-A, Leeman, B., Brown, W.V., and Lindgren, F.T. Evidence for heterogeneity of low density lipoprotein metabolism in the cynomolgus monkey. Biochim. Biophys. Acta 879, 197-185 (1986).

Henderson, R., Baldwin, J.R., Downing, K.H., Lepault, J., and Zemlin, F. Structure of purple membrane from Halobacterium halobrium: Recording, measurement, and evaluation of electron micrographs at $3.5 \AA$ resolution. Ultramicrascopy 19, 147-178 (1986).

Hook, G.R., Bantacky, J, Conhaim, R.L., Staub, N.C., and Hayes, T.L. A new methnd for pulmonary edoma research: scanning electron microscopy of frozen-hydrated odematous lung. Scanning, Vol. 9, 71-79 (1987).

Hughes, T.E., Sanak, W.V., Ordovas, J.M., Forte, T.M., Lamon-Fava, S., and Schaefer, E.J. A novel cell line (Caco-2) for the study of intestinal lipoprotein synthesis. J. Biol. Chem. 262, 3763-3767 (1987).

Jaffe, J.S. and Gleeser, R.M. Difference Fourier analysis of "surface features" of bacteriorhodopsin uning glucose embedded and frozen hydrated purple membrane. IRtramicrascopy 83 , 17-28 (1987).

Krauns, R.M. Relationship of intermediate and low density lipoprotein subupecies to risk of coronary artery dicease. Amer. Heart Journal 113, (No. 2, Part 2), 678-582 (1987).

Krauns, R.M. Effects of oral contraceptives on lipid metabolium. J. Reprod. Med. 31 (Suppl. 6), 549-550 (1986).

Krauss, R.M., Lindgren, F.T., Williams, P.T., Kelsey, S.F., Brensike, J., Vranizan, K., Detre, K.M., and Levy, R.I. Intermediate density lipoproteins and coronary artery disease progression in hypercholesterolemic men. Lancet ii (July 11, 1987), 62-66 (1987).
Kwiterovich, P.O., Jr., White, S., Forte, T., Bachorik, P.S., Smith, H., and Snidermen, A. Hyperapobetalipoproteinemia in a kindred with familial combined hyperlipidemia and familial hypercholesterolemia. Atteriosclerosis 7, 211-215 (1987).

LaBelle, M. Computer-assisted collection and analysis of enzyme-linked immunosorbent ansay data. I. Immunol. Methods 102, 251-258 (1987).

Lamon-Fava, S., Ordovas, J.M., Mandel, G., Forte, T.M., Goodmun, R.H., and Schaefer, E.J. Secretion of apolipoprotein $A I$ in lipoprotein particles following tranufection of the human apolipoprotein AI gene into 3T3 celle. J. Biol. Chem. 262, 8944-8947 (1987).

Maestre, M.F. The effect of animotrupic properties of randomly oriented particles on polarized light: an operational calculus for spatially neterogenous distributions. Eiopolyniers 26, 1357-1379 (1987).

Mickols, W., Maestre, M.F., and Tinoco, I., Jr. Differential polarization microscopy of changes in atructure in spermatocyte nuclei. Nature $328,452-464$ (1987).

Musliner, T.A., McVicker, K.M., Iosefa, J.F., and Kraus, R.M. Lipolysis producte promote the formation of complexes of very low density and low donsity lipoproteins. Biochim. Biophys. Acta 979, 97-110 (1987).

Musliner, T.A, MeVicker, K.M., Ionefa, J.F., and Kraums, R.M. Metabolizm of intermodiate and very low density lipoprotein uubfractions from normal and dyahetalipoproteinemic plasma: in vivo studies in the rat. Arterioscierasis 7 , $408-420$ (1987).

Nichols, A.V., Gong, F.L., Blanche, P.J., Forte, T.M., and Shore, V.G. Pathways in the formation of humen plasma high density lipoprotein 
subpopulations containing apolipoprotein A-1 without apolipoprotein A-11. J. Lipid Research 28, 719-732 (1987).

Palmer, R.H., Nichols, A.V., Dell, R.B., Ramakrishnan, R., Lindgren, F.T., Gong, E.L., Blum, C.B., and Goodman, D.S. Lack of relationship in humsns of the parameters of body cholesterol metabolism with plasma levels of subfractions of HDL or LDL, or with ApoE isoform phenotype. J. Linid Res. 27, 637-644 (1986).

Shore, V.G., Smith, M.E., Perret, V., and Lankarit, M,A. Alterations in plasma lipoproteins and apolipoproteins in experimental allergic oncephalomyelit's. J. Lipid Res. 28, 119-129 (1987).

Stefanick, M.L., Williams, P.T., Krausn, R.M., Terry, R.B., Vranizan, K.M., and Wood, P.D. Relationships of plasma estradiol, testonterone and sex hormone-binding globulin with lipoproteins, apolipoproteins, and high density lipoprotain subfractions in men. J. Clin. Endocrin. Metab. 64, 723-729 (1987).

Tinoco, I., Jr., Mickols, W., Maestre, M.F., and Bustamante, C. Absorption, scattering, and imaging of biomolecular atructure with polarized light. Ann. Rev. Biophysics and Engineering 16, 319-349 (1987).

Williarss, P.T., Krauns, R.M., Kindel-Joyce, S., Dreon, D.M.,Vranizan, K.M., and Wood, P.D. Relationship of dietary fat, protein, cholesterol, and fiber intuke to atherogenic lipoproteins in men. Am. J. Clin. Nutr. 44, 788-797 (1986).

\section{CONTRIBUTIONS TO BOOKS AND PRO. CEEDINGS}

Baldwin, J.M., Ceskn, T.A., Glaeser, R.M., and Henderson, R. Stmicture analysis of becteriorhodopsin ky electron crystallography. Pages 101-116 in Crystallography in Molecular Biology, D. Monas, J. Drenth, B. Standberg, D. Suck, and K. Wilson, eds. Plenum Publ. Corp., New York (1987).
Brśtacky, J. Review of G.F. Marshall, ed., "Laser Beam Scanning", Optn-Mechanical Devices, Systems, and Data Storage Optics. Scanning 9, 45 (1987).

Downing, K.H. Overcoming beam-induced specimen motion: a major advar.cc in improving image contrast for organic specimens. Pages 3-9 in Proceeding of the 45th Annual Meeting of the Electron Nicroscopy Society of Amnrica, G.W. Bailey, ed. San Francisco Press, Inc., San Francisco, $S A$ (1987).

Downing, K.H. and Gisener, R.M. Effect of jllumi nation spot size on high-resolution image contrant for radiation-sen.itive upecimens. Pages 36-36 in Proceedings XII International EM Congrese, Kyoto, Japan (1986).

Finch, G.L., Hayes, T.L., Mosmman, B.T., Chang, M.J.W., and Fiuher, G.L. SEM of tracheal respiratory epithelium exposed in vitro to $\mathrm{Ni}_{2} \mathrm{~S}_{\mathbf{2}}$, Pages 391-393 in Microbeam Analysis - 1986, A.D. Romig, Jr. and W.F. Chambers, eds. San Francisco Press, Inc., (1986).

Glaeser, R.M. High resolution electron microscopy of radiation sensitive crystals. Pages 17-18 in Praceedings XII Intemational EM Congress, Kyotc, Japan (1986).

Irauss, R.M. Physical heterogeneity of apolipoprotein B-containing lipoproteins. Pages 15-21 in Proceedings of the Workstiop on Lipoprotein Heterogeneity, K. Iippel, ed. NIH Publication No. 87-2646 (September 1987).

Krauss, R.M. Lipids and lijuproieins in postinenopausal women. Pages 5G-60 in Postgraduate Medicine: A Speciol Report, W.A. Peck and R.A. Lobc, eds. Custom Communications, New York, (1987).

Krauss, R.M. and Nichols, A.V. Metabolic interrelationships of HDL subalasses. Pages 17-27 in Advances in Experiment 1 Medicine and Biology, Volume 201: Lipoyrotein Deficiency 
Syndromes, A Angel and J. Frohlich, eds. Plenum Press, New York (1986).

Nichols, A.V., Gong, E.L., Blanche, P.J., Forte, T.M., and Shore, V.G. Origin and heterogeneity of HDL subspecies. Pages 331-340 in Proceedings of the Workshop on Lipoprotein Heterogeneity, K. Lippel, ed. NIH Publication No. 87-2646 (September 1987).

Norum, R., Forte, T.M., Alaupovic, P., and Ginsbere, H.N. Clinical kyndrome and lipid metabolism in hederitary deficiency of apolipoproteins A-I and C-II, variant 1. Pages 137-149 in Proceedings of Symposium on Lipoprotein Deficiency Syndromes, A. Angel, ed., Plenum Press. (1986).

Perlman, J.A. Krauss, R.M., Ray, R., RussellBriefel, R, Ezxati, T., and Lieberknect, G. Smoking, oral contraceptive use and other risk factors for atherosclerotic heart disease. Pages 27-35 in Smoking and Reproductive Health, M.J. Rosenberg, ed., PSG Publishers, Littleton, MA, (1987). 


\section{$24 / 25$}

\section{Section 2. Cell and Molecular Biology}

These are exciting times for biology in general and for the cell and molecular biology effort at LBL in particular. The Cell and Molecular Biology Group was formed four years ago. Through its own activities and by its representation on the LBL Panel to Explore New Directions (PEND), it succeeded in an effort to fonter a coordinated programmatic approach to research in life sciences at LBL. This effort has integrated ongoing research and is one of the driving forces behind attempts to initiate programs in hemopoiesis, in biotechnolocy and bioprocessing, and with the cooperation of the Chemical Biodynamica Division, in the Human Genome Conter. The activity of the Group was part of the impetus for reorganization and formation of the Cell and Molecular Biolowy Divition that took effoct in January 1888, implementing a recommen- dation of the LBL Life Sciences Task Force. During FY 1987, an important consolidation was the integration of hemopoietic research into other efforts in cell and molecular biology and differentiation. Formation of the Cell and Molecular Biology Division consolidates and integrates programs in atherogenesis, macromolecular structure, and radiation biology with the historic four subgroups, DNA repair, DNA replication and recombination, carcinogenesis, and differentiation. Thene investigatora will all continue to interact and produce pioneering research.

The following summary of research activitien outlines the major scientific goals and recent achievements of the Group and whows the direction of future studies.

\section{ACTIVTTIES OF THE CELL AND MOLECULAR BIOLOGY GROUP}

\section{Carcinczenesis}

Generation of acti spocies

Mixed function oxidase

Arachindonate cascade

Charactorization of damace to DNA

Alkylation products

Bulty adducts

Oxidative damage

Induction of trancformation

Charactorization of atages, target population, cellular nubstrates

Development of selective and quantitative ansaye for human epithelial cells

Role of viral and cellular oncogenes

Factors involved in promotion and progreasion

Active oxygen/inflammatory reiponce

Cell agonists and antagonists

Cell-cell and cell-ntromal interaction.
Scientiats

M. Alhadeff

J.C. Bartley

M.J. Biscell

R. Goth-Goldutein

A.R. Howlett

S.A. Laadon

B. Singer

S.J. Spengler

M.R. Stampfor

A.W. Stoker

A.N. Tischler
Technical Staff and Graduate Students

L.G. Hayashi

C. Hatier

M.M. Hosobuchi

A.C. Pang

M. Sieweke 
Scientists

Technical staff and

Graduate Students

Differentiation

Regulation of normal differentiation and

development cell types

Mammary epithelial cells (rodent and human)

Fibroblasts

Hemopoietic cells

Factors

Hormonal, extracellular matrix

Relation whip between normal gene and exprestion and carcinogenetis
M. H. Barcellos-Hoff

J.C. Bartley

J.C. Beck

M.J. Bissell

G. Brecher

G.K Clemons

K.L. Miller

G. Parry

D.E. Prosen

R.I. Schwarz

P.H. Silverman

M.R. Stampfer

J.D. Stubb:

J.T. Brown

P.K. Cooper

M.S. Esponitio

J.C. Game

J. Hosode

R.K. Mortimer

N.L. Rudin

D. Schild
L-H. Chen

B.L. Cullen

D.J. DeManicor

U.N. Dinh

D.E. Erkenbrack

B.R. Kullyren

G.A. Lovine

L.Moss

L,J. Mahlmann

S.S. Neben

T.G. Ram

J.S. Scherer

K.R. Zottl

M.Aker

M. Bell

Q.E. Gipson

J.A. Kans

T.J. MoKey

H.W. Moire

Protein-protein and protein-DNA interactions

In vitro and in vivo model plasmidic syatems

Physical monitoring of chromosomal recombination

Purification and characterization of proteins involved in recombination

Maintenance of genomic integrity during recombination

Effects of DNA damage on replication

\section{Repair of Induced DNA Damare}

Characterization of inducible networks repairing DNA Damage

Repair of DNA damage in specific sequences or at specific wites

Transcribed and nontranscribed sequences analysis of importance of excision repair at or near growing forks

Influence of DNA-protein interactions

Use of model substrates and purified polymerases to

examine coding properties of DNA containing defined lesions

Isolation and molecular characterization of genes

P.K. Cooper

M.S. Esposito

J.C. Game

R. Goth-Goldstein

J. Hosoda

S.A. Leadon

L.S. Miller

R.K. Mortimer

D. Schild

B. Singer

S.J. Spengler
F. Chavez

S.L. Goe

M.K. Hughes

C.B. Kinglsey

D.A. Lawrence involved in cellular responses to DNA damage 


\section{Molecular and Genetic Studies of DNA Damage and Repair}

The DNA of living cells is continuously subject to damage, both from endogenous events within the cell and from a variety of exogenous environmental agents to which humans are routinely exposed, ranging from ordinary sunlight to naturally occurring carcinogens present in foods. Organiams at all levels of complexity have evolved an elaborate array of enzymatic mechanisms to maintain the integrity of their genetic material, and the mutagenic or cytotoxic consequences of any particular lesion in DNA will depend in large part on the nature and timing of the cellular procensing of that lesion and on the interaction of repair processes with other anpects of DNA metaboliom wach a replication, recombination, and transcription. The broad objectives of our DNA repair studies are to underatand the biochemical and molecular basis for the processing of damaged DNA and the genetic control of repair procesues (also described in the section on DNA Roplication and Recombination). Individunl research groups approach these questions using a variety of systems ranging from purified enzymes in vitro to in vivo studies employing phage, bacteria, yeant, rodent and primate cell lines, established human cell lines, and primary cultures of human cells.

\section{MOLECULAR MECHANISMS OF DNA DAMAGE BY CARCINOGENS}

\section{Mono- and Bifunctional Aldehydes}

The biochemistry of mono- and bifunctional aldehydes is being studied in vitro to provide accurate and well defined conditions permitting the isolation and identification of metabolic products. The aldehydes arise both from environmental carcinogens, such as vinyl chloride, as well as metabolic procening of natural substrates. Monofunctional aldehydes are being ueed to study the initial reaction with nucleosides and the further reaction between these products and other molecules present in the cell. Bifunctional aldehydes can form DNA derivatives that contain an additional ring on the base. This ring destroys at least one base-pairing site in the nucleoside and distorts DNA structure to varying degrees. The mutagenic efficiencies of these etheno derivatives have been determined by measuring the levels of error: introduced following replication in vitro with a variety of polymerases. High mutagenic efficiency coupled with small amounts of physical distortion of the DNA helix may be the hallmark of a derivative, such as N2,3-ethenoguanosine, that is likely to be an initiator of carcinogenesis (Fig. 2.1). Bifunctional aldehydes can also form interstrand crosslinks in DNA. Although the extent of formation of this type of damage may be low, the biological consequences are likely to be severe. Thus, in vitro studies are being extended to measuring the extent of crosslinks formed in DNA in animals exposed to vinyl chloride by inhalation, the normal route of human exposure.

\section{Bea Singer and Sylvia Spengler.}

\section{N-nitroso Alkylating Agents}

The reaction products of another clast of ubiquitous carcinogens, N-nitroso alkylating agents, have been well characterized. The biological consequences of this damage involve both mutation and cell killing. Mutagenicity has been associated most frequently with alkylation of exocyclic oxygens of both purines and pyrimidines. Mammalian cells and $E$.coli have similar enzymes to repair alkylation damage. N-alkyl-purines are removed by $\mathbf{N}$-glycosylases while $\boldsymbol{O}^{*}$-alkylguanine (the principle lesion responsible for the carcinogenicity and mutagenicity of alkylating agents) is repaired by a rather unique mechanism. A small protein, O-alkylguanine alkyltransferase (MT), directly transfers the alkyl group in a stoichiometric manner to a cysteine residue on the protein, resulting in suicide inactivation of the protein. Both the MT and N-glycosylase activities can be measured in crude cell extracts using in vitro alkylated DNA as a substrate. There is evidence that the common baker's yeast Saccharomyces cerevisiae might differ from $E$.coli and mammalian cells in the repair of alkylation damage. No MT

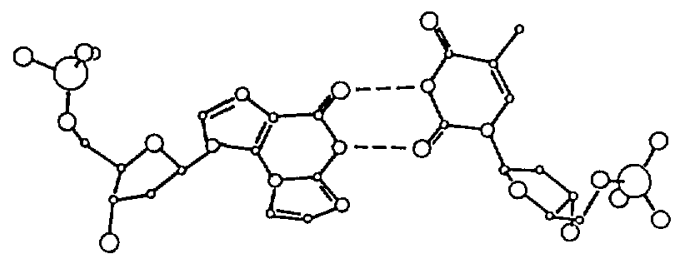

Fip. 2.1. N,3-ethenoguaronine can form two hydrogen bonds with thymidine. The mutgenic base pair does not dintort the helix aignificanlly, and the additional ethero ring can be accommodated in the groove. (XBL 881-7237) 
activity or N-glycosylase activity can be detected in extracts from yeast cells. However, using a radioactively labeled alkylating agent, it was found that methylated purines and $O$-methylguanine are lost from the yeast DNA relatively rapidly and therefore, are presumably repaired. DNA repair mutants of yeast, described later in this report, will be used to determine whether alkylated bases are repaired by a different repair system in yeast.

It is less well understood which alkylated DNA bases cause cell death. In E.coli, 3-methyl purines could be identified as lethal lesions. However, in mammalian cells no specific lesion has been implicated in alkylating-agent-induced cell death. The identification of such lethal lesions has been attempted by two approachen: 1) comparien of the cytotoxic effects of alkylatins agents which form different upectra of alkylated bases, and 2) compari. con of DNA repair in alkylating agent sensitive and resintant cell variants. Neither approach was succescful in identifying a specific lethal levion. Rather, there seem to be soveral alkylated bases that can contribute to cell death and as yet unidentified factors that modify the cytotoxic effect of specific DNA alterations. Since the alkylating agent resistant cells apparently do not differ from sensitive cells in repair of methylated DNA bases, other cellular responses to alkylation damage were investigated. It was found that following treatment with $\mathrm{N}$-methyl- $\mathrm{N}$-nitro-N-nitroso-guanidine, intracellular levels of diadenosine tetraphosphate (Ap4A) are elevated to a greater extent in resistant than sentitive cells. Since cellular Ap\&A levelu are increaced in response to various environmental stressors, they might trigger a cellular mechanium that increases cellular survival. This mechanism apparently does not function as efficiently in a number of tumor-derived cell strains characterized by hyperenentivity to the cytotoxic effects of alkylating agents and by lack of repair of $0^{4}$. methylguanine.

Regine Goth-Goldotein and Mildred Hushes.

\section{PROCESSING OF LESIONS IN THE VICINITY OF REPLICATION FORKS}

The mutagenic or lethal consequences of any particular lesion in DNA depend on cellular processing of that lesion, often by responses that are induced by the damage itself. $A$ damage-inducible repair process in E.coli, long patch excition repair, has been shown to be of general importance in resistance to lethal and replication-blocking effects of DNA damage. Results from a variety of experiments have suggested that the inducible process is required for repair of lesions near DNA replication forks, where structural constraints might hinder constitutive excision repair. Our recently developed technique for resolving DNA fragments containing replication forks from linear DNA fragments by two-dimensional agarose gel electrophoresis has been used to detect the replication of a pecific gene in a synchronously dividing culture. Determinations of the timing of replication of a gene near the origin of replication (polA) was made by hybridization of a cloned probe to slot blots of CaCl donsity cradient fractions of DNA prepared from umples taken at various times after initiation of replication in bromouracil. Parallel samples of puriffed DNA were digested with a restriction endonuclease, analyzed in the two-dimentional electrophoresin nyutem, blotted to nitrocellulose by capillary tranofer under neutral conditions, and hybridized with the probe DNA. Hybridization in the position of replicating DNA (the minor arc) was detected at the time predicted by the $\mathrm{CsCl}_{3} \mathrm{Cradient}$ rewults. The two-dimentional gel electrophoresis system and the ability to detect the replication of specific genes will allow the inventigation of human cenetic repsir deficiency dicsases wuch as the varient form of xeroderma pigmentosum and ataxia telangiectania, both of which may have a defect in the processing of lesions in the vicinity of replication forkt. In addition, this system will be used to determine whether the integration of transfected plasmid DNA into the mammalian genome takes place via replicative intermediates.

Priscilla Cooper and Sherry Gee.

\section{EFFICIENCY OF REPAIR AND TRANSCRIP- TIONAL ACTIVITY}

The analyois of DNA repair in eukaryotic cells is complicated by the various levels of DNA condenution in chromatin atructure and by the complexity of the multiple tandem replication units. An increasingly important aspect of DNA damage and excivion repair is whether all sequences in the eukaryotic genome are affected by damage to the same extent. The repair of uv damage in the human metallothionein (MT) gene family is being studied using an immunological method that isolates DNA fragments containing bromouracil in repair patclies by means of a monoclonal antibody that recognizes bromouracil. The presence of the MT genes in the repaired and unrepaired DNA 
fragments can be detected by using a cDNA probe for the genes. Repair in four members of this gene family was measured: the expreased MT-LA and MT-IIA genes, the MT-IB gene whose expression is tissue specific, and the non-expresued MT-IIB pseudogene. Ultraviolet dumage was repaired at least twice as fast in the transcribed MT-IA and MT-IIA genes than in the genome overall. Repair in the MT-IB and MT-IIB genes was about the same as in the rest of the genome. When the expression of the MT-IB and NT-IIB senes is increased 15- to 20-fold by incubation of the cell cultures with cadmium, the rate of repair in these genes was 4- to 5-fold fastor than in the genome overall (Fig. 2.2). The rate of repair in the MT-IB and MTI-IIB genes, whose expression cannot be induced by cadmium, remained about the same as in the rest of the genome. These results indicats that the efixciency of repair of DNA damage in a particular sequence is influenced by the transcriptional activity of that sequence.

Steven A. Leadon and Marganet M. Snowden.

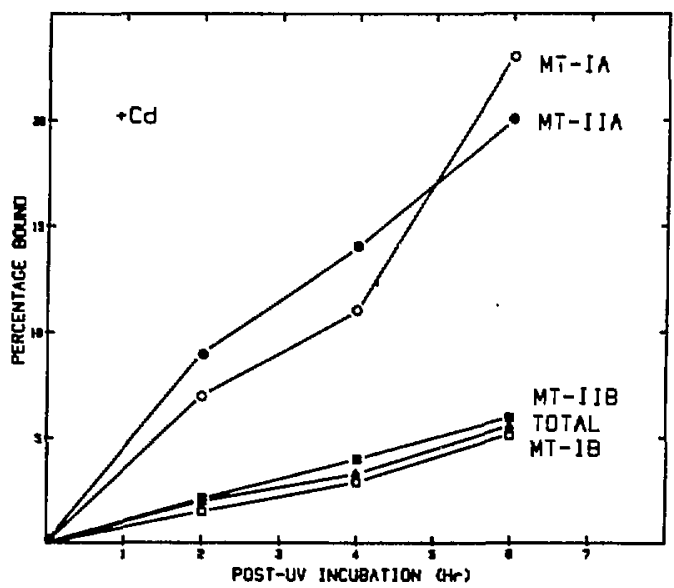

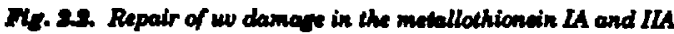
enes, under conditions when their trenceriptional octlulty is inducad, is 4 - io 5-fold forder than in the enome overall. The rote of repair in the matallothiontin IB and IIB enes, whon exprescion cannot be induced, is about the eame as in the reat of the renome. (ABL 881-7238)

\section{OXIDATIVE DAMAGE AND DIRECT ADDUCT FORMATION IN CARCINOGENESIS}

There is increasing evidence implicating the involvement of free radicals, particularly those derived form molecular oxygen, in many stages of chemica' carcinogenesis. The production and repair of two types of DNA damage, direct benzo(a)pyrene adducts and indirect oxidative damage, produced during the metabolic activation of the carcinogen benzo(a)pyrene by human mammary epithelial cells, have been examined. Thymine glycols, one type of oxidative DNA damage, were detected uning a monoclonal antibody specific to this bace modification (Fig. 2.3). The number of thymine glycols formed in the DNA was vimilar to that of benzo(a)pyreno-DNA adducts. Since thymine glycols represent only a portion of the oxidative damage postribly produced, these renult indicato that the total amount of oxidative damage induced by exposure of human mammary epithelial celle to benzo(a)pyrene greatly exceeds the amount of direct adduct formation and that complete carcinogens such as benzo(a)pyrene may exert their biological effects by both direct DNA binding and the production of indirect damage.

Jack.Bartley, Steven A. Leadon, and Marthe Slampfer.

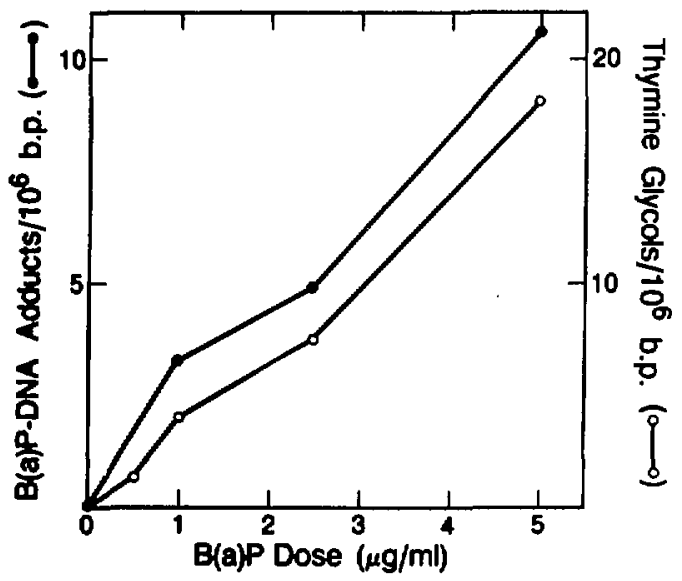

It. 2.5. Benso(o)pyrene produces both dinct DNA adducts and thymine dycol. Human memmary epithelial cells were exposed to FH. benco(a)pgnene and the DNA icolated. Beneo(a)pyreneDNA odducts (-- ) were detormined from the specific activity of the DNA. Thymine glycols (o-o) were determined from competilive immuroasays with a monoclonal antibody to thymine Cirool. (ABL B81-7239) 
DNA Replication and Rocombination

\section{INTRODUCTION}

An understanding of the mechanisms of DNA replication and recombination is a fundamental prerequisite to studies of the role of genomic changes in normal development and dicenve states. The molecular and biochemical studies of genes and proteins required for DNA replication, repair, and recombination complement the studies of DNA repair and carcinogenesis described above. The focus of one program is to characterize the activities, DNA-protein, and protein-protoin interactions of bacteriophage T4 gene products that function as an intecrated replication-repair-recombination multiprotein complex during the $\mathbf{T} 4$ life cycle. $A$ related research goal is to identify the biological roles of spontaneous mitotic recombination in Saccharomyces cereviniac and to identify and characterize $R E C$ genes and proteins compriting the partial reactions of mitotic and meiotic recombination. Several invertigators are conducting a comprehensive study of RAD50-57 family of yeant genes involved in repair of double trand breaks, recombination, homothallic mating type switching, chromosome disjunction, and moiosis.

\section{POSTREPLICATION RECOMBINATIONAL REPAIR}

The major genes encoding proteins involved in postreplication recombinational repair (PRR) of bacteriophage T4 have been identified in previous studies and provide an opportunity to examine the DNA-protein and protein-protein interactions of gene 32 protein (ep32), a helix destabilizing protein; the uvs $\mathrm{X}$ gene product, a RocA-like protein; and the product of genes 46 and 47 (gp46 and cp47), a putative exonuclease.

\section{Functional Domains of $8 p 32$}

Previous studies employing limited proteolysis products and an in vitro DNA replication system provided support for the model that $\mathbf{g p 3 2}$ consists of three functional domains and that the carboxy terminal A-domain not only participates in DNA replication, recombination, and PRR activities, but also controly the the properties of replicationrepair-recombination multiprotein complexes through direct protein interactions. Recent studies have been focused on the structural and functional roles of $\mathrm{Zn}(\mathrm{II})$ and "Zn-finger" sequence located in the central domain of $\mathbf{g p} 32$.

The "zinc-finger" emerged in the last few years as a novel protein motif for nucleic acid recognition and binding. Although it was originally discovered in repeated tandems in the Xenopus transcription factor IIIA(TFIII), similar sequences have been found widespread throughout many different organisma-from human cells to bacterial viruses. They are present within the structure of a large number of regulatory proteins and seem to serve as modules for the building up of specific nucleic acid binding domains.

Our preliminary atudies indicate that many $\mathrm{Zn}$ suppreasible gene 32 mutations induce conformational changes that make the normally protease resiatant central domain sueceptible to proteases. Such conformational changes have been analyzed by limited proteoly is of crude lyaates from mutant infected cells, followed by Western-blot detection of the proteolysis products. These findinge demonstrate that $\mathrm{Zn}$ (II) is essential for stability of the protein and that mutations within the zinc-finger alter the conformation of that portion of the molecule where the terminal domain A connects to the central core (the hinge of the $A$ domain). The functional significance of relationuhipw between the rinc-finger and the terminal domains is currently being inventigated.

\section{Purification of $8 p 46 / 8 p 47$}

Properties of temperature sensitive and amber noncense mutants of genes 46 and 47 provide ovidence that they encode an exonuclease activity that expands single strand nicks into gaps, an activity required for biparental recombination and production of concatenated DNA, a precurnor of mature bacteriophage. Purification of $\mathrm{gp} 46 / 47$ to near homogeneity has been achieved, as shown in the SDS-gel picture (Fig. 2.4). The gp46/47 preparation contains a nuclease activity that converts both double-stranded and single-stranded T4 DNA to acid soluble material. Purification of the gp46/47 protein from temperature sensitive mutants is in progress. The purified proteins from the wild-type and mutants will provide direct evidence of the catalytic role of $8 p 46 / 47$, its involvement with other proteins such as gp32 and uvsX, and its role in DNA strand exchange, DNA unwinding, DNA annealing, and branch migration. In collaboration 


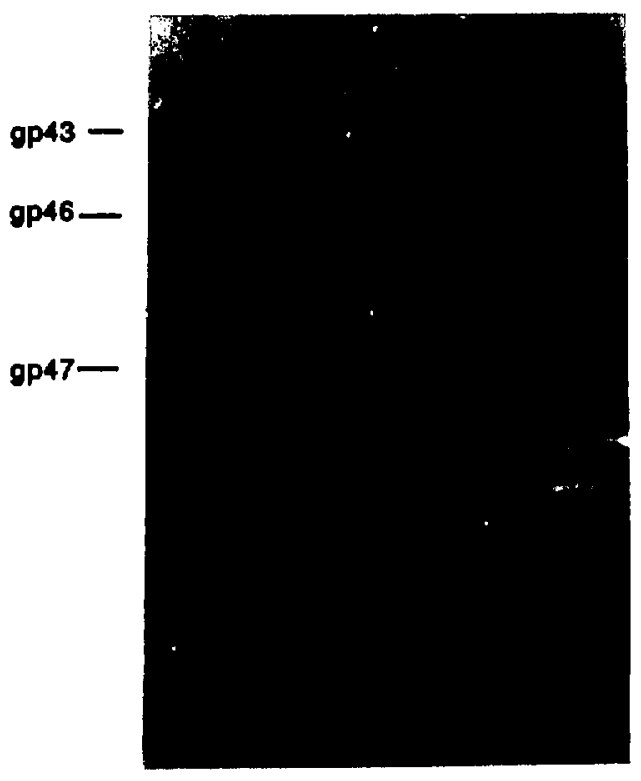

Fi. 24. ID-PAGE of DDAE-cellulowe column fractions containins $T 4, A P 46$, and $a p 47$. (XBB 889-897)

with Michael S. Esposito, differential DNA affinity chromatograpy and in vitro assay methods developed for T4 studies are being adoptod to characterize analogous proteins of Saccharomyces cerevisiae and rec mutants. This approach is particularly appropriate since the yeast $R A D 52$ gene (also known as $R E C 2$ ) complements gp46/47 mutations of bacteriophage T4 in vivo.

Junko Hosoda, Herbert Moise, and Ellen Sisk.

\section{MITOTIC RECOMBINATION AND DNA REPAIR}

Previous studies demonstrated that interhomolog mitotic recombination of Saccharomyces cerevisiae differs from meiotic recombination with respect to the time of initiation of recombination relative to chromosomal replication, the lengths of conversion tracts, mismatch repair modalities, the relative frequencies of Holliday structure intermediates containing asymmetric or symmetric heteroduplex DNA, and reciprocality of intergenic recombination. A braad spectrum of hyporecombination and hyperecombination mutants affecting spontaneous mitotic single site gene conversion, in- tragenic recombination, intergenic recombination, and genomic stability were isolated to attempt to understand the differences between spontaneous mitotic and meiotic recombination and to test the predictions of current molecular models of chromosomal recombination.

\section{Isolation of REC Gene Mutants}

An $\mathrm{N}+1$ hyperhaploid strain disomic for chromosome VII (LBL1) was employed for direct isolation of rec mutants affecting spontaneous recombjnational events and chromosomal segregation. Heterozygous and heteroallelic marker,i on chromosomo VII permit simultaneous monitoring of recombination in several genetic intervsls and detection of dominant and recessive rec mutations induced in the remainder of the genome. Spontaneous mitotic recombinational proficiency per se was used to identify ultraviolet-light-induced rec mutants of novel $R E C$ loci comprising five phenotypic clanses: 1) conversion negative, intergenic mcombination negative; 2) convertion positive, intergenic recombination nezative; 3 ) conversion negative, intergenic recombination positive; 4) conversion positive, intergenic recombination elevated; and 5) convertion elevated, intergenic recombination elevated. Several rec mutations affect in vitro plasmidic recombination and exhibit meiotic defects when rec/rec diploids are exposed to meiosis inducing sporulation medium (Table 2.1).

\section{Characterization of the REC1 Gene and Protein}

Ongoing research focuses upon cloning and sequencing of the REC1 gene and isolation of the $R E C 1$ gene product since it is required for all modes of mitotic recombination, chromosomal tability and meiosis (Table 2.2). Since the rec1-1 mutation is defective for in vitro plasmidic recombination the $R E C 1$ protein will be isolated by in vitro complementation. The amino acid sequence of the purified protein will be determined and compared to the amino acid sequence inferred from DNA sequencing of the cloned structural gene to provide confirmation that the correct protein has been purified. The purified protein will be tested for strand transfer activity, exo- and endodeoxyribonuclease activities, and ability to cleave Holliday junctions using protocols developed in collaboration with Junko Hosoda.

Michael S. Esposito, John Brown, Norah Rudin, and Greg Delory. 
Table 2.1 Mitotic recombination mutents isolated following ultraviolet light mutagenesis of LBLI.

Average spontaneous mitotic recombination frequencies

\begin{tabular}{|c|c|c|c|}
\hline Phenotypic groups & $\begin{array}{l}\text { No. mutants } \\
\text { obtained }\end{array}$ & $\begin{array}{l}\text { Cyhr conversions } \\
10^{n} \text { cells }\end{array}$ & $\begin{array}{c}\text { Cyhr intergenic } \\
\text { recombinations } \\
10^{\circ} \text { cells }\end{array}$ \\
\hline I. Conv-Inter. Exch- & 13 & 1.5 & 0.8 \\
\hline II. Conv.* Inter. Exch.- & 24 & 22.8 & 0.8 \\
\hline III. Conv.* Inter. Exch.*+ & 13 & 15.3 & 121.9 \\
\hline IV. Conv.-Inter. Exch.* & 1 & 0.8 & 19.7 \\
\hline V. Conv.*+ Intor, Exch.*+ & 3 & 94.7 & 1006.4 \\
\hline Control LBL1 (25 colonies) & & 19.4 & 29.1 \\
\hline
\end{tabular}

Table 2.2 Properties of four REC gene mutants.

\begin{tabular}{lcccc}
\hline Mutants & rec1 & $\operatorname{rec2}$ & rec3 & rec46
\end{tabular}

Mitotic gene conversion

Mitotic intergenic recomb.

Mitotic chromosomal atability

Meiosis of rec/rec diploid

\section{RECOMBINATIONAL REPAIR MEDIATED BY $R A D$ GENES}

The radiation sensitive mutents of Saccharomyces cerevisioe are a valuable genetic resource for studying repair in a eukaryote. The main focus of research is to understand the roles played by the $R A D 50$ to $R A D 57$ genes in recombinational repair and in mitotic and meiotic recombination. Some important genes, such as RAD50 and RAD62 have already been extensively studied. Others such as RAD24, RAD51, RAD54, RAD55, and RAD57 remain to be characterized. Several $R A D$ genes have been cloned and sequenced (e.g., RAD 51 , $R A D 62$, and $R A D 64$ ) providing reagents to characterize the transcriptional control of these genes and whether regions $5^{\prime}$ to them bind regulatory proteins. 


\section{Transcriptional Regulation}

Recent studies of RADS4 demonstrate that this gene is inducible approximately 3 - to 5 -fold by $x$ rays, ultraviolet light, and methyl-methane sulfonate, but not by heat shock. Regions 5 ' to the RAD54 gene are involved in its regulation. Delotion analywis is being employed to identify the exact sequences involved in regulation both in mitotic and meiotic cells and to determine whether this gene is under positive or negative transcriptional control. A vimilar analyuis of the RAD61 gene will reveal whether this gene is similarly regulated and whether RAD51 and RAD54 are coordinately regulated.

Uning lacZ furions of both the RAD52 and RAD54 gones, ovidence has been obtained that these genes are induced in diploids during meionis during the period of meiotic recombination. No induction was obeerved when haploid cells, incapable of meiosis, were incubatod in sporulation medium. Preliminary atudies indicate that induction of RAD52 and RAD54 is blocted in rad50-1 mutent diploids, known to arreat aftor promeiotic DNA rynthesis and before the onuot of meiotic recombination.

\section{Characterization of Primary Gene Products}

$R A D 51$ and $R A D 54$ have been sequenced and the sequencing of RAD55 and RAD57 in in progress. These data are employed to infer the amino acid wequence of the encoded protoins. RAD51, $R A D 54$ and RAD55 have been placed under the control of yeant ADH1 and GAL1 promoters and protein gels are being employed to identify the $R A D$ proteins. $R A D$ genes are also being ovorexpressed in $E$.coli as fusion proteins, which will be isolated to produce antibodies for further protein purification. Purified $R A D$ protoins will be tented for various enzymatic activities auch as ATPase, nuclease and DNA binding activities.
Visualization of Recombination and Recombinational Repair by Pulsed Field Gel Electrophoresis

Pulsed field gel electrophoresis allows DNA molecules the size of yeast chromosomes to be resolved on gels. One form of this technique, orthogonal field alternation gel electrophoresis, OFAGE, has been used to study double strand breaks and repair of linear chromosomes. A novel aystem has aleo been developed to detect double utrand breaks, intor-homolog recombination, and wistar chromatid exchange (SCE) on OFAGE geln. The technique employs a circular derivative of chromosome III. Rocombination between this circular chromotome and its linear homolog is topologically equivalent to integration of the circle into the linear molecule. Thus, molecules of a new wize claws are generated that are detectied on OFAGE gols by Southern hybridization. Similarly, SCE botween two sister circles generatas a new type of molecule, a double circle. The double circle does enter gels until it is linearized by introdustion of a double strand break by $x$-ray exponure. Thene tochniques provide methodu to examine repuir of linear chromosomes, recombination between homologe, recombination betwoen sister chromatids and the effects of RAD gene mutations upon repair of DNA damage and the normal progress of meioiis.

The novel technique for detection of SCE exchange represents a aignificant advance over methods that detect only unequal SCE events. The circle by circle exchanges detoct all SCE events and the rad50-1 mutant blocks meiotic SCE. The OFAGE technique further demonatrates that there is a low but detectable number of double strand DNA breaks during meiosis and that there is a twohour delay between commitment to genetic recombination and actual recovery of phyaically recombined molecules.

Rabert K. Mortimer, John Game, David Schild, and Rebecca Contopoulou. 


\section{Differentiation}

Understanding how cells precisely regulate tissue-specific function in responwe to signals from their environment is a fundamental problem in modern biology. In the Cell and Molecular Biology Group, an understanding of this complex problem is sought from three distinct but complementury systems. Mammary cells of epithelial origin are studied as a model of cells with polarized secretion, hormonally regulated gene expression, and great sensitivity to external environment. Tendon cells, archetypal fibroblasts producing very high levels of collagen, are an ideal model for determining molecular mechanisms controlling the production of an extracellular matrix protoin. Hemopoienis encompasees a sories of distinct cell lineages leading to the various circulating blood cells derived from a common pluripotent stom cell. Hemopoiesis throughout the life of the organinm is a model for many of the critical processes that take place during embryogenesis such as detormination and maturation.

\section{MAMMARY CELLS AS A MODEL FOR STUDIES OF GENE EXPRESSION AND POLARIZED SECRETION}

\section{Cell-ECM Interaction and Gene Expression}

Study of the regulation of gene exprestion in cultured cells, particularly in epithelial cells, has been both hampered and facilitated by the lows of function that accompanies culture on traditional plastic s.zbutrata. However, with the recognition that the unit of function in higher organisms is larger than the cell itself and that gene expression is dependent upon cell interactions with hormones, substrata, and other cells, came the underatanding that the epithelial cell is stimulated by its extracellular environment to express its phenotype. In the last decade epithelial cell research has centered on studies of functional differentiation with very promising and important results. Using cultured mammary epithelial cells as a primary model of these interactions, a framework has been delineated in which gene expresnion may be studied based on three premices:

1) That the unit of function in higher organisms includes the cell and its extracellular environment.

2) That the extracellular matrix (ECM) on which the cells sit is an extension of the cells and an active participant in regulation of their function, i.e., that the ECM is an "informational" entity in the sense that it receives, imparts, and integrates structural and function:l signals.

3) The ECM-induced functional differentiation in the mammary gland is mediated through changes in cell shape, i.e., that the structure is a large part of the message to maintain differentiated gene expression.

Based on these tenets and the data generated at LBL, ceveral years ago a model of "dynamic reciprocity" was proposed wherein the ECM is postulated to exert an influence on gene expression via tranomembrane proteins and cytoskeletal components. The cytoskeleton, in turn, through its ansociation with polyribonomes may affect mRNA stability and rates of protein wythesis, and through its interactions with the nuclear matrix may affect mRNA processing and, postibly, rates of transcription.

The study of mammary gland epithelial cell biology has addreseed the role of the ECM in controlling the expression of tissue specific function by measuring the expression of mill proteins, both at the level of mRNA synthesis snd protein secretion. Extension of previous studies led to the identification of transferrin (Tf) as a major mouse milk protein for which a cDNA has also been isolated and characterized. In vivo mammary Tf protein and mRNA levels are dramatically increased by pregnancy and lactation, during which time they are comparable to those found in liver (Fig. 2.5). In culture, the steady-state Tf mRNA and protein levels are relatively insensitive to lactogenic hormones compared to those of $\beta$-casein. However, mRNAs of both milk proteins' expression are markedly increased in cells cultured on basement membrane over those cultured on plastic (Fig. 2.6). It is therefore postulated that changes in the basement membrane composition that occur in vivo play a role in regulation of transferrin and possibly other milk protein.

In the past year, the form and function of mammary epithelial cells cultured on a substratum of reconstituted basement membrane prepared from EHS tumors (Engelbreth-Holm-Swarm) have been characterized. In comparison to cells cultured on plastic, and even to those cultured on floating collagen cels, EHS elicits a dramatic increase in tissue-specific function. $\beta$-casein mRNA was shown to increase 70-fold in cells cultured on EHS atop a floating collagen gel. Cells on EHS are characterized by a unique three-dimensional organization into matrix-adherent spheres surrounded by a 


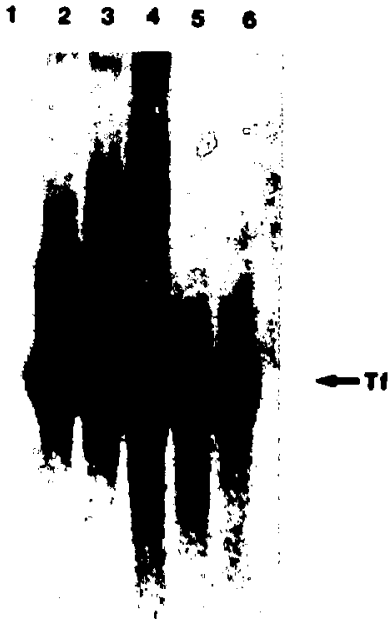

Fig. 26. The idenlification of mammary gland traneforin (T) $m R N A$ and its modulation by premancy and loclation. Thtal cellular RNA (10 HO) was extracted trom manmary glands of virgin (lones 1 and 2), premant (lanes $s$ and 1), and loctoting (lanes 5 and 6) mice. The RNA from mammary glands (Ranes 1,3 , and 5) and from liver (lanes 2, 4, and 6) were exporoted on formaldehyde-aygrarowe cel, blotted to Cene Serwen Plus membrane, and hybridiend with nich-tranclated $T F$ probe by stendard procedures. (XBB 882-884)

distinct basement membrane, in which the apical surfaces of the polar columnar cells face a central lumen (Fig. 2.7). That this morphology is accompanied by vectorial secretion of milk proteins was determined by comparing the protein componition of the medium exposed to the basal surfaces of the cells to that obtained after opening junctions between cells. This procedure extracts the medium sequestered within the lumina of the spheres. Immune-precipitation using a polyclonal antibody to akim mouse milk proteins of the bacal medium versus the luminal medium indicates that a greater proportion of the luminaly secreted proteins are milk proteins (Fig. 2.8). These data indicate that in addition to the dramatic changes in gene expression reported previously, EHS allows formation of functional three-dimensional structure resembling secretory alveoli in vivo. Thus basement membrane plays a role in both the structure and the function of the mammary gland and the underlying mechanism of this influence on gene expression is being pursued. Preliminary data have been ob-
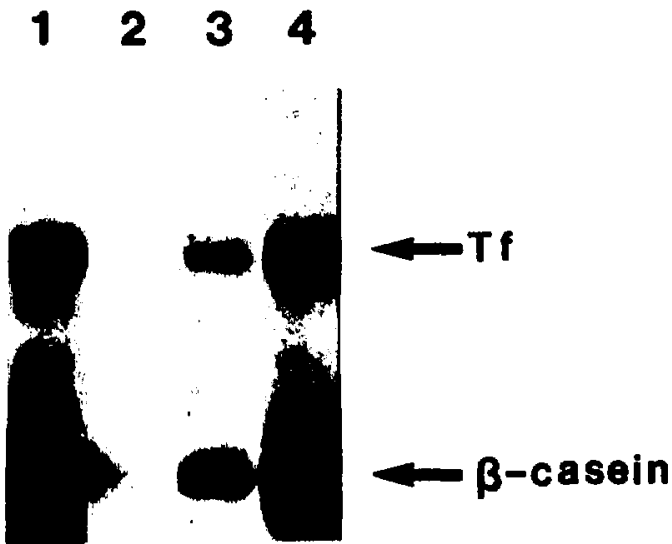

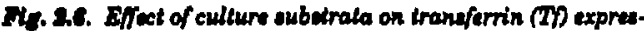
sion. Cull were iolated from mammary gland of presnant mice and culluned in the presence of lacto unic hormones on

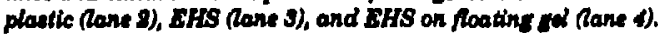
Lane 1 was RNA icolated from laclatiny mammary sland.

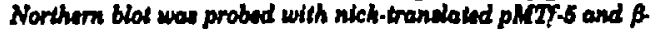
cosin eDNA cimultaneuly. Trensforrin-spucifle mRNA was detactable in lane 8 ofier longer autoradio raphic expoure. (RAB 878-9018)

tained suggesting that EHS may stimulate the production of baral lamina by mammary epithelial cells in culture. How the production of new basement membrane may affect cellular function and whether apecific disruption in cell-ECM interaction leads to loss of polarity and hence function are under tudy. The level of regulation of milk protein by nubstrata (i.e., tranceriptional or posttranscripticnal) is also being investigated uning nuclear run-on and pulse-chave experiments. Mina Binsell, Mary Helen Barcellos-Hoff, LiHow Chen, Tracy Ram, and Charles Streuli.

\section{Cell Polarity and Secretory Activity}

Research in the aren of epithelial cell polarity has focused on two areas: 1) the generation and maintanance of plasina membrane polarity; and 2) the significance of cell polarity for expression of ifferentiation in culture. In studying plasma membrane polarity, monoclonal antibodies have been used that are ractive with a high molecular weight glycoprotein (PAS-0), that is restricted to the apical plasma membrane of differentiated epithelial cells in the lactating mammary gland. PAS-0 is also expressed on the surface of cultured human mammary carcinoma cells (734B), a modei system for these studies. PAS-0 is polarized to the 

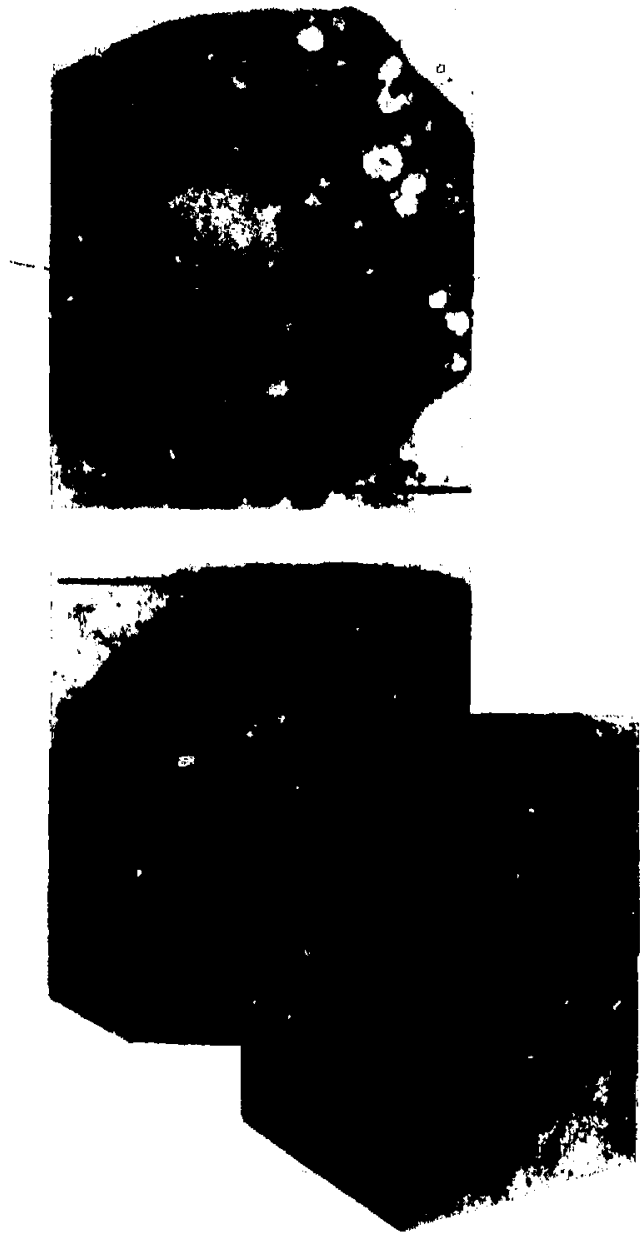

Ity. 27. Morpholovy of primary mammary celle on a rocomstituled bavement membrane (NFS). Thees etructures rewemble functional werstory alvedi in vivo. (OBB 889-883)

apical domain of the plasma membrane in the cultured celts independently of culture density. Experiment were designed to determine the relative ignificance of cell-cell, cell-subatratum, and membrane-cytoakeleton interactions in controlling the domain distribution of PAS-0. Immunofluoretcence and immunoelectronmicroscopy experinents (Fig. 2.9) demonatrated that all three interkstions were important for maintaining a polarized disstribution of PAS-0, and that they were interrelated. Experiments using druge that disrupt cytoskeletal
Milk Protein / $\mu g$ DNA

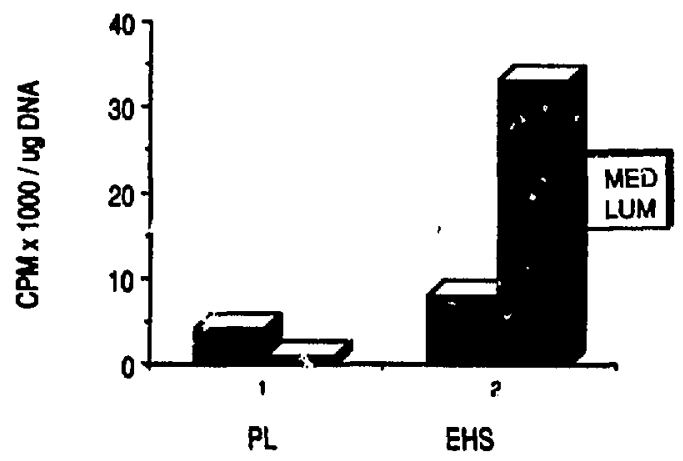

Hy. 2. Colle cocrete much hisher lowlo of milk protedius on the AHS matrix in addition, almost all the caseine are eccreted veclorlally int the lumin. $M(B D=$ medim; $L U M=$ lumin). COL 881-787,1)

clements in the cell, and in particular, the actincontaining microfilaments, led to the con slusion that PAS-0 was rentricted in its distribution by association (either direct or indirect) with submembranous microfilaments (Fig. 2.10). The stability and organization of this network, however, was dependent upon cell-cell and cell-substratum interactions.

While these results present a novel view of how specialized domains are established in the membrane of epithelial cells, they also provide intight into one of the ways by which cell-cell and cellubstratum interactions san influence structural differentiation in epithelia. Further studies of this simple model syutem may well contribute simificantly to our understanding of cell-cell and cellubatratum effects in more complex epithelial cells.

The fact that epithelial cells are polarized has important implications for the way in which they interact with their environment. In the mammary sland, the basal surface exclusively is involved in uptake of nutrients into the cells and in interacting with hormones and growth factors. The apical surface, in contrast, is active in secretion. The importance of such a polarized interaction with the environment for optimal differentiation was studied in mouse mammary epithelial cell straing (COMMA-1-D) in culture. Experiment utilizing a variety of exogenous extracellular matrices as culture substrata demonstrated that culture conditions that met the polarity constraints of the cell permitted differentiation and secretion. This was shown directly by culturing cells on nitrocellu- 


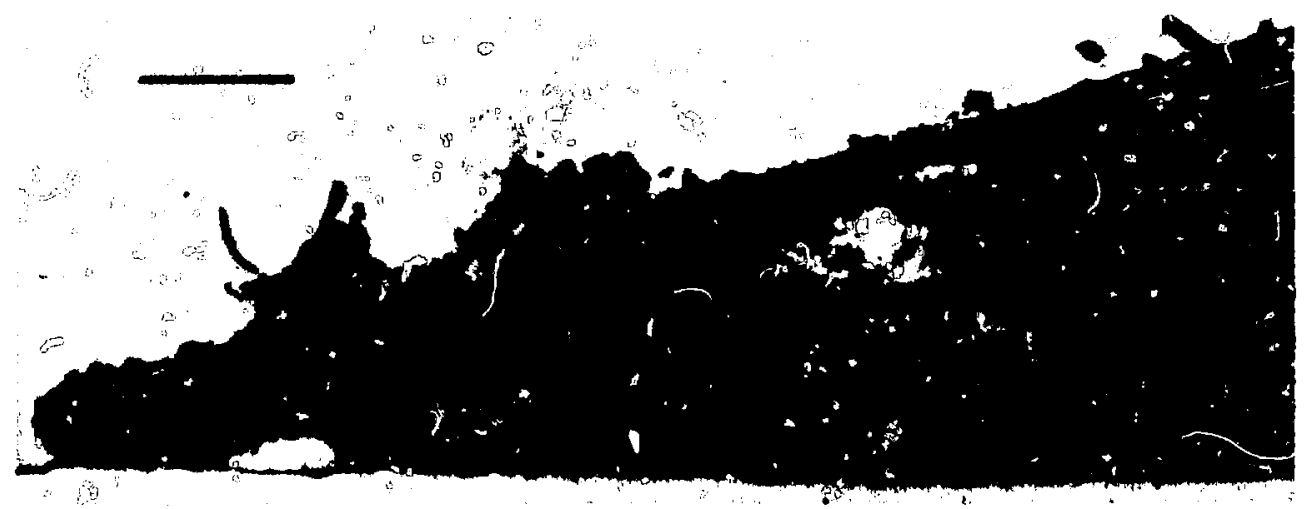

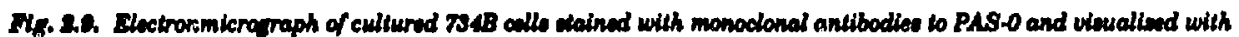

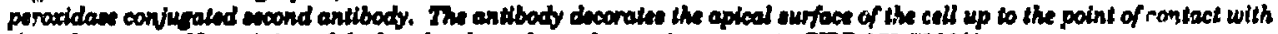

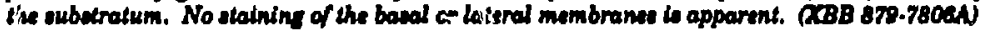

lose filter in Millicell chambers in which the basolateral ourface of the celle was exposed. Under these condition the cultures differentiated and secreted their differentiated products, namely milk proteins, in a highly polaried fachion (Fig. 2.t1).

These studies thus indicate that cell-exiracellular matrix and cell-cell interactions influence expression of differentiation in terminally differentiated cells. Whether cell-ECM interactions lead to estublishment of polarity which in turn leads to changes in gene sxprestion remains to be determined.

Gordon Parry, Lenny Mass, Betsey Cullen, and James Beck.

\section{TENDON CELLS}

In higher organisms, iiscues involved in structural organization must ayn shronize their own growth in relation to that of the whole organism.

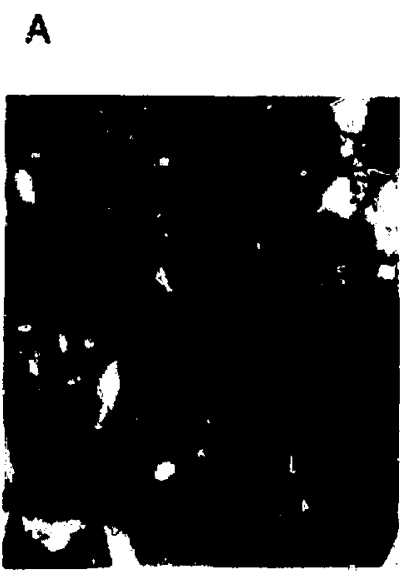

$\mathbf{B}$
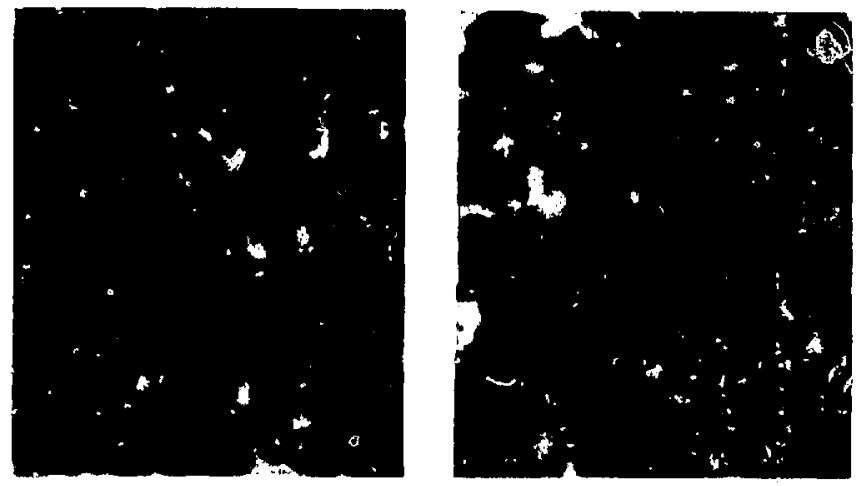

Bip. 3.10. Immunoflworacence analywie of PAS.O distribution on untreated and cytochalasin-B treated 73\&B cells. The PAS-O molecules were visualied waing a polyclonal antibody to PAS.O. (A) Untreated celle where the antigen is found exclusively on the apical aurface; (B) cylochsiaxin-B treated cello where the $P$. $S$-moleculs has redietributed to the baso. lateral membranes; (C) antibody-induced patehing of PAS-O after cytocholasin treatment. Patchine did not oceur in the absence of cylocholasin (A). (XBB 870-9177) 

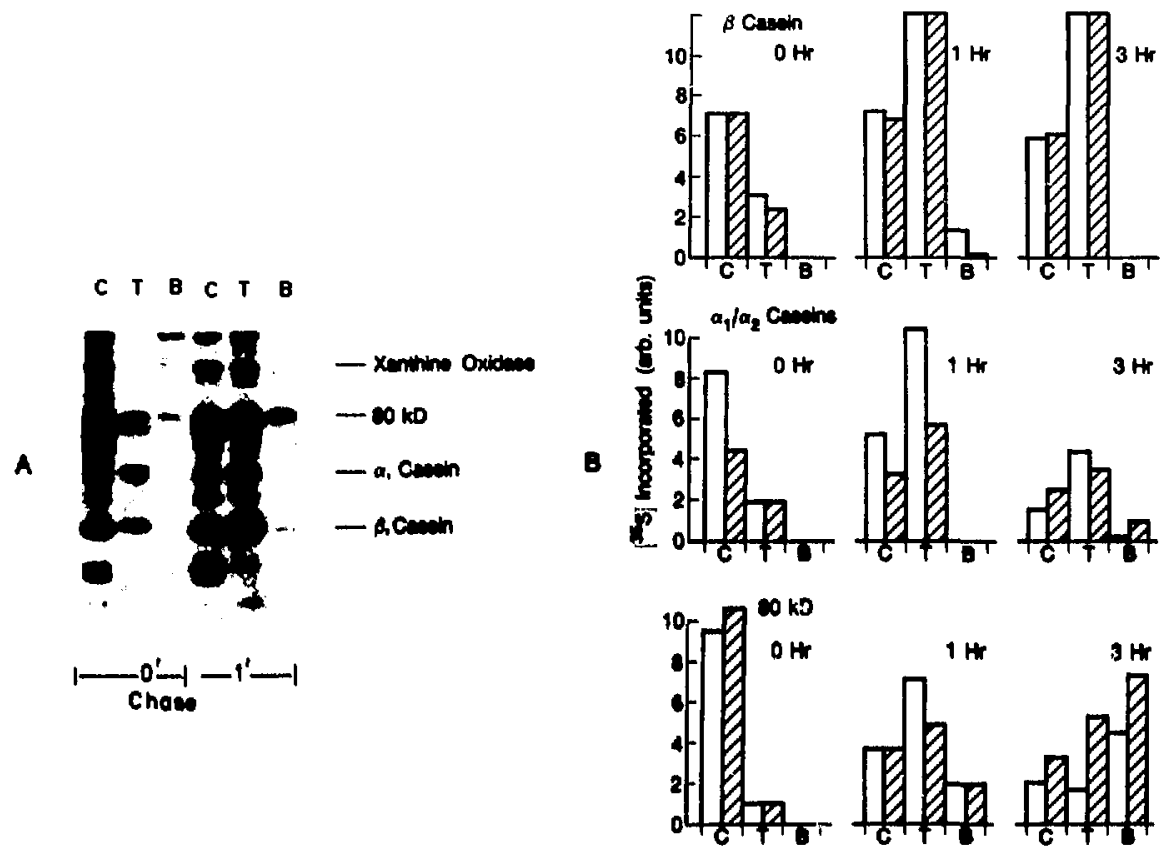

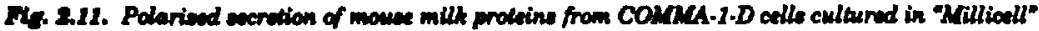

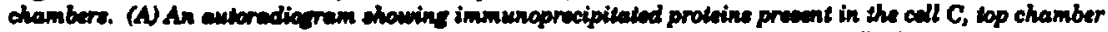

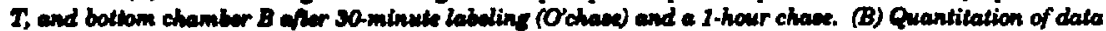

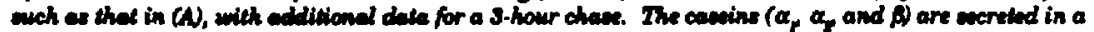

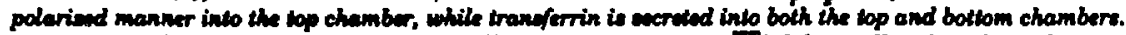
Coatine the "Millioull" chambers with extro-eallular matrix prodeine ( $Q$ ) did not affect the polarized

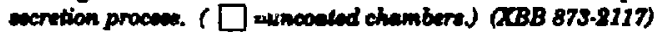

Since overall growth rate changes radically over the course of development, this raises important questions as to how tissues regulate their own size. In tendon, the important growth parameter is length, and this is determined to a firat approximation by the level of collagen production, since collagon is the major protein component. Deciphering the merbanivins controlling collagen production in tendon cells has importance not only because it is crucial to underetanding the regulation of the differentiater" state of a tendon cell bat also because it thede light on how tiemues coordinate growth regulation.

In this regard two important facts have emerged from studies of tendon cells in culture. First, the steps in the collagen pathway are tightly coupled allowing for foedback control. Socond, the cell responds to the density of its neighbors and only produces high levels of collagen at high cell density. In the past it was thown that the level of $a$ collagen modifying enxyme, prolyl hydroxylase, and procollagen mRNA are cell-density dependent. To further pursue how a cell detects its neighbors, the cell density increase in procollagen mRNA was used to develop a quantitative in situ hybridization auay (Fig. 2.12) so that the level of procollagen mRNA could be measured in individual cells. Uning this assay it can be thown that a tendon cell can detect the presence of other cells over a $1-\mathrm{mm}$ distance. Whether this is due to chemical gradients or physical changes such as expression of extracellular matrix components is under investigation.

$$
\text { Richard I. Schwarz. }
$$

\section{HEMOPOIESIS}

The basic problems in hemopoiesis are fundamental to many systems in biolczy. What directs a pluripoient stem cell to a spacil ; lineage? How does this differ from ? 'f-replicazion "- hat are thfactors that cause a co.nmitted cell to Lature? In addition, there are also unique characteristics of 


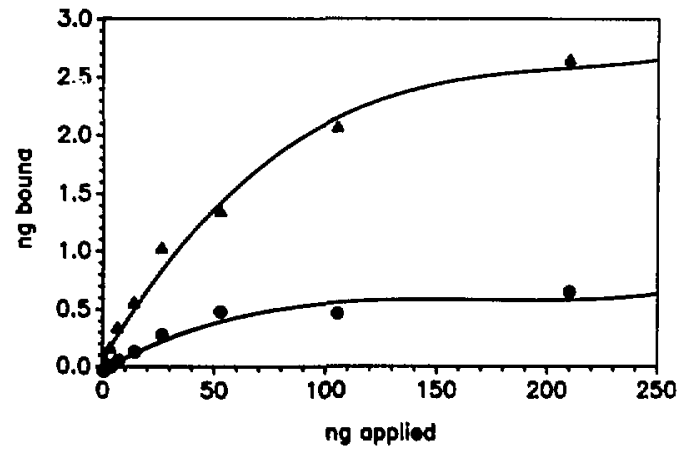

Fi. 2.12. Saturation of hybridiuble sites of procollagen

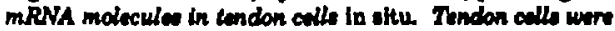
brown with (4) and willowt (o) asoorbals. The 6-fold increase in procollaren mRNA indwad by ascorbale (as shown previouly by dot hybridisation ueing purthed coled BNW is quantilatiody reproduced by in sttu hybridiuation. (ARL ent-7ise)

hemopoiesis that are poorly underntood. A hemopoietic atem cel! can wander throughout the blood stream but will be functional only in a fow sites in the body. The factors that contribute to this "hemopoietic inductive microenvironment" are not well underatood, and yot it influence cannot be doubted. A single stem cell injected into the peripheral blood can repopulate the bone marrow and start producing the $3 \times 10^{4}$ red blood cells per day and all the other blood types necessary for the survival of a lethally irradiatod mouse. In addition, numerous factors play a role in the induction and proliferation of hemopoietic cells and their mode of action needs to be understood. For example, erythropoietin is one of the firat factors shown to stimulate the erythroid lineage, but neither the exact producer cell in the kidney nor the receptor cell in the marrow have been clearly identified. With this lack of understanding of normal control, it is not surpriaing that the underlying mochanisms that cause this tightly controlled cell system to malfunction (leading to anemias, leukemias, immunodeficiency, etc.) are also poorly understood. Our approach is multidisciplinary, combining classical hemotological techniques with those of modern molecular biology. Each activity below focuses on a specific subset of questions in hemopoiesis but all share overlapping techniques and interest in the process as a whole.

\section{Erythroid Lineage}

Identifying Early Committed Stem Cell and the Inductive Microenvironment: The technique of in situ hybridization has been adapted for use with bone marrow smears. Using a hemoglobin mRNA probe, one can readily identify the late progenitor cells, normoblasts and reticulocytes, as well as earlier committed stem cells that would be impossible to identify by histological stains (Fig. 2.13).

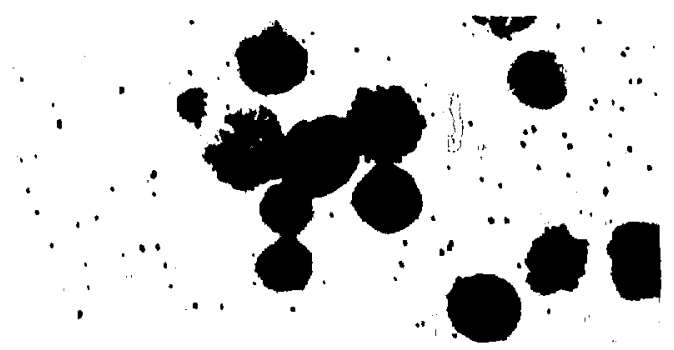

Fy. 21s. Cybepin of bone marrow celle from mien bloched in erthropoisis by hypertranctucion. Commilled elem calls can cill be detected by their abillty to hybridise in ditu to a $\beta$ hema lobin probe. The hemo sobin in mRNA contant is eatimated to be aboul 10 molecules (a)l. (ABB 889-885)

The ability to stimulate erythropoiesis by injection of erythropoietin or to inhibit erythropoiesis by hypertransfusion allows one to manipulate the flow through this lineage. Currently, in situ hybridization is used to follow a synchronous stimulation of the orythroid lineage by first repressing the marrow by hypertranafusion and then atimulating the committed stem cells with erythropoietin. Combining this information with ability of in situ hybridization to give spatial information about the organization of the various erythroid precureor cells in frozen sections of bone marrow should aid in our undertending of the hemopoietic inductive environment.

\section{Richard I. Schwarz and Mark Hertle.}

Action of Erythropoietin (Ep): The main objectives of this research are to investigate 1) the ontogeny and physiology of erythropoietin producing tissues, 2) the action of Ep at the receptor level in blood forming tissues, and 3) whether the expression of the Ep receptor gene is modulated by other hormones or growth factors during fetal, neonatal, and adult life. 
The production of red blood cells in the normal animal is regulated by Ep. However, as in other hormonal systems, the endocrine control of blood forming tissues, while Ep dependent, is also the result of complex interactions with other factors. Conversely, our recent finding of high Ep levels in the fetus and neonate indicate that $E_{p}$, besides being responsible for red blood cell production, might also have additional functions. Very high Ep levels were found in salivary glands, and it was shown that these glands are not the cource of extrarenal Ep. Rather, they may be the result of accumulation after puberty because no mRNA for Ep can be demonatrated in tienues derived from hypoxic rats. In addition, woxual dimorphism existo in rodents in that more Ep is found in male saliary glands than in fomales. Whether Ep plays a role in wound healing similar to nerve, epidermal, and transforming frowth factors dorived from the alivary stand is under inventigation. Renal Bp production is also being investigated in the adult animal as a function of insulin.like growth factor 1 (IGF1) and growth hormone.

To further define the action of $\mathrm{Ep}_{\mathrm{p}}$ a radioreceptor assay for Ep is presently being developed. Our laboratory is the firat to show that radiolabeled Dp retains its full biological activity, a fundamental prerequisite for the development of such an aseray. The use of a radioreceptor amany is manifold. It will allow the study of the kinetica and afifinity of the receptor in membrane preparations, the action of Ep at the receptor level during development and maturation, the modulation of the receptor gene expreasion as a function of other hormonal interactions, and the ontogeny of Bp receptors in blood forming tienues.

Givela K. Clemons and Darlene DeManincor.

\section{Megaharyocyte Lineage}

The overall goul is to understand the mechanisms that regulate megakaryocytopoiesis leading to the formation of platelets. Several approaches are being used:

A culture system has been developed where megakaryocytes can be stimulated by the plasma from thrombocytopenic rabbits to undergo changes that show many features of platelet formation in vivo. Plasma from normal rabbits is inactive. Current models predict that thrombopoietin, an as yet uncharacterized hormone, is elevated during thrombocytopenia and is responsible for the changes we observe in these cultures. Part of the observed changes are dependent on extension of microtubules that provide structural support for long cytoplasmic processes. In addition, microtubule coils that are characteristic of mature blood platelets may also form in the cytoplasmic extensions of the cultured megakaryocytes before intact platelets are released. Small cytoplasmic fragments that are ultrastructurally similar to platelets and respond to platelet activators are found in these cultures. Currently, a detailed analysis of cytoskeletal organization during the process of megakaryocyte fragmentation is being undertaken. This work is primarily by the use of immunocytochemistry and electron-microscopy.

A study is being made of the Wistar Furth rat, a strain that has a seneifically controlled abnormality of platelet size and number. Ultrastructural analyois has led to our belief that there may be a biochemical abnormality in the megakaryocyte membranes of these rats that leade to abnormal platelet formation. This work has been done in collaboration with Dr. Fern Davis at the Univertity of California, Davis. In addition, lipid and proteoflycan analyeses of the platelet from these animals have been underway to resolve biochemical alterations that may underlio the obverved abnormalities in membrane structure.

Studies of the unique characteristics of the zene expression in megaknryocytes are being initiated. Techniques for isolation of megakar. yocyte RNA have been developed, and currently the expression of protooncogenes and platelet alpha granule proteins is under inventigation. It is thought that protooncogene expreasion may play a role in the development of polyploidy, an unusual characteristic of megakaryocytes. Several alpha granule protein s appear to be specific for megakaryocytic cells. Therefore detection of the expression of these proteins may be a useful tool to detect otherwire unrecognizable early-committed percursor celle in the bone marrow.

Shirley Ebbe, Robert Leven, Donothy Carpenter, and Tamlyn Yee-Neben.

\section{Disease Models: Malaria}

The cellular mechanisms involved in the anemia and immunosuppression associated with malaria infection are boing investigated. Anemia, a major complication of malaria, accounts for the major morbidity and mortality of this disease. Our current focus is on how products of the immune system, such as interleukins and tumor necrosis factor (TNF), may mediate these pathological sequelae via their regulatory effects on stem cell 
proliferation and/or differentiation.

It has been shown that infection of mice with three strains of malaria (Plasmodium vinchei, $P$. berghei, and $P$. chabaudi adami) results in the depletion of bone marrow pluripotent stem cells (from which all erythroid and myeloid cells derive) and a concomitant increase in stem cells in the blood and spleen. Apparently, an increase in stem cells in the spleen does not compensate for the loss of erythropoietic activity of the bone marrow. Mice infured with recombinant TNF, a product of activated macrophages, show a similar depletion of bone marrow stem cells and an increase in spleen stem cells. Studies are now under way to determine whether such mobilized stem cells are functionally altered during malaria infection and therefore contribute to the anemia and immunosuppression observed in malaria-infected mice.

Studies using in vitro colony asuny for erythroid progenitor cells and an in vitro assay to measure erythroid precureor cell proliferation in responce to erythropoietin ( $\mathrm{Sp}_{\mathrm{p}}$ ), the hormone required for mature red blood cell development, demonatrated that committed erythroid progenitor cells as well as pluripotent stem celle are altered by malaria infection. Both early erythroid progenitor cells, colony forming unit erythroid (CFU-E), and later erythroid progenitor cells, burst forming unit erythroid (BFU-E), are present in reduced numbers in the bone marrow and apleen over the course of malaria infection (Fig. 2.14). Evidence suesests that a soluble factor may be responaible for the ineffective erythropoiesis obeerved in infocted mice. Conditioned media produced from upleen cells of malaria infected mice, or normal spleen cells incubated with malaria infected red blood cells, are able to inhibit the proliferative response of erythroid precursor cells to erythropoietin. What factor(s) ia/are involved is not known. Interleukin1 (IL-1), a product of macrophages and other cell types, has been shown by J.C. Schooley and colleagues to suppress the proliferative response to $\mathrm{Ep}$ in the same assuy.

In addition to anemia, malaria infection is also associated with immunosuppression, as shown by the depression of the in vitro responie of lymphocytes from malaria-infected mice to mitogens and/or antigens. The relationship of the immunosuppression to the inhibition of erythropoiesis and whether similar mecharisms are involved is currently under investigation.

In conclusion, it has been shown that malaria infection leads to alterations in the kinetics of
EFFECTS OF P.BERGHEI WFECTION ON BFUE \& CFUE
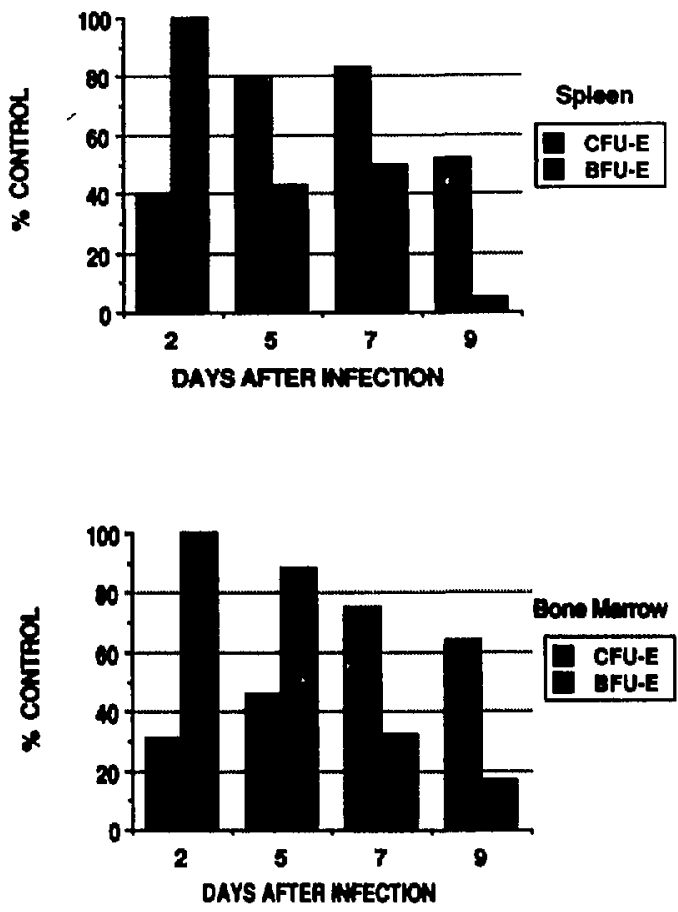

My. 224. The number of colony forming units erythroid (CFU. B) and burat forming units arythroid (BFU.B) in the splen and bone marrow of BALE/C mice af various times arter infection wilh P. berghoi. CFU.E and BFU-E were delermined by in vitro colony aseays. Reculta are expresed as the percantage of control values for normal BALB/c mice. (XBL 8711-4911)

pluripotent stem cells and in the functional capacity of committed erythroid progenitor cells and lymphocytes.

Investigations continue into the nature of the inhibitory factor(s) in conditioned media from malaria infected spleens, whether the target cell is a pluripotent stem cell or a committed erythroid progenitor cell, the molecular basis of the inhibition, and the role played by factors such as IL-1 and TNF. This research will not only increase our understanding of how hemopoiesis is normally regulated but will also aid in the development of therapeutic strategies for the anemia and immunoupresuion that are aseociated with number of infectious diseases such as malaria.

Paul H. Silverman, Kathleen L. Miller, Lynn J. Mahlmann, and Birgitta Kullgren. 
Bone Marrow Transplantation and the Pluripotent Stem Cell

Both pluripotential atem cells and precursor cells committed to the different lineages have been cultured and characterized in vitro. However, the relationship of pluripotential and precursor cells is poorly understood in vivo, because there are no methods to identify the early stem cells. Such methods must be highly sensitive, because the pluripotential stem cells represent a vanishing small number in the bone marrow. At the moment, only the progeny of these cells can be studied, mout satisfactorily after transfusion of marrow into a new host in which the pluripotential stem cells seed and proliferate. Present mothodology requires umples of at least 15,000 cells for this purpose. The development of a much more censitive mothod for the recognition of a fow hundrud traneplanted stem cells is thus badly needed for understanding of the kinetics and phyajology of atem cells. A major effort is under way to produce a monoclonal antibody to meet this methodological requirement.

\section{Carcinogenesis}

\section{INTRODUCTION}

The transformation of normal cells to malignancy is a multi-step process, involving derangements in cellular growth control, differentiation, and senescence. Myny factors are known to affect this process as initiators or promoters of carcinogenesis. These include chemical and physical agents (such as chemical carcinogens and radiation), viruges and cellular oncogenes, and dietary components. An individual's genetic makeup can also influence relative susceptibility to development of cancer. Members of the Cell and Molecular Biology Group are examining several different aspects of the carcinogenic process, ranging from assessments of the effect of chemical carcinogens, radiation, and viral infection on cells and animals. These studies should provide an increased understanding of both the causes of, and mechanisms accurring during oncogenic transformation, and should draw upon insights into DNA repair, replication and recombination, and responses to carcinogens described in the preceding sections.
In the meantime, work is in progress on the progeny of donor pluripotential stem cells While a single stem cell can repopulate a lethally irradiated mouse completely and permanently, it has been demonstrated, in collaboration with E.P. Cronkite, that there exist other stem cells that can repopulate the irradiated recipient only partially. The host's own stem cells may then recover and repopulate the entire animal. The ecology of the bone marrow stroma is being investigated to clarify these findings. Marrow transfused into a lethally irradiated mouse was retransfused subsequently into both secondary lethally irradiated hosts and normal-nonirradiated secondary hosts. The marrow exposed to a lothally irradiated environment repopulated the entire marrow of the recondary lothally irradiated hont, but failed to grow at all in the normal hout. This was the case, even when the number of marrow celle was increased to contain as many CFU-S as sufficed to produce a $30 \%$ level of donor cells in a normal, nonirradiated secondary host.

George Brecher, Marilyn Yee, and Steven Neben.

\section{ENVIRONMENTAL CARCINOGENS}

In an effort to evaluate the potential hazard to human health of exposure to chemical carcinogens, the Group has developed a Carcinogenic Potency Database (CPDB). This database includes the published results of chronic animal carcinogenesis biossays from about 4000 experiment involving 1000 different chemicals. Estimates of the TD. values of rodent carcinogens vary more than 10 . millionfold. These TD, values have been used to rank possible hazards to humans from exposure to chemicals known to be carcinogenic in rate or mice, in particular, 41 chemicals for which there are also defined OSHA Permissible Exposure Levels (PEL). When the PEL (mg/kg/day) for these chemicals are compared to the rodent $\mathrm{TD}_{w}$ the resulting ratios differ by more than 100,000-fold from each other. It therefore seems reasonable to give particular attention to the reduction of allowable worker exposure to those substances that appear to be 
hazardous by this iridex, and that some workers may be exposed to full-time near the PEL, namely ethylene dibromide, ethylene dichloride, 1,3butadiene, tetrachloroethylene, propylene oxide, chloroform, formaldehyde, methylene chloride, dioxane, and benzene.

\section{Bruce Ames and Lois Gold.}

\section{HUMAN MAMMARY CANCER}

\section{Interaction of Human Mammary Cells with Growth Factors and Oncogenes}

Much of the work in the carcinogenesis group utilizes a human mammary model system developed by Martha Stampfer. This culture aystem permits long-term active growth of normal human mammary epithelial cell (HMEC) in a serum-free medium. In vitro exposure of normal HMEC to the chemical carcinogen benzo(w)pyrene has also led to the development of two immortalized cell lines. Transformation to malignancy can occur when these cell lines are further exposed to tumor virus oncogenes. These unique cell substrates are being used in many laboratories at LBL and around the world to study and compare the properties of normal and transformed human epithelial cells. A major effort in the past year (in collaboration with Marc Lippman and Bob Dickson at NIH) has involved examining these cells' requirements for, responses to, and production of growth factora, hormones, and their receptorn. In particular, TGF$\beta$ growth inhibition and receptor levels are being assessed as a function of transformation, ape in culture, and presence of other growth factorn, while TGF- $\alpha$ and EGF receptor mRNA and protein synthesis have been shown to be active in all the HMEC types examined. Subpopulations of the immortalized cell lines that have altered growth requirements or responses have been isolated to aid in the dissection of the mechanisms of cell responses to growth factors. Growth in restrictive media also appears to select for cells altered by further exposure to a chemical carcinogen. It is hoped that this selective growth will astist quantitation of the transformative potential of different carcinogens.

\section{Interaction of Human Mammary Epithelial Cells with Carcinogenic Hydrocarbons}

The normal HMEC have been used to study another aspect of chemical carcinogenesis, the metabolism of pro-carcinogens such as benzo(a)pyrene (BaP) to their ultimate carcinogen form, in this case, the benzo(a)pyrene-diolexpoxide (BPDE). Reaction of BPDE with DNA may result in mutation or cellular transformation. The group has previously shown that HMEC readily convert $\mathrm{BaP}$ to the active BPDE form, whereas fibroblast cells from the same tissue are much less capable of this reaction. This work is continuing by determining whether arachidonic acid, particularly cyclooxygenase, plays a role in this conversion by the HMEC. Pretreatment of normal HMEC with cold $\mathrm{BaP}$ has been found to increase the overall :onversion of tritiated BaP to BPDE, as measured by BP. 7,8-diol and tetraol hyrolysis products of BPDE identified by reversed-phase HPLC. Methods to quantitate the BPDE-derived tetraols by periodate oxidation and calcium oxide treatment are being developed. Cyclooxygenase inhibitors appear to partially inhibit this tertraol production, while thus far, inhibitors of lipoxygenase have no effect. Hence, of these two pathways the cyclooxygenase appears to be the predominant one in HMEC. Recently, 'H-BaP-7,8-diol was found to be a superior subutrate to ' $\mathrm{H}-\mathrm{BaP}$ in that it produces $\mathrm{BPDE}$ derived tetraols both more readily and cleanly. Use of this substrate should allow a quantitative dissection of the key step, the conversion of BP-7,8-diol to BPDE by evaluating the effect of inhibitors of cytochrome P-450 as well as inhibitors of the arachidonic acid cascade. In a collaborative effort with Mina Bissell and co-workers, the possible role of the arachidonic acid cascade in wound-promoted tumors in Rous sarcoma virus infected chicks is under investigation.

Martha Stampfer, Jack Bartley, Allan Tischler, Myriam Alhadeff, Linda Hayashi, Midori Ho. sobuchi, Gerri Levine, and Amnie Pang.

\section{NOVEL APPROACHES TO VIRAL CARCINO- GENESIS: HOST-VIRUS INTERACTIONS IN DIFFERENTIATION AND MALIGNANCY}

The recent advent of techniques for the incorporation of foreign genetic information into animal host in vivo has allowed us to embark on a systematic and ambitious project to apply modern cell and molecular biology to answer basic questions in tumor biology. Since it has been shown that the embryo is capable of regulating the malignant properties of Rous sarcoma virus (RSV), the system affords the exciting opportunity to evaluate some of the key elements in the transformation process. In the past year it has been shown that while the level of pp60src (the product of the transforming gene of 
RSV) is not proportional to the expression of other viral structural proteins such as p19 (a compound of group-specfic antigens), nevertheless src is expressed in the early embryo and further, it is active because it phosphorylates tyrosine residues of proteins. To trace the lineage of the target cells and to investigate whether the older embryo could become permissive for sarcoma, it was first necessary to prevent viremia and to prolong the life of the embryo. To achieve these goals, we developed a
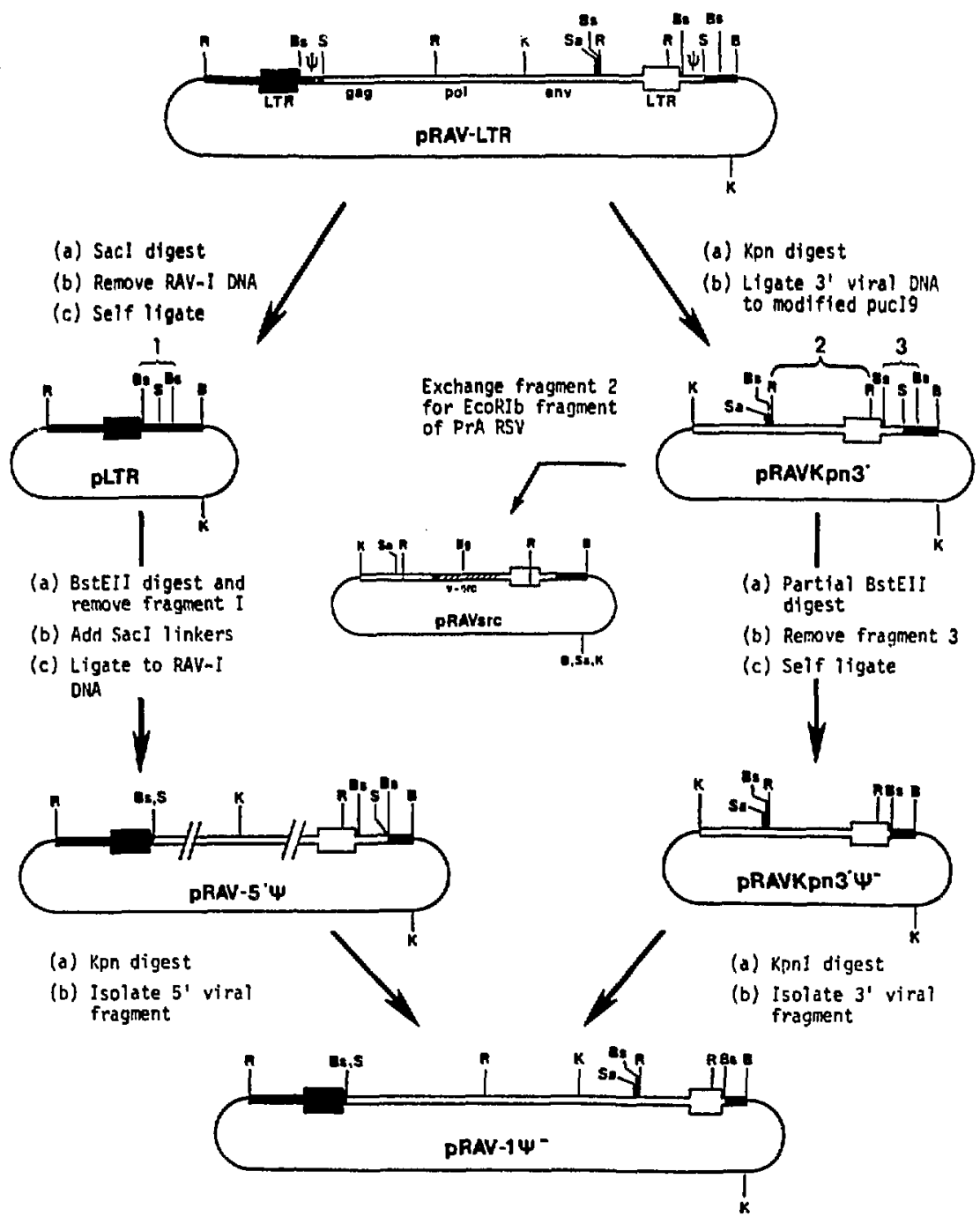

Fi. 215. Sehematic repreantation of pRAV-1 4 condruction. Baxd regions represent proviral DNA, RAV-I (open baves), AEV10 (closed baves). Single lines represent bacterial plasmid DNA. Duplicated RNA encopaidation equences, \%, are indicated in pRAV-LTR. Relevant entyme cleavage siles are indicated; $B, B a m H I$ (sices within RAV.I DNA are not shown); $B g, B g I I ; B s, B s t E I I ;, K p n I ; R, E c o R I$, S, SacI; Sa, SAII. RAL 876-264OW 
vector-packaging quail cell line, stably infected with an avian leukosis virus-derivative deficient in packaging sequences $\psi$. The construction of this derivative (named pRAV-1\%) is shown in Fig. 2.15. Novel replication-defective $v$-sre constructs containing drug-resistant genes were transfected into pRAV-1w, and the resulting colonies were shown to stably produce up to $2 \times 10^{2}$ replication-defective (RD) infectious viral particles. These viruses are currently being injected into the embryo. Preliminary results indicate that unlike the wild type virus that was expressed early in the skeletal muscle only and would not allow viability beyond days 12-14, the $R D$ virus appears to be expressed in the limb connective tissue post-day-12, but allows embryo survival at least to day 18 at which time it appears to form sarcoma. These experiments verify the verwatility of the embryo system and should lead to identification of factors that appear (or disappear) between days 12-18 that allow the expression of the malignant phenotype. In another complementary approach, we are exploring the mechanism by which wounding acts as a cocarcinogen in RSV tumorigenicity in hatched chicks. Techniques have been developed for sectioning through the wounded area (Fig. 2.16) to follow the course of activation of silent integrated virus, for subsequent localization of virus and dividing-cells using antibodies, immunohistochemistry, and in situ hybridization with riboprobes of viral genes. In collaboration with Michael Sporn of NIH, the pattern of TGF- $\beta$ expression after wounding and its possible role in RSV-tumorigenicity is also being investigated.

Mina J. Bissell, Anthony Howlett, Andrew Stoher, Michael Sieweke, and Jill Hatier.

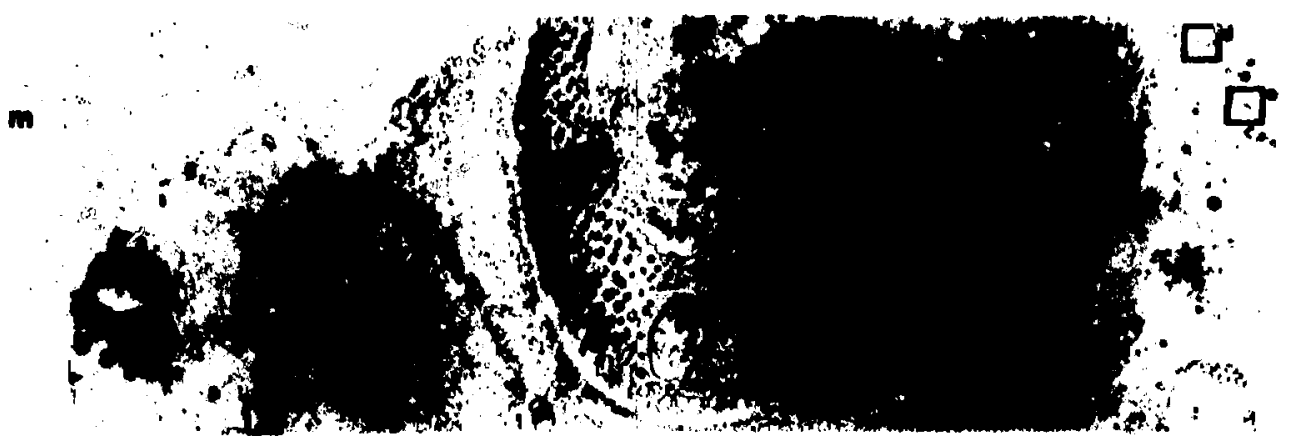

FI. 2.16. Phase contrast imase of a tranevere frosen saction $(6 \mu \mathrm{m})$ of a cuture wound at the midpoint of the radius-ulne region I of the right wire of a 16 -day-old chichen 20 hours afler wounding. The suture allows the procice localization of

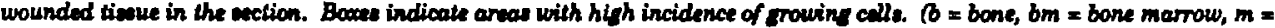
muacle, $1=$ uture). (XBB 882-886) 
Publications: Cell and Molecular Biology

\section{CONTRIBUTTONS TO JOURNALS}

Ames, B.N., Magaw, R., and Gold, L. S. Ranking possible carcinogenic hazards. Science 236, 271-280 (1987).

Bernstein, L., Gold, L.S., Ames, B.N., Pike, M.C., and Hoel, D. Some tautologous aspects of the comparieon of carcinogenic potency in rats and mice. Fundamental and Appl. Toxicol. 5, 79-86 (1985).

Brecher, G., Beal, S.L., and Schneiderman, M. Renewal and releawe of hemopoietic stem cell. Does clonal succession exist? Blood Cells 12, 103-112 (1986).

Chan, L.-M., Hatier, C., Parry, G., Werb, Z., and Bissell, M.J. Collagen-fibronectin interaction: in normal and Rous sarcoma transformed avian tendon cells: Possible mechanism for increased extracellular matrix turnover after transformation. In Vitro Cell and Molec.

Biology 23, 308-314 (1987).

Chandra, M., McVicar, M., Clemons, G., Mossey, R.T., and Wilkes, B.M. Role of erythropoietin in the reversal of anemia of renal failure with continuous ambulatory peritoneal dialysis.

Nephron 46, 312-315 (1987).

Clemons, G.K., DeManincor, D., Fitzsimmons, S.L., and Garcia, J.F. Immunoreactive erythropoietin studies in hypoxic rat. and the role of the salivary glands. Exp. Hematology 10, 18-23 (1987).

Cole, G.M., Schild, D., Lovett, S.T., and Mortimer, R.K. Regulation of RAD54- and RAD52-lacZ gene fusions in Saccharomyces cerevisioce in response to DNA damage. Molecular and Cellular Biology 7, 1078-1084 (1987).
Contopolou, C.R., Cook, V.E., and Mcrtimer, R.K. Analysis of DNA double strand breakage and repair using orthogonal field alternation gel electrophoresis. Yeast 3, 71-76 (1987)

Dixon, M.L. and Mortimer, R.K. A yeast screening system for simultaneously monitoring multiple genetic endpoints. Mutation Research 161, 49-64 (1986).

Eckhardt-Schupp, R., Siede, W., and Game, J.C. The RAD24(=Rs) gene product of Saccharomyces cerevisioe participates in two different pathways of DNA Repair. Genetics 116, 83-90 (1987).

Gold, L.S., Bernstein, L., Kaldor, J., Backman, G., and Hoel, D. An empirical comparison of methods used to estimate carcinogenic potency in long-term animal bioassays: Lifetime vt. summary incidence data. Fundamental and Appl. Toxicol. 6, 263-269 (1986).

Gold, L.S., Wright, C., Bernstein, L., and deVeciana, M. Reproducibility of results in "nearreplicate" carcinogenesis bioassays. J. Natl. Cancer Inst. 78, 1149-1158 (1987).

Goth-Goldstein, R. MNNG-induced partial phenotypic reversion of the Mer-cells. Carcinogene. sis 8, 1449-1453 (1987).

Goth-Goldstien, $\boldsymbol{R}$. and Hughes, M. Cell killing by various monofunctional alkylating agents in Chinese hamster ovary cells. Mutation Ressearch 177, 267-276 (1987).

Goth-Goldstein, R. and Hughes, M. Characterization of a $\mathrm{CHO}$ variant in respect to aklylating agent-induced biological effects and DNA repair. Mutation Research 184, 139-146 (1987). 
Guzman, R.C., Osborn, R.C., Bartley, J.C., Imagawa, W., Asch, B., and Nandi, S. In vitro transformation of mouse mammary epithelial cells grown serum-free inside collagen gels. Cancer Research 47, 275-280 (1987).

Howlett, A.R., Cullen, B., Hertle, M., and Bissell, M.J. Tissue tropism and temporal expression of Rous sarcoma virus in embryonic avian limb in ovo and after transfer to cell culture. Oncogene Res. 1, 25F-263 (1987).

Kusmierek, J.T., Jenren, D.E., Spengler, S.J., Stolarski, R., and Singer, B. Synthesis and properties of $N^{2}, 3$-ethenoguanosine and $N^{2}, 3$ ethenoguanosine 6'-diphouphate. J. Organic Chem. 62, 2374-2378 (1987).

Leadon, S.A. Production of thymine glycols in DNA by radiation and chemical carcinogens as detected by a monoclonal antibody. Brit. $J$. Cancer 55 (Suppl. VIID, 113-117 (1987).

Lee, E.Y.-H., Barcellos-Hoff, M.H., Chen, L.H., Parry, G., and Biscell, M.J. Transferrin is a major mouse milk protein and is synthesized by mammary epithelial cells. In Vitro Cellular and Molecular Biol. 23, 221-226 (1987)

Li, M.L., Aggeler, J., Farson, D.A., Hatier, C., Hassell, J., and Biseell, M.J. Influence of a reconstituted basement membrane and it components on casein gone expression and secretion in mouse mammary epithelial cells. Proc. Natl. Acad. Sci. USA 81, 136-140 (1987).

Lin, J.P., Aker, M., Sitney, K., and Mortimer, R.K. First position wobble in codon-anticodon pairing: amber suppression by yeast glutamine tRNA. Gene 49, 383-388 (1986).

Lovett, S.T. and Mortimer, R.K. Characterization of null mutants of the RADS5 gene of Saccharomyces cerevisiae: Bffects of temperature, osmotic strength and mating type. Genetics $116,547-553$ (1987).
Medina, D., Li, M.L., Oborn, C.J., and Bissell, M.J. Casein gene expression in mouse mammary epithelial cell lines: Dependence upon extracellular matrix and cell type. Exp. Cell Res. 172, 192-203 (1987).

Menon, R., Bartley, J.C., Som, S., and Banerjee, M.R. Metabolism of 7,12-

dimethylbunz(a)anthracene by mouse mammary cells in serum-free organ culture systems. European J. Cancer and Clin. Oncology 23, $395-400$ (1987).

Parry, G., Cullen, B., Kaetzel, C.S, Kramer, R., and Moss, $L$. Regulation of differentiation and polarized cecretion in mammary epithelial cells maintained in culture: Extra-cellular matrix and membrane polarity influencen. J. Cell Biol. 105, 2043-2051 (1987).

Pavlovic-Kentera, V., Clemons, G.K., Djukanovic, L., and Biljanovic, L. Erythropoietin and anemia in chronic renal failure. Experimental Hematology 15, 785-789 (1987).

Preston, B.D., Singer, B., and Loeb, L.A. Mutagenic potential of $\mathrm{O}^{4}$-methylthymine in vivo determined by an enzymatic approach to wite-specific mutagensil. Proc. Natl. Acad. Sci. USA 83, 8501-8505 (1986).

Preston, B.D., Singer, B., and Loeb, L.A. Comparicon of the relative mutagenicities of O-alkylthmines site-specifically incorporated into $\phi \times 174$ DNA. J. Biol. Chem. 262, 13821-13827 (1987).

Roth, R.M., Game, J.C., and Peak, M.J. Sensitivities to monochromatic $254-\mathrm{nm}$ and $365-\mathrm{nm}$ radiation of closely related strains of Saccharomyces cerevisiace with differing repair capabilities. Photochem. Photobiol. 45, 479-843, (1987).

Schooley, J.C., Kullgren, B., and Allicon, A.C. Inhibition by interleukin-1 of the action of erythropoietin on erythroid precursors and its 
possible role in the pathogenesis of hypoplastic anemia. Brit. J. Haematology 67, 11-17 (1987).

Schwarz, R.I., Kleinman, P., and Owens, N. Ascorbate can act as an inducer of the collagen pathway because most ateps are tightly coupled. N.Y. Acad. Sci. 498, 172-185 (1987).

Silverman, P.H., Schooley, J.C., and Mahlmann, L.J. Murine malaria decreanes hemopoietic stem cells. Blood 69, 408-413 (1987).

Singer, B., Spengler, S.J., Chavez, F., and Kusmierek, J.T. The vinyl chloride-derived nucloowide, $N$, 3-ethenogunnouino, is a highly efficiont mutagen in tranweription. Carcinogenesis 8 , 746-747 (1987).

Smith, H.S. and Bissell, M.J. Cancer at the cellular level. Cancer Res. 47, 3337-3338 (1987).

Stoker, A.W. and Bissell, M.J. Quantitative immunocytochemcial assay for infection avian retroviruses. J. Gen. Virology 68, 2481-2485 (1987).

Teramo, K.A., Widness, J.A., Clemons, G.K, Voutilainen, P., Saarinen, R, McKinlay, S., and Schwartz, R. Amniotic fluid erythropoietin correlates with umbilical plasma erythropoietin in normal and abnormal pregnancy. Am.J. Obst. Gynecol. 69, 710-716 (1987).

Tischler, A., Bailey, P., Dallob, A., Witzel, P., Durette, P., Rupprecht, K, Allison, D., Dougherty, H., Humes, J., Ham, E., Bonney, R. Egan, R., Gallagher, T., Miller, D., and Goldenberg, M. L-652,343: A novel dual 5-lipooxygenasd cyclooxygenase inhibitor. Advarces in Prostaglandins, Thromboxanes and Leukotrienes Research 16, 63 (1986).

Tischler, A.N. and Lanza, T.J. 6-Submtituted indoles form 0 -halonitrobenzenes. Tetrahedron Letters 27(15), 1653 (1986).
Tyndall, M.R., Teitel, D.F., Lutin, W.A., Clemons, G.K., and Dallman, P.R. Serum erythropoietin in patients with congenital heart disease. $J$. Pediatrics 110, 538-544 (1987).

Walle, A.J., Wong, G.Y., Clemons, G.K., and Garcia, J.F. Erythropoietin-hematocrit-feedback circuit in the anemia of endstage renal disease: effects of transfusions, hemorrhage and hemodialysis. Kidney International 31, 1205-1209 (1987).

\section{CONTRIBUTIONS TO BOOKS AND PRO. CEEDINGS}

Bisuell, M.J. and Agreler, J. Dynamic reciprocity: How do extracellular matrix and hormones direct gene expression? Pages 251-262 in Mechanisms of Signal Transduction by Hormones and Growth Factors, M. Cabot, ed., Alan Lims Inc, New York (1987).

Bissell, M.J. and Hall, H.G. Form and function in the mammary gland: The role of extracellular matrix. Pages 97-146 in The Mammary Gland, M.C. Neville and C.W. Daniel, eds., Plenum Publ. Corp., New York (1987).

Bissell, M.J., Li, IM.L., Chen, L-H., and Lee, E. Y-H. Regulation of mills protein in the mouse mammary epithelial cells by extracellular matrix and hormones. Pages 155-186 in Growth and Differentiation of Mammary Cells in Culture, J. Enami and R. Ham, eds., Japan Scientific Societieı Presı, Tokyo, Japan (1987).

Brecher, G. Commentary on M. Rosendaal, S. Villa, and C. Hooper: Correspondence between the development of hemopoietic tissue and the time of colony formation by colony-forming cells. Blood Cells 12, 625-626 (1987).

Brecher, G., Commentary on M. Rosendaal and J. J. Adam, Hemopoietic progenitors in different parts of the femur perform different functions during regeneration. Blood Cells 12, 641-643 (1987). 
Brecher, G., Beal, S.L., anù Schneiderman, M. Reply to commentary: Renewal and release of hemopoietic stem cells: does clonal succession exist? Blood Cells 12, 127 (1987).

Clemons, G.K. Some endocrine aspects of renal and extrarenal erythropoietin in normoxic and hypoxic rats. Pages 177-186 in Molecular and Cellular Aspects of Erythropoietin and Erythropoiesis, I.N. Rich, ed., NATO ASI Series, Volume H8. Springer-Verlag Berlin Heidelberg (1987).

Esposito, M.S. Book Review: "Meionis." P.M. Moens, ed., Academic Press, Orlando, Forida; 1987. (391 pp) Cell 50, 821-822 (1987).

Goth-Goldstein, R. and Hughes, M. Characterization of two CHO variants in respect to MNNGinduced cell killing, mutations, and repair of methylated DNA bases. Pages 47-451 in Radiation Carcinogenesis and DNA Alterations, F.J. Burns, A.C. Upton, G. Sillini, eds., Plenum Publ. Corp., New York (1986).

Ham, R.G., Hammond, S.L., Stampfer, M.R., and Bartley, J.C. Normal human mammary epthelial cells in serum-free medium. Pages 59-108 in Growth and Differentiation of Mammary Cells in Culture, J. Enami, ed., Japan Scientific Societies Prem, Tokyo (1987).

Hanawalt, P.C., Bohr, V.A., Leadon, S.A., Mancbridge, J.N. and Reusch, M.K.H. Comparative analysis of cutaneous DNA repair in vivo ard in vitro.. Pages 217-231 in Proceedings of 4 th U.S. -Japan Conference on the Processes in Epidermal Differentiation, 1. Bernstein and T. Hirone, eds., Praeger, New York (1987).

Hosoda, J., Holbrook, E.L., Moise, H., Bjornstad, K., Maleas, D., and Esposito, M.S. Fractionation of DNA metabolic proteins of Saccharomy. ces cerevisiac by DNA cellulose chromatography: SSB-1, 8sDNA-dependent ATPase, DNA polymerase, DNA primase, topoisomerase I, and resolvase. Pages 171-192 in Biological Research on Industrial Yeasts, Volume II; G.G. Stewart, I. Russell, R.D. Klein, and R.R. Hiebsch, eds., CRC Press, Inc., Boca Ratnr, Florida (1987).

Klitz, W., Kuhner, M.K., Robinson, W.P., and Esposito, M.S. Analysis of genetic and serological traits typed in multiply affected IDDM families. Presented at NIII-NATO-INSERM Advanced Research Workshop, September 1987. Genetic Analysis Workshop 5, 1-5 (1987).

Leadon, S.A. Immunolorical probes for lesiony and repair patches in DNA. Pages 331-336 in DNA Repair: A Laboratory Manual of Research Procedures, Volume III, E.C. Friedberg and P.C. Hanawalt, eds., Marcel Dekker, New York (1987).

Singer, B., Spengler, S.J., Chavez, F., Sagi, J., Kusmierek, J.G., Preston, B.D., and Loeb, L.A. O-alkyldeoxythymidines are recognized by DNA polymerase I as deoxythymidine or deoxycytidine. Pages 37-10 in N-Nitroso Compounds: Occurrence, Biological Effects and Relevance to Human Cancer, J.K. O'Neill, et al, cds., IARC, Volume 84, L.von (1987).

Stampfer, M.R. and Bartley, J.C. Growth and transformation of human mammary epithelial cell in culture. Chapter 20 in Cellular and Molecular Biology of Experimental Mammary Cancer, D. Medina, W. Kidwell, G. Heppner, and E. Anderwon, eds., Plenum Publishing Corp., New York (1987).

\section{LBL REPORTS ISSUED}

Hosodn, J., Bell, M., Bjornstad, K., Hosobuchi, M., Moise, $H$., and Esposito, M.S. Single-strand upecific DNA binding proteins of Saccharomy. cef cerevisiae. Lawrence Berkeley Laboratory report LBL-22091 (1986). 


\section{Section 3. Radiation Biophysics}

The Radiation Biophysics Group brings an interdisciplinary approach to understanding both the harmful and beneficial effectis of a large variety of ionizing and nonionizing, radiations. This understanding is being developea through fundamental studies at all lovels of biological orranization - the physical, chemical, molecular, cellular, tiunue, and orran levels. The ultimate goals are $\$$ to determine the health ritk from very low levele of radiation such as those found : : spacc, or the natural and occupational environrnents; 2) to develop procedures to mitigate the risk due to lons term radiation exposuren; and 3 ) to optimize the utilization of different qualities of radiation for the treatment of cancer and certain non-neoplastic brain disorders.

The research activities related to these goals are quite broad in scope. "The formal training or background of each member of the group is in either physics, chemintry, or biology. However, over the years, weveral have crossed their boundaries and extended themse'ven into other areas. The members and their affiliated activities are shown below.

Our main interest in nonionizing radiations concrarn the biological effect of static magnetic fields and radio-frequency ( $\mathrm{r}$ ) radiation. A new 9.0-\{esla $(90,000$ gauas) stperconducting magnet facility has recently been intalled to atudy the respunses of cellular, tissue, and animal systum. when exposed to such ultrahigh magnetic fields.

Ionizing radiation studies center around the Bevalac, a unique source of energetic heavy particles that is capable of acielerating ions of masses ranging from hydrogen to uranium. These accelerated ions are extremely valuable for probing various cellular properties. In addition, nome of these ions are currently used in cancer therapy and in treatment of certain brain disorders. Many basic radiobiological studies are being extended to understand the health effects of alpha particles (energetic helium ions) en itted from the decay products of radon gas. Re ton, a natural pollutant, is of national concern because of its effect in inducing lung cancer. The central focus of research activities in ionizing radiations will continue to be the elucidation of the effects of heavy charged particles in biological materials at various levels of organization. It is becoming increasingly clear that the knowledge gained from particle studies can improve the understanding of the effects of $x$ rays and gamma rays in biological materials.

Physicists are engaged in research related to 1) the qualitative and guantitative aspects of the physical nature (charge, mass, energy loss, etc.) of radiation fields associated with heavy charged particles, and 2) the energy deponition patterns within region equivalent in size to cellular dimensions. This information is essentis? for basic tudies at well as for pianning radiation exposure in clinical applications, and for ensuring the radiologic enfety of personnel in space.

The information obtained from phytical studies then becomes the basis for evaluating chemical changes in a biological target. The end result is ontabliahing a better quantitative relationship between the radiation quality and the initial cellular damage.

The DNA inside the cellular nucleus is considered to be the most critical radiological target becuuse it contains all the genetic information. Any chemical change in this important molecule has far icaiching biological consequences. Chemical changer associated with a given site (sugar or base) on a DNA molecule caused by ionizing radiation have been considered through two mechanisms: 1 ) by hydroxyl radicals produced from water in the cell, and 2) by direct depusition of energy on the DNA itself. These two mechanisms then define the molecula- isature of the damage and become the starting point for our studies in molecular radiobiology.

Research in molecular radiobiology is concerned with investigation of the repair, misrepair, and unrepair of the various types of damage to mammalian DNA caused by ionizing radiation. Chromatin and chromosome breaks are also included in these studies. The central problem is the identification of those initial chemical changes that lead to either mutation or transformation if not repaired adequately. The chemists and molecular biologists work together to understand the correlation between chemical changes and their possible biological consequences. They explvit high-LET radiatior $s$ to better understand the processes leading to repair or misrepair of radiation-induced lesions. Preliminary studies indicate that high-LET radiation causes a larger number of unrepaired (or possibly misrepaired) lesions per unit dose than dc $x$ rays or toxic chemicals. While most basic studies 
in molecular radiobiology are done in vitro, the fundamental knowledge acquired is subsequently further studied in cellular environments.

One focal point in the overall research efforts by physicists, chemists, and molecular radiobiologists is understanding the responses of mammalian cells when insulted by ionizing radiation. They interact with the cellular biologists to analyze cellular data in terms of the fundamental physical, chemical, and molecular processes involved. Cellular radiobiologists are trying to understand the correlation between damage and repair processes in the cellular environment to characterize cell-cycledependent changes. They also try to understand the correlation between molecular changes in DNA and chromosomal changes. The overall research efforts of cellular radiobiologists purue ur m. standing of the relationthip between forni . of DNA adduct and cell transformation. Sever l] current studies concern various biological end points, including acute dose-survival effects, cell progression delays, cellular repair, and tranuformation as a function of radiation quality (including nuclear fragmentation proceusen). A major emphasis is given to work with synchronized human cells. In addition to basic research, cellular radiobiolo. gist ore also providing important data for applications in clinical therapy. Cancer patients are being treated with heavy ions from the Bevalac (see Section 4, Research Medicine) and, before treatment planning can be done, it is essential that radiobiological data concerning cell killing, oxygen effect, and the effiviency of cell killing by the heavy charged particles in comparison to $x$ rays or gamma rays are available. Ali this information is provided by the cellular radiobiologist in collaboration with radiation therapists.
Theoretical models are being developed and, as we learn more and more about the basic physical, chemical, an? biological processes involving ionizing radiation, the time-svolution and the mechanistic aspects of radiation damage are becoming more apparent .

The section on in vivo biophysics describes research radiation effects at the tissue and organ levels. The objective is to obtain data to develop models for the assessment of health-risk and to elucidate mechanisms that relate lethal and nonlethal damage in in vivo systems to different qualities of radiation (natural and man-made). The focus is principally on carcinogenesio, in vivo ceilular radiobiolopy, and early asin late damage to timsues and organ where ccll lons, altered function including metabolism, and regstation of cell proliferation are important. The in vivo biophysics program complements and extends the molecular and cellular studies conducted with pro- or eukar. yotic yutems in vitro: it uses organized tissues or intact rodents to address questions that cannot be studied productively in vitro where cell, tissue, and orfan system interactions and homeontatic regulatory mechanisms are absent. However, much attention is being given to determination of the molecular and cellular basis for these tissue effects.

A strong component this program is the application of accelerated charged particles in the treatment of cancer and for radiounrgery. It it important to assess possible damage to normal and healthy cells during this radiation therapy, and the evaluation of such damage to critical organs adjacent to a tumor volume to bi treated by radiation is one of the special concerns in the in vivo biophysical studies. 
Phyrice

Physical nature of high-LET radiation field (nuclear interactions), dosimetry associated with high-LET charged particles and magnetic fields.

Tranuport of heavy ion beam.

Mechanium of enery deposition and track structure in water, DNA, and colla.

Statistical fluctuation in enerry lose for low dose studies.

\section{Chomitry}

Eneray deporition and the initial yield of chemical upecies $(\bullet \mathrm{OH} \bullet \mathrm{H}$, etc.).

Radical attack (-OH) on DNA, Chemical nature of DNA damage

Excitation and jorization of DNA, chemical nature of DNA damage

\section{Molecular Biolowy}

Chemical nature of DNA damage and repair and misrepair, chromatin and shromosome breaks

Molecular characterivation of mutation

Protooncogene activation and neoplantic tranaformation.

\section{Cellular Biolosy}

Damage and repuir proceseses in a cellular environment; cell cycle effects

Human thromosome in a hybrid cell line

Role of protoin syntheais

Role of intra- and extra-cellular matrix

T. Yang
D. Blakely
M. Docker
M. Dixon
L. Flatky
A. Rodriguez
R. Roots
T. Tenforde
C. Tobias
T. Yang

Scientists
A. Chatterjee
S. Curtis
W. Holley
W. Schimmerling
T. Tenforde
M.Wong

Technical Staff and

Graduate Students
J. Afal
J. Schorer
A. Chatterjee
W. Holley
R. Roots
E. Blakely
M. Dixon
R. Jiburdy
R. Roots
C. Tobias
K. Bjornstad
P. Chang
K. Goncz
E. Goodwin
G. Ivery


Scientists

Technical Staff and

Graduate Students

\section{In Vivo Biophysice}

Molecular and cellular basis for tissue effects

Tumor radiobiology and cell kinetics

Cellular mechanism of early and late effect

in critical organs

Carcinogenesis at low dose and low dose rates

Effects of magnetic and electromegnetic fields

Actinide element biokinetics

Modelin:

Initial damage

Repair-misrepair model

Lethal and potentially lothal model

Carcinogenesis

\section{Ionixing Radiation}

\section{RADIOLOGICAL PHYSICS AND RADIATION CHEMISTRY}

Over the yours, from experience in doing resenrch with ionising radiations, it has become very clear that studies with energetic charged particles (also called high-LET radiations) are extremely important for an overall underatanding of biological effects. There are many intrintic properties of cells that cannot be explored by using only $x$ rays or gamma rays (also called low-LET radiations). ifence, a strong component of this program has been the utilization of accelerated charged particles from the Bevalac, a Lawrence Berkeley Laboratory national resource accelerator complex.

The Bevalac can produce energetic particles across the periodic table from helium to uranium. These particles can pepetrate to depths of $30 \mathrm{~cm}$ or
J. Afzal
R. DeGuzman
J. Aingworth
K Kavanau
D. Alpen
P. Powers-Risius
S. Curtis
P. Durbin
C. Gafiey
R. Liburdy
A. Rodriguez
T. Tenforde
A. Chatterjee
S. Curtis
C. Tobias

more in human tissue or in a tinsue-like modium. For a given enerty, each particle has a precise depth of penotration with little scattering as compared to $x$ raye, and about $90 \%$ of the radiation dose is deposited near this stopping point. These foatures make such particles enpecially uneful (as compared to $\mathrm{x}$ rays) for the treatment of localized tumor volumes. However, physical processes annociated with these particles, such as their microscopic energy deposition patterns or the occasional break-down of their heavy nuclei during propagation, introduce complexities that must be understood for optimal utilization.

In FY 1987, these physical processes were investigated through experimental and theoretical studies. Specifically, results were obtained on the break-down, or nuclear fragmentation, of $670-\mathrm{MeV}$ / $u$ neon ions. At this energy these ions penetrate a depth of about $32 \mathrm{~cm}$ in water (a tissue-like me- 
dium). Along their flight-path, some of the neon nuclei break down into protons, carbon, oxygen, etc., with the resulting nuclei having mass numbers lower than neon. The extent of fragmentation depends upon the parent nucleus and the depth of the medium traversed. This research involves identification of each of the fragments at a given depth, and thereby provides information on the spectral nature of the radiation field.

Analyuis of fragmentation data for $670-\mathrm{MeV} / \mathrm{u}$ neon nuclei in a water absorber at the Bevalac Biomedical Facility has continued. An identification algorithm for particle charge was developed based on the relationship between average energy loss in a thick detector and the stopping power calculated for a proton using the meanured time of flight (TOF). With this algorithm, fluence upectra (i.e., number of particles por unit area) were obtained for particles with charges between $Z=4$ (Be) and $Z=10$ (the primary neon and its ieotopes) as a function of water-abeorber thickness. At each depth the number of particles per equare centimeter emitted with a given value of linear energy transfer (LET) was obtained. Typical LET apectra at the entrance and at the Bragg peak of neon, are shown in Figs. 3.1 and 3.2. At the entrance to the Brage curve the LET spectra are narrow, even for the fragments accompanying the beam. These fragments are due to residual material in the beam line such as vacuum windows, beam flattoning lead foils, etc.

The measurement of radial distribution of energy around a charged particle trajoctory is of

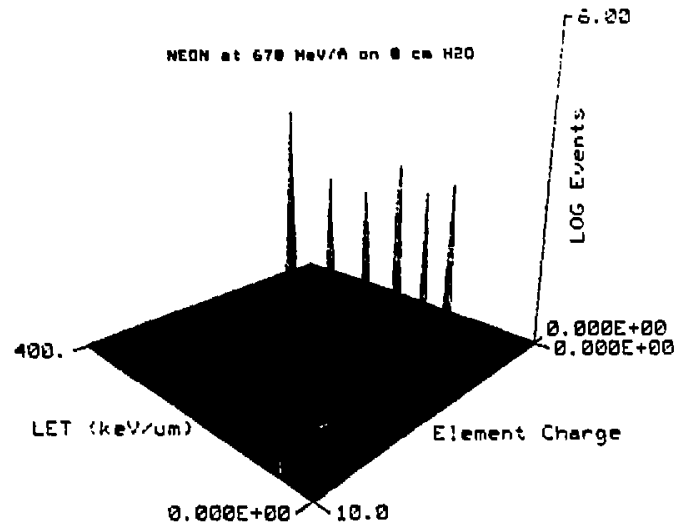

FI. 3.1. LET epectre of neon at $670 \mathrm{MeV} / \mathrm{A}$ incident on a water column; beam contaminants,also shown, are present at the 1\% level. (XBL 811-111)

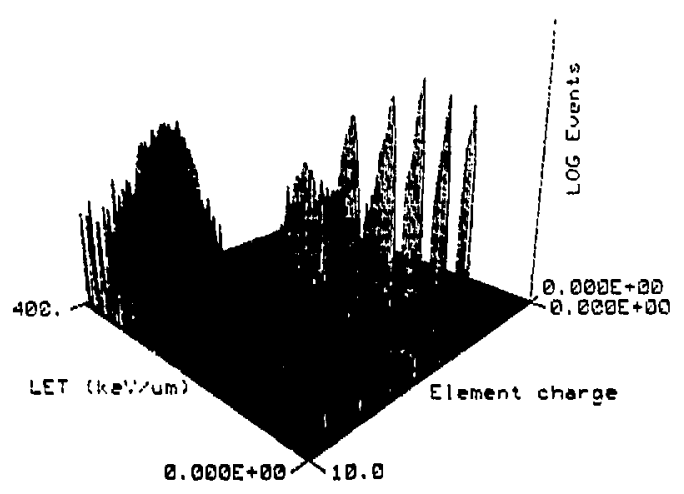

N5. 2. LET apectra of neon and fragments produced after 92 cm of uater on which noon was incident at $670 \mathrm{KCV} / \mathrm{A}$. XJL 881-110)

primary importance to the overall research effort. Rocently Metting and co-workers from Battelle Pacific Northwest Laboratory completed an analyis of single-event energy deposition distributions measured in a 1.3- $\mu \mathrm{m}$ diameter site, using iron beams extracted into the Bevalac Biomedical Facility. These had been measured as a function of radial diatance $b$ from the trajectory of $600-\mathrm{MeV} / \mathrm{u}$ iron ions. Specific energy (z), spectra of single energy deposition events, and the frequency mean $\left(\mathrm{z}_{\mathrm{h}}\right)$, were obtainod as function of $b$. Figure 3.3 thows the experimentally determined values of $\left(z_{b}\right)_{3}$, where the width of each rectangle indicates the range of $b$ over which each $\left(z_{2}\right)$, was averaged to obtain adequate statiatics, and where the height of each rectangle is baved on the number of eve ts detocted. Beyond $\sigma \mu \mathrm{m},\left(Z_{6}\right)$, is determined mainly by single electrons, whose energy spectrum no longer changes appreciably as a function of $b$. These tingle-electron events occur more rarely, but when they do, the energy they impart in a microscopic volume can be significantly greater than the average absorbed dose, calculated as $\mathrm{D}(b)=\mathrm{R}_{\mathrm{f}}\left(\mathrm{z}_{\mathrm{i}}\right)$, (where $\mathrm{R}$ is the number of events at the same distance $b$ ) and also is shown in Fig. 3.3 to be in substantial agreement with homogeneous track models.

Heavy nuclei undergo multiple scattering during their passage through matter. A quantitative understanding of this physical process is needed, primarily for purposes of dosimetry. The physicists are involved in measuring these scattering phenomena in order to make comparisons with 


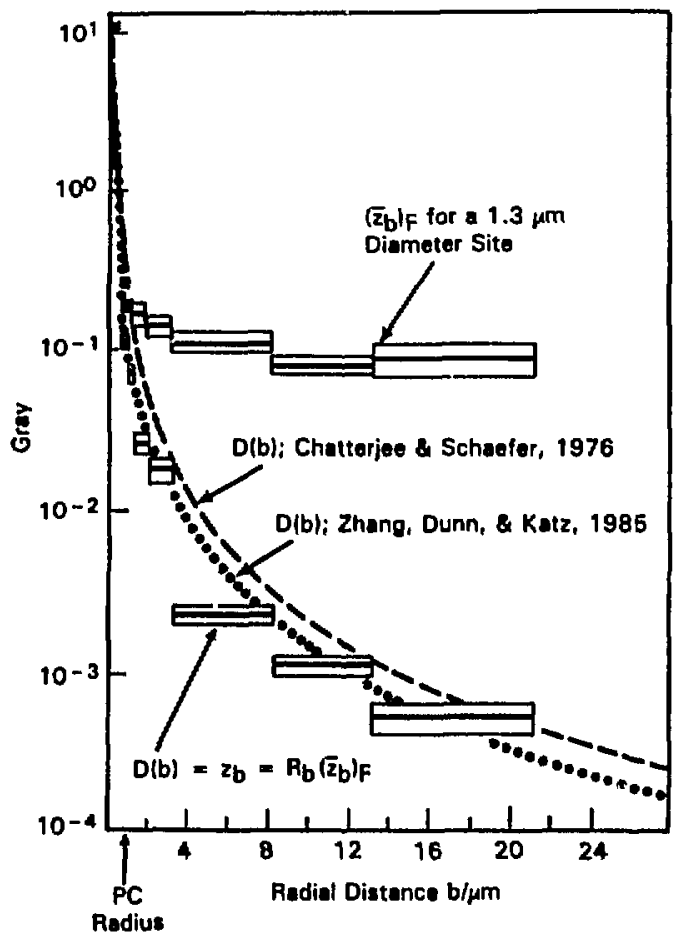

Ais. 3.3. Single-event mon specific enero $\left(z_{2}\right)$, and radial aborbed dove (rectangles) and homarneous track ofructure predictions (curves). (XBL 881-119)

the existing theoretical formulae. The multiple scattering studies are categorized as 1) measure. ment of heavy charged particle multiple scattoring angular distributions, 2) development of calculational methods to compare the rosults of experiment with multiple scattering theory, and 3) calculation of the loss of particles to multiple scattering in nuclear fragmentation experiments.

Measurements of the multiple scattering of $\sim 600-\mathrm{MeV} / \mathrm{u}$ beams of neon, iron, and uranium ions in targets of water, aluminum, copper, and lead have been made. Position-sensitive detectors (psd's) are used to determine the spatial trajectories of individual particles before and after target scattering. The angle through which an incident trajectory is deflected is then a messure of the multiple Coulomb scattering of the beam particle by the target nuclei. In this method there is no physical collimation of the beam, so that possible effects of collimator edge scattering or particle fragmentation are eliminated. The method is also independent of beam divergence.

The focus is an analysis of data obtained for the most massive particle accelerated at the Bevalac, uranium, to provide a stringent test of the theoretical descriptions of the multiple scattering of very heavy charged particles relative to those for protons.

The pod's make possible differential measurement of the multiple scattering deflection angle. $A$ computer simulation of the experiment using Monte Carlo techniques has been made to allow detailed atudies. In this simulation, individual particles are tracked through the system, with the effects of particle enercy loss, multiple scattering, and detector resolution all takon into account. The overall angular resolution of the aystem is measured with the "target-out data." The conclusion from this analysis of uranium data is that the standard theory of multiple Coulomb scattering for elomentary charged particles appears to describe adequately the wcattering of very heavy charged particles from target nuclei.

To underatand the chemical stage in the evolution of radiation-induced damage, an attempt has been made to understand the effects on biological material at the molecular level by studying the physical phenomena of the energy deposition process and the subsequent physico-chemical and chemical processes leading to DNA strand breaks. Both the indirect and direct mechanisms of damage have been studied theoretically. Initial studies were confined to a linear form of DNA, but during the past your a systematic atudy of the effects of higher order structures in the formation of damage has been started.

In conjunction with the theoretical studies above, the experimental procram aimed at tenting and verifying the theoretical models and, in particular, attempting to understand the detailed mechanism involved in radiation-induced DNA strand breaks have been continued.

\section{Theoretical Studies}

The earlier work - atudying the indirect effects of radiation on isolated DNA using SV 10 viral DNA in dilute aqueous solution as a model system-has continued. These calculations involve the following main features: 1) computer simulation of the SV40 DNA molecule using standard geometric stereochemical parameters (obtained from $x$-ray diffraction studiea); 2) simulation of the production of $\mathrm{OH}$ 
radicals and other water radiolysis products around the DNA by the track of an ionizing particle; and 3) simulation of the diffusion of the radicals and their reactions with each other, with other scavenging agents in the solution (Tris buffer), and ultimately with the DNA molecule. Reactions with the deoxyribose ring lead to strand breaks while reactions with the bases lead to other forms of damage.

These studies have been carried out using a series of Monte Carlo computer codes to simulate the actual process. The probabilities of single strand break (SSB) formation for a variety of incident radiation qualities and wcavenger concentrations (to mimic the cellular environment) have been calculated.

During the past year, these calculation: have been extended to include the efifects of the presence of associated proteins by studying the effects of nucleosomes (see Fig. 3.4) on the probability of strand break formation. The results are given in Table 3.1. The presence of the histones reduces the probability of single strand break formation by approximately a factor of two for the DNA that is in contact with the proteins. When moving away from the histones onto the linker DNA the probability of strand breaks gradually increases until it reaches approximately the uncomplexed DNA valun after about 170 base pairs. Future studies will investigate the effect of organized groups of nearby nucleosomes to more closely simulate the complex utructure of chromatin.

The development of computer codes to model the direct action of radiation on DNA has als, continued. This model is based on concepts of track

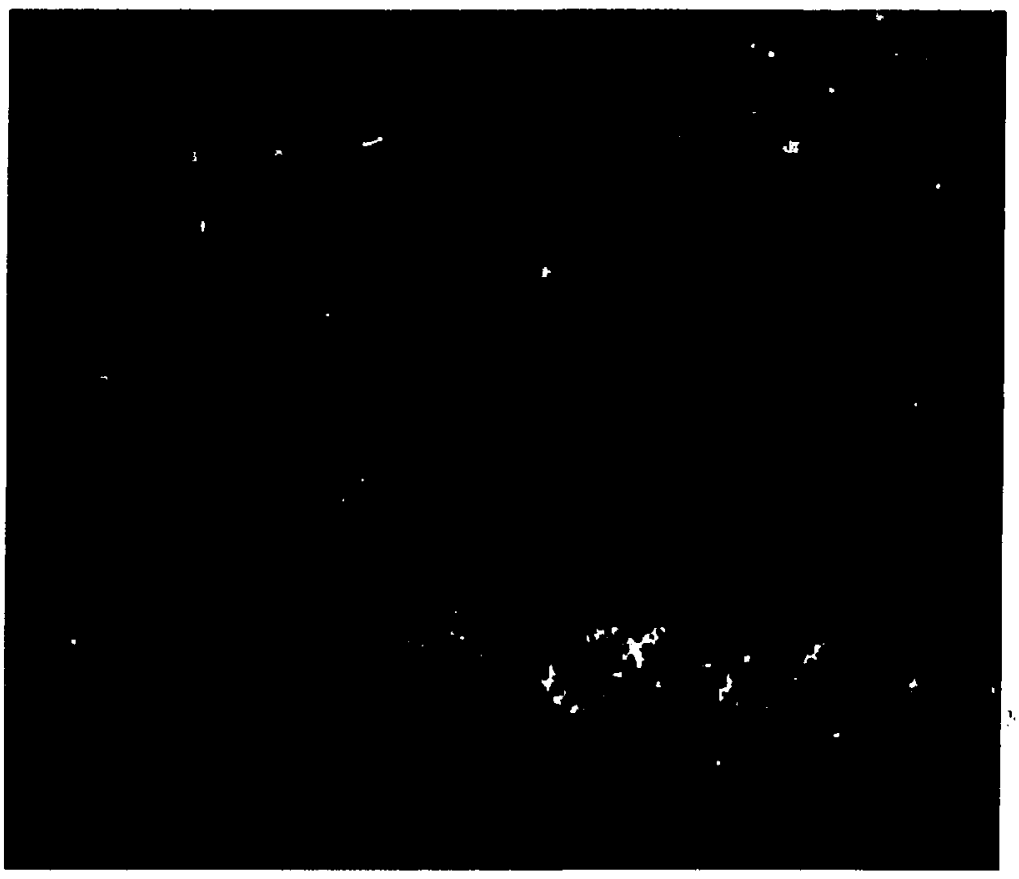

Pig. 2. A computer maphic representation of a DA molecule wrapped around a centrul histone core, which is not vitible in this fintr. Such a reprecentation has provided ws with a thredimensional consideration of damagte caused by

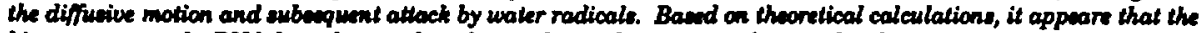
histone protects the DNA from damare by a factor of two when compared to eimilar damage to DNA without histone. However, the linher part of the DNA is not protected to any oignificant extent by the prevence of histone. (CBB 869-7725) 
Table 3.1. Comparison between B-DNA with and without histones.

\begin{tabular}{|c|c|c|c|c|}
\hline DNA structure & $\langle\mathrm{P}\rangle_{\text {oupar }}$ & $\langle P\rangle_{\text {ban }}$ & $\begin{array}{l}90 \text { sugar } \\
\text { attack }\end{array}$ & $\begin{array}{l}\text { \% base } \\
\text { attack }\end{array}$ \\
\hline $\begin{array}{l}\text { Linear } \\
\text { (No Histones) }\end{array}$ & $4.70 \times 10^{-3}$ & $1.83 \times 10^{-2}$ & 20.0 & 80.0 \\
\hline $\begin{array}{l}\text { Linker } 1 \\
\text { (171 Base Pairs) }\end{array}$ & $4.59 \times 10^{-3}$ & $1.90 \times 10^{-2}$ & 19.5 & 80.5 \\
\hline $\begin{array}{l}\text { Nucleosome } \\
\text { (210 Base Pairs) }\end{array}$ & $2.04 \times 10^{-3}$ & $7.18 \times 10^{-3}$ & 22.1 & 77.9 \\
\hline $\begin{array}{l}\text { Linker } 2 \\
\text { (171 Base Pairs) }\end{array}$ & $4.10 \times 10^{-3}$ & $1.87 \times 10^{-2}$ & 18.0 & 82.0 \\
\hline
\end{tabular}

structure, stopping-power theory, and the Brags rule. Monte Carlo computational techniques are used to treat both glancing and knock-on collisions.

Previous studies made une of a simple smooth radial energy distribution to calculate the direct effects of the penumbra (knock-on electrons). During the last year, these calculations have been incorporated into a more detailed model for electron interactions.

Furthermore, these electron results have been combined with the results for the core of heavy-ion tracks to calculate the single- (SSB) and doublestrand break (DSB) yiolds as functions of LET for a series of particles.

Strand-break production in oxygenated cells it generally considered to be due mainly to indirect effocts at low LET and to direct effects at high LET. The calculated yields (normalizod to breaks rad-" dalton'1) in Fig. 3.5 shown as wolid lines (direct) and dotted lines (indirect) are compared in the adjacent plot with a selection of exporimental measurements of radiation-induced primary single- (SSB) and double- (DSB) utrand-break yields an functions of LET. In addition, recent results for the yields of chromatin breaks are also shown. The satisfactory agreement of the theoretical results with experimental data suggest that most of the important effects are at least approximately accounted for in these calculations.

In addition to the indirect effect studies, there is also an interest in looking at the influence of the higher order organization (nucleosome, chromatin, and eventually chromosome) of DNA in cellular nuclej on directly induced strand-break yields and on the spatial distribution and correlations of the damage along the DNA chain.

\section{Experimental Studies}

Through collaboration with Dr. G. Kraft (GSI, Germany), data have been accumulated on the formation of strand breaks in viral DNA irradiated in dilute aqueous solution ( $\mathrm{pH}$ 7.6) with a large

\section{Yield of DNA Strand Breaks}

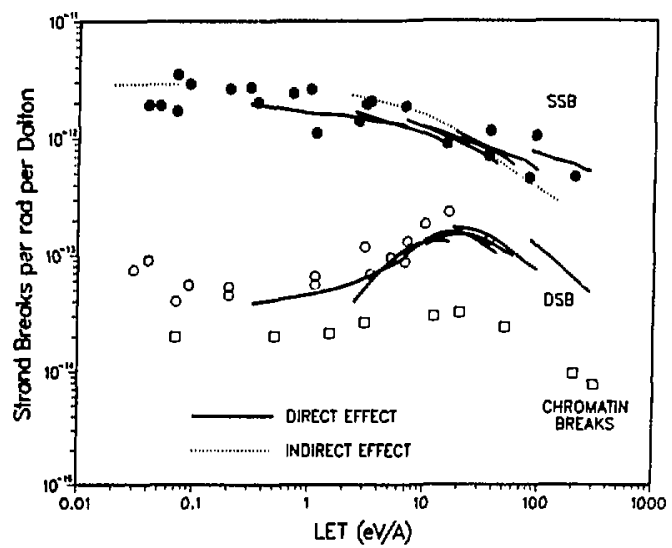

Fit. 3.5. Theoretical yields of DNA strand-breaks in cells for direct effects (colid curves) and indirect effects (dotled curves). For comparion elected experimental meanurements are shown for yields of single-strand ( 1$)$, double-atrand (o), and chromatin (口) breaks. (XBL 881.112) 
number of charged particles, ranging from helium to uranium. A plot of the DSBVSSB ratios plotted against LET for several ion species is shown in Fig. 3.6. It becomes evident that a biological effect that varies because of radiation quality must be studied separately for each particle species. Data collected should cover a range in velocities for each particular ion species, with a ceries of curves thereby obtained. The number of DSBs relative to the number of all breaks (or SSBs) increases as the LET of the specific ion species increases, as shown with SV40 DNA irradiated in a buffered solution. However, this same relationship also holds true for irradiation of mammalian cellular DNA with alpha particles, shown by the dashed line in Fig. 3.6. Aloke Chatterjee, William Holley, and Ruth Roots.

\section{MOLECULAR AND CELLULAR STUDIES}

In the field of molecular radiobiolory, the offorts are focused in three arean: 1) detection of radiation-induced DNA damage and repair; 2) LET dependence of chromatin breaks and rejoining; and 3) evaluation of neon-ion-induced rearrangements in the single human chromosome using a dual species-specific fluorescence hybridization method.

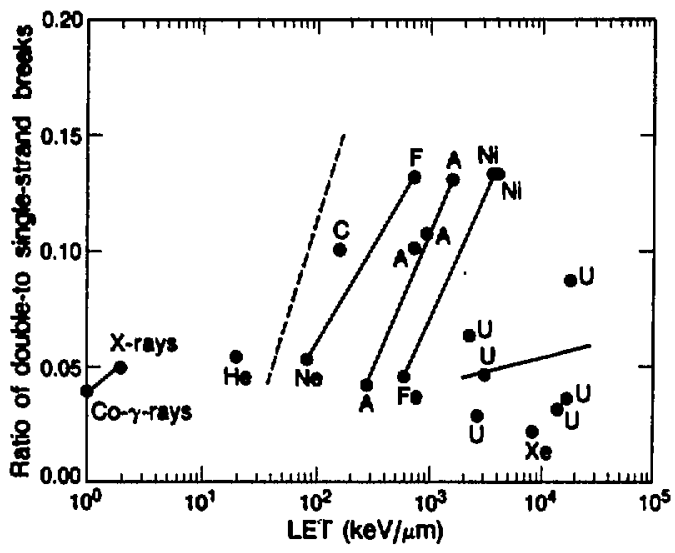

Fix. 3.C. Measurements of the yields of DNA, DSB, and SSB as a function of ionization density $($ he $V / \mu \mathrm{m})$. A variety of ion epecies were used, ranging from alpha particles to uranium. Particle energies at the DNA target ranged from 6 to $900 \mathrm{MCVI}$ $u$, appraximataly. Data oblained for DNA imadiated in volution are represented by solid lines. The dashed live represents data oblained for mammalian cellular DNA irradiated with alpha particles. These dala were calculated from a publication by Fampf and Eich hom, 1983. (XBL 881-7219)
In each of these studies, heavy charged particles have been used and the comparison of the data with measurements from $x$ rays are in progress. A brief summary of each of the studies is reported here.

\section{Detection of Radiation-Induced DNA Damage}

In these experiments intact cells were irradiated and asuays of the damage and repair processes were done by pulsed-field-gradient electrophoresis tochniques that have been succesnfully employed to separate restriction fragments ranging from $50 \mathrm{~kb}$ to $3000 \mathrm{~kb}$. The objective is to atudy the effect of radiation-induced DNA strand breakage and rejoining in normal and repair-doficiont synchronous and anynchronous human and Chinese hamiter (CHO) celly. The restriction enzymes used include the eight-base cutter Notl, Sfil and sixbase cutters Mlul and Eagl. Preliminary results using LKB Puleaphor electrophoresis equipment in conjunction with a unique Pulcewave awitcher from BioRad indicate that DNA preparation is a critical tep in obtaining consintent repeatable results. Factors include age of cells, control of trypeinization, crade of agarose employed, temperature used in each procedure, and the use of sterile qualitygrade solutions to avoid shearing the DNA samples. The human lymphoblastoid cell line TK6, irradiated with $320-\mathrm{MeV} / \mathrm{u}$ silicon ions has yielded results that whow a dose-dependent banding and show repeatedly that with or without irradiation there is a difforent restriction pattern with Notl, Sfil, and Eagl than with hamoter or other humancell lines. Work is in progress to detormine if these different restriction patterns are due to differences in radiosensitivity, or are an artifact of cell preparation, methylation, or incomplete digestion with onzyme. Breakage and repair of specific TK6 fragments are being studied by probing with a thymidine kinase gene using Southern procedures to identify molecular alterations due to radiation exposure and to determine if repair incubation periods will ullow restitution of the radiationinduced changes. In addition to these studies, results from irradiated wild-type and temperature. sensitive CHO cells are being analyzed and show a disappearance of a band with heat following irradiation. Synchronous $G_{1}$ cells with and without irradiation run more completely out of the well and down the gel than do the asynchronous cell populations. Therefore, future research will involve synchronous cell populations in $G_{1}$ phase to evaluate dose-deperident DNA damage and repair. 


\section{LET-Dependence of Chromatin Breakage and Rejoining}

The RBE for cell survival is well known to be LET-dependent, firat rioing with increasing LET to a broad peak in the 100-200 keV/um range and then steadily decreasing. If the postulate that chromatin breaks are the only lesions that influence cell survival is accepted, then the premature chromosome condensation (PCC) technique can be used. This allows one to fuse an irradiated cell with a mitotic inducer cell, prematurely condense the chromatin of the test cell, and examine chromatin breaks in individual interphase cells within 30 minutes after irradiation, permitting evaluation of the chromatin damage before it is altered by the processes of repair and coll cycle progression. Three hypotheses to explain why the RBE for survival is a function of LET can then be examined. These hypotheses, which are not mutually exclutive, are that 1) the initial number of chromatin breaks produced per coll per cGy is LET-dependent, that 2) high-LET lesions are lest repairable than low-LET lesions either because there is an LETdependent fraction of the initial chromatin breaks that cannot be rejoined by cellular repair mechanisms, or because high-LET-induced lesions are more likely to be misrepaired, and that 3) cluatering of lesions (the production of multiple chromatin breaks per cell by uingle nigh-LET particle traversals) may affoct the officiency of cell killing. Results from the ongoing study with th. PCC system indicate that the RBE for survival vs. LET curve reflects an LET dependence on the initial number of lesions per $\mathrm{CG}_{\mathrm{y}}$. but this alone may not fully account for the magnitude of the RBE at $10 \%$ survival in radioresistant cell lines. A comparison between survival and chromatin breakage RBE values is shown in Fig. 3.7 for radioresistant T-1 cells, hamster cells of intermediate sentitivity, and radiosensitive A-T cells. Beyond $-100 \mathrm{keV} / \mu \mathrm{m}$, the survival RBE consistently exceods the chromatin breakage RBE in the radioresintant T-1 and hamater cell lines, but not in the radionensitive A-T cell line. There appears to be a slow or nonrejoining fraction of chromatin breaks that increases with increasing LET, and clustering of chromatin breaks at high LET, resulting in non-Poisson distribution: of initial lesions has been demonatrated. The average number of chromatin breake produced by a single particle pasting through a cell nucleus was found to be a sigmoidal function of LET. At $\sim 65$ $\mathrm{keV} / \mathrm{um}$, each particle yields an average of one chromatin break per cell in the hamster cell ayatem. In the high-LET region above $65 \mathrm{keV} / \mathrm{\mu m}$, single particles produce multiple chromatin breakn $\rightarrow$ process known as cluatering of radiolesions. These investigations should provide a more quantitative explanation of the LET dependence of the survival in both radioresintant and radiosensitive cell lines.

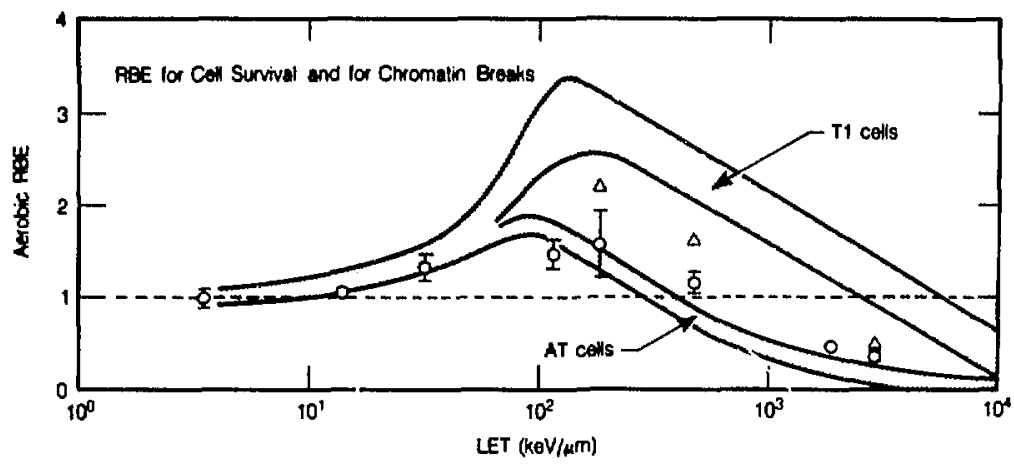

Ph. 2.7. Comparion belween survival and chromatin breabage RBE. For CHO cells, circlas (0) and triancles (A) indicale RBEs for chromatin breshase and eurvival, respentively. Only the envelopes for the previously reportad TI and AT cull ourvival RBE are shown (no PCC dafe are available for $T 1$ and $A T$ cellos. Beyond $-100 \mathrm{keV} / \mathrm{\mu m}$ the wrvival $R B E$ consintently excends the chromatin breahage $R B E$ in the rodioreditant $\mathrm{Tl}$ anc $C H O$ cell lines, but not in the radiosensitive AT cell line. (XBL 877-10828) 
Evaluation of Neon-Ion Induced Rearrangements in a Single Human Chromosome Using a Dual Species-Specific Fluorescence Hybridization Method

Experiments using a human-hamster cell line that has a karyotypically stable hamster genome containing a single copy of human chromosome number 2 have been initiated in which plateau phase culture have been irradiated with single doses of Brags-peak neon ions at an LET of 183 $\mathrm{keV} / \mu \mathrm{m}$ and are processed with the premature chromosome condensation technique either immediately or after $37^{\circ} \mathrm{C}$ incubation period of up to 8 hour. Fixation and dual-fluorescence staining then permitted a scoring of the immediate number of human chromosome fracments produced and an evaluation of rejoining events during the postirradiation repair poriod. Preliminary results indicate a doce-dependent increase in production of neon-ion-induced fragments and a time-dependent decrease in the total number of fracments. There is also evidence for a time-dependent increase in illegitimate furions between human and hamater chromatin. Result of these experiments are to be compared to $x$-ray atudies that are in progress.

In cellular radiobioloesy, fundamental research as well as research applicable to radiation therapy continue to be carried out, using high-LET and lowLET radiation qualities. The various studies initiated were 1) the effect of clastogenic factor on normal cells irradiated with $x$ rays, 2) the role of protein synthenis in repair of leaionn, 3) the effocts of cell cycle and survival of aynchronized human cells when irradiated with split doses of heavy ions, and 4) clinical radiobiolocy. A brief summary of each follows.

\section{Effects of a Clastogenic Factor}

A diffusible clastogenic factor in the culture medium of ataxia telangiectasia (A-T) cells that increases the incidence of chromosome aberrations of normal cells cultivated with this medium has been reported. This clastogenic factor is a paptide with a molecular weight of 500 to 1000 daltons. Conditioned media from both A-T and normal fibroblasts were collected after 8 days of growth when the clastogenic factor was reported to be maximum. These media were used to cultivate normal fibroblasts transferred to the conditioned media either 3 days before or just before irradiation. In both cases, the irradiated cells were trypsinized and plated into the conditioned media, which were then removed after 3 days and replaced with fresh media. Preliminary studies indicate there is an increased $x$-ray sensitivity of $20-30 \%$ (at $1 \%$ survival) for normal cells grown in A-T conditioned medium presumably containing this clastogenic factor compared to the controls cultivated with either normal conditioned or fresh unconditioned media. This effect was most pronounced when the cells were grown in the conditioned media prior to irradiation. This clastogenic factor is being isolated from the conditioned medium by a series of filtration steps to be used for further studies.

\section{Role of Protein Synthesis}

CHO wild-type cells (SCI) and temperatureentitive mutants (TSHI) have been subjected to $42^{\circ} \mathrm{C}$ continuou heat treatment and asuyed for heat shock proteins (hepe) using one-dimensional polyacrylamide gel electrophoresia. Autoradiograms indicate that constitutive levels of proteins in the two cell lines are identical, but upon heat shock, SCI have elevated lovel of heat ahock proteins and TSHI do not. If the cells were subjected to a trigrer dose of 6 minutes at $45^{\circ} \mathrm{C}$, then incubated at the permisuive temperature of $35^{\circ} \mathrm{C}$ for up to 6 hourn, both cell lines thowed heps. A parallel experiment with a trigrer dose of 5 minutes at $45^{\circ} \mathrm{C}$, followed by incubation at the nonpermiutuive temperature of $40^{\circ} \mathrm{C}$ for up to 5 hours, ahowed that SCI cells have hups but the TSHI cells do not. In another experiment the temperaturesensitive mutant and wild-type cells were each exposed to a priming dose of radiation to kill down to $10 \%$ survival (4.5 gray of 160-kVp x rays or 2.0 gray of neon) and heated to $41.5^{\circ} \mathrm{C}$ for up to 6 hourt. The tomperature-ensitive mutant cells heated to inhibit their protein synthesis indicated an additive response with the radiation killing but with no synergiem, whereas the same experiment with wild-type cells thowed the expected enhanced cell killing reported in the literature for both radiation qualities. This suggested that protein synthesis plays an important role in the repair of lexions produced by high-and low-LET radiations. Lack of protein synthesis protects the mutant cells from the combined effects of the two deleterious treatments. Hyperthermia following radiation is more effective when the radiation is low-LET than when it is high-LET; this points to differences in the types or quantity of lesions produced or in the mechanisms of repair. Preliminary survival results also indicate that thermotolerance is still expressed in the wild-type cells and is absent in the mutant cells after chronic exposure to heat post-irradiation, 
but confirmatory studies still have to be carried out using polyacrylamide gel electrophoresis.

\section{Effects of Cell Progression Kinetics and Survival of} Synchronized Human Cells Irradiated with Split Doses of Heavy Ions

The rationale for this work is to extend early hamster cell work that indicated 1) a lack of splitdose recovery and perhaps even a potentiation of cell killing with dose fractionation of neon Braggpeak ions and 2) a lack of independent action of sequential doses of high and low-LET radiations. There is particular interest in the cell-cycle-dependont kinetics of these dose fractionation effects in a human cell with longer cell-cycle times. Firures 3.8 and 3.9 summarise the results. Figure $3.8(\mathrm{~A})$ illustrates split-does survival kinotics of asynchro. nous cell populations irradiated with two low-LET or two high-LET doses. Figure 3.8 (B) jllustrates similar date obtained with cell populations synchronized either in the middle of $G$, phase or $S$ phase. Recovery occurs in the exponentially growing cells irradiated in the plateau, but not in the Braps peak, resulting in an enhanced peak-toplateau differential effectiveness with dose fractionation. Figure 3.9 summarizes dati obtained from aynchronized cell populations ir. ated with a sequence of high-LET radiation followed by low-

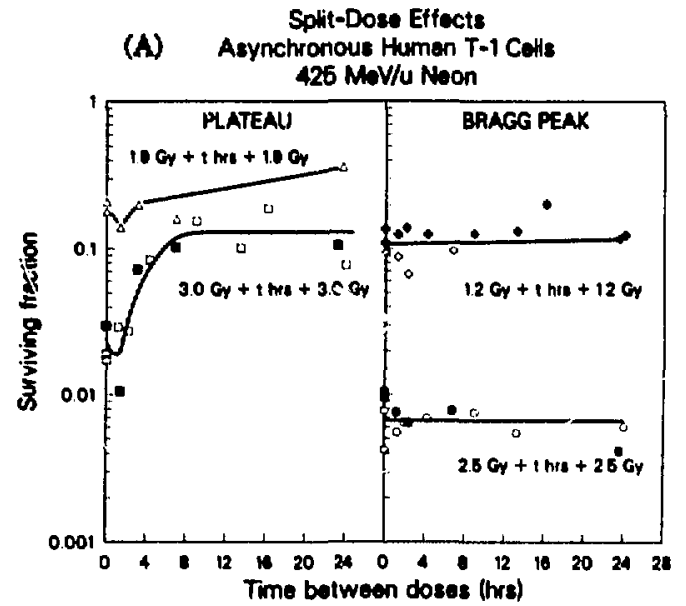

LET radiation. The sequential doses of neon Bragg-peak and plateau ions administered within several hours can result in human cell killing that is greater than expected from the independent action of each radiation. The cell-cycle-dependent sensitivity to sequential doses of high-LET and lowLET radiations can be further modified by cell progression to more radiosensitive or radioresistant cell cycle phases occurring with elapsed time between the two doses. Future extensions of these experiments are planned that will be of value to jmproved clinical dose fractionation schemes.

\section{Clinical Radiobiology}

Several cellular experimento have been com. pleted by membert of the Radiobiology Gruup to directly upport clinical radiotherapy with heavyion beams. These included studies of enhanced biological effectiveness of particle radiotherapy beams cuntrolled by magnetic wobbling and an evaluation of the potential of combined chemotherapy with cisplatinum and particle treatment. The latter invectigation has been completed by Mary Decker, a UCSF Radiation Oncology Resident, who is working $50 \%$ time in the heavy-ion radiobiology experimental program.

Eleanor Blakely, Cornelius Tobias, Tracy Yang, Marthe Dixon, Edwin Goodwin, Rolly Chang. Kathy Bjornstad, Gayla Ivery, and Kaarin Goncz.

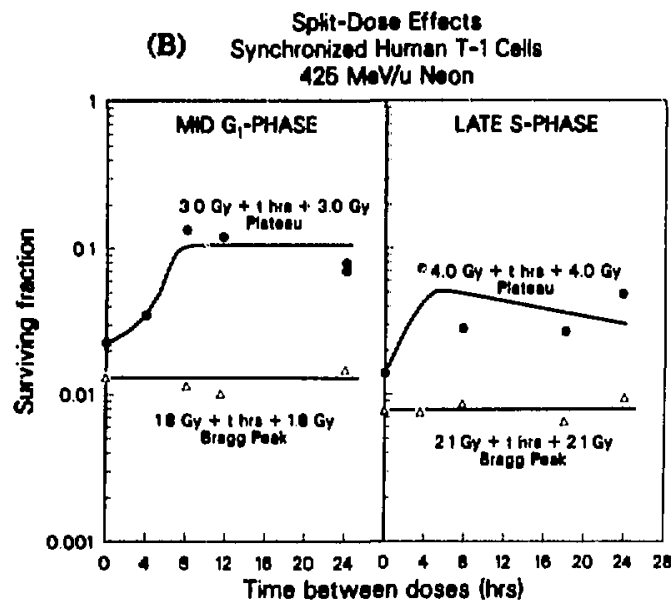

Fit. 3.L. Split-dowe ffects of aymchronous and synchronised human T.1 atls. (A) Complilation of data from replicate experiments to

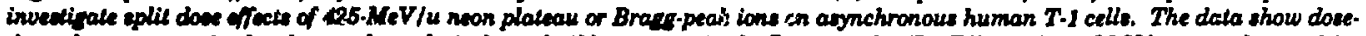

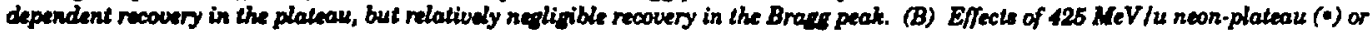

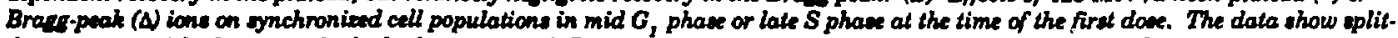
dowe reovery with plateau and a lack of recovery with Bragg-peak ions. [(a) XCG 872-6773, (b) XCC 872-6778] 

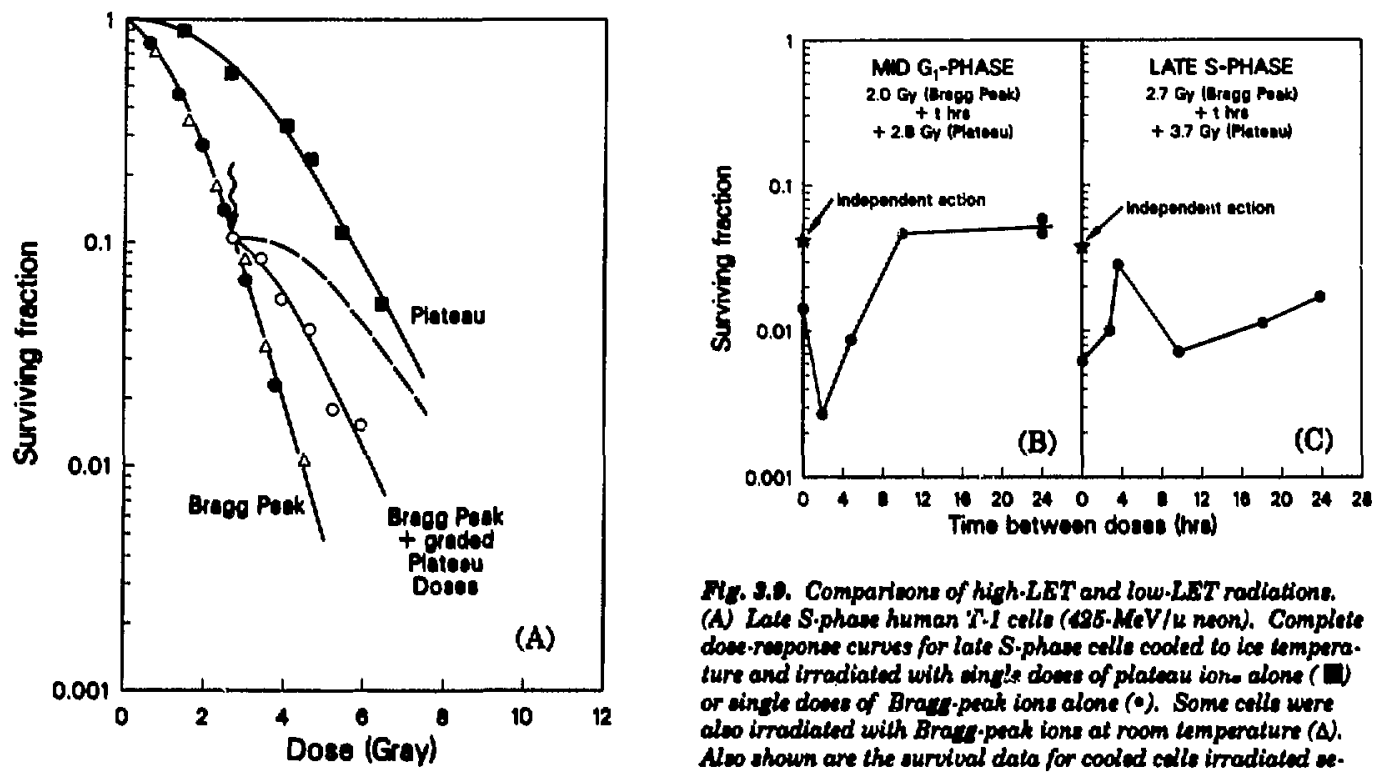

IV. 3.0. Comparicons of high-LET and low-LET radiations. (A) Lake S.phase human ir.I collo (96-MeV/u neon). Compliste dose-respones curuss for late S-phase celle cooled to ice umpere. ture and irrediated with tingle dowe of plateau ione alone (D) or eingte dowe of Brayspeat ions alone ( $)$. Some cells were also irrodialed with Bravs -peak ions at room hemperature (A). Alo shown are the survival data for cooled calls irradialad ae. quentially with 2.7.Gy Brang peak ions follownd within 2

minutes by graded dowes of plakeau ions (0). The survival of this last srowp was simificanlly lese than that expected from the indeperdent action of the two radiations (...). (B) Mid G, phase and (C) late S-phase or late S phase at the time of a fwrt dove of Bramgpeak ions followed at various times by a dow of plateau ions. The stare represent the survival lewt expneted from the independent action of each radiation. The dals show that $G$, phase cells are more ennitive than expected and become even more radionnaltive with a 2-hr interval between the two doess as the calls move to the $G, I S$ border. The cells then show increasing radionesistance that levels off with an 8-hr fractionation interval. The late S-phase cells are also much more senvitive than expecled with the combined radiation treatment, but become mans: recistant with split-times up to $\mathrm{f}$ it and then more radionensitive when the cells divide and enter $G$, phase (confirmed by Row cytometry). I(a) XCG 872-6774, (b) XCG 872-6776]

\section{THEORETICAL MODELING OF CELLULAR AND MOLECULAR EFFECTS}

The experimental program has been accompanied by the development of mathematical models. A goal is to describe the essential nature of processes that take place when ionizing radiation or other environmental variables perturb the mechanisms that control cell progresnion and proliferation. One such model is the "repair mitrepair (RMR) model," which has been under development for several years. Its central theme is that cells attempt to repair injuries in their own genome using enzymatic processes: macroscopic expressions of observable effects are the consequences of misrepair, defined as the inability to finish the repair process, or the occurrence of molecular mistakes as this process occurs.

Another model that has been developed is the "lethal-potentially lethal (LPL) model." The differ- ence between it and the RMR model is that the former asurumes two distinct classes of lesions, irreparable (lethal) and repairable (potentially lethal), while the RMR model assumes one type of lesion that is initially "uncommitted" and whose fate is determined by lesion interaction and the fidelity of the repair process. One consequence of the LPL model is that sublethal and potentially lethal damage repair are manifestations of the same repair process.

The intent is to examine various mechanisms thist may occur in interactions between the progeny of transformed cells and the tissues of the living organism. It must be kept in mind that, while developing quantitative approaches for modeling transformation processes, the events leading to cell division and proliferation are statistical processes.

Aloke Chatterjee, Cornelius Tobias, and Stanley Curtis. 
CELL TRANSFORMATION AND SOMATIC MUTATION STUDIES

The induction of neoplasms and of somatic mutations are two of the major damaging effects of ionizing radiation. Our focus is to determine how effective energetic heavy charged particlen (primary cosmic rays) are in producing these effects. Uning the results from these studies, it may be possible to assess potential riek for apace workers on a longterm space mission.

\section{Low Dose Rate Effects}

The oncogenic effects of high-LET radiation, using accelerator-produced heavy-particle radiation and mouse embryo cells (C3H10T1/2), have been studied for many yearn. The exposure dose rate of space travolers is very low, leas than 1 eGy/min, and thus it is important to have data on this low dose rate of heavy ions for riwk assosement. The earlier dose-rate studies with energetic iron particles $(600 \mathrm{MeV} / \mathrm{u}, 200 \mathrm{keV} / \mathrm{m})$ indicatod an enhancement effect of low dowe rate $(2 \mathrm{cGy} / \mathrm{min})$ for cell transformation, as ahown in last year's Annual Report. In FY 1987 the dose-rate studies have been extended to other ions, and LETs and dose response curves for $425-\mathrm{MeV} / \mathrm{u}$ neon and $\mathrm{l}-\mathrm{MeV} / \mathrm{u}$ argon ions have been obtained. A timils. enhancement effect for cell transformation was observed for argon ions, but not for neon particles. These results clearly uugrest that the low-dose-rate effect for cell traneformation is LET-dependent, enhanced at about 140-200 keV/4m and reduced at about 32 keVhum. Whether there is an enhancement effect of low dose rate for LETs greator than $200 \mathrm{keV} / \mu \mathrm{m}$ is uncertain at present, because some recent data have indicated that $300-\mathrm{MeV} / \mathrm{u}$ iron particles ( 430 $\mathrm{keV} / \mathrm{\mu m}$ ) were equally effective at 47 and $2.7 \mathrm{cGy} /$ min in inducing neoplaatic cell tranaformation.

\section{$R B E$ Repair and LET}

Human skin fibroblauts and rat embryonic cells (Rat-2) at a confluent state have been used as model systems in continuing studies to determine the mutagenic effect of heavy ions, and investigations on the repair of potential mutation lesion: have been initiated. An analyais of dose-response curves for various heavy ions, including uranium particles, showed that the RBE and LET relationship for the 6-thioguanine resistant mutation is very similar to that for cell traneformation. This good correlation suggests that the mutation lesion, possibly deletion, may be important for cell transformation by ionizing radiation. Studies on the repair of potential mutation damage indicated that heavy ions produce fewer repairable lesions than photons and that no repair of potential lesions could be detected in celis irradiated by $320-\mathrm{MeV} / \mathrm{u}$ silicon ions $(85 \mathrm{keV} / \mu \mathrm{m})$. The molecular nature of repairable and irreparable mutation lesions has not been carefully investigated and is totally unknown.

Systematic studies with heavy ions, which are effective in producing irreparable mutation lesions, may provide insights on the initial lesions for mutation.

\section{Initial Primary Lesions}

Neoplantic cell transformation is a multi-step process, including initiation, fixation, promotion, and progreunion to the malignant state. Various experimental findings sugrest that nuclear DNA is the primary target for radiogenic cell traneformation. The nature of the primary DNA lesion(s) responaible for initiation of cell traneformation is unclear, although double-atrand breaks have been sugrested as possibly important ones. In the past several years, considerable dose-response data with carton, neon, silicon, argon, iron, and uranium particles have been collected, and information on the repair of potential tran aformation damage as a function of LET has been obtained. A simple analysis of these data indicates that two specific primary ionizations within $80 \mathrm{~A}$ in DNA may form transformation damage. Further studies with restriction endonucleases are being undertaken to verify this interesting finding.

\section{Genetic Changes in Transformants}

Numerous instances have now been provided on the links between protooncogene alterations in some form or another and the presence of various forms of neoplasms. To understand the genetic basis for radiation-induced cell transformation, come investigations on the radiation-mediated genetic changes in specific genes have been initiated. At present, this research concentrates on the molecular changes of the c-myc protooncogene in transformed cells.

Normal diploid Syrian hamster embryo cells at secondary or tertiary passages were traniformed by $x$ rays. The transformed foci were then isolated and tested for anchorage-independent growth in 
coft agar medium. Large colonies formed in soft agar medium were cloned again, grown into large cell populations in culture, and tested for alterations in gene expressions of specific genes at various times after cloning. To date, the changes in the c-myc protooncogene of one transformed clone have been analyzed. Byiusing Southern and Northern analyses, it was found that restrictionfragment-length polymorphism (RFLP) occurred in the c-myc locus during the progression of cell transformation and that the $c$-myc gene expreasion (the c-myc mRNA level) alco changed.

It appears that some changes developed at a Pst-1 site in c-myc gene during the progression and that certain changes of o-myc mRNA species also occurred at the mame time. Figure 3.10 show the mRNA changes of the c-myc gene.

Current studies are attompting to sind out if specific chromosomal alterations have occurred in the c-myc locus by applying the in situ hybridization technique to metaphase chromosome spreads. In the near future these studies will be extended to include other protooncogenes (e.g., the ras family), and to determine whether these observed changes are general phenomena in radiation-induced cell transformation.

Tracy Yang and Ruth Roots.
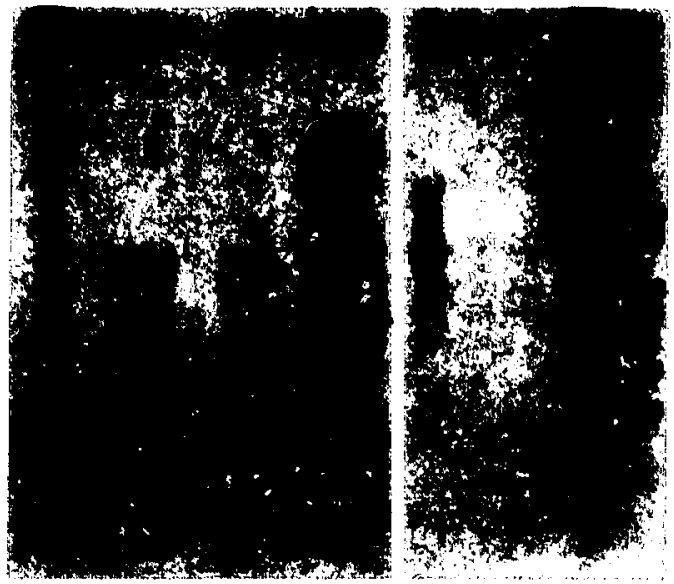

My. 3.10 Northern plot of cyloplasmic C.MMC mRNAs. (Left pard) C.MYC mRNA it thown for normal (lanes 1,9) ve. traneformed (lanes 3,4) hamster cells. The (P.7-hb) C.MYC mRNA from nomal human cells (MTR-90) it thown in lanes 6,6. (Right panel) The charactoriotic 2.7-kb mRNA of C-MYC in human cello (MMR-90) is shown in lane 7 lowlher with lambda molecular weight martera at the right. (XBB 877-6732N)
OXYGEN-GLUCOSE DEPRIVATION AS THE CAUSE OF NECROSIS IN A TUMOR ANALOG

A sandwich system was recently developed as an in vitro tumor analog. Like spheroids, sandwiches are organized, multicellular systems in which the interplay between diffusion and consumption leads to the formation of spatial gradienta; a necrotic center and a viable cell border subrequently develop. Adjacent to the necrotic center is a region of hypoxic cells. Within the viable border, there are gradients of oxygen, nutrients, cell-cycle atate, morphology, and ultrastructure. These gradients of biological state result in gradients of radiation response and response to chemical perturbations or labeled aubitances. All cells are viewable during the time the sandwich matures. The gradients can be avoided by removing the top slide; this reoxygenates tho cells and restores them to favorable growth conditions. Sandwiches of the 9L, V79, and EMT6 cell lines have been uned to investigate questions relevant to formation of necrosis in solid tumors, the presence and behavior of hypoxic cells, the radiation response of the tumors, and the results of reoxygenation.

The effects of oxygen and giucose deprivation on the onset and formation of necrosis were investigated. The data indicate that in sandwiches necrosis is a result of a joint shortage of both substances. Complementary cell monolayer experiments to determine a number of consumption parameters were performed. On the basis of the data, a joint oxygen-glucose deprivation model for V79 cell necrosis was proposed. It is assumed a cell dies when oxygen deprivation in conjunction with glucose deprivation lowers the cell's ATP production rate below a critical value. Interactions of the concentrations and consumptions of oxygen and glucose were analyzed theoretically; concentration profiles are obtained by numerically solving coupled nonlinear integral equations arising from the diffusion equation. The predicted viable border widths are in good agreement with the observed values.

Sandwiches were labeled with 'H-misonidazole. Location of cells within a sandwich was preserved by fixation and misonidazole binding was assessed by autoradiography. Heavy binding was seen in all cells bordering the necrotic center, with a greater than 50 -fold difference between cells in the innermost hypoxic region vs. the outer oxygeriated region. Misonidazole binding profiles were, at least approximately, consistent with oxygen profiles 
computed previously for V79 sandwiches from the model described above. It was possible to count grains per cell rather than grains per unit area. No preferred binding in the nucleus, other organelles, or cytoplasm was noted. Detailed statistics on percell binding are consistent witk a two-fold intrinsic variation of misonidazole binding per cell in the outer region of the viable border, where most cells are normally cycling, with a smalle: intrinsic variation in the hypoxic region near the necrotic center. The results suggest misonidazole binding is proportional to cell size. The cell kinetics and response to other labels of those sandwich cells that bind misonidazole heavily were investigated both before and after reoxygenation.

There was a gradient of ' $\mathrm{H}$-thymidine labeling index for the sandwich cells, with the index dropping to less than $10 \%$ for the cells adjacent to the necrotic center. When these cells were reoxygenated and restored to favorable nutrient conditions by removal of the top slide, the "H-thymidine labeling index rose considerably within 24 hours; the minimum value after removal of the top slide occurred for the cells adjacent to the necrotic center and was 60\%. Using the DMIPS, viability was assessed using formation of mini-colonies as a criterion after removal of the top slide. It was found that $80 \%$ of the cells in the hypoxic region were viable. Thus such hypoxic colls could contribute to repopulation. The biology of the hypoxic cells after reoxygenation was analyzed using a number of additional labels, including fluorescent labels; the results were compared to labeled $\mathrm{Rl}$ tumors from rats shortly after the removal and sectioning of the tumors.

The conclusion was that sandwich hypoxic cells are viable and resume cycling after restoration of favorable growth conditions, a property relevant to tumor repopulation after radiation therapy. It was also concluded that the cell state continues to reflect their former hypoxia for at least 24 hours, a property relevant to diagnosis using tumor sections.

Because of the presence of self-induced or imposed gradients, the potential usefulness of sandwiches is not confined to their role as tumor analogues. They can be used to study situations where diffusion gradients are relevant, cells in a continuu's of local environments, cells subjected to a continuum of toxin or drug concentrations, and cell pupulations heterogeneous with respect to kinetic states.

$$
\text { Iynn Hlatky. }
$$

\section{IN VIVO BIOPHYSICS}

\section{Normal Tissue Studies}

There are iwo main objectives of studies on radiation effects in normal tissues. The first is to determine the relationship between the relative biological effectiveness (RBE) in normal tissues and the linear energy transfer (I.ET) of heavy charged particles. It has been shown that the highest RBE for acute effects after single doses of radiation occurs at about $90 \mathrm{keV} / \mathrm{\mu m}$ (Fig. 3.11). Fractionated doses are being used at present to determine the RBE and the repair capacity of mouse kidney and rat spinal cord, which are late responding tissues. The purpose is to test the hypothesis that the RBE for late effects after heavy ion irradiation is higher than for early responding tissues.

The second is to study the effects of radiation on differentiated normal tissue cell function and the regulation of function. These studies are being performed with cultured pig kidney cells (LLCPK1) and rat proximal tubule kidney cells. Implications of these studies are fundamental as well as applied.

Mouse kidney functions are measured to determine the target cell type responsible for the kidney late radiation syndrome. Urinary frequency (tubular damage) changes are found to occur early (4 days) after neon irradiation, with an RBE of 1.9. This effect is clearly separate from hemodynamic effects (glomerular filtration, plasma flow) that do not occur before 10 to 12 weeks postirradiation. By 20 weeks all the functions have similar doseresponse relationship (RBE of 1.45). Data analysis indicates that there is less repair after neon radiation.

Rat spinal cord paralysis studies with neon indicate a large sparing effect with fractionated helium plateau and neon plateau ( $\alpha: \beta$ of 1.51 and 2.23 respectively). There is much less sparing for fractionated doses of distal Bragg peak neon $(\alpha: \beta$ of 12.85). The $R B E$ is 2.0 for neon clateau and 5.2 for the distal Bragg peak. It appears that the RBE for late effects after fractionation is higher than for early-responding tissues.

Studies on the regulation of sodium-activated glucose transport in pig kidney cells indicate that this process can be impaired in a dose-dependent manner and there is no sparing effect on glucose transport regulation with fractionated doses. However cell killing is spared. These studies implicate a target or targets other than DNA that are inactivated for functional impairment. 


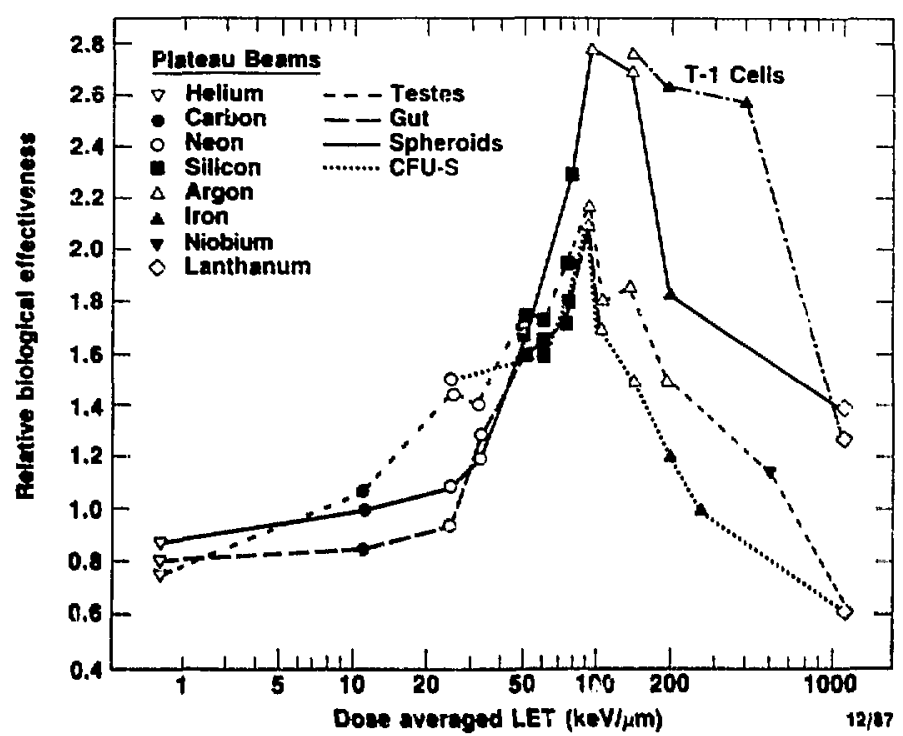

Fis. 2.11. RBE for acuke effects in normal tibuse. Relative biolorical effectiveness $(R B E)$ as a function of linower mero inurefor (LET) for $T I$ (hidncy) calls and multicellu. lar epheroids, end the following murine normal tione gedems: teates weicht loes, intontinal erypt adl mervival, and colony-forming writa: eplert. (XBL 8611-6485B)

Future studies include 1) irradiation of normal tissues with 1-2 Gy per fraction of low- and highLET radiation, and 2) determination of the radiation-sensitive target of functional impairment in pig sidney cells.

\section{Radiation Carcinotenesis in Mouve Handerian Gland}

The pituitary-promoted mouve Harderian gland tumorigenesis model was used to examine carcinogonic effects of heavy ions representing LET values from 1.6 to $650 \mathrm{keVh \mu m}$. High LET radiation carcinogenesis for doses in the range of $5 \mathrm{CGy}$ to 40 $\hat{c} \mathrm{G} y$ in the mouse Harderian gland has an RBE range of 2 for plateau helium ions at $1.6 \mathrm{keV} / \mu \mathrm{m}$ to values in excess of 25 for the highest LET of 650 $\mathrm{keVhum} \mathrm{(argon} \mathrm{distal} \mathrm{peak)} \mathrm{ss} \mathrm{shown} \mathrm{in} \mathrm{Fig.} \mathrm{3.12.}$ The important generalization from these data is that there is no evidence for a peak in the RBELET relationship as is found for cell killing and other tissue late effects. Future studies will include induction of Harderian gland tumors with low doses $(0.02-0.4 \mathrm{~Gy})$ of plateau heavy ions.

\section{Life Shartening Effects in Mice}

The goal of this project is to relate carcinogenic effects in viso to particle LET, track structure, or other phytical parameters so that cancer risk models may be formulated. Life-span shortening in irradiated mice reflects the total radiation-induced tumor burden in terms of increased tumor incidence and/or shortened tumor latency. From the results of pilot studies on life shortening in CB, male mice irradiated (total body) with particles ranging in LET from $30-200 \mathrm{keV} / \mu \mathrm{m}$, several important conclusions were drawn. The hypothesis that LET has predictive value was rejected because stopping carbon particles are far less effective than fission neutrons for life shortening after either a single dose or 24 weekly fractions. Surprisingly, iron particles produced no detectable life shortening at doses of 40,80 , or $160 \mathrm{cGy}$. Cataract evaluations indicated that weekly fractionation with carbon particles significantly enhanced cataract severity.

Results from these pilot studies are an essential prerequisite for the design of future tumori- 


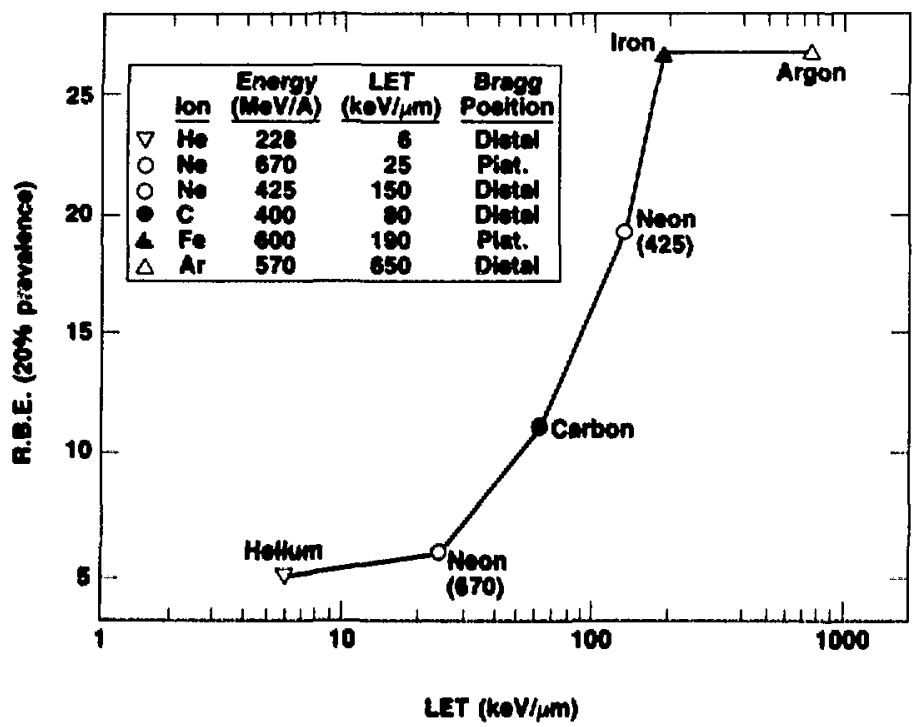

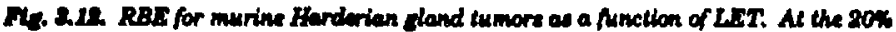

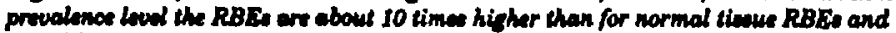
the RBE remeins elevated at a hinh LET: OBL 8911-6484)

genesis studies, probably with high-enercy wilicon particles. The objective will be to define the initial slopes of dose-response curves for various radiation-induced/promoted tumors over a range of low uingle or fractionatod doses.

\section{Marrow Stem Cell Inactivation}

The RBE-LET relationship for CFU-S inactivation in vivo has been defined for both high enercy and stopping particles. Result indicate maximum RBE or cross section, at about $80 \mathrm{keV} /$ $\mu \mathrm{m}$, and no detectable difrorences between high enercy or stopping particles where LET entimates are the same. New data collectod for high enerey protons (150 MeV/u) and stopping argon particles $(330 \mathrm{MeV} / \mathrm{u})$ indicate $R B B \mathrm{~s}$ of 1.0 and 0.8 respectively compared with gamma photons. Future inactivation studies will focus on fragmentation of iron particles to determine how RBE increases as the ratio of primary particles to spam ints decreases.

Studies continue on the mecinanisms a. : $N=d$ particle damage to CFU-S uxir "-- rauiviviviectors WR 2721 and prostaglandirs. Results indicate independent action, if not aynergism, when Miso- protol is given at 2 hours and WR 2721 at 0.6 houre before exposure to gamma radiation. Future studies will focus on metabolic and membrane alterations produced by Misoprostol.

\section{Tumor Radiobiolazy}

The response of a rat thabdomyosarcoma tumor cystem to irradiation with heavy charged particles is being evaluatod from experiments conductod both in vivo and in vitro. The radiobiological endpoints studied include tumor volume response, cellular survival after in situ tumor irradiation, and cell kinetic parameters measured by flow cytometry. The primary emphasis of research during the pant year has been in the following areas: 1) tumor repopulation kinetics following fractionated doses of low-and high-LET radiations; 2) phase-specific cell survival and cell kinetics following low- and high-LET radiations, and 3) studies on the immune system response to irradiated tumors.

Measurements were made of the time course of clonogenic cell survival in rat tumors after fractionatod doses of either $225-k V p \times$ rays or $557-\mathrm{MeV} / \mathrm{u}$ neon ions in the distal position of a $4-\mathrm{cm}$ extended peak. Rhabdomyosarcoma R-1 tumors (the R2C5 
subline) were irradiated in situ with daily fractionated doses ( 4 fractions in 3 days) of either peak neon ions ( $1.75 \mathrm{~Gy}$ per fraction) or $x$ rays ( $6 \mathrm{~Gy}$ per fraction). These doses were administered to achieve a cell survival of approximately $2-3 \%$ by the end of the four-fraction schedule. The most significant new finding of these experiments mas that with both radiation modalities a large delayed decrease in cell survival was observed at 1 to 3 days aftor completion of the fractionated dose schedule as thown in Fig. 3.13. The rate of cellular repopulation was consistent with the postirradiation tumor volume regrenuion and regrowth pattern for both radiation modalities.

Several factors related to tumor-hoat interactions and to tumor cell environment following irradiation are boing concidored in an attempt to explain the delayed decrease in clonogenic cell survival. These studies have clearly implicated a specific host immune reupones against $x$-ray. irradiated R2C5 tumors as a factor that influences post-irradiation tumor cell survival properties. Future atudies will focus on determining the relative role of this factor in producing the postirradiation dip in cell survival.

The results of experiments reported here sueseat several new treatment regimens that may prove to be highly efficient in achieving tumor cure. Because the clonogenic cell survival is dramatically decreased following fractionated doset of either $x$ rays or posk neon ions, a top-off dose of radiation adminintered at that time may be highly efficient in sterilizing the small residual fraction of clonogenic cells. In addition, the results sugest the possible advantages of uning monoclonal or polyclonel antibodies directod against tumor antigens that are expresed following irradiation. By combining immunotherapy and radiotherapy, it may be possible to achieve tumor sterilization with radiation doses that are substantially less than the tolerance limit of normal tissue structures within the radiation field.

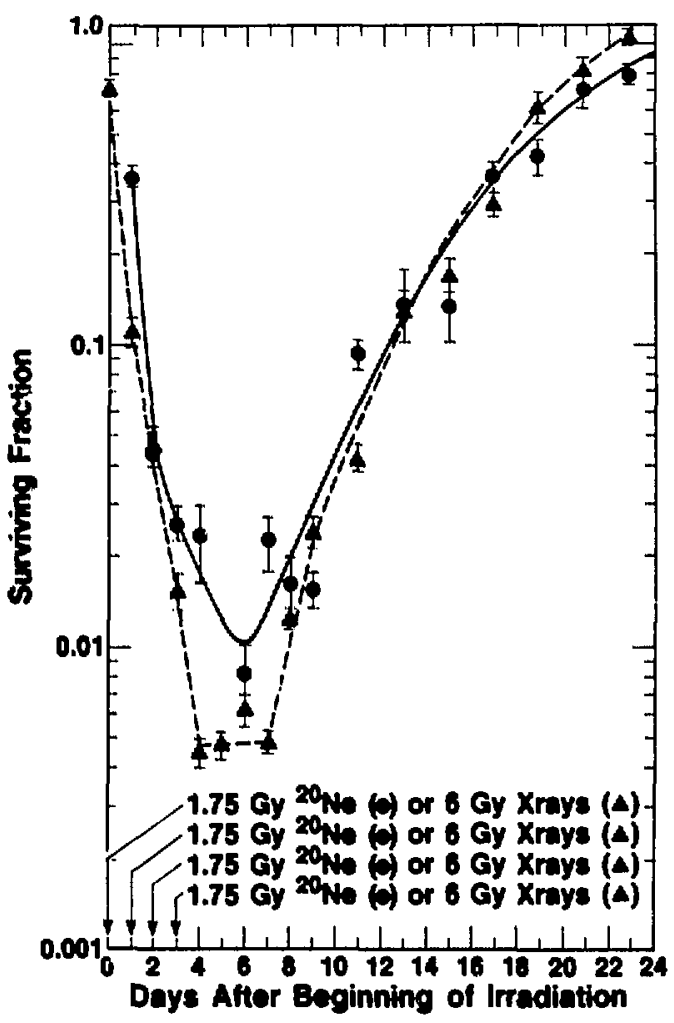

Ity. 2.12. Surviving fraction of rat rhabdomyonarcoma tumor culle as a function of time during and ofter in situ exponure to dailly froctionaled dowes (4 fractions in 3 doya) of either $657 . \mathrm{MeV}$ pack noon lowe in the dietal position of $4 \mathrm{~cm}$ extended poak (o, $1.75 \mathrm{~Gy}$ per froction) or $285, k V_{p} \times$ raye $(4,6.0 \mathrm{~Gy}$ per froction). Groupe of 3 to 4 tumors were aneayed at each time point. (Brror bers repreant \pm 1 SEIYJ (RBL 881-7211)

Edward Alpen, Adrian Rodriguez, John Ainsworth, Stanley Curtis, and Javed Afzal. 
The primary objectives of the nonionizing radiation program are 1) the development of a detailed experimental and theoretical understanding of the mechanisms through which static magnetic fields, extremely-low-frequency (elf) electromagnetic fields, and radiofrequency ( $\mathrm{r} f$ ) fields interact with biological systems; 2) the une of static magnetic fields and of fields to facilitate the release of encapsulated chemotherapeutic drues from liposomes into target colls; 3) the application of static magnetic fields with intensities up to 9.0 tesla $(90,000$ gauus) for magnetic circular dichroitm analysis of DNA structure; and 4) the development of novel chromatographic procedures in which if fields and pulsed electric fields are used to enhance the separation of chemical species wuch as DNA fragments and arterial plaque proteins. Progress in elected areas of the nonionizing radiation program are described hers.

\section{FIELD-INDUCED CHANGES IN MEMBRANE PERMEABILITY}

The interactions of atatic magnetic fields and if radiation with the phospholipid bilayer membranes of liposomes and various eukaryotic cell membranes were analyzed using neveral structural and functional end points. The liposome vesicle membrane is normally not permeable to solutes at temperatures below the thermal phase transition. However, when expowed to static macnetic fields at prephase transition temperatures, liposomes were obeerved to release an encapsulated chemotherapeutic drug, cytosine arabinofuranoside. This observation indicates that it may be possible to medically control drug relense in a given target tissue by manipulating membrane permeability with a focused macnetic field. A detailed theoretical model of liposome membrane interactions with magnetic fields at prephase trancition temperatures has provided a structural explanation for these findings. These investigations will be $\mathrm{ax}$ tended to eukaryotic cell membranes in future research.

In related experiments, the ability of of fields to facilitate solute transfer from liposomes into various target cells was investigated using a fluorescent dye marker: 6-carboxyfluoroscein (6CF) was self-quenched inside liposome bilayer membranes comprised of lecithin or other phospholipids with 14- and 16-carbon chain lengths. Hu- man erythrocytes and lymphocytes, rodent lymphocytes, rodent tumor cells, and rodent macrophages were treated with 6-CF-liposomes to promote cellsurface binding. Washed liposome-cell complexes were subsequently exposed to $2.45-\mathrm{GHz}$ microwaves or sham-treated at identical temperatures below the phase transition for the liposome system, and fluorescent dye transfer between the bound liposomes and the target cells was assessed by fluorescence microscopy and by a spectrofluorometric asmay. The microwave exposure was found to significantly facilitate dye transfer from the liponomes as compared to the sham-treated control amples maintained at the same temperature. This finding indicates that the membrane permeability changes leading to dye transfer are not attributable to thermal interactions with the microwave field. Future studies will explore the feasibility of using microwaves to facilitute drug delivery from liposomes into various target tissues in vivo.

\section{STRUCTURAL CHANGES IN EUKARYOTIC CELL MEMBRANES}

Studies have demonstrated that microwaves physically alter the structure of eukaryotic cell membranes. It is known that erythrocytes shed proteins from the membrane surface at the thermal phase transition. When human erythrocytes were placed in a 2.45-GHz microwave field, it was observed that the total protein released in the phase transition temperature range was doubled. Further, the type of proteins shed as a consequence of microwave exposure were relatively nonpolar and possessed a positive electrostatic charge, which distinguiched these proteins from those released as a result of conventional heat treatments.

\section{CARDIOVASCULAR EFFECTS}

The magnetohydrodynamic interaction of highintensity static magnetic fields with blood flow have been studied in monkeys, dogs, and rodents at field levels up to 1.5 tesla. Circulating blood in an applied magnetic field generates electric currents, and a volume force on the fluid is produced from the interaction of these induced electric currents with the magnetic field. Theoretically, this volume force can cause a retardation of axial blood flow velocity. Mathematical models of this magnetohy- 
drodynamic phenomenon have predicted the slowing of blood flow in intense magnetic fields. However, studies on carotid artery blood flow rates in rats have shown no effects from a 1.5-tesla uniform field. Further studies are planned using magnetic field intensities up to 9.0 tesla in order to determine the threshold field level for producing a measurable magnetohydrodynamic effect on blood flow dynamics. Cardiovascular effects of prolonged exposure to high-intensity magnetic fields are also being studied by continuous radiotelemetry monitoring of the electrocardiogram (ECG) in rodents subjected to a 1.5-tesla static magnetic field. At this field level, the magnetically-induced currents within the central circulatory syctem are $2-3$ times as large as the endogenouv currents normally present in the region of the sinoatrial node that controlu cardiac pacing. Data obtained from implantod ECG radiotolemetors in 12 adult rats have demonstrated that $a$ 3-4\% decrease in heart rate cocurs during a continuous 10-day exposure to a 1.5-tesla field relative to the heart rato measured during the 10-day pre-exposure interval. However, this change in heart rato is completely roversible upon termination of the magnetic field exponure. The results of these experiments indicate that the

\section{Future Studies}

Most of the research efforts described above will continue in order to achieve the defined goals. Within the scope of these studies, efiort in the area of molecular radiobiology will be expanded. The key questions to be addremed are related to mechanisms underlying radiation effects, such as damage mechanisms, protective mechanisms, response mechanisms leading to irreversible changes, etc. Emphasis will be given to the late comatic and genetic effects of external radiation (low- and high-LET). The problem of low-level radiation effects on human health will be specifically addressed in the coming years. It is hoped that the knowledge gained from present ongoing studies of basic processes involved in radiation damage and repair (including misrepair) will be sufficient so that many of the low-level effects can be understood from simple statistical considerations.

A recent new initiative deals with the problem of cell transformation by radon progeny. The goal of this study is to provide experimental evidence at induced electrical potentials and currents present in the central circulatory system during prolonged magnetic field exposure have only a small, and probably insignificant effect on cardiac pacing.

\section{APPLICATIONS OF ELECTROMAGNETIC FIELDS IN SPICTROSCOPY AND CHROMA- TOGRAPHY}

Progress in this research area includes 1) the completion of instrumentation for magnetic circular dichroism analysis of DNA structure using a 9.0tesla uniform magnetic field produced by a superconducting magnet; 2) the demonstration that the separation of arterial plaque protein species uning reverse-phase HPLC can be enhanced by the application of an of fiold at nonthermal intenvities; and 3) a pulned-electric-field chromatography system designed for use in the separation of large DNA fragments. There applications of nonionizing radiation in spectroscopy and chemical separation procedures will be an integral component of the future research program.

Thomas Tenforde, Cornelius Gaffey, and Robert Litiurdy.

the physical, chemical, and molecular levels for a causal link between the incidence of lung cancer and the presence of radioactive nuclides deposited in the air passageways of the lung by the progeny of the decay of radon gas. The primary interest is in the sector of the DNA damage that eventually results in malignant transformation and the induction of a tumor.

The Radiation Biophysics Group is also going to be involved in technology transfer with respect to the recent interest in the medical community regarding heavy-particle accelerators. The Merritt Peralta Medical Center (MPMC) in Oakland, California, is planning to build a light ion biomedical research accelerator and supporting laboratories for expanded medical research and cancer therapy with high-LET particles. The MPMC has asked the Group to provide input for the determination of the beam characteristics for this accelarator. In addition, the Group will provide assistance in dosimetry and beam development for a variety of clinical applications. 


\section{Publications: Radiation Biophysics}

\section{CONTRIBUTIONS TO JOURNALS}

Afzal, S.M.J. and Ainsworth, E.J. Radioprotection of mouse colony forming units-spleen (CFU-S) against heavy charged particle damage by WR 2721. Radiat. Res. 109, 118-126 (1987).

Ainsworth, E.J. Early and late mammalian responses to heavy charged particles. Adv. Space Res. 6, 153-165 (1986).

Chatterjee, A, Koehl, P., and Magee, J.L. Theoretical consideration of the chemical pathways for radiation-induced atrand breaks. Advances in Spece Research 6 (11), 97-105 (1986).

Curtis, S.B. Track structure in biological models. Adv. Space Res. 6, 179-185 (1986).

Curtis, S.B., Atwell, W., Beever, R., and Hardy, A. Radiation environments and absorbed dose eatimations on manned space missions. Adv. Space Res. 6, 269-274 (1986).

Doss, K.G., Gustafsson, H.A, Gutbrod, H.H., Kampert, K.H. Kolb, B., Lohner, H., Ludewigt, B., Poukanzer, A.M., Ritter, H.G., Schmidt, H.R, and Wieman, H.H. Nuclear collective flow as a function of projectile energy and mass. Phys. Rev. Lett. 57, 302 (1986).

Gauger, G.E., Tobias, C.A., Yang, T.C., and Whitney, $M$. The effect of space radiation on the nervous system. Adv. Space Research 6(11), 243-249 (1986).

Hagen, M.P., Holahan, E.V., and Ainsworth, E.J. Effect of heavy ions on cycling stem cells. Adv. Space Res, 6, 201-211 (1986).

Hanson, W.R., Fry, R.J.M., Sallese, A.R., Frischer, H., Ahmad, T., and Ainsworth, E.J. Compari- son of intestine and bone marrow radiosensitivity of Balb/c and the C57BL/6 mouse strains and their B6CF1 offspring. Radiat. Res. 110, 340-352 (1987).

Kraft, G., Kraft-Weyrather, W., Blakely, E.A, and Roots, R. Heavy-ion effects on cellular and subcellular systems: inactivation, chromosome aberrations and strand breaks induced by iron and nickel ions. Adv. in Space Research 6(11), 127-136 (1986).

Liburdy, R.P. Neuroimmunomodulation and cancer. The Cancer Journal 1, 198 (1987).

Liburdy, R.P. and Tenforde, M.S. Marnetic-field induced drug permeability in liposome vesicles. Radiation Research 108, 102-111 (1987).

Liburdy, R.P. and Vanek, P.F., Jr. Microwaves and the cell membrane: III. Protein shedding is oxygen dependent and temperature dependent: evidence for cation bridge involvement. Radiation Reseanch 109, 382-395 (1987).

Renner, T. and Chu, W.T. Wobbler facility for biomedical experiments. Med. Phys. .14, 825-834 (1987).

Schimmerling, W., Rapkin, M., Wong, M., and Howard, J. The propagation of relativistic heavy ions in multielement beam lines. Med. Phys. 13, 217-228 (1986).

Swiegert, S.E. and Alpen, E.L. Dynamics of cell kinetic parameters during 9L spheroid growth. Cell Tissue Xinetics 19, 567-576 (1986).

Swiegert, S.E. and Alpen, E.L. Radiation-induced division delay in 9L spheroid versus monolayer cells. Radiation Research 110, 473-478 (1987). 
Tenforde, T.S. and Kaune, W.T. Interaction of extremely low frequency electric and magnetic fields with humans. Health Phys. 53, 585-606 (1987).

Urie, M., Goitein, M., Holley, W.R., and Chen, G.T.Y. Degradation of the Bragg peak due to inhomogenieties. Phys. Med. Biol. 31, 1-15 (1986).

Wren, M.W., Durbin, P.W., Willis, D.L., and Singh, N.P. The potential toxicity of uranium in water. J. Amer. Woterworks Asen., 177-184 (April 1987).

Yang, T.C., Craime, L.M., Moi, M., Tobias, C.A. Dose protraction atudies with low. and highLET radiations on neoplantic cell tranuformation in vitro. Adv. Space Research 6(11), 137-147 (1986).

\section{CONTRIBUTIONS TO BOOKS AND PRO. CEEDINGS}

Blakely, E.A., Tobias, C.A, Ludowigt, B.A, and Chu, W.T. Some physical and biological properties of light ions. Pages 19-41 in Proceedings of the Fifth PTCOG Meeting and International Workehop on Biomedical Accelerators, (Lawrence Berkeley Laboratory, Dec. 1-2, 1986), LBL-22962 (1987).

Chatterjee, A., Llacer, J., Collier, M., Renner, T., Henderson, S., and Chu, W. Diagnostic applications of radioactive beams. Pages 213-230 in Proceedinge of the Fifth PTCOG Meeting and International Workshop on Biomedical Accelerators , (Lawrence Berkeley Laboratory, Dec. 1-2, 1986), LBL-22962 (1987).

Chatterjee, A. and Magee, J.L. Track models and radiation chemical yields. In $A$ Textbook of Modern Radiation Chemistry, M.A.J. Rodgers, ed., Verlag Chimie International (1986).
Chu, W.T. and Kuenning, R.W. Limitations of dynamic beam delivery systems. Pages 185-196 in Proceedings of the Fift PTCOG Meeting and International Workshop on Biomedical Accelerators, (Lawrence Berkeley Laboratory, Dec. 1-2, 1986), LBL-22962 (1987).

Durbin, P.W. Metabolic models for uranium. Pages F-1 to F-65 in Biokinetics and Analysis of Uranium in Man, R.H. Moore, ed., United States Uranium Registry, Hanford Environmental Health Foundation Report USUR-05HEHF-47 (1986).

Goodman, E.M., Greenebaum, B., Marron, M.T., and Tonforde, T.S. Effects of Electropollution: Brain Tumore and Experimental Models, S.K. Dutta, R.M. Millis, eds., Information Ventures, Inc., Philadelphia, PA (1986).

Liburdy, R.P. Immunological effects of electromagnotic effects. Section 6, Chapter 9, in Review of Radio Science 1984-1986, G. Hyde, ed., International Union of Radio Science, Brussels, Belgium (1987).

Magoe, J.L. and Chatterjee, A. Theoretical aspects of radiation chemistry. In A Textbook of Modern Radiation Chemistry, M.A.J. Rodgers, ed., Verlag Chemie International (1986).

Metting, N.F., Howard, J., Braby, L.A., Schimmerling, W., Rossi, H.H., Wong, M., Kliauga, P.J., and Rapkin, $M$. Measurement of energy deposit near high energy, heavy ion tracks. Pacific Northwest Laboratory Report No. 6950 (1986).

Stannard, N.J., Auxier, J.A., Bair, W.J., Durbin, P.W. Eckerman, K.J., McClellan, R.O., Morrow, P.E., Schlenker, R.A., and Thompson, R.D. General Concepts for the Dasimetry of Internally Deposited Radionuclides. Report No. 84, National Council on Radiation Protection and Measurements (1985). 
Tenforde, T.S. Static magnetic fields. Pages K-10 to K-11 in Review of Radio Science 1984-1986, G. Hyde, ed., International Union of Radio Science, Brussels, Belgium (1987).

Tenforde, T.S., Levy, L., and Veklerov, E. Monitoring of circadian waveforms in rodenta exposed to high-intensity static magnetic fields. Pages 307-326 in Interaction of Biological Syatems with Static and ELF Electric Magnetic Fields, L.E. Anderson, B.J. Kelman, and R.J. Weigel, eds., Proceedings of 23rd Hanford Life Sciences Symponium (Report No. CONF-84), Pacific Northweat Laboratory, Richland, WA (1987).

Yang, V.V. and Ainsworth, E.J. A histological study on the cataractogenic effocts on heavy charged particles. Proc. Nat. Sci. Counc. B.ROC. (Trupei, Taiwan) 11, 18-28 (1987).

\section{LBL REPORTS ISSUED}

Berger, S.E. The radiation response of murine erythroid-colony-forming units (CFU⿺). Ph.D.
Thesis. Lawrence Berkeley Laboratory report LBL-23843 (July 1987). 129 p.

Tenforde, T.S. Interaction mechanisms, biological effects and biomedical applications of static and extremely-low-frequency magnetic fields. Lawrence Berkeley Laboratory report LBL22321 (1986) $57 \mathrm{p}$.

Tobias, C.A. Dynamic models in radiobiology. Presented at the workshop on mechanisms of radiation interaction with DNA "Potential Implications for Radiation Protection" (San Diego, Calif., January 21-22, 1987). Lawrence Berkeley Laboratory report LBL-23334 (1987) $21 \mathrm{p}$.

White, D.L., Durbin, P.W., Jeung, N., and Raymond, K.N. Specific sequestering agents for the actinides. 16. Synthesis and initial biological teating of polydentate hydroxypyridinonate ligands. Lawrence Be-'keley Laboratory report LBL-21714 (1987). 


\section{Section 4. Research Medicine}

\section{Introduction}

The Research Medicine Group has as its principal focus the investigation of physiology and disease processe using nuclear chemistry and nuclear physics methodn and instruments. This program of research evolved over the past fifty years with its beginnings in 1937, when Dr. John Lawrence joined a small group at the Radiation Laboratory on the Univervity of California Berkeley campus. Now, in its fiftieth yenr of progrens, the Donner Laboratory and the Biology and Medicine Division have participated in the exploration of various disease diagnoses and therapies uning radiotracers and accelerated particles. Though the general characteristics of the research approach have not changed, current topics of focus emphasize the study of mental ditorders, including cchizophrenia and Alzheimer's disease, the evaluation of metabolism in tumors, and the investigation of atherosclerosis by noninvasive imaging methods and tracer methods that detect abnormal metabolism.

Along with physiologic and disease oriented studies in human subjects, there is a continuing thrust on the development of specialized instruments for understanding human disease. Among these instruments is the high resolution positron emission tomograph, which this year achieved a resolution of $2.3 \mathrm{~mm}$, far beyond the available resolution of instruments elsewhere. Recent instrumentation development includes the establishment of NMR spectroscopy and whole-body imaging instruments at Lawrence Berkeley Laboratory close to the existing positron emission tomographic instruments.
Therapy with charged-particle beams has been successful in clinical trials involving tumor sites of the head, neck, spinal cord, and prostate gland. The program of heavy-ion radiosurgery for the ablation of arteriovenous malformations in the human central nervous system continues to have excellent results in disease situations that are not approachable by neurosurgical methods.

Collaborative programs between researchers creating new instrumentation and radionuclides for the study of disense and those interented in their applications in the clinical environment have increased over the past fow years to include investigutors from the University of California, Berkeley College of Engineering, and Departments of Physical Education and Nuclear Engineering; the University of California, San Francisco Departments of Neurosurgery, Radiology, and Neuropnychiatry; the University of California, Davis Department of Neurology; the University of Illinois, and Harvard Medical School.

A modern biology has emphasized more fundamental investigations of the molecular biology associated with life and disease processes, the Research Medicine Group has emphasized the basic in vivo chemical techniques of tracking metabolism while investigating the time rate of change of metabolic products that can be measured by the integration of HPLC techniques with radiotracer methodolosy.

The Research Medicine Group has also made major contributions to studies of environmental radiation, radiation used in diagnosis and therapy, and the health effects of oscillating and atatic magnetic fields. 
ACTIVITIES OF THE RESEARCH MEDICANE GROUP

Scientists

Technical Staff and

Graduate Students

Physics and Mathematics

Detector inatrumentation

Positron emiasion tomography

Single photon tomograph

Computer based algorithms

Reconutruction methods

Statiotical analyuit

Kinetics modeling

\section{Chemistry}

Radiopharmaceutical tracers

Brain and heart blood flow; metabolium

Neuroreceptors
S.E. Derenzo
R.H. Huesman
W. Mores
E. Salmeron
D. Uber

J. Baker

J. Cahoon

M. Colina

A. Geyer

T. Vulotich
J. Gerdes
C. Mathis
Y. Yano

S. M. Hanrahan

New isotope generators

Medicine and Phyaiology

Blood clotting

Platelets

Megakaryocytes

Atherosclerosis

Coronary artery disease

Platelets

Metabolic patterns

Alzheimer's disease

Diagnosis

Cause(s)

K.M. Brennan

K. Bristol

T.F. Budinger

D. Carpenter

K. Dalal

S.N. Ebbe

S. Gregr

R. Himelman

S. Knezevic

W.J. Jaguat

R. Leven

B. Periera

D. Prozen

T. Sargent III

J.P. Seab

Schizophrenia

P.E. Valk

N. Kusubov

M. Morimoto

J. Twitchell

Tumor metabolism

Nuclear Magnetic Resonance

NMR probe:

H. Ikehira

N. Bolo

NMR imaging syutems

R. Newmark

B. Knittel

M. Roos

M. Kessler

S. Wong 
Scientists

Technical Staff and

Graduate Students

Heavy Ion Therapy

Intercranial AVM:

Heavy ion radiotherapy physics

Heavy ion radiobiology

Treatment planning and

dose localization

Radiotherapy physics

Tumor radiosenuitivity

predictive ansays

PEBA

$\begin{array}{ll}\text { J.R. Castro } & \text { K. Baken-Brown } \\ \text { F. Chuang } & \text { N. Dodson } \\ \text { J.M. Collier } & \text { M. Foster } \\ \text { J.I. Fabrikant } & \text { E. Holloway } \\ \text { K.A. Frankel } & \text { J. Judnick } \\ \text { S. Henderson } & \text { C. Rathbun } \\ \text { M. Kessler } & \\ \text { R.P. Levy } & \\ \text { E.H. Lo } & \\ \text { J.T. Lyman } & \\ \text { N. Manley } & \\ \text { P. Petti } & \\ \text { M.H. Phillipa } & \\ \text { S. Pitluck } & \end{array}$

J.R Castro

F. Chuang

N. Dodson

M. Foster

D. Holloway

K.A. Frankel

C. Rathbun

M. Kessiler

R.P. Levy

E.H. Lo

J.T. Lyman

N. Manley

M.H. Phillipa

S. Pitluck

\section{Brain Function and Dieease Studies}

Neurological and paychiatric diseases are being studied by using positron emission tomography (PET), nuclear magnetic resonance (NMR), vingle photon emission computed tomography (SPECT), and metabolic tracers. The research activities with these advanced techniques encompass creation of new instrumentation and new tracers, and physiological investigations with animals and patients. The dicases of interest are Alcheimer's dementia, white matter lexions, stroke, brain tumors, radintion necrosis, schizophrenia, and depression. Each is being studisd by two or more of the above techniques.

PFT is used to obtain images of the localization of any biochemical that can be labeled with a positron-emitting isotope. From these images accurate data can be obtained to give the amount of activity in any selocted region, and these data can be determined over short time intervals after injection to derive kinetics for the time course of the label in the brain. Critical to the usefulness of these kinds of data are the choice of the labeled compound and the knowledge of how it is metabolized. For example, glucose metabolism is measured by fluorodeoxyglucose, labeled with 110-min fluorine-18. This is used to measure regional cerebral metabolic rate (rCMR), which is reduced in opecific aress in Alsheimer's dementia, stroke, and brain tumors. An important additional measure is the regional cerobral blood flow (rCBF), which is altered by the brain in accord with metabolic demand. A new radiopharmaceutical, 1DI-HIPDM $[N, N, N$-trimethyl-N(2-hydroxyl-3-methy]-5iodobenzyl)-1,3-propanediamine], has been developed by our group for measuring rCBF.

\section{SCHIZOPHRENIA AND AFFECTIVE DISORDERS}

There prychotic diseases are being investigated to find the biochemical abnormality that is believed to underlie their clinical manifestations. For schizophrenia there is evidence that the abnormality is in methyl metabolism, and an abnormal oxidation of the methyl carbon of methionine has been demonstrated by our group in these patients. This is studied by administering methionine labeled in the methyl group with carbon-14 and measuring the expired ${ }^{14} \mathrm{CO}_{2}$. The abnormality found in schizophrenia is a reduced rate of oxida- 
tion of the methyl carbon, with the total quantity oxidized being reduced to about one-half of normal at 2 hours. Chromatographic methods have been developed to separate the metabolic products that have become labeled with the carbon-14. To detect and measure these metabolites use of the new Cyclotrino developed by the Nuclear Science Division is being investigated, which is expected to increase the senvitivity for detection of the ${ }^{14} \mathrm{C}$ labeled metabolites by a factor of 1000 . With such sensitive methods, it is hoped that the abnormal biochemical step in metabolism that is associated with schizophrenia will be identified. Early preliminary data sugrest that the methyl carbon is also oxidized abnormally in deprension; studies with such patients have been started to confirm these findinge.

Investigations at other laboratories have reported abnormalities in glucose metabolism and blood flow in upecific brain areas in echizophrenia and depression. Our inventigators have measured glucose metabolism in a carefully controlled group of schizophrenics and did not find the abnormality reported by others, but did find differences in the rate, rather than the total amount of glucose metabolized. With the new radiopharmaceutical (12I-HIPDM) for measuring brain blood flow developed here, our investigators have the capability for this meanurement, and studies may be undertaken to confirm the findinge reported by other laboratories. However, it is felt that these measurements are not as contributory to underatanding the basic cause of schizophrenia as the methionine work, where our effort is concentrated.

Thornton Sargent III and Natalia Kusubov.

\section{CLINICAL AND METABOLIC SIGNIFICANCE OF CEREBRAL WHITE MATTER LESIONS SEEN ON NMR IMAGING}

Introduction of nuclear magnetic resonance imaging has revealed the presence of deep whitematter lesions (WML:) in $30 \%$ of elderly subjects. It has been suggested that thece lesions represent diffuse cerebral vascular disease of the type that leads to dementia, and that patien's with deep WMLs have a higher probability of developing dementia than age-matched controls. The purpose of this study is to test these hypotheses.

A five-year study of 120 patients is underway. Half $(60)$ of the patients will be intellectually normal on entering the study and 60 will show mild dementia. Half of each group will have cerebrovascular-disease risk factors, such as hypertension or ischemic heart disease, and the other half will not. All patients are being studied by NMR imaging, to look for WMLs, and by PET with "F-2-fluoro-2deoxyglucose ("F-FDG) to look for cortical areas of reduced glucose metabolism. Cognitive testing, NMR imaging, and PET studies will be repeated three years later.

So far, 38 patients have been studied for the first time: 37 were intellectually normal subjects and 1 had mild dementia. Half the patients had CV risk factors. WMLs have been graded 1 to 4 in severity. Eleven of the nondemented patients had grade 1 or 2 lesions and the remainder were normal. The demented patient had grade 3 lesions. None of the subjects has so far shown abnormalities of FDG uptake. NMR ine $30 \mathrm{c}$ from a demented patient and a control pati nt are shown in Fig. 4.1.

This study is expected to elucidate the pathophysiological significanc s of deep WMLs and to determine the relations ip of these lesions to cerebrovascular divea $;$, dementia, and gray-matter glucose metabolism, as demonstrated by PEr.

Peter E. Valk and Thomas F, Budinger ( $L B L$ ); Craig Van Dyke and George Fein (VA Medical Center, San Francisco).

\section{QUANTITATIVE NMR MEASUREMENTS OF BRAIN ATROPF $Y$ IN NORMAL AGING AND ALZHEIMER'S JISEASE}

Alsheimer $\mathrm{s}$ disense (AD) is a progressive degenerative dementia of unknown cause with pathological changes occurring first and most severely in the grey matter of the temporal and parietal lobes of the brain, including the hippocampus, as shown by autopsy studies. Positron emission tome rraphy (PET) and single photon emission compute $d$ tomography (SPECT) atudies of glucose metabo.ism and blood flow have shown functional correlaces of this regional pattern of involvement in $A D$ with the greatest deficits occurring in the same regions as one finds the pathological abnormalities. Anatomic imaging performed to date has shown general differences between $\mathrm{AD}$ patients and normal controls; however, these procedures do not specifically evaluate the grey matter regions of the brain that are most prominently involved in $\mathrm{AD}$ and that can be clearly visualized with NMR imaging. The purpose of this study was to image and quantify changes in the temporobasal greymatter regions of the brain in $A D$ patients and in normal aged controls in order to betiar understand changes in these brain structures and their relation to clinical symptoms and pathophysiology. 


\section{BRAIN WHITE MATTER DISEASE}

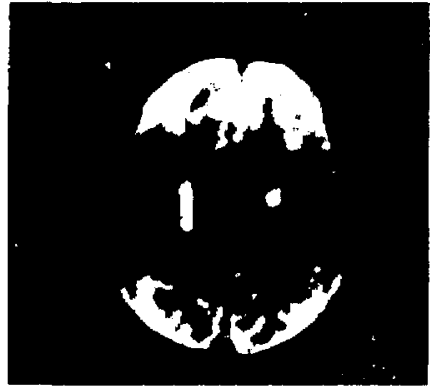

Dementia

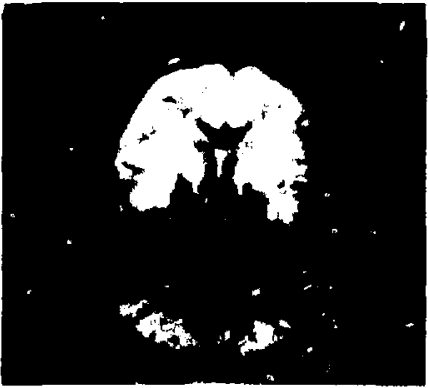

No Dementia

Wy. 4.1. Whits-matlor lesions appear as abnormal retions of hth stmal, daply located in sach hemiophere. They are located in the cervbral whit matts, around the lateral ventricles, whers

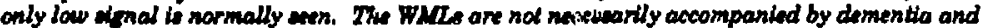
the patient with the more esurs levions was cosnitively normal in thin case. (BBC 870-8736)

Representative images are ghown in Fig. 4.2. There was more than a $40 \%$ reduction in mean normalized hippocampal area of the $A D$ patients $(0.194 \pm 0.025)$ compared to controls $(0.341 \pm 0.034$, $p<0.0001$, see Fig. 4.3). Severity of hippocampal atrophy did not correlate with severity of overall dementia as measured by the mini-mental status examination (MMSE) in the AD patients (see Fig. 4.4). It also did not correlate with severity of overall atrophy as measured by percant brain volume, age of onset, or duration of $\therefore \mathrm{D}$.
The percent ventricular size and percent sulcal size were aignificantly greater in the $\mathrm{AD}$ group compared to elderly controls $(p<0.02$ and $p<0.01$, respectively). The mean values for overall atrophy also differed significantly ( $p<0.01$ ), with the AD patient showing a smaller relative brain size $(75.1 \% \pm 6.5 \%)$ than elderly controls $(81.7 \% \pm 2.7 \%$, see Fig. 4.5). The individual values for the two group overlapped considerably for these three mesaures of atrophy. There was a correlation between overall atrophy and overall dementia
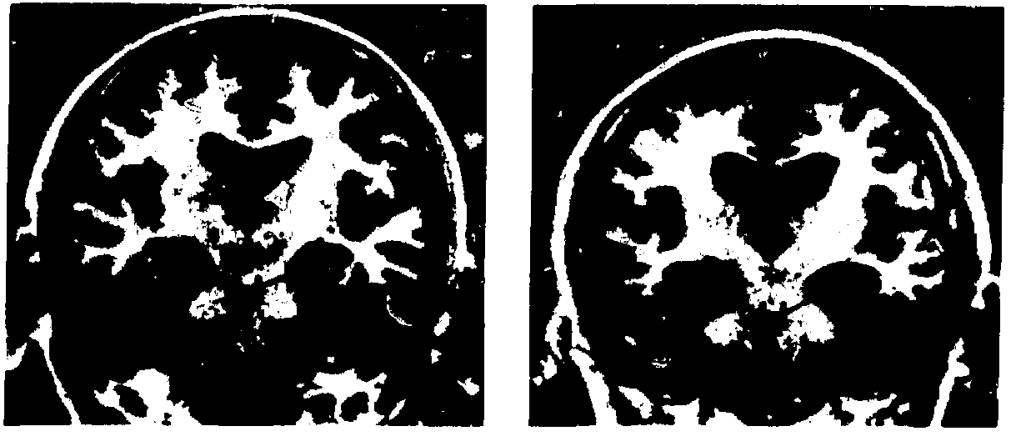

Pix. 42. Repreantative cononal inversion recovery images showing the hippocampus of a normal aged control (hefi) and an Alsheimer's disease patient (right). $H=$ hippocampus. (XBB 878-6624N 


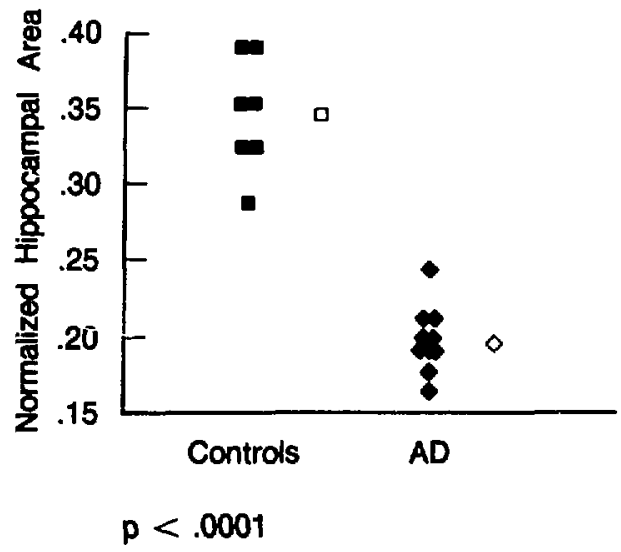

Fi. 4. Normalized hippocampal area for the control group and the Als' simer's diveane group (AD). Solid symbols indicale individual ubject values; open symbole indicale group means. $P<0.0001$ (Student's t-test).

(XDL 877-7822)

severity as measured by the MMSE $(r=0.89, p<$ 0.001).

A major finding of this NMR study is that there is atrophy of the hippocampus that can be measured in vivo, and which is greater in $\mathrm{AD}$ patients then in normal aged controls. Hippocamal atrophy does not correlate with overall brain atrophy, implying that it reflects an aspect of $\mathrm{AD}$ pathology that differs from that seen in overall atrophy. While hippocampal size, percent ventricular size, percent sulcal size, and percent brain size

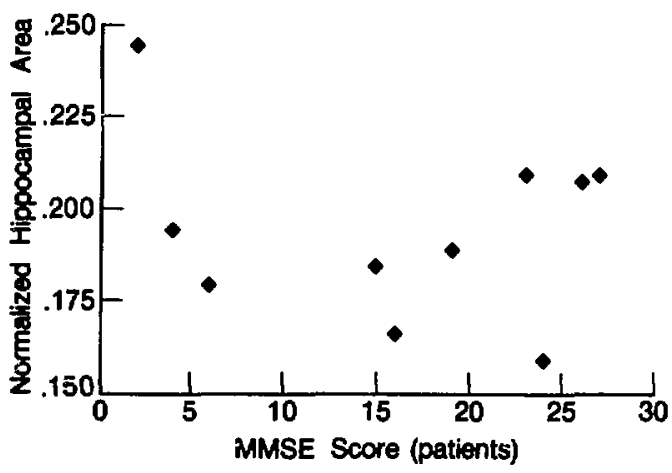

Fit. 4t. Graph of normalived hippocampal area versus minimental status examination ecore as a measure of dementia severity, illustrating the lack of cornelation between these two meanures in the Alcheimer's disease group.

QBL 8711-8006)

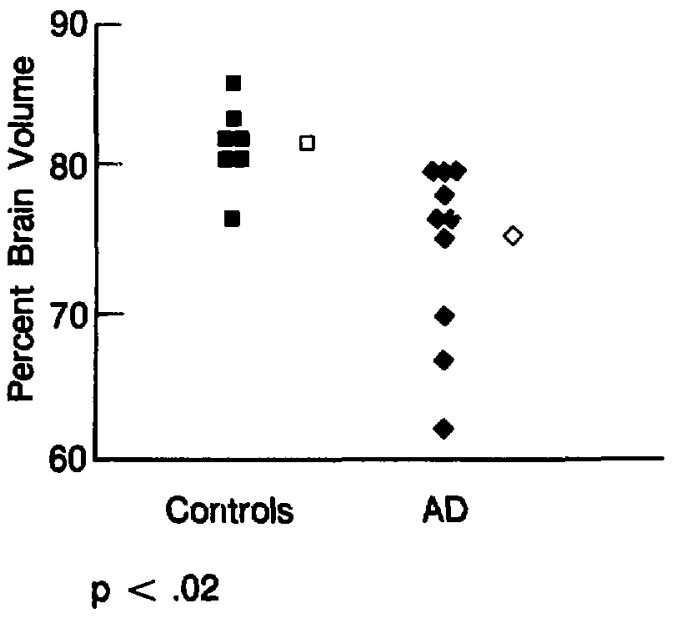

Fig. 4.6. Percent brain volume, a meanure of overall atrophy, for the control group and the Aizheimer's disecue group (AD). Solid symbols indicale individual subject values; open symbols indicale group means. $P<0.02$ (Student's t-lest). ABL 877.7826)

were all different between control and $\mathrm{AD}$ subjects, only the hippocampal measurements separated the two groups in this study without overlap of individuid velues. A conclusion from these findings is that hippocampal atrophy occurs early in $\mathrm{AD}$, and may be more sensitive to the presence of the disease than measurements of ventricular size, sulcal enlargement, or overall brain atrophy.

J.P. Seab, W.J. Jagust, S.T.S. Wong, M.S. Roos, B.R. Reed, T.F. Budinger

\section{INVESTIGATION OF CEREBRAL SEROTONIN RECEPTOR-STTES WITH RADIOLABELED AMPHETAMINE ANALOGS}

The study of cerebral receptor systems in vitro and in vivo is an area of active research for many reasons. Receptor systems have been shown to play an important role in normal and abnormal cerebral function. Serotonin receptors have been identified as mediating a number of behavorial and physiological actions, and the 5-HT, serotonin receptor subtype has been implicated as playing a role in depression and psychosis. In addition, severe reductions in the density of 5-HT, receptors have been noted in Alzheimer's disease. Quantitation of 5-HT, receptor densities could yield informa- 
tion on normal receptor densities and abnormal densities associatod with disense states.

Substituted amphetamine analogs have been tudied by this group for many years as potential brain blood-flow agents. Two of these, the 2,5dimethoxyamphetamines substituted in the 4position with either iodine (called DOI) or bromine (called DOB), have recently been identified as 5HT, ligands. The compounde wore labeled with radioiodine and radiobromine so that they could be utilised to identify 5-HT, receptors in vitro and in vivo. The in vitro work to identify the equilibrium receptor binding constents in rat brain was conducted in collaboration with Dr. David Nichole at Purdue University (DOI) and Dr. Steven Peroutka at Stanford (DOB); Dr. Dennis MeKenna at the National Institute of Mental Health conductod in vitro autoradiographis studies to identify the specific sites of receptor localization in rat brin alices. The results of these studien are shown in Table 4.1 and Figuse 4.6.

The values in Table 4.1 indicate that DOI and DOB are strongly bound to receptor syatom in the rat brain (low discociation constant. $K_{4}$ ), and that DOI labeis a greater number of sites than DOB (higher B . $_{\text {. }}$. Other data (not thown) indicate that these two agents specifically label the S. $_{\text {. }} \mathrm{HT}_{2}$ serotonin receptors. The resison for the highor $B_{\text {. }}$ values for DOI is currently uider study.

DOI and DOB are known to be potent psychosctive agents that cause hallucinations in man. The cerebral site of action of hallucinogens has not been determined, but the $\mathbf{S - H T}$, receptor aystem has been implicated a playing a role in the action of these agents. Figure 4.6 is an autoradiograph of rat brain slices incubated with $1-I$-labeled DOF and imI-LSD. One of the areas that shows high receptor denaity with DOI and iodo-LSD is the claustrum; it is known to have extensive afferent and efforent connections to sensory brain regions and is in-

Table 4.1. Binding characteristics of $D O I$ and $D O B$ in rat brain homogtenates.

\begin{tabular}{lcc}
\hline & $\begin{array}{c}\mathbf{K}_{\mathbf{s}} \\
(\mathrm{nM})\end{array}$ & $\begin{array}{c}\mathrm{B}_{\mathbf{m}} \\
\text { (nM/g protein) }\end{array}$ \\
\hline R-[m]-DOI & 1.3 & 99 \\
S-[M]]-DOI & 2.3 & 63 \\
R-[MBr]-DOB & 0.19 & 10 \\
\hline
\end{tabular}

$$
1251-D O 1
$$
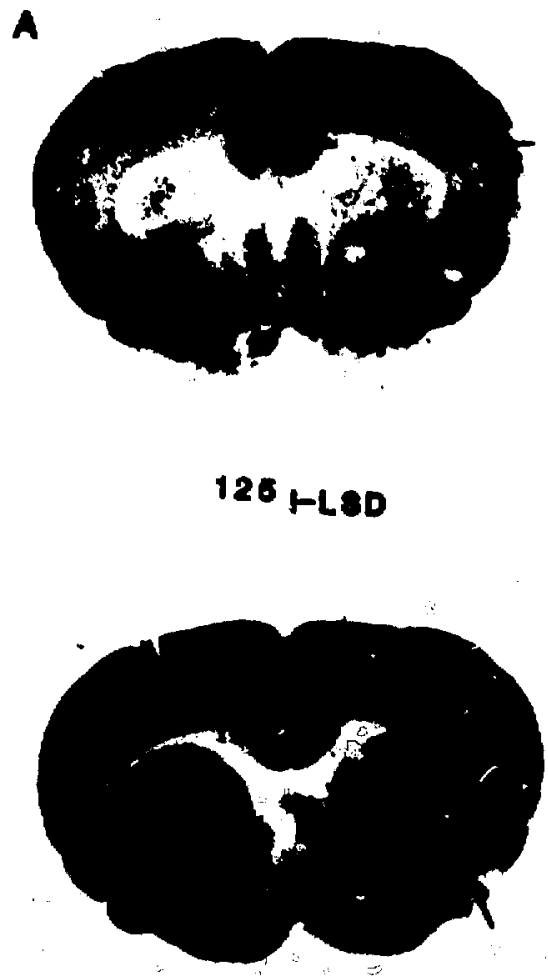

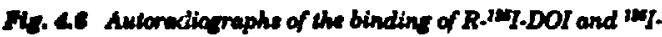
LSD in ros forebruin exetlons. Arrowe indicale the claustrum, parivel cortex, and eingulate cortex. The etriatum (contral eney' matter recion), which is rich in dopamine receplors, showe dignifrant bineing with iodo.LSD, but not with DOr. This indicales that DOI is more a specific lovand for exrotonin reosplore than iodo-LSD. (XBB 8710-9812)

volved in the processing of visual and auditory information. The high denvity of DOI and jodo-LSD binding in the claustrum sugreat that the actions of hallucinogens may involve common receptors in the claustrum.

The ultimate soal of this research is to qunntify serotonin B-HT, receptors in vivo in normal and abnormal human subjects utilizing noninvasive imaging techniques such as positron emission tomography (PET) and single photon emission computed tomography (SPBCT). Studies such as those described above are necessary to identify and quantitate the binding characteristics of agents 
that someday may be useful as radiopharmaceuticals. Future studies will include mapping of the distribution of these agents by autoradiography and evaluation of compounds for use with PET and SPECT studies in vivo.

C.A. Mathis, A.T. Shulgin, and T.W. Sargent, III. Collaborators: D. Nichols, S. Peroutka, and $D$. MaKenna.

\section{DIFFERENTLATION OF ACTIVELY GROWING TUMOR FROM INACTIVE TUMOR IN VTVO, USING POSITRON EMISSION TOMOGRAPHY}

The purpose of this study is the diagnosis of tumor activity in brain tumor patients with histologic evidence of viable i.tamor.

PET atudies usin: ubidium-82 ( $\left.{ }^{\mathrm{R}} \mathrm{b}\right)$ and wPfluoro-2-deoxyclucose ("F-FDG) were done in 18 pationts with malignant brain tumors. All patients had presented with deterioration, following initial stubilization, 4 months to 2 yeurs aftor treatment by interatitiul irradiation. Surgery was performed to relieve intracranial pressure and to obtain tisuse for a histological diagnosis in order to differentiate tumor regrowth from radiation necrosis. Viable tumor cellı were veen in all patients, but clinical follow-up clearly separated the patients into two groups: 9 who deteriorated without anti-tumor therapy and 9 who did not. It was apparent that the tumor tissue was inactive and nonproliferating in half of the patients, despite histologic appearances that were identical to the other group. Asgessment by PET with FDG howed a relatively high level of glucose metabolism in 8 of the 9 who had clinically active tumor and relatively depreased Ir:atabolism in 7 of the 9 who did not.

This study was originally undertaken with the intention of comparing PET results to hintologic diagnosis of tumor recurrence. Initial rasults, reported in 1986, showed apparently good correlation between the two. However, subsequent clinical follow-up has shown that the histologic diamosis is unrelated to clinical tumor progression and is of no value for patient manacement. On the other hand, the results of PET with $-R b$ and $" F-F D G$ do correlate with clinical tumor progression and can be used to determine the need for anti-tumor therapy. This is the first time that in vivo PET studies have succesufully demonstrated clinical activity or inactivity of tumors that appear histologically identical.

Peter $E$. Valk and Thomas F. Budinger (LBL); Philip Gutin, Victor ALevin, and Pamela Silver (UCSF Medical School).
QUANTITATION OF HYPOXIA WITH MISONIDAZOLE DERIVATTVES

Radiolabeled compounds that could be utilized to determine the hypoxic content of tissues in vivo would be of considerable benefit. There are a number of potential uses of these agents in conjunction with noninvasive imaging modalities such as positron emission tomograpy (PET); these applications include quentitation of hypoxic cells in solid tumors, stroke, and ischemic heart disease. The ability to quantitate and temporally follow the extent of hypoxia in diseased tissues before and after various therapeutic regimes could be of great clinical value.

Solid tumors in animals and man are known to consiat of cells that are heterogeneous in proliferation and oxycenation itatus. Numerous studies have provided evidence that oxygen concentration is an important factor in tumor growth kinetics and the presence of viable hypoxic cells in tumors has been inferred histologically or by their radiobiological responwes since no direct assay or marker for these cells has been available. Hypoxic cells in solid tumor can control radiocurability because they are known to be about 3 times more resistant to ionizing radiation than are oxygenated cells. Radiation therapy is directed at the treatment resistance of hypoxic cells, and their role in tumor responsiveness has clinical relevance. The identification of viable hypoxic cells in stroke and ischemic myocardium to assess potentially recoverable tissue may also be of great benefit in helping to evaluate various therapeutic problems such as selecting patients for cerebral artery and cardiac bypass operations or determining the efficacy of drug, ensyme, and hyperbaric oxygen treatments.

A number of compounds, including quinones, anthracyclines, paraquat, and heterocyclic nitro compounds such as nitrofurans and nitroimidazoles, have been shown to undergo enzyme-catalyzed redox cycles in biological systems. The 2-nitroimidaroles (2-NI), originally developed as antiprotozoal agents, were shown to be effective as radiowensitizers of hypoxic cells in the early $1970 \mathrm{~s}$. The 2-NIs enter cells and the nitro group is reduced to the nitro anion free-radical due to the high electron affinity of the compounds. Formation of the nitro anion free-radical can occur either metabolically by enzyme catalyzed redox cycling in the absence of ionizing radiation, or by the transfer of an electron from a transient species formed by ionizing radiation. The nitro radical anion reacts with dioxygen to form the original nitro compound 
and accounts for the selective action of these agents upon anaerobic or hypoxic cells. The details of the mechanism of action of these compounds have not been fully elucidated, but it is believed that the nitro anion radical is not the primary alkylating species formed by nitro reduction, but rather that it is an intermediate in the formation of these species. Of concern to the development of hypoxic tissue imaging agents are the observations that 2-nitroimidazoles covalently bind selectively to hypoxic mammalian cells both in vitro and in vivo. The details of this binding process are not clear, but it is evident that binding rates to intracellular biomolecules (including DNA and macroproteins) occur in inverse proportion to oxysen concentration within the cells; rate differences of 50 -fold have been reported for binding of 2-NIs to cells under hypoxic condition compared to aerobic conditions.

A collaborative research effort was begun with J. Rasey, K. Krohn, and J. Grierson (Univertity of Washington School of Medicine) to label a 2-nitroimidazole derivative with a positron emitter (15) and conduct organ distribution and imaging studies in normal and tumor-implanted rate. Tumorimplanted rats were provided by S. Curtis and T. Tenforde of the Radiation Biophysics Group (myosarcomas) and by J. Rasey's colleagues at the University of Washington (gliomas).

Labeling experiments were conducted at the 88 Inch Cyclotron at LBL to synthesize "F-labeled fluoromisonidazole (Fig. 4.7). Labeling yields of 1-10\% were achieved, which were sufficient for preliminary studies in small rodents, and animal
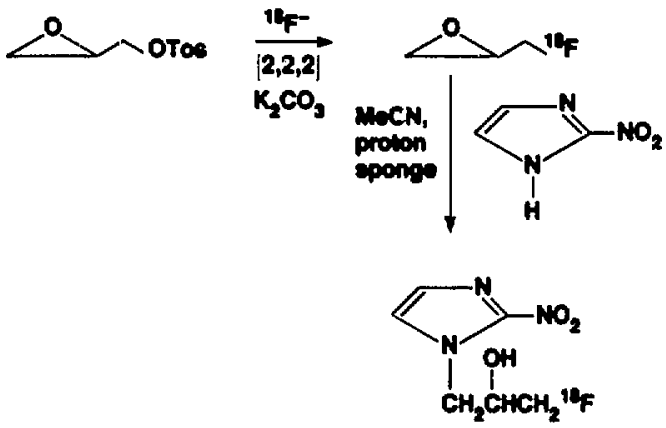

14F-Fucromitonidazele

Fif. 47. Radiangnthenis of the hyparic call marter M.tabeled misonidacde. The onthenis involues the formation of "F-pi. Avorohydrin, ite coupling with 2-nitroimidanole 10 produce "f?" labeled fworomivomidasole, and was performs. in collaboration with John Grierwen. ARL 875-9059) studies utilizing normal rats and rats in which glioma and myosarcoma tumors were implanted were begun. It was found that the "F-fluoromisonidazole distributed rapidly to all organs in the rat and cleared from all tissue except bladder, large intestine, and tumor. An Anger positron camera photograph of a rat with implanted myosarcomas is shown in Fig. 4.8. The activity in the two tumors on the animal's shoulders is evident; activity in the caecum was found to be contained in its contents, consistent with the binding of the 2-nitroimidarole by anaerobic bacteria. A PEI image taken with the Donner 280-Cryatal Tomograph through a longitudinal rection of a rat with an implanted glioma is shown in Fig. 4.9 ; high leveil of activity are evident in the tumor and bladder. Bladder activity is consintent with clearance of the compound from the blood via the kidneys.

These preliminary results demontrate the featibility of imaging hypoxic tiusue in vivo. The anthesis and preliminary evaluation of several

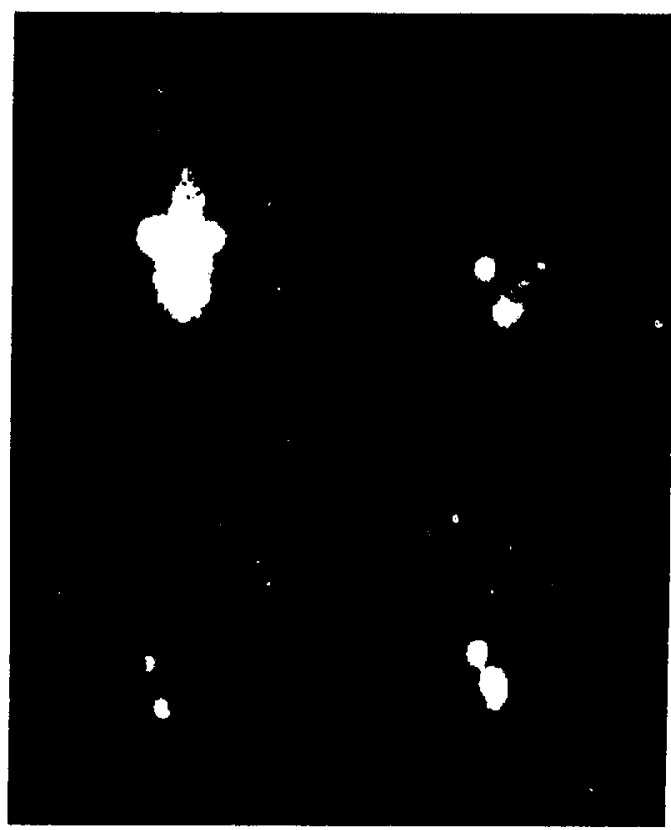

Wh. 4h Aner potitron camare inares of a bumor-bearing rat at veriows times afler the injection of Hefworomiconidanole. At 1 how the activity is distributed throwhout the rat and the tumars on the choulders contain the hirhest concentration of activity; at 3 hours and 4 hours only the two tumors on the rat's shoulders are visible along with the contents of it large inteative. $\mathrm{OBL} 8710-9092 \mathrm{~N}$ 


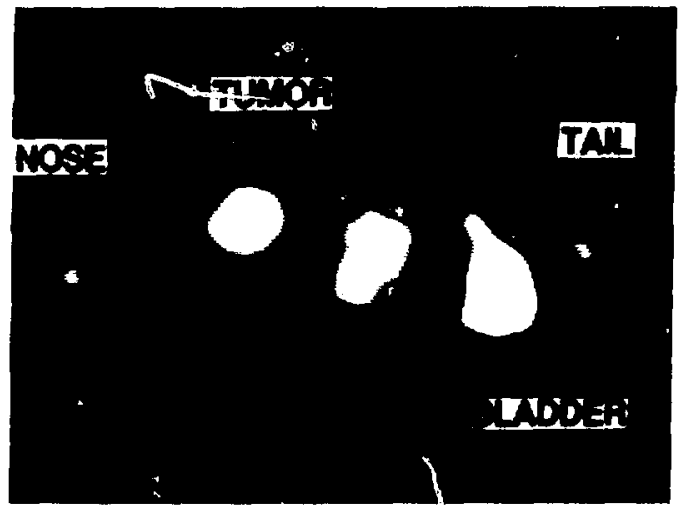

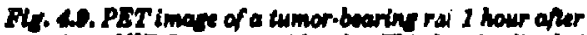

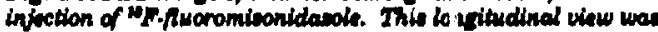

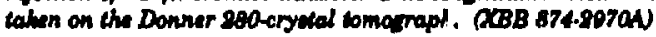

other 2-nitroimidasole derivativis that may be more useful in higher animal srecies inciuding man are also under investigation. While the rodent is a convenient experimental choice, many metabolic processes are 2-6 times more rapid in the rodent than in dogs and primates. Misonidazole and fluoromisonidazole have been shown to clear slowly from dog blood with a plasma clearance half-time of 9 hours. The eventual apphication of the 2-nitroimidiazoles to quantitating hypoxia in man will require a plasma clearance time considerably less than the half-life of "F (110 min). While other longer-lived positron emitting radio nuclides exist, considerations regarding patient dosimetry, ease of radionuclide production, and convenience to eventual clinical application make their use in this application less desirable; fluorine- 18 has a relatively low-energy positron and a convenient halflife for radiochemistry and imaging. We plan to evaluate fluorominoniciazole is well as other 2-NI analoge as potential quantitative hypoxic cell markert.

C.A. Mathis, T.F. Budinger, Y. Yano, J. Gerdes, and S. Hanrahan. Collaboraturs: S. Curtis, T. Tenforde (Radiation Biophysics Group), J. Rasey, K. Krohn, and J. Grierson (University of Washington).

\section{Heart and Atheroncleronis Studies}

The atudies of cardiovascular diveases encompas investigations of the cenetic relations to lipoprotein patterns in patients, the biochemistry of normal and abnormal lipoprotoins, the development of mothods to mensure the lipoprotein receptor activity in the human using tracern, development of methods for dotecting arterial lesions, and studies of heart muscle blood flow.

\section{IMAGING ATHEROSCLEROSIS}

Arteriosclerosis studies using methods of imaging vessel patholory have focused on human platelet imaging, affinity of atheraclerosis for hematoporphyrins, and use of labeled low density lipoproteins. New findingt on porphyrin and LDL diatribution that thow promice in the development of a method for studying the natural history of the atheromata that block human arteries are presented below.

\section{Evaluation of Radioporphyrins for Uptake in Vascular Lesions}

Inventigations were continued on the uptake of radioporphyrins in balloon-catheter deendothelialined rabbit aorta relative to normal aorta for the detection of vascular lesions. Whole-body positron emiusion tomography (WB-PET) and tissuecounting experiments were done to determine the time-course distributior of $m$ Ga-porphyrins in normal and hypercholesterolemic-diet rabbits.

The uptake of $m$ Ga-tetra(4-sulfonatophenyl)porphyrin ( ${ }^{-G a-T P P S 4}$ ) in various tissues, including normal and damaged aorta was determined from 30-300 minutes postintravenous injection. The ratios of uptake in damaged to normal aorta were calculated and plott:Ad (Fig. 4.10) io show an increase from 2.3 at 30 winutes to a muximum of about 4.7 at 180 minutes and then a decline to 2.8 at 300 minutes. 


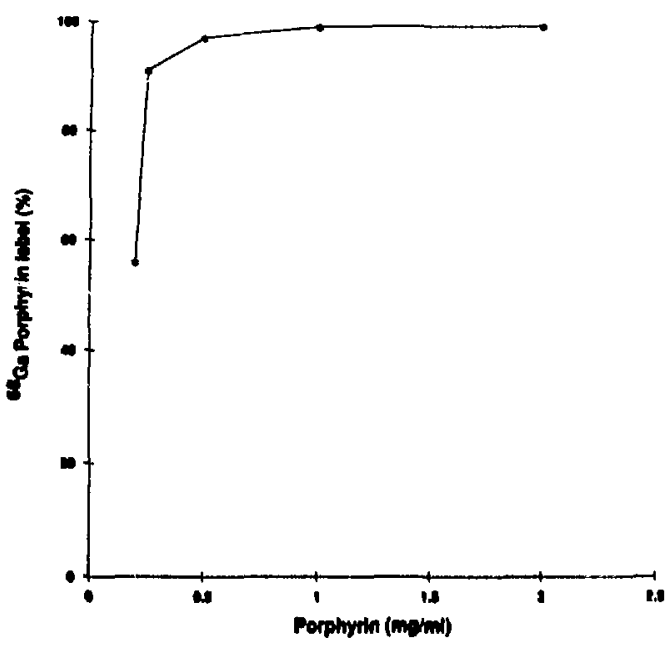

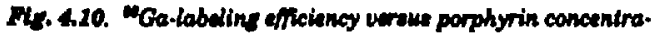

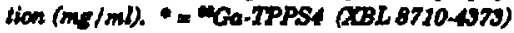

WB-PET scans with the 280 BGO detector PET system ( $7-8 \mathrm{~mm}$ resolution) were obtained from $0-30,30-60$, and $60-90$ minutes post-intravenousinjection of balloon-catheter deendothelializedaorta rabbits on normal and hypercholesterolemic diets. Figure 4.11 demontrates scans done at 0.5 and 1.5 hours showing anteroposterior and lateral views.

Table 4.2 show the uptake in various tissues of normsl and hypercholesterolemic-diet rabbits at 120 minutes postintravenous injection.

The damaged to normal sorta uptake ratio (4.7) at 150-180 minutes is greater than maximum ratios with ${ }^{-G a}$-labeled platelets (3.5) at $30-60$ minutes. Funhermore, the radiolabeled porphryin: are preforable to platelets, which require separation from plasma.

Tissue distribution results in normal as compared to hypercholesterolemic-diet rabbits showed similar uptake at 120 minutes postintravenous injection, except, for the liver and scraped/deendothelialized aorta, which had about $40 \%$ less uptake in the hypercholesterolemic-diet rabbits.

Yukio Yano, Kathleen M. Brennan, Shirley $N$. Bbbe, and Thomas F. Budinger.
Table 4.2. Ma-TPPS, distribution in rabbits

(\% injected dose /gram tissue 120 minutes post intravenous injection).

\begin{tabular}{lcc}
\hline \hline \multicolumn{1}{c}{ Tissue } & $\begin{array}{c}\text { Normal } \\
\operatorname{diet}(\mathbf{n}=3)\end{array}$ & $\begin{array}{c}\text { Hypercholesterol } \\
\operatorname{diet}(\mathbf{n}=1)\end{array}$ \\
\hline Blood & 0.278 & - \\
Kidneys & 0.109 & 0.103 \\
Lungs & 0.122 & 0.150 \\
Liver & 0.123 & 0.071 \\
Spleen & 0.113 & 0.118 \\
Normal-proximal & & \\
aorta & 0.064 & 0.062 \\
Scraped-distal & & \\
aorta & 0.258 & 0.163 \\
\hline \hline
\end{tabular}

Average uptake ratio of scrapped-aorta to normal aorta:

$\begin{array}{ll}\text { Normal-diet rabbit } & 4.03 \\ \text { Hypercholesterol-diet rabbit } & 2.63\end{array}$

Autoradiographic Studies with a Radiolabeled Analog of Low Density Lipoproteins

Preliminary studies on the development of a radiolabeled analog of low denuity lipoprotein (LDL) for human diagnosis resulted in the successful radioiodination of tyramine-cellcbiose (TC) adduct of LDL. The work reported hore extends those atudies to autoradiographic imaging of the localization of TC-LDL in the rabbit aorta and gives promise to the pousible imaging of the progression and regression of atherosclerosis in humans.

[19TTC-LDL was injected into male New Zealand white rabbits with control or hypercholesterolemic diets $(1.0 \%$ cholesterol $+4 \%$ peanut oil for 8-15 wooks, or $0.5 \%$ cholesterol $+2 \%$ peanut oil for 14-21 woeks). The rabbits were sacrificed 4 hours postinjection and the aortas removed, opened longitudinally, and washed several times with meline. The clean aortas were wrapped in plasticwrap and sandwiched between Kodak diagnostic film, then rtored at $-70^{\circ} \mathrm{C}$ for 3.5 days. The exposed film was developed with standard Kodak solutions. 


\section{NORMAL DIET}

0.5 hr Post Injection

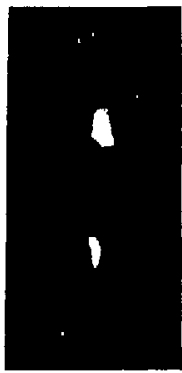

1.5 hr Post Injection
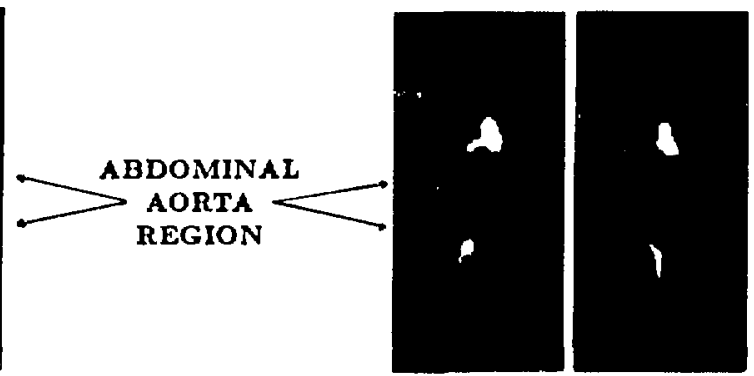

\section{HYPERCHOLESTEROL DIET}

0.5 hr Post Injection
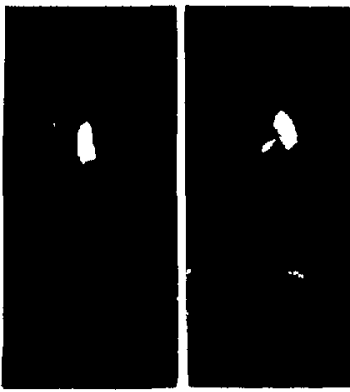

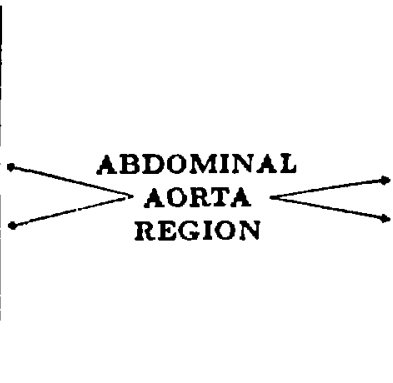

$1.5 \mathrm{hr}$ Post Injection
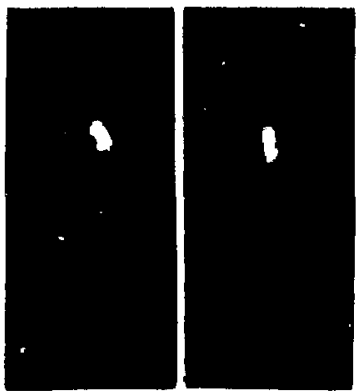

Piy. 411. "Ga-porphyrin activity on the scraped aorla: Normal versus hyperchdesterolemic rabbits. (BBC 875-4195)

The opened aortas are shown in the left half of Fig. 4.12, which shows a marked accumulation of foam cells in an advanced aortic lesion. Autoradiographic images sre shown in the right half of the figure, demonstrating the localization of the ['II]TC-LDL in the atherosclerotic areas of the hypercholesterolemic aorta, while the control aorta is virtually free of radiolabeled TC-LDL.

Future work will include imaging with radiolabeled TC-LDL in studies of LDL metabolism in various patient populations and in studies using the rabbit model to evaluate the efficacy of pharmacological intervention in LDL metobolism.

K. Dalal, S. Ebbe, D. Carpenter, T. Yee, $Y$. Yano, K. Brennan, and T. Budinger.

\section{HEART STUDIES}

The efforts to perfect a method of evaluating heart muscle blood flow using radionuclide tracers are motivated by the need for an alternative to coronary catheterization. In the past this need was based on the desire to have a noninvasive diagnostic method. More recently, there has developed a vital need for performing repeated studies to monitor the effects of chemical therapy for lysing clots in coronary arteries and to evaluate the efficacy of intracoronary artery atheromata removal techniques such as laser ablation.

Our radionuclide-tracer method continues to be validated as a good measure of myocardial perfusion. A typical patient study is shown in Fig. 4.13. 

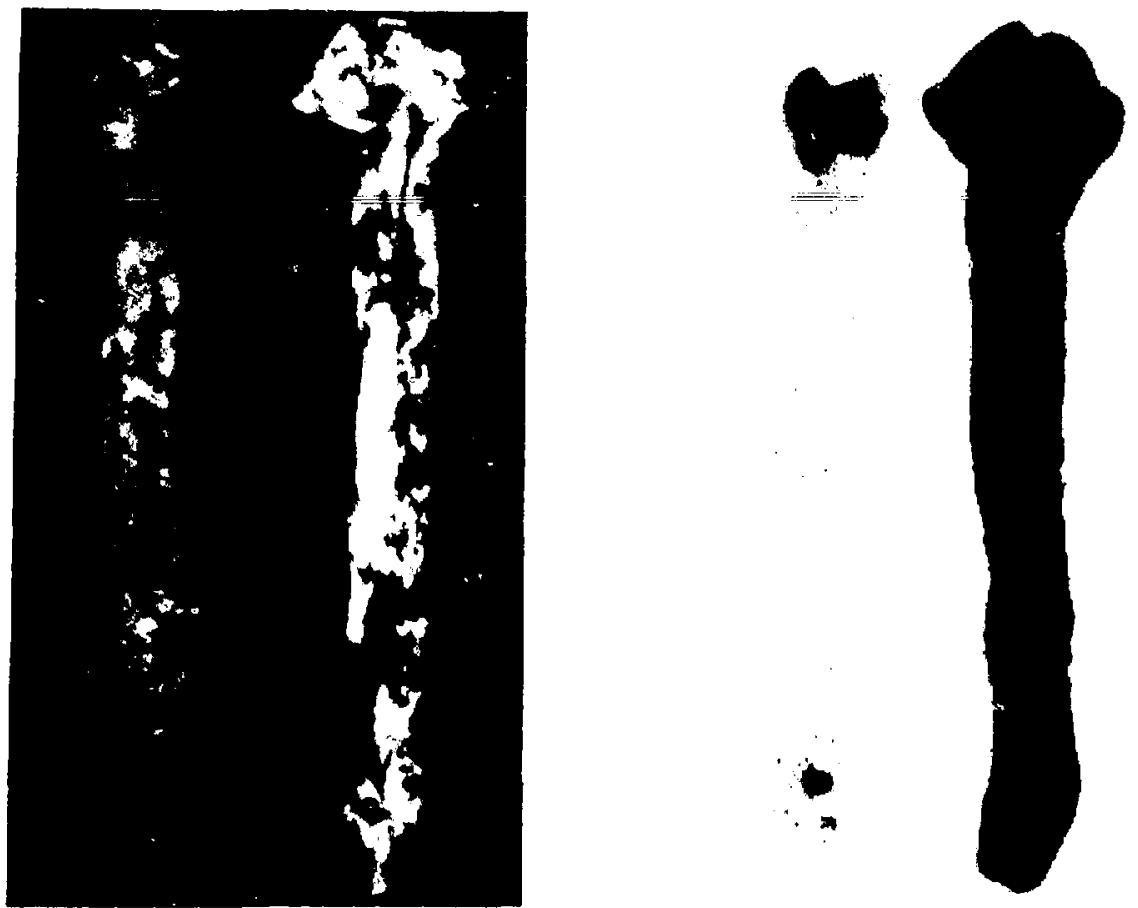

Fir. 412. At left is a photograph of aortas removed from a control-diet rabbit (ANR) and a hypencholesthralemic diet rabbit (right). The hypercholesterolemic aorla chows a great accumulation of foam cells, while the control aorta is relatively free of lesions. At right are the autoradiographic images, demonstrating the accumulation of [DIJTC-LDL in the hypercholenteralemic aorta (right) and the lack of accumulation of the radialabeled TC.LDL in the control worla (lefi). (BBC 876-64134)
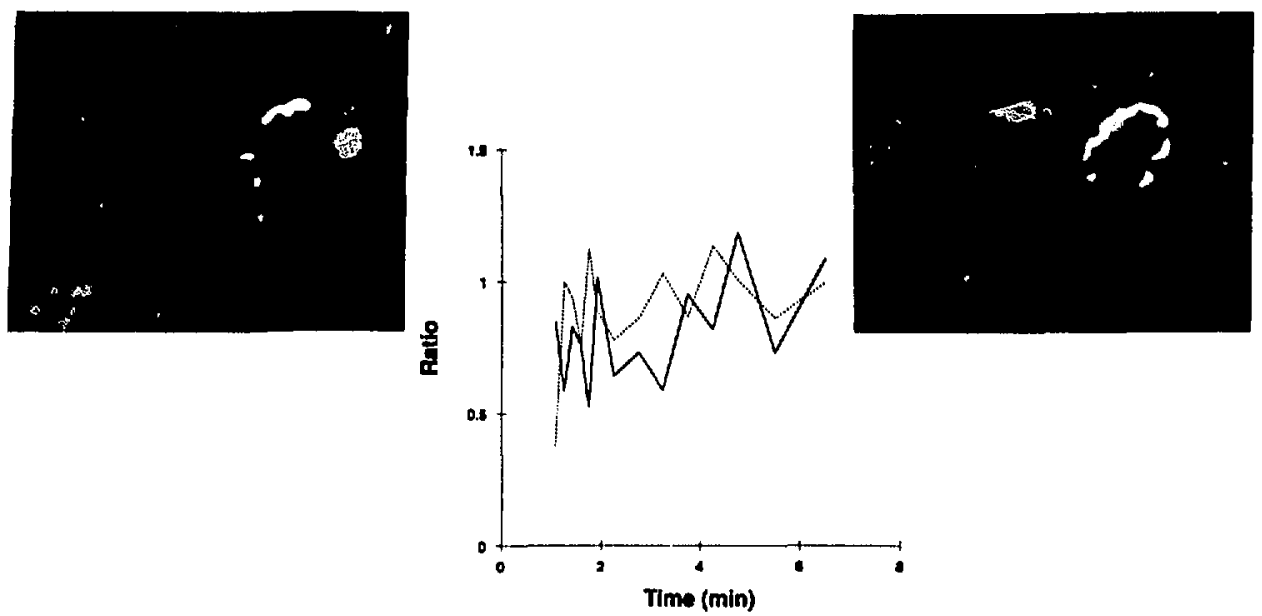

Fiz. 1.19. Myocardial perfusion study for a typical patient. Left: during stress (-). Right: 30 min poststress (......). Curves show ratio of $m b$ accumulation in defect area to that in the anterior septum. (BBC 875-4047) 


\section{REVIEW OF HEAVY CHARGED PARTICLE RESEARCH TRIAL FOR FY 1987}

The Heavy Charged Particle Clinical Research Trial continued to accrue patients in studies of dose-localization radiotherapy for uveal melanoma, base-of-skull and para-CNS chondrosarcoma/ chordomas, and other histologies.

A randomized Phase II study in conjunction with the Department of Radiation Medicine of Masmachusetts General Hospital and the Harvard Cyclotron was opened through the Radiation Therapy Oncology Group to study patients with chordoma/chondrosarcoma in the head and neck. It has accrued 20 patients.

A phase III randomized trial in uveal melanoma has also continued to accrue patients (100 patients to date) in comparing helium-jon therapy againut iodine-125 plaque therapy. This is the only randomized study in the world contrasting these two forms of alternative therapy for uveal melanoma.

Other Phase III randomized trials for locally advanced carcinoma of the prostate (12 patients) and unresectable carcinoma of the lung (25 patients) are continuing.

The National Cancer Institute has recently renewed the Procram Project Grant supporting the treatment of human cancers with heavy charged particles from October 1, 1987 through February 28, 1992. With the closure of the 184-Inch Cyclotron, the entire charged particle therapy program will be "iloved to the Bevatron. It is anticipated that it will be postible to carry out the proposed studies at the Bevatron with an accrual rate of about 160 patients per year.

Since local control rates in over 400 patients treated with helium-ion dose-localization therapy range from $50 \%$ (residual soft tissue sarcoma) to $70 \%$ and $90 \%$ (chordoma-chondrosarcoma and uveal melanoma, respectively), this has been highly successful treatment. However it is important that both biological and technological studies of optimieation techniques for this therapy continue, as well as the randomized atudies in uveal melanoma and head/nock chordoma-chondrosarcoma.

Our major emphasis in 1988 will be on comparing high-LET charged particles (neon) directly against low-LET photon irradiation and helium ion therapy, using randomized protocols in locally advanced tumors of the lung, prostate, brain, nasopharynx, paranasal sinuses, and sarcomas of bone and soft tissue. The key aim will he to establish the role of the high-LET charged particles in the clinical therapy of human cancers.

\section{TREATMENT PLANNING DEVELOPMENTS IN RADIOTHERAPY}

Developments in three major areas occurred in treatment planning uning charged particles at LBL during the past year. The firat was the implementation of PLAN3, a thro-dimensional treatment planning aystem developed at Massachusetts General Hospital by Michnel Goitoin. Witl this sytom it is possible to plan composite treatments with photons and charged farticles. It is also ponsible to plan nonecpianar beams. The program calculates not only nominal dowe distributions but also the maximum and minimum distribution. that could occur given uncertainties in patient ponition, CT number, and calibration. This information is extremely useful since it allows one to quantify the maximum postible dose received by a critical structure and the minimum dose to the target volume.

The second major development in treatment planning at LBL was the clinical implementation of image correlation. The ability to transfer volumes of interest from one imaging study to another has become an increasingly valuable treatment-planning tool in defining both tumor volumes and critical structures for brain lesions, in particular chordoma and chondrosarcoma. This technique, developed at LBL over the jast fow years by Kessler, Chen, Petti and Pitluck, has thus far been used for 11 patients. In all of these rases, target volumes and/or brainstem or opinal-r,ord contours were transforred from MRI to ${ }^{-3}$ scans (coe Fig. 4.14). Two techniques exist for calculating the traneformation between two different studies, the point-to-point method, which relies on either external or internal landmarks, and surfacefitting algorithms, which minimize the difference between murfaces (e.g., those defined by the skull) in each study. In general, surface fitting or internal landmarks were uwed when the MRI scan came from an outside institution. Surface fittiz 8 was 


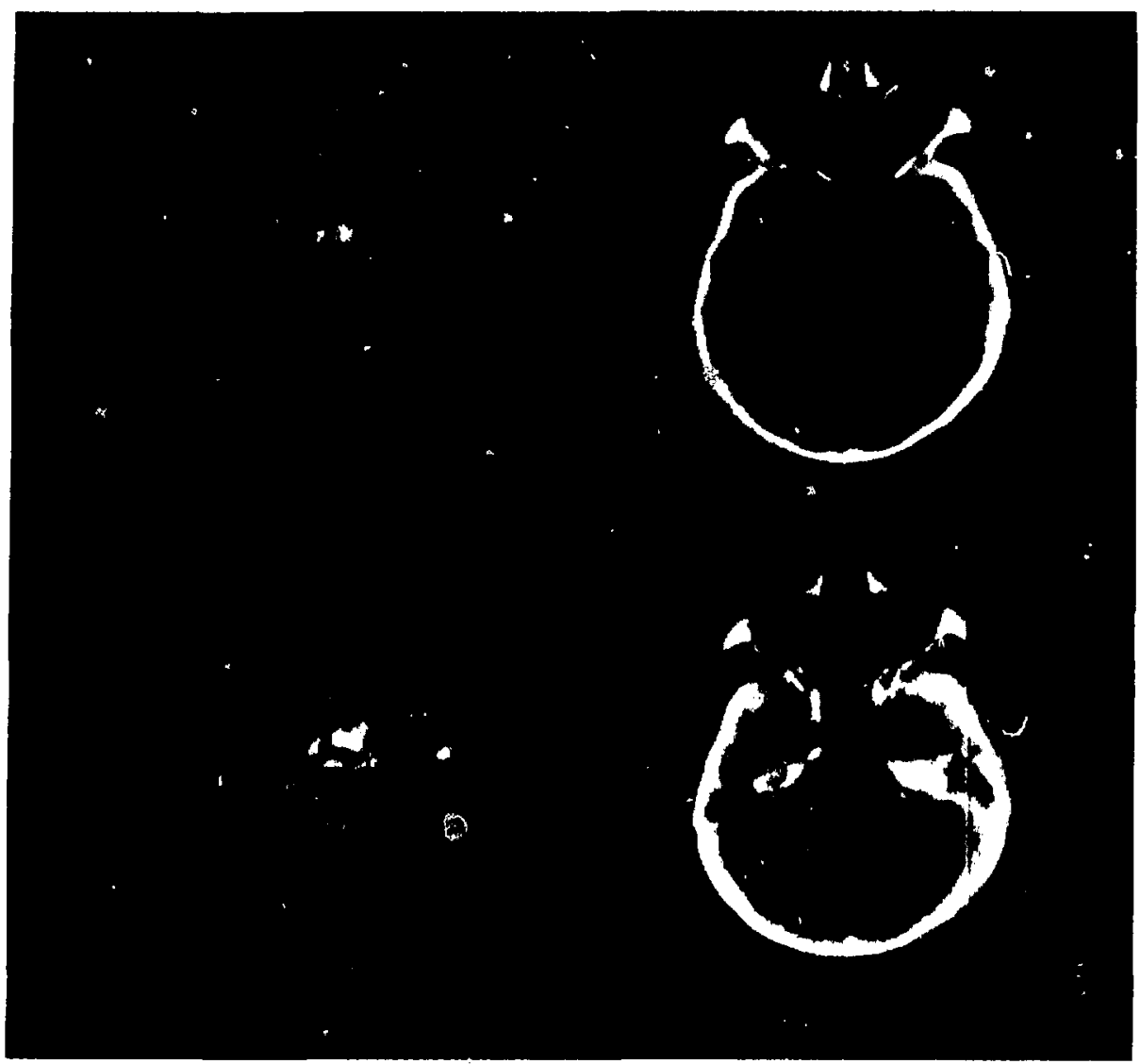

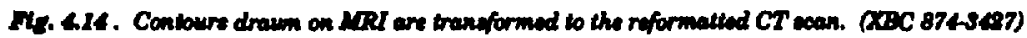

used in only one of the 11 patients. Of the remaining ten, in three the point-to-point method was used with external lendmarke only, in another three only internal landmarks were wed, and in the remaining four, a combination of both internal and external landmarks was employed. These tochniques have been an important advance in planning treatments for patients when the lesion lies in clome proximity to the spinal cord or brainutem, and image correlation will continue to be used on a regular basis for wuch patients.

The third area is the truatment plan optimization for charged-particle-beam therapy. This optimization is based on the evaluation of a treatment plan by a probabiliatic model that was developed with the support of a National Cancer Institute corntreat for Particle Beam Treatment Plan- ning Intercomparizon. This model entimates the probability of an uncomplicated local control of a tumor based on dose-volume histograms of the three-dimenrional dose distribution of the target. and the critical normal-tisnue volumes.

A program has been initiated for the validation of this model based on both retronpective and prospective studien of the expected and observed normal-tisuue complication following chargedparticle therapy. The validation will be based on dose distributions calcriated by the Massachusetts General Hospital treatment-planning program. This is believed to be the most accurate program currently available for calculation of both chargedparticle and photon beams; many of the patients in the retrospective study received a significant portion of their therapy with photon irradiation. 
The recent developments in treatment plan optimization have been directed to the determination of optimal weighting of the selected beams that will be used for irradiation of the tumor volume. These optimal weightings are determined by a constrained minimization subroutine and the calculated probability of an uncomplicated local control.

A new development in the treatment planning program has been investigation of the improvements that can be expected by development of a variable beam-modulation delivery systern with a raster scanner and variable-beam collimator. These improvement in beam delivery will lead to improved dose localization with charged-particle beams.

J.M. Collier, S.D. Henderson, P.L. Petli, M. Kessler, S. Pitluck, J.T. Lyman, K. Baken, J.R. Castro, T. Phillips, and J. Mefferd.

\section{STEREOTACTIC HEAVY CHARGED PARTICLE RADIOSURGERY}

Research in the stereotactic radiosurgical treatment of intracranial arteriovenous malformations (AVMs) has continued using the Brags peak of accelerated charged-particle beams. Intracranial AVMs can be debilitating and life-threatening; they produce hemorrhage, seizures, recurrent headaches, and neurological deficit. There lesions are developmental abnormalities of the newborn, and patients often present with symptoms in youth or middle-age. Once hemorrhage has occurred, the risk of further homorrhaging is greater. These factors make it desirable that the AVM be treated promptly so that the patient may enjoy a long and productive life.

Neurosurgical removal of the AVM, occasionally combined with flow-directed or intraoperated embolization of the AVM, is tho treatment of choice. However, these techniçues are not always possible, or if possible, not always completely succesuful, owing to the position of the AVM in a deep or critical region of the brain, or due to the complex network of feeding arteries and draining veins. These surgically-inaccessible intracranial AVMs have been treated at the LBL 184-Inch Synchroc;clotron using stereotactically-directed heavy charged-particle beams.

Building on the experience and techniques developed at LBL since the use of charged-particle beams for the treatment of pituitary tumors, stereatactic imaging techniques are used to direct the Bragg peak of heavy-charged-particle beams into the lesion while sparing adjacent brain tissue. Properties characteristic of fast charged particle beams that make them very useful in such an application are the fixed range of the beam with rapid fall-off of dose beyond the end of the range, the increased energy loss at the end of the range compared with the plateau region of the beam (Brags peak), and the small amount of lateral beam scattering.

This clinically applied research focuses on improving treatment planning techniques and following the response of paitients clinically and neuroradiologically in order to assess the effects of the radiosurgical treatment. In the past year, 76 patients have been treated, bringing the total since 1981 to 276 patients. These patients are evaluated in collaboration with neuronurgical and neuroradiological colleagues at Stanford University Medical Center and University of California Medical Center, San Franciwco. A series of atereotactic imaging procedures (cerebral angiography, computed tomography, and magnetic resonance imaging) is performed in the specially-designed patient immo. bilization mask and stereotactic frame in order to localize the leaion accurately within the brain. Treatment plans are calculated on a VAX 11-780 computer, using three to five beams, shaped and positioned in order to maximize the dose to the AVM volume and minimize the dose to surrounding normal brain tissue. Treatment occurs over one or two days, depending on the size and location of the intracranial AVM.

This year the use of image correlation techniques with the stereotactic frame and mask have been extencied to include nuclear magnetic resonance (NMR) imaging. NMR imaging is extremely useful in that it images the anatomical characteristics of the AVM, the large draining veins, and critical structures in the surrounding brain. It has proven particularly useful in the treatment of cryptic, or occult, AVMs. These are AVMs that cannot be imaged with cereliral angiography but are seen to some extent on contrast CT images and very clearly on NMR scanning. Computer techniques allow the accurate transfer of information between CT and NMR images. Figure 4.15 shows the charged-particle radiation isodose contours overlaid on an NMR image of a patient with an AVM in the brain stem. These contours were calculated using the AVM target imaged by NMR and transferred to the CT scan that contains energy-loss information for the charged-particle beam. The isodose contours were then transferred 


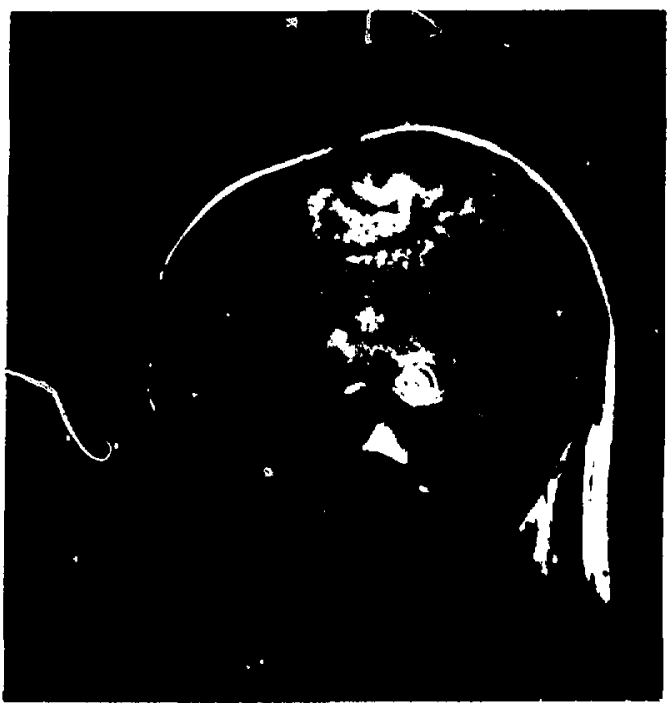

DI. 4.15. A wattlal NMR imeye of a patione with a cryptic arleriouenous malformation in the pons: the icodom contours for helium charged-particle treatment are overlaid. The AVM was defined and contoured on the NMR (arial prajections) and the carget contoure were tranefierred to CT images. A treatment plan was calculated using the CT dalo. The rewlting inodan contours were then traneforned to the NMR acitlal imases in order to define the rudiation dave to adjacent critical brain structures. The treatment plan is for three beams of helium ions; one port is in the sarillal plane chown; the ofher two ports are in parasanitlal planes of \pm 30 detreen (BBC $8712-10688)$

back to the NMR image in order to define the dose delivered and the dose distribution to critical structures such as the surrounding brainstem.

Follow-up of patients after radiosurgical treatment consists of clinical examinations either here at Donner Pavilion or by the patientu' own neurosurgeons when they do not live in the area. To date, the clinical results show that $67 \%$ of the patients have remained normal or improved neurologically, 25\% have shown no change neurologically and have remained stable, 2 nd the remainder have worsened neurologically' io far, thers have been 7 cases of hemorrhage frori: he AVM prior to 15 months following therapy, well below the expected rate of occurrence in a similar population of untreated patients that follow the natural course of the disease ansociated with a high spontaneous rate of hemorrhage. Three other types of complications can occur. The first is vasogenic edema in the cerebral white matter extending outside the raciation field; this appears to occur in about $10 \%$ of patients, with about 5\% experiencing clinical symptoms. The second is a $2-4 \%$ incidence of stroke (including arterial occlusion, venous thrombosis, or embolism), frequently occurring during the final phase of obliteration of the AVM. The third is delayed brain injury leading to radiation necrosis; this may have occurred in two patients (unconfirmed without tissue diagnosis). Taken together, the complication rate appears to be low, and less than the surgicel risk or the risk of death or neurological damage from the natural course of the disease.

Neuroradiological followup examinations, performed at the Stanford University Medical Center, The University of California, San Francisco, or the patient's local hospital, consiat of cerebral angiography, CT, and NMR scanning. For patients followed at least one year post-treatment, $50 \%$ of the patient achieve complete obliteration of the AVM in 1 to 2 years. Partial or complete obliteration occurred in 70\% of patient by 2 years, and no change (less than $50 \%$ obliteration) was apparent in $15 \%$ of the patients. The data indicate thi protection aguinut hemorrhaging is achieved in most patients even if complete obliteration does not occur.

Current research with other investigators in the Research Medicine Group and colleagues in collaboratints university hospitals is exploring the uses of NMR imaging and positron emission tomography (PET) in evaluating radiation-induced thanges in the AVM and the surrounding brain tissues. NMR is proving to be useful as a noninvasive procedure for evaluating morphological changes in the AVM, and thereby indicating the optimum time for more complete and detailed evaluation using cerebral angiography. Vasogenic edoma, visible in its early stages only by NMR imaging, can now be recognized and followed before clinical symptoms become apparent. A prospective study using PET and NMR, and correlating these with $\mathrm{m}$ Jrpholegical alterations in brain tissue, is in progreas to examine physiological changes following radiosurgery.

Through the end of 1987 , all radiosurgical treatments have been performed using the 230$\mathrm{MeV} / \mathrm{u}$ helium-ion beam at the 184-Inch Synchrocyclotron at LBL. Beginning in January 1988, the program will move to the Bevalac accelerator. Work in in progress, in collaboration with the Acrelerator Division and the radiotherapy physicists to produce and characterize the $165 \cdot \mathrm{MeV} / \mathrm{u}$ helium beam at the Bevalac, with plans to eventually use carbon-ion beams for stereostactic radiosurgery. Comparative studies are being carried out 
to determine the differences between various species of charged-particle beams and photons in the treatment of intracranial AVM.

\section{J.I. Fabrikant, K.A. Frankel, M.H. Phillips,} R.P. Levy, J.T. Lyman, N. Manley, E.H. Lo, M.L. Foster, F. Chuang, and P. Valk.

\section{NEUROBIOLOGICAL EFFECTS OF HEAVY PARTICLE IRRADLATION}

In parallel with the heavy-ion radiosuryery research program, fundamental investigations are being carriod out to understand the batic physical and biological mechenisms underlying the neurobiological responses to irradiation with focal beame of heavy charged particles (e.B., helium, carbon, neon). The objectives of this research program are to examine cellular and motabolic effects in mammalian (including human) brain in relation to alterations in regulatory control mechanisms, the sites of DNA damage and repair, cellular proliforation and differentiation, the process of myelination and myelin maintenance, and regional cerebral blood flow dynamics; and to develop and apply nuclear medicine procodures for investigating cellular and metabolic ovents in brain irradiated with heavy chargod particles.

Studies of the physical properties of the heavy charged-particle beams have been focused on multiple Coulomb ccattering and particle production in heavy-ion collixions. Multiple scattering of the charged particle is a limiting factor in delivering a uniform dose to a target volume, and is one of the criteria in ovaluating the done-localization properties of beam f different ion upecies. Parallel effort in computer calculations of the offect of multiple scattering and experimentai meanurements have procoeded in collaboration with other physicints of the Biolory and Modicine Divinion. Afreement has been found between theory/ and experiment for clinically important benms, such as protons and carbon ions as well as more exotic ions such as uranium.

Calculation of neutron production in heavy-ion collixions provides further information on the characterization of heavy-ion beams and the distribution of dose. Excellent agreement has been achioved betwoen calculations perforrned uning a cascade code and experimentai work by Schimmerling and his colleagues in the Radiation Biophynics Group.

Biological research on the effects of heavy charged particles has proceeded along several directions. In collaboration with Dr. K. Rosander of Sweden, we are studying the induction and repair kinetics of DNA damage in single cerebral and cerebellar oligodendroglial and capillary endothelial cells from rat and mouse brain following selected dose increments of heavy-ion beams, in order to characterize dose-response and timedependent relationships. The technique involves meanuring fluorescent dye intensity as an index of DNA single- and double-stranded breaks using a microscope photometer following DNA unwinding. The data thus far indicate a general increase in DNA damage with neon ions relative to helium ions, and the dose-dopendent effect is much greater for oligodendroglial cells than for cerebral endothelial cells. DNA damage in vivo in repaired rapidly in both glial and endothelial cells, and the greatest amount of repair occurs within 30 minutes following irradiation with a linear dose-effect relationship for both low-LET and high-LET rudiation (Fig. 4.16). The results sugrest difforent post-repair behavion for the two typos of cella; the endothelial cells may be lets radiosensitive.

In order to overcome the difficulties in defining changes in cells in the highly integrated brain tissue, tochniques have been developed to inolate and maintain defined mammalian brain cell populations in thort-term culture, and to identify potential cell-specific properties for use as indicators of cell damage and altered vell metabolism. Of

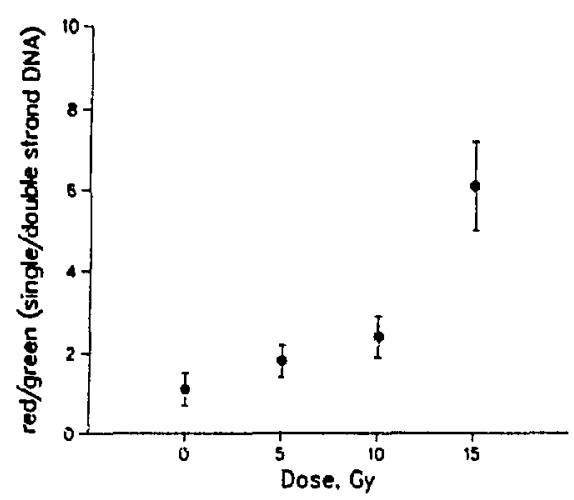

It. 416. The lowe-neponse for cerebral endathelial cells 6 minute after heliuk-ion irrediation. (Six minuten in the minimum dme aucilable after irradiation.) The ratio of red/ crem fuoracence (aingle/double atrunded DNA is slotted as a function of dave for mouse brain endothelial cells irradiated in vivo. (XBL 8712-8029) 
particular interest is purifying and maintaining glial cell populations in order to examine the effects of heavy-ion irradiation on myelin renewal and the maintenance of myelin.

Pulse-labeled mitosis is one of the techniques being used to study the brain cell population kinetics of the subependymal layer of the mouse brain. Cell-cycle parameters have been measured for these cells in unirradiated mice and in mice irradiated with either helium or neon ions. The responses of different cell population in the subefandymal layer to different types of radiation ( $x$ rays, helium ions, neon ions) and a range of doses have been measured. Figure. 4.17 illustrates the population doubling times of the subependymal cells following exposure to $230-\mathrm{MeV} / \mathrm{u}$ helium ions. The doubling time is markedly reduced after irradiation with $45 \mathrm{~Gy}$, from a normal value of about 140 hours to about 45 hours in the irradiated cortex, and to about 55 hours in the unirradiated cortex of irradiated mice. The glial cell kinetic data in normal and irradiated mouse brain are consistent with the conclusions that in the subependymal plate the light cells remaining after radiation represent a resistsint stem cell population with a relatively slow rate of renewal. The dark cells comprise a rapidly proliferating stem cell population, which is relatively radiosensitive, and it is this stem-cell pool that is responsible for recovery following heavy-charged-particle irradiation.

\section{Imaging, Instrumentation, and Muthods}

\section{NEW POSITRON EMISSION TOMOGRAPH INSTRUMENTATION}

Imaging studies using a new very high resolution medical imaging system, the Donner 600Crystal Positron Tomograph, have recently begun. This system was designed and built at LBL to 1mage positron-emitting tracer isotopes in the human brain and neck with a spatial resolution a factor of two finer than any other tomograph. The instrument consists of a ring of 600 bismuth germanale (BGO) crystals 3-mm wide coupled individually to $14-\mathrm{mm}$ phototubes. When the tracer isotope decays, it emits a positron (the anti-electron) that comes to rest in the tissue nearby and annihilates with an electron. In this process, the

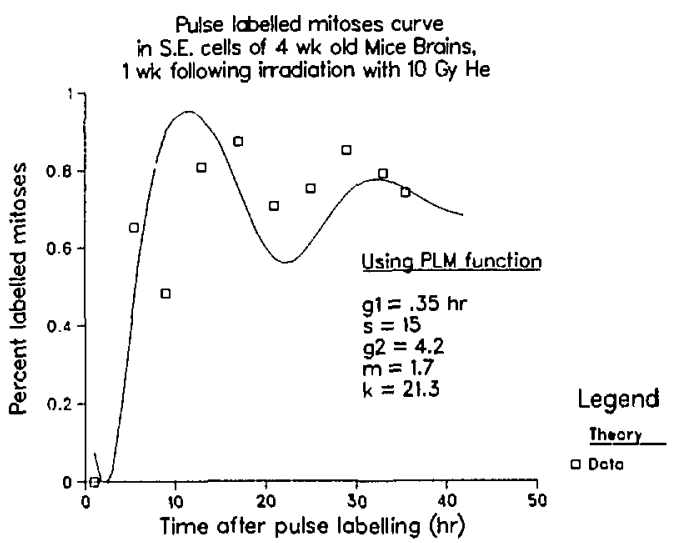

Fiv. 417. Percent of labeled miloses following pulse labeling with tritiated thymidine in the oubependymal celle of 4-week-old mouse brain, 1 weeh following irradiation with $10 \mathrm{~Gy} H:(160$ $M d V / u)$. The open equares are the measured points, the amooth curve is a fit to the data using the theory of Tahaiwahi. The durations for the cell cycle paramelers derived from the fit are listed. Work is curnently in progress to extend the curve fitting 10 include variations in the cell cycles by means of a Monte Carlo approach. XBL 8712-8030)

J.I. Fabrikant, K.A. Frankel, M.H. Phillips, R.P. Levy, J.T. Lyman, N. Manley, E.H. Lo, M.L. Foster, and F. Chuang. positron and electron disappear, and their energy is immediately converted into two photons that fly off in opposite directions. Whenever two BGO crystals detect two photons within 10 billionths of a second, the event is recorded in high speed memory. The image of the tracer distribution is reconstructed from these data using an array processor.

As a test of image sharpness, a very small source of positron emittei was positioned at the center of the instrument. The resulting image was a circle with a diameter (full-width at half-maximum) of $2.6 \mathrm{~mm}$. Another test of image sharpness was performed using the object shown in Fig. 4.13, which consisis of a pattern of hollow channels drilled into a solid plastic cylinder. The stannels 
$5 \mathrm{~mm} \mathrm{c}-\mathrm{c}$

$1.25 \mathrm{~mm}$ diam

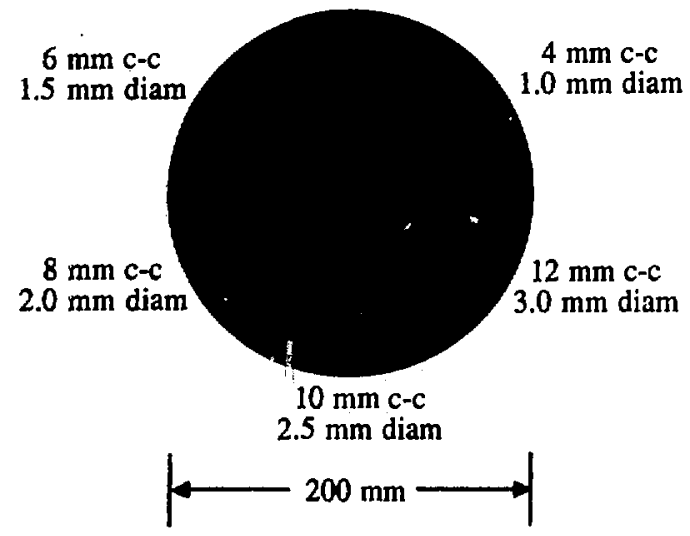

Fis. 1.18 Shetch of a platic cylinder containing isolope-filled channels. The finest channels are $1 \cdot \mathrm{mm}$ diameter on $4 . \mathrm{mm}$ centers. (XBL 8610-4032)

were filled with a solution of the positron emitting isotope "F and imaged (Fig. 4.19). Near the center of the tomograph, individual channels with $4-\mathrm{mm}$ center-to-center spacing can be individually resolved. Channels with 5 -mm center-to-center spacing can be individually resolved throughout the field of the tomograph.

The detector configuration and electronic circuits 'were designed for high speed, as well as high spatial resolution. To correct the emission data for absorption of photors in the tissue, a positron source of $20 \mathrm{mCi}$ of ${ }^{m} \mathrm{Ge}$ runs around the outside of the patient, and events are collected at a rate of 800,000 per second. This represents a factor of 8 speed improvement over previous designs and reduces the time to acquire the attenuation correction data from $\mathbf{1 5}$ minutes to 2 minutes. These data can be "cionstructed to produce an image, of the absorficon of annihilation photons in the human head [see Fig. 4.20(a)]. This source is withdrawn into the lead shielding for collecting emission data.

The positron-emitting tracer compound "Ffluoro-dearyglucose is used to image metabolic

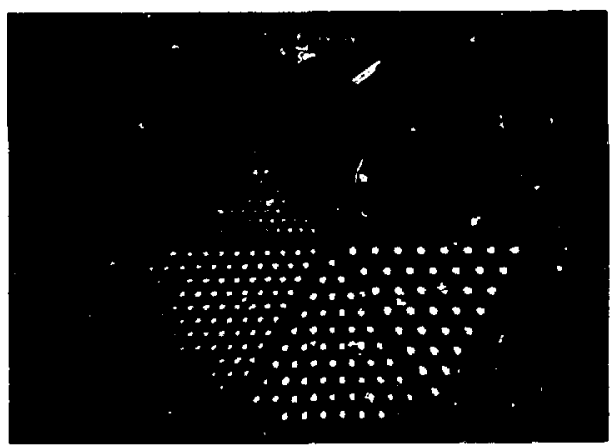

Fis. 1.10 Image of the isotope "WF in the plastic cylinder taken by the Donner 600.crystal positron tomograph. (ABB 878-7172)

activity in the brain because its accumulation closely mimics the absorption of glucose, the primary fuel of the brain. This compound is administered with a simple intravenous injection, and data from the ${ }^{10} \mathrm{~F}$ are acquired to produce an image of the uptake of glucose in the human brain [Fig. 4.20(b)].

Stephen E. Derenzo, William W. Moses, Ronald H. Huesman, and Thomas F. Budinger.

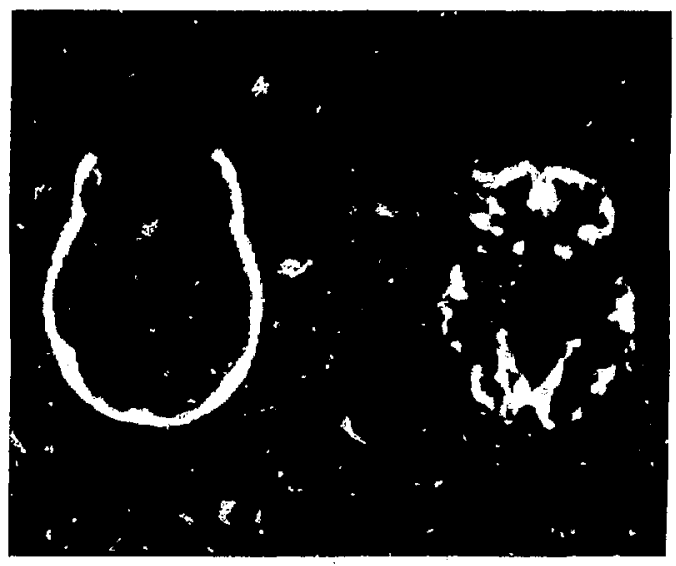

Fit. 120 (Lef) Image of a slice through the human head taken by the new tomograph using an externr! positron source, showing the bones, sofi tissues, ard nasal passages. (Right) Image of the tracer m-fluoro-dsoxygluccse in the same slice of the human brain, showing the uptake of sugar. (XBB 87E-4261) 


\section{NMR METHODS}

\section{Slow Flow Imaging with Steady Stale Free Precession}

Nuclear magnetic resonance studies of moving opins began with diffusion experiments and have evolved to include measurements of bulk flow, including in vivo angiography. This study concerns in vivo imaging of tisaue perfusion without tracers, that is, detection of flow in the capillary bed. Each imaged unit-volume or vaxel is assumed to contain capillaries with many different orientations, so the flow model thares some properties of both random (diffurive) flow and laminar flow. Typical flow velocities are on the orrier of $1 \mathrm{~mm} / \mathrm{sec}$. Conventional flow imaging experiments require very large magnetic field gradients to detect such small velocities, with accompanying instrumentation problems. Steady-atate free-precestion (SSFP) imaging is used for improved sensitivity and horter acquisition time.

The SSFP experiment consists of a sequence of identical if pulses separated by an interpulse interval $\tau$. For static spins, a steady state is established that is a function of the relaxation times $T_{2}$ and $T_{2}$ the of tip angle, and the angle through which the epin precesmes during $\tau$. In the presence of an applied gradient $G(t)$, the marnetization is a periodic function of $r$ and has a spatial wavelength $\lambda: \lambda=1 /\left(\gamma G_{-}\right)$. $G_{-m}$ is the effective gradient atrength, which is the time average of $G(t)$ over the interval $t$. $\gamma$ is the gyromagnetic ratio of the proton.

Since the macnetization is a periodic function of position, a moving epin will continually try to approach the local steady state. Howover, because a finite time is required for the steady state magnetization to be established, moving epins do not attain the maximum response. The response of flowing spins is expresed in terms of the dimensionless paramoter $\phi$ defined as $\phi=v \tau / \lambda=\gamma \mathbb{G}$. $v t$ where $v$ is the speed in the epin in the direction of the effoctive gradient.

The response of moving spins was determined experimentally with a phantom consisting of a tube packed with 3-mm diameter polystyrene spheres. Doped water is introduced at one end and removed at the other, establishing a net flow in the axial direction. The gradient wal oriented perpendicular to the tube's axis in order to measure the transverse velocity component. Data were collected while varying the net flow and gradient strength.
The response, normalized by the response of static spins, is plotted versus the dimensionless parameter $\phi$ in Fig. 4.21.

The velocity distribution in the phantom was measured using a spin echo sequence with velocity encoding gradients. The SSFP response was calculated by numerical solution of Bloch's equations using the measured velocity distribution and a simple model in which each spin is assumed to have a constant velocity. This model, shown as a line in Fig. 4.21, predicts a larger response than observed. This is probably due to the constant velocity assumption and niagnetic field inhomogeneity near surfaces in the phantom. Work is underway to refine both the model and the experiment.

For imaging slow flow two experiments conducted at difforent $G$, are ubtracted (Fig. 4.22). The response from atatic spins cancels, and $G_{-}$can be chosen to yield maximum sensitivity in a desired volocity range. Subtraction experiments have been demonatrated on phantoms, and will be tested in human subjects in early 1888.

S. Wong, M.S. Roos, and S. Patz (Harvard Medical School).

...... Theoretical response

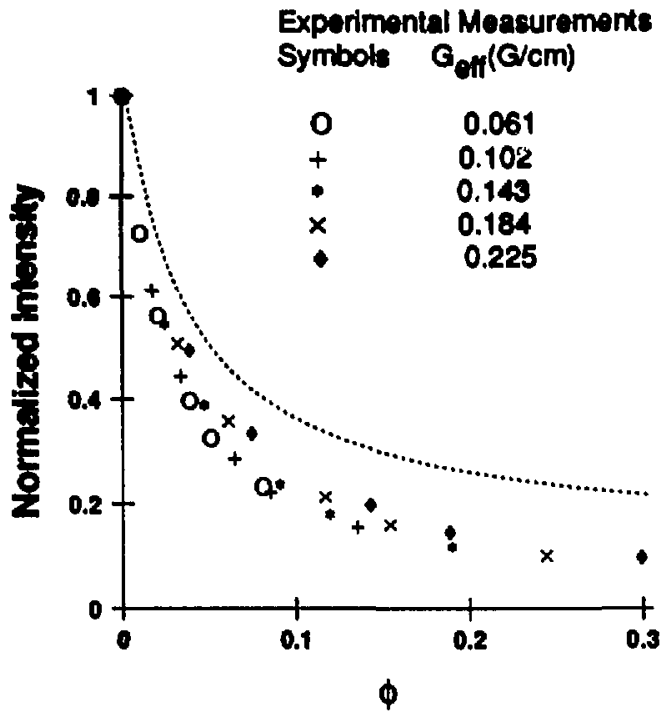

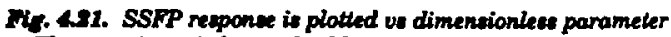
- Flow rate is varied at each of five values of $G$. The dothed cure it a prediction baned on the simple flow model. QBL 8712 . 8032) 


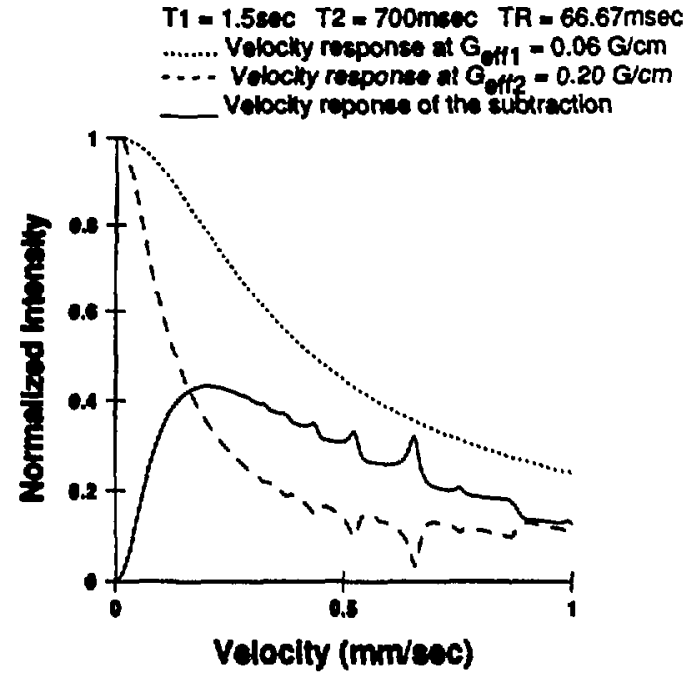

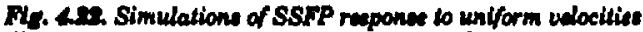
illuetrake how date con uined at two values of $G$, can be

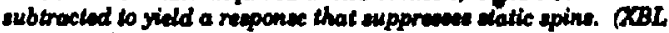
8712-8035)

Potentials of High Field NMR In Vivo with the Quadrupolar Nuclei Deuterium, Oxygen-17, Sodium-23, Chlorine-35, and Rubidium-87.

In addition to the dipolar spin one-haif nuclei, ${ }^{1} \mathrm{H},{ }^{12} \mathrm{C},{ }^{n F}, " \mathrm{P}$, quadrupolar nuclei have been shown to have potential for imaging and spectroscopic studies in vivo. For example'H administered intravenously may be used for the evaluation of blood flow and body-water distribution, and determination of rubidium tissue concentrations is of particular interest in treatment evaluntion studies for manic-depressive patients treated with rubidium. These and other biologically important nuclei such as oxygen-17 and lithium-7 have line broadening associated with the interactions of the quadrupole moment with biological media. The feasibility of high magnetic field studies in vivo (e.g., at 5 tesla and greater) using either endogenous signals or exogenously administered compounds depends on visibility, which is related to line broadening. The purpose of this study is to determine the visibility of these quadrupolar nuclei in aqueous solution and in biological tissues.

Studies of line shape and broadening in tissues (blood, heart, liver, and kidney) relative to nonorganic media were made at 4.3 tesla in a Nicolet vertical bore spectrometer $\left({ }^{2} \mathrm{H},{ }^{12} \mathrm{O},{ }^{\mathrm{m}} \mathrm{Na},{ }^{\mathrm{N}} \mathrm{Cl}\right)$ and at 2.3 tesla in a Bruker $40-\mathrm{cm}$ horizontal-bore imaging spectrometer ( $\left.{ }^{n} \mathrm{Rb}\right)$. The transverse relaxation of quadrupolar nuclei can be characterized by a biexponential decay with a fast and slow component. Line broadening associated with tissue interactions was measured as the width at half height that approximates the slow-relaxation component of the broadening. Transverse relaxation mes of sodium were measured using the CPMG pul i sequence. The data fit a mono-exponential deca; in the case of salt solutions and a bi-exponential decay in the cave of tissues. ' $\mathrm{H},{ }^{\mathrm{Na}},{ }^{\mathrm{NCl}}$, and ${ }^{\prime r} \mathrm{O}$ men surements wore obtained from endogenous signals "rom excised tissue. Recycle delays were between $\mathbf{5 0}$ and $100 \mathrm{~ms}$ for ${ }^{2} \mathrm{Na},{ }^{*} \mathrm{Cl}$, and ${ }^{17} \mathrm{O}$, and between 400 and $1000 \mathrm{mu}$ for ${ }^{\mathrm{H}} \mathrm{H}$. " $\mathrm{Rb}$ measurements were performed on a White New Zealand Rabbit with a surface coil in vivo after intravenous inject. on of 160 moskg of a sterile $\mathbf{R b}$ solution. Signal v as acquired at the level of the kidneys for $45 \mathrm{~m}$ nutes to obtain sufficient signal to noise ratio. Sigtal was then acquired at the level of the heart for $5 \mathrm{n}$ inutes.

Figure 4.23 compares upectra obtained from aqueous solutions and tissues for some of the nuclei cudied. Non-Lorentzian line shapes due to the two relaxation components are observed in the spectra from tissue whereas a single Jorenizian line shape is observed in the salt solutions where the nuclei are in the extreme narrowing regime. Figure 4.24 compares the measured line widths and the ratios of line widths from different media. In the case of rubidium, the tissue spectrum and line-width data are for heart tissue in vivo. The overall broader line width of rubidium, which has the same quadrupole moment as sodium, is due to the larger

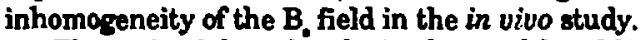

The ratio of the salt solution line width to blood line width or blood to tissue line widths are similar for all nuclei observed except for the chlorine nucleus where broadening due to quadrupolar interactions with tissue is stronger. This is most likely due to the pardicular outer shell electron 

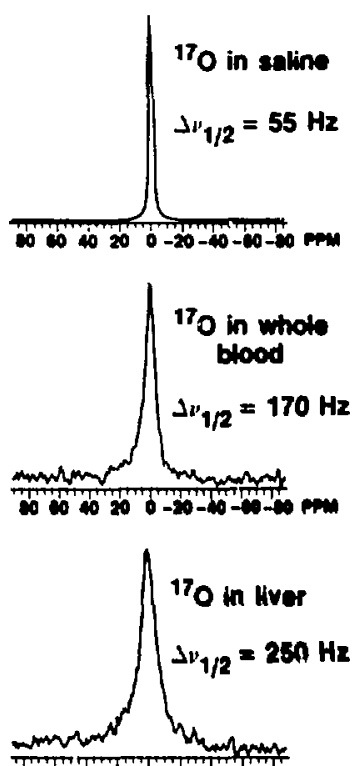
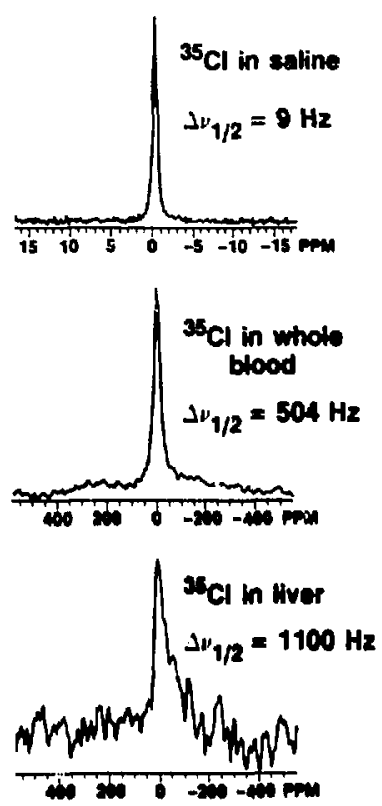
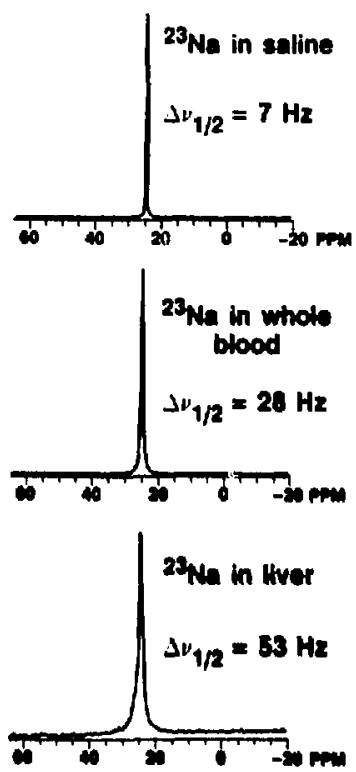

Fis. 4.25. Spectra of nome quadrupolar nuclei oblained at 4.3 tecla. (XBL 871.7554N)

configuration of the chlorine atom, which creates stronger electrical field gradients at the nucleus during interaction with tissue components.

The amount of broadening of nuclei with quadrujole moments due to tissue interactions is not so great as to prevent studies of tissue concentrations in vivo, and possibly chemical shift, with the exception of intracellular chlorine. Previous studies of chlorine line broadening are summarized elsewhere. We expect chlorine nignals to be proportional to the the extracellular fluid space because broadening due to covalent binding and quadrupolar interactions within the cell make it silent to NMR. Interest in evaluation of ' $L i$ and " $R b$ tissue concentrations is related to mealurements in vive on patients treated for manic-depression and depression.

Nicolas R. Bolo and Thomas F. Budinger.

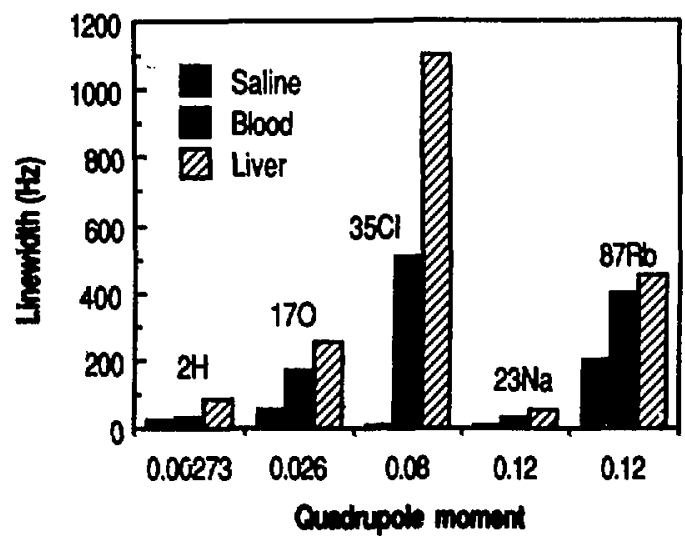

Iig. 424 Chart of line width in herte of the quadrupolar rucles studied. The quadrupole moment is given in units of 100 m. (ABL 8712-8031) 
PUELICATIONS: Research Medicine

\section{CONTRIBUTIONS TO JOURNALS}

Castro, J.R., Gademann, G., Collier, J.M., Linstadt, D., Pitluck, S., Woodruff, K.H., Gauger, G.E., Char, D.H., Gutin, P., Phillips, T.L., Chu, W., and Henderson, S.D. Strahlentherapie mit schweren teilchen am Lawrence Berkeley Laboratory der Universitat von Kalifornien: Klinische untersuchungen der Northern California Oncolog. Group. Strahlentherapy und Onkologie 163, 9-16 (1987).

Doyle, W.K., Budinger, T.F., Valk, P.E., Levin, W.A., and Gutin, P.H. Differentiation of cerebral radiation necronis form tumor recurrence by "F.FDG and " $R b$ positron emission tomography. J. Comput. Aesist. Tomogr. 11, 563-750 (1987).

Ebbe, S., Bentfeld-Barker, M., Adrados, C., Carpenter, D., Mortensen, C., Yee, T., and Phalen, E. Functionally abnormal stromal cells and megakaryocyte size, ploidy, and ultrastructure in SLSI mice: Normal atromal cells may control megakaryocytopoiesis. Blood Cells 12, 217-232 (1986).

Ebbe, S., Leven, J., Miller, K., Yee, T., Levin, F., and Phalen, E. Thrombocytopoietic response to immunothrombocytopenis in nude mice. Blood 69, 192-198 (1987).

Fabrikant, J.I. Adaption of cell renewal cystems under continuous irradiation. Health Physics $52,561-570$ (1987).

Friedland, R.P., Jagust, W.J., Ober, B.A, Dronkers, N.F., Koss, E., Simpson, G.V., Ellis, W.G., and Budinger, T.F'. The pathophysiology of Pick's disease: a comprehensive case study. Neurolه8y 36 (Suppl. 1), 268 (1986).

Goodman, D.F., Char, D.H., Crawford, J.B., Stone, R.D., and Castro, J.R. Uveal melanoma necro- sis after helium ion therapy. Amer. J. Ophthalmology 101, 189-193 (1986).

Jagust, W.J., Budinger, T.F., Huesman, R.H., Friedland, R.P. Mazoyer, B.M., and Knittel, B.L. Methodologic factors affecting PET measurements of cerebral glucose metabolism. J. Nucl. Med. 27, 1358-1361 (1986).

Jagust, W.J., Budinger, T.D., and Reed, B.R. Tho diagnosis of dementia with single photon eminuion computed tomography. Arch. Neurolo8y 14, 258-262 (1987).

- Kim, M.K., Char, D.H., Castro, J.R., Saunders, W.M., Chen, G.T.Y., and Stone, R.D. Neovascular glaucoma after helium ion irradiation for uveal melanoma. Ophthalmology 93, 189-193 (1986).

Lagunas-Solar, M.C., Carvacho, O.F., Harris, L.J., and Mathis, C.A. Cyclotron production of ${ }^{2 x} \mathrm{Xe} /$ inI for positron emission tomography. Current methods and potential developments. Int.J. Radiat. Appl. Instrum., Part A, Appl. Radiat. Isot. 37, 835-842 (1986).

Leven, R.M. Megakaryocyte motility and platelet formation. Scanning Microsc. 1, 1701-1709 (1987).

Leven, R.M. and Yee, M.K. Megakaryocyte morphogenesis stimulated in vitro by whole and partially fractionated thrombocytopenic plasma: a model system for the study of platelet formation. Blood 69, 1046-1052 (1987).

Lyman, J.T. and Wolbarst, A.B. Optimization of radiation therapy, III: A method of assessing complication probabilities from dose-volume histograms. Int. J. Radiation Oncology Biol. Phys. 13, 103-109 (1987). 
McKenna, D.J., Mathis, C.A., Shulgin, A.T., Sargent, T.W., III, and Saavedra, J.M. Autoradiographic localization of binding sites for ${ }^{1 \mu \mathrm{H}}$ DOI, a new psychotomimetic radioligand, in the rat brain. Eur. J. Pharmacol. 137, 289-290 (1987).

Mathis, C.A, Moerlein, S.M., Yano, Y., Shulgin, A.T., Hanson, R.N, and Kung, H.F. Rapid labeling of radiopharmaceuticals with iodine122. J. Label. Cmpd. Radiopharm. 23, 1259-1261 (1986).

Moerlein, S.M. Use of aryltrimethylgermanium substrates for facile aromatic chlorination, bromination, and iodination. $J$. Organic Chem. 52, 664-667 (i987).

Moerlein, S.M., and Laufer, P., Stoecklin, G., Pawlik, G., Wienhard, K., and Heiss,W-D. Evaluation of ${ }^{\pi} \mathrm{Br}$-labeled butyrophenone neuroleptics for imaging cerebral dopaminergic receptor aren using positron emission tomography. Eur. J. Nucl. Med. 12, 211-216 (1986).

Moerlein, S.M., Mathis, C.A., Brennan, K.M., and Budinger, T.F. Synthesis and in vivo evaluation of "I- and "I-labeled iodoperidol, a potential agent for the tomographic assessment of cerebral perfusion. Int. J. Radiat. Appl. Instrum. Part B., Nucl. Med. Biol. 14, 91-98 (1987).

Moerlein, S.M., Mathis, C.A, and Yano, Y. Comparative evaluacion of electrophilic aromatic iododemetallation techniques for labeling radiopharmaceuticals with iodine-122. Int. J. Radiat. Appl. Instrum. Part A, Appl. Radiat. Isot. 38, 85-90 (1987).

Moerlein, S.M., Stoecklin, G., Pawlik, G., Wienhard, K. and Heiss, W-D. Regional cerebral pharmacokinetics of the dopaminergic neurotoxin MPTP as examined by positron emission tomography in the living baboon brain is altered by tranylcypromine. Neurosci. Lett. $16,66(2)$, 205-209 (1986).
Reimers, M., Castro, J.R., Linstadt, D., Collier, J.M., Henderson, S., Hannigan, J., and Phillips, T.L. Heavy charged particle radiotherapy of bone and soft tissue sarcoma: A phase I-II trial of the University of California Lawrence Berkeley Laboratory aris the Northern California Oncology Group. Amer. J. Clin. Oncol. (CCT) 9, 488-493 (1986).

Urie, M., Goitein, M., Holley, W.R., and Chen, G.T.Y. Degradation of the Bragg peak due to inhomogenieties. Phys. Med. Biol. 31, 1-17 (1986).

Yano, Y, Essentials of a rubidium-82 generator for nuclear medicine. Int. J. Radiat. Appl. Instrum. Part A, Appl. Radiat. Isot. 38, 205-211 (1987).

\section{CONTRIBUTIONS TO BOOKS AND PRO- CEEDINGS}

Budinger, T.F. Single-photon emission computed tomography: physics, potentials and limitations. Pages 223-247 in Technetium in Chemistry and Nuclear Medicine 2, M. Nicolini, G. Bandoli, U. Mazzi, eds., Raven Press, New York(1986).

Budinger, T.F. Safety of NMR in vivo_imaging and spectroscopy. Pages 215-231 in Medical Magnetic Revonance Imaging and Spectroscopy, T.F. Budinger and A.R. Margulis, eds., Soc. Magnetic Resonance in Medicine, Berkeley, CA (1986).

Budinger, T.F. New technologies for noninvasive imaging in aging and dementia. Pages 175-199 in Advancing Frontiers in Alzheimer's Disease Research, Glenner, G.G., Wurtman, R.J., eds., University of Texas Press, Austin, Texas (1987).

Budinger, T.F., Derenzo, S.E., Huesman, R.H., Cahoon, J.L. Vuletich, T. Dynamic positron emission tomography with $2.5 \mathrm{~mm}$ resolution. Pages 17-33 in Biomedical Imaging, 0 . 
Hayaishi and K. Torizuki, eds., Academic Press, Tokyo (1986).

Castro, J.R. Californium-252. Pages 317-323 (Chapter 33) in Modern Brachytherapy., Pierquin, B., Wilson, J.F., Chassagne, D., eds., Masson Publ. USA Inc. (1987).

Castro, J.R. An update of results of radiotherapy with heavy ions. Pages 148-154 in Progress in Radio-Oncolagy III. (Proceedings of the Third Meeting on Progress in Radio-Oncology, Vienna, Austria, March 27-31, 1985). K.H. Harcher, ed., International Club for Radio. Oncology, Vienne (1987).

Chen, G.T.Y. and Cantro, J.R. Charged particle treatment plannin. Pages 101-110 in A Categorical Course in Radiation Therapy: Treatment Planning, B.R. Paliwal and M.L. Griem, eds., Radiological Society of North American Division of Editorial and Publishing Services, Oak Brook, IL (1986).

Derenzo, S.E. Recent developments in positron emistion tomography (PET) instrumentation. In Physics and Engineering of Computerized Multidimensional Imaging and Processing, 0 . Nalcioglu, Z.H. Cho, and T.F. Budinger, eds. SPIE Vol. 671, 232-243 (1986).

Derenzo, S.E. Potential improvements in instrumentation for PET. Physics and Engineering of Medical Imaging, NATO Advanced Studies Institute Series D: Applied Sciences 119, 913-925 (1985).

Derenzo, S.F. and Budinger, T.F. Advanced instrumentation for positron emiscion tomography. Phyrics and Engineering of Medical Imaging, NATO Advanced Studies Institute Series E: Applied Sciences 119, 855-873 (1985).

Derenzo, S.E., Huesman, R.H., Cahoon, J.L., Geyer, A, Uber, D., Vuletich, T., and Budinger, T.F.
Initial results from the Donner 600 crystal positron tomography. IEEE Trans. Nucl. Sci. NS-34, 321 325 (1987).

Draves, D.J., Timiras, P.S., and Manley, N.B. Glial hormone receptors: Thyroid hormones and neurotubules in gliomas and neuroblastomas. Pages 183-201 in Astracytes, Volume 3, CelluLar Neurobiology, S. Federoff, A. Vernadakis, eds., Academic Press, New York (1986).

Fabrikant, J.I. Radiation hormesis. Report to Committee $I$ of the International Commission on Rediological Protection, (4 pages) Jerusalem, Irrael (November 1986).

Fabrikan', J.I., Bond, V.P., Modan, B., and Upton, A.C. Probability of causation. Report to Committee 1 of the International Commiszion on Radiological Protection, (33 pagen) Jerusalem, Israel (November 1986).

Fabrikant, J.I., Frankel, K.A, Phillips, M.H., and Levy, R.P. Stereotactic heavy charged-particle Brags peak radionurgery for intracranial arteriovenow malformations. Pages 23.1-23.34 in Cerebral Vascular Diseases of Childhood and Adolescence, M.S.B. Edwards and H.J. Hoffman, edu., Williams and Wilkins, Baltimore, MD (1987).

Fabrikant, J.I., Land, C.E., and Schull, W.J. Risk coefficient for radiation-induced bladder cancer. Repart to Committee 1 of the International Commission on Radiological Protection, (8 pages) Jerusalem, Israel (November 1986).

Friedland, R.P., Budinger, T.F., Jagust, W.J., Yano, Y., Huesman, R.H., and Knittel, B. Positron emission tomography and the blood brain barrier in Alzheimer's disease. Pages 85-93 in Acute Cerebrovasular Diseases Pathopharmacology: New Brain Imaging in Cerebrovascular Disease, N.A. Lassen and J. Cahn, eds., J. Libbey and Co., Ltd. Montrouge, France (1986).

Friedland, R.P., Budinger, T.F., Jagust, W.J., Yano, Y., Huesman, R.H., and Knittel, B. Blood brain 
barrier integrity in Alzheimer's disease; Dynamic positron emission tomographic studies using "Ga-EDTA. In Proceedings of the Brain 85: XII International Symposium on Cerebral Blood Flow and Metabolism, Lund, Sweden, June 16-20, 1985 (1986).

Glicksman, A.S. and Fabrikent, J.I. Analysis of post-irradiation sarcomas: correlation of clinical data with experimental results. Pages 4-22 in International Symposium on Biolagisal Effects of Low Level Radiation, L. Wei, D.C. Wu, and X.H. Wang, eds., Society of Radiological Medicine and Protection, Chinese Medical Association, Nanjing, China (1985).

Goldman, M., Anipaugh, L., Catlin, R.J., Fabrikant, J.I., and Gudiksen, P. The nuclear reactor accident at Cherncbyl. Interim Repart of the Committee on Asessment of Radiological Effects and Consequences (CAREC). Prepared for The Office of Health and Environmental Research, U.S. Department of Enerty, Wachington, D.C. (July 1986).

Goldman, M., Anspaugh, L, Catlin, R.J., Fabrikant, J.I., and Gudiksen, P. Amesament of the Dosimetric and Health Implications of the Chernobyl Reactor Accident. Interim Report of the Committee on Asesement of Radiological Effects and Consequences (CAREC). Prepared for The Office of Health and Environmental Research, U.S. Department of Enerwy, Washington, D.C. (Augint 1986).

Goldman, M., Anspaugh, L, Catlin, R.J., Fabrikant, J.I., and Gudiksen, P. Health and Environmental Consequences of the Chernobyl Nuclear Power Plant Accident. Report to the U.S. Department of Enersy, Office of Health and Environmental Research from the Inter. Laboratory Task Group on Fealth and Bnvironmental Aspects of the Soviet Nuclear Accident. Prepared by the Committee on the Assessment of Health Consequences in Exposed Population, U.S. Department of Energy, Washington, D.C. (January 1987).
Jagust, W.J., Budinger, T.F., Reed, B.R., and Colina, M. Single photon emission computed tomography in the clinical evaluation of dementia. Pages 217-233 in Advancing Frontiers in Alzheimer's Disease Research, G.G. Glenner and

- R.J. Wurtman, eds., University of Texas Press, Austin (1987).

Lyman, J.T. Treatment plan optimization. Pages 51-58 in Proceedings of the Fifh PTCOG Meeting and International Workshop on Biomedical Accelerators, Lawrence Berkeley Laboratory, December 1-2, 1986, LBL-22962 (1987).

Mazoyer, B.M. and Huesman, R.H. Tomographie d'emiusion dynamique: analyse des donnees loresque la fonction d'entree est. Pages 183 in Actes du XXVI Colloque de Medecine Nucleaire de Iangue Francaise (Deauville-Caen, 18-20 September 1986), J. Biophysique et de Biomeconique 10, 183 (1986).

Moerlein, S.M., Laufer, P., Stocklin, G., Wienhard, K., Pawlik, G., and Heiss, W.D. Comparative evaluation of mbr-labelled butyrophenone neuroleptics for PET studies of cerebral dopam. inergic receptor area. In Proceedings of the European Nuclear Medicine Congress, London, September 3-6, 1985 (1986).

Turko, B.T., Zizka, G., Lo, C.C., Leakovar, B., Cahoon, J.L., Huesman, R.H., Derenzo, S.E., Geyer, A.B., and Budinger, T.F. Scintillation photon detection and event selection in highresolution positron emission tomography. IEEE Trans. Nucl. Sci., NS-34, 326-331 (1987).

Valk, P.E. NMR and PET imaging in beam localination. Pages 199-206 in Proctedings of the Fifth PTCOG Meeting and International Workshop on Biomedical Accelerators, Lawrence Berkeley Laboratory, December 1-2, 1986, LBL-22962 (1987). 


\section{LBL REPORTS ISSUED}

Cullander, C. Local Hurnan Skin PotentialSpatial Distribution, Magnitude, and Origin. (Ph.D. Thesis) LBL-23450 (173 pages) April 1987.

Fabrikant, J.I. BEIR IV. The Effects on Populations of Exposure to Intemally Deposited Alpha-Einitting Radionucliden: Healch Risks of Radon and other Internally Depositod AphaDimitters. LBL-24173 (16 pages) Ssptomber 1987.

\section{PATENTS ISSUED}

Derenzo, S.E. Improved readout for multi-crystal gamma cameras. D.O.E. patent file RL 9482. U.S. Patent 4,672,207, issued to the U.S. Department of Energy, June 9, 1987.

Sargent III, T., Shulgin, A.T., and Mathis, C.A. Rapid Brain Scanning Radiopharmaceutical. U.S. Patent 4,647,446, March 3, 1987. 


\section{APPENDIX A}

I. Projects supported by the Office of Health and Environmental Research of the United States Department of Energy under Contract DE-AC03-76SF00098

\section{INVESTIGATOR}

E.L. Apen

J.C. Bartley

J.C. Bartley

A.J. Bearden

M.J. Biswell

M,J. Bisuell

T.F. Budinger

A. Chattorjee

G.K. Clemons

A. Chatterjee

P.K. Cooper

S.E. Derenzo

S.N. Ebbe

S.N. Ebbe

M.S. Esposito

J.I. Fabrikant

J.I. Fabrikant

T.L. Hayes

J. Hosoda

R.M. Kraus:

R.P. Liburdy

R.K. Mortimer

R.K. Mortimer

G. Parry

T.W. Sargent III

P.H. Silverman

J.C. Schooley

M.R. Stampfer

T.S. Tenforde

C.A. Tobias

Y. Yano

\section{PROJECT}

Long Term Biological Effects

Effect of BaP on Humans

Center for Cellular and Molecular Cancer Biology

Rononance Studies in Photosynthesis

Mechanism of Tumor Promotion

Molocular Careinogenesis

Experimontal Modicine Clinical

Radiological Physics and Chemintry

Endocrine Receptor Studies

Tracer Studies with Radioactive Beams

Carcinogonic DNA Damage

Pocitron 3-D Imaring Instrument

Vascular and Blood Diseases

Molecular Biology of Hemopoienin

Mitotic Rocombination and DNA Repair

Effect. of Heavy Particle Radiation

Heavy-Ion Radionurgery

Microdosimetry of Particulates

DNA Repair Mochanizm:

Human DNA Polymorphism.

Electromagnetic Fiold Effects

Genetic Study on Yeant

Human Gonome Center

Studies of Cell Surface Organization using Monoclonal

Antibodies

Metabolism in Brain Disorder

Hematoson and Erythropoiesis

Hematopoietic Cell Proliferation

Rapid Traneformation Astay

Biological Effects of Marnetic Fields

Molocular Mochanisms of Cell Effects

Experimental Medicine Development 
II. Non-DCE Contracts and Grants Supporting Portions of Work Presented in this Annual Report

INVESTIGATOR

E.J. Ainsworth

E.J. Ainsworth

E.L. Apen

E.L. Alpen

E.L. Alpen

M.A. Austin

J.C. Bartley

M.J. Birsell

E.A. Blakely

G. Brecher

T.F. Budinger

T.F. Budinger

T.F. Budinger

T.F. Budinger

J.R. Castro

A. Chatterjee

G.K. Clemons

P.K. Cooper

S.B. Curtis

K.H. Downing
CONTRACT OR GRANT

NASA P.O. T3516-G

Life-Shortening Effects of HzE Particles on Mice/Heavy Ion Cell Tranformation

AFFRI P.O. N86I014

Murine Bone-Marrow Damage Produced by Charged Particles

PHS Grant CA 30236

Advanced Design Research: Heavy Ion Medical Accelerator

PHS Grant RR 05918

Growth Radiation Response in an In Vitro Tumor Model

PHS Grait CA 44668

Growth \& Radiation Response of an In Vitro Tumor Model

PHS Grant HL 38760

Genetics of LDL Subelasen in Hypercholesterolemia

PHS Grant CA 38889

Human Mammary Cella: Modulation of Difforentiated States

Monsanto 1856-29

Mechaniams of Extracellular Matrix Influences on Gene Expression

PHS Grant RR 05918

Repair and Misrepair of Irradiated Single Human Chromosomes

PHS Grant AM 27454

Kinetics of Tranefued Stem Celle in Normal Mice

PHS Grant HL 25840

Cardiovascular Fow and Metabolism

PHS Grant AG 05890

Corebral Blood Flow Patterns in Alsheimer's Disease

PHS Grant HI 07367

Quntitative Cardiovascular Research, Training Grant

UCSF Subcontract 8378-01

PEI Studien

PHS Grant CA 19138

Treatment of Cancer with Heavy Charged Particles

PHS Grant CA 27024

Bracog Peak Localization by Radioactive Beams

PHS Grant HL 22469

Radionseay of Erythropoietin

PHS Grant CA 32986

Inducible Responses to Carcinogenic DNA Damage

PHS Grant CA 17411

Response of Rat Tumor Cells to Heavy Ions

PESS Grant RR 03637

Macromolecular Surfaces by Scanning Tunneling Microscopy 
P.W. Durbin

P.W. Durbin

S.N. Ebbe

S.N. Ebbe

M.S. Euposito

T.M. Forte

T.M. Forto

C.T. Gaffey

R.M. Glaeser

L.S. Gold

R. Goth-Goldstein

R. Goth-Goldstein

T.L. Hayes

J. Hosoda

J. Hosoda

J. Hosoda

I. Mlatky

R.H. Huesman

B.K. Jap

R.M. Krauss
NRC IAG 60-85-012

Development of Metabolic Models for Alkaline Earth and Actinide Radionuclide:

PHS Grant DS 02698

Biological Testing of New Actinide-Chelating Agents

PHS Grant AM 21366

Kinetice of Megaleryocyte and Platelet Turnover

PHS Grant RR 05918

Regulation of Megakaryocytes by Bone Marrow Stromal Cells

PHS Grant GM 29002

Comparative Analytis of Mitotic and Meiotic Recombination

PHS Grant HL 07279

Lipoprotein Nothodolosy, Structure and Function Training Grant

PHS Grant HL 38686

Nonhumen Primats: Iovelopmont of Lipoprotoin Subclasese

PHS Grant NS 24997

Nerve Bioplectric Activity in Ultrahigh Magnetic Field

PES Grant GM 36884

Mombrane Proteins: High Resolution Electron Microscopy

PHS LAG 292-Y01-RS-10066

Quantitative Specien Extrapolation in Carcinogenesis

PHS Grant ISS 03603

Inducible Rasistance to Alkylating Carcinogens

PHS Grant RR 05018

Repair of Allylation Damage in Yeast

PHS Grant TW 01234

Electron Microscopy of Frosen-Hydrated Biospecimens

PHS Grant GM 16841

Structure and Function of Holix Stabilizing Protoin

PHS Grant RR 05018

Purification and Characterixation of Yeast Recombination/Repair Ensymea

PHS Grant RR 05918

Mapping of Protain Conformational Changes by Limited Proteolysis

PHS Grant RR 06918

Chemical Studies Uning the Sandwich Syatem

PIS Grant CA 38086

Scatter Compenation is Emiexion Tomography

PHS Grant RR 08918

3-D Cryatallization of Becteriorhodopuin for Molecular Structure

Determination

PHS Grant HL 33577

Plasma Lipoproteins in Coronary Artery Disease 
R.M. Kraues

R.M. Krauss

S.A. Leadon

H. Lecar

R.F. Liburdy

R.P. Liburdy

R.P. Liburdy

F.T. Lindgren

J. Llacer

J.T. Lyman

J.T. Lyman

J.T. Lyman

M.F. Maestre

M.F. Masatre

M.F. Maentre

C.A. Mathis

C.A. Mathis

M. McCall

R.K Mortimer

T.A. Musliner
USC Medicial Center 8072-22

Lipid and Protein Analysis

Stanford University Contract P.O. *PR 4699-3

D \& G Analyses

PHS Grant CA 40453

DNA Repair in Specific Sequences of Mammalian Cells

PHS Grant RR 05918

Distribution of Ion Channels in Stretch-Receptor Neurons

ONR Contract N00014-84-F-0186

Mechanisms of "Fictowave Interactiona with LiposomeMembranes

Liposome Technolomies Incorporated 1856-31

Electromagnetic-Field Triggered Drug Delivery via Liposome

Vesicles into Tarrot Celle

PHS Grant RR 05918

Electromagnetic Pield-Trigrered Liposome Drug Delivery

PHS Grant RR 05918

US-USSR Dicerepancies Rolating HDL Concentrations and

Coronary Heart Divease

PHS Grant CA-39501

Algorithmm and Processing Architectures for Tomography

PHS LAG Y01-CM-20110

Evaluation of Treatment Planning for Particle Beam Radiotherapy

FHS CA 42940

Treatment Planning Optimization

PHS Grant CA 22286

AAPM B682-19

Charged Particle Beam Desimetry Tauk Group: Dosimetry Protccol

PHS Grant AI 08427

Physical Structure of Virusen, Chromosomes \& Cell Nucioi

PHS Grant RR 02757

Jaseo BOOC Circular Dichrograph with FDCD and MCD

PHS Grant RR 05918

Duyaens Flattening Corrections Technique for Optical Spectra

PHS Grant NS 22899

10I Blood Flow and Blood Volume Agent for PET Studies

PHS Grant RR 05918

Developinent of Radiopharmaceuticals for the Quantitation of Hypoxia

PHS Grant RR 05918

Multiuser Inverted Microscope with Phase Optics

PHS Grant GM 3C990

Yeat RAD Genes in Repair, Recombination and Meiesis

PHS Grant RR 05918

Radioinotopic Tranking of Apolipoprotein Associations with

Lipoprotein Subepecies 
A.V. Nichols

A.V. Nichols

S.E. Bicknese

J.C. Owicki

G. Parry

A. Rodriguez

T. Sargent, III

D. Schild

W. Schimmorlins

W. Schimmerling

W. Schimmerling

R.I. Schwarz

R.I. Schwarz

P.H. Silverman

B.A. Singer

M.R. Stampfer

M.R. Stampfer

C.A. Tobias
PHS Grant HL 18574

Lipoprotein Methodology and Biomedical Applications

PHS Grant RR 05918

FDCD Spectral Analysis of Synthetic Peptide Models of

Apolipoprotein A1

PHS Grant AI 19605

Immunological Recognition of Model Membranes

PHS Grant CA 44398

Proteoglycan Influence on Mammary Cell Differentiation

PHS Grant RR 05918

Radiation Effects on Gene Expression in Differentiated Cells: An In Vitro Model

PHS Grant MH 36801

PET Brain Blood Frow \& Motabolism in Alsheimer's Disease

PHS Grant RR 06918

Cloning of Human Genes Uting Complementation of Yeant Mutations

PHS Grant CA 23247

Phyaical Characterintice of Heavy Ion Boams

NASA P.O. Lo2996A

To Measure the Production of Neutrons by High Enorgy Heavy Ions

NASA P.O. L9650C

Iron and Oxygen Fragmentation Experiments

PHS Grant CA 37968

Manipulation of the Differentiated State by Oncogenesis

PHS Grant RR 05918

Underetanding Celluler Control of Oncogene Expression

PHS Grant GM 39143

Pulse Programmer, Automated Measurement Syatem, NMR Probe

PHS Grant CA 42736

Alkylation of Polynuclectides in vitro and in vivo

PHS Grant CA 2484

Charecterization of Human Mammary Cells

PHS Grant CA 30028 (R.Ham, Univ. Colorado)

P.O. 426881

Defined Medium for Human Mammary Epithelial Cells

PHS Grant Ch 15194

Heavy Ion Radiobiology Related to Oncology 


\section{APPENDIX B: Biolosy and Medicine Divinion Staff \\ September 30, 1987}

The accomplishmente of the Biology and Medicine Division are due in large measure to the capability and dedication of its staff. Linted below are those who have participated in the Division's programs during fiscal year 1987 as full or part-time employees, consultants, and participating guests. The guest staff includes visiting scientists, postdoctoral trainees, resident physicians, graduate and undergraduate students, and summer research participants.

\section{DIVISION HEAD}

Paul H. Silverman

John C. Bartley, Doputy

\section{ADMINISTRATION STAFF}

Igor R. Blake

Mary P. Curtis

Janice C. DeNoor

Diane E. Duhnke

Wendell Hom

Allan W. Long

Vera Martin

Lucy A. Nixon

Georgia A. Peternon*

Lovice Ray

Karen S. Roess

Dolores Ruff

Lori E. Ryan

Robert W. Springateen

Katherine A. Swenson

Frank T. Upham

Chritine P. villalue

Mary L. Worth

\section{DIVISION SCIENTIFIC STAFF}

James R. Abney

S. Javed Afral

Judith Argeler

Larrence P. Aagerbeck

E. John Ainsworth

- Left Biology and Medicine Divition prior to

September 30, 1987.

'Retired during Fiveal Year 1987

'Faculty UC Berkeley

-Faculty UC San Francisco

Paculty UC Davis
Myriam Alhadeff

Julius J. Almasi"

Edward L. Alpen'

Bruce N. Ames'

Lynn Anderton'

Molisen A. Auntin

Mary H. Barcellos-Hoff

S. Jacob Bastacky

Alan J. Bearden'

James C. Beck

Andrew S. Belmont

Eugene V. Renton

Lealie Bernatein

Edward A. Berry

Anthony M. Berson'

Guy M. Besuon

Stephen E. Bicknese

Nina J. Biseell

Eleanor A. Blakely

William F. Blakely*

Alan R. Brautigan

Georze Brecher"

Kathloen M. Brennan

Thomat F. Budinger',

Frederick T. Burkhard

Vincent P. Carabillo"

Joweph R. Cantro*

Lorraine A. Champion'

Devid Chappell

Aloke Chatterjoe

William T. Chu

Gieela K. Clemon:

J. Michael Collier

Priccilla K. Cooper

Christopher Cullander

Stanley B. Curtis

Kanu B. Dalal

Maya M. Das:

Mary M. Decker

Richard L. Deming

Stophen E. Derenzo

Danjelle Dhouailly" 
Martha L. Dixon

Odilon M. DoCanto"

David S. Dolberg

Kenneth H. Downing

Patricia W. Durbin

Shirley N. Ebbbe?

Barry L. Engelstad

David E. Erkenbrack*

Michael S. Esposito

Jacob I. Fubrikant"

James A. Fisher

Wendy L. Fitch"

Paula F. Flicker

James Fontanesi"

Trudy M. Forte

Heinz Fraenkel-Conrat'

Kenneth A. Frankel

Michael Freelingt

Corneliue T. Gaffoy

John C. Game

Edwin G. Garcia

Grant E. Gaupor

Peter S. Geienler

John M. Gerdes

Sandra H. Gianturco*

Robert M. Glaener

Michael Goitein

Lois S. Gold

Regine Goth-Goldstein

Martin H. Graham'

Stephen G. Grege?

Thomas L. Hayes

Sheri D. Hendereon

Ronald L. Himolman

Lynn R. Hatky

Libby L. Hollorook'

William R. Holley

Youhio Hosobuchi"

Junko Hoeodn

Jerry Howard

Anthony R. Howlett

Mirko I. Hrovat'

Li-Shar Huang

John P. Huberty

Ronald H. Huesman

William J. Jagust

Bing K. Jap

John R. Johnston"

Talwinder S. Kahlon

Jonathan A. Kans

Loon N. Kapp"

Parris M. Kidd

Stevo Knezevic

Ronald M. Kraues?
Michael La Belle

John H. Lawrence'

Steven A. Leadon

Harold Lecar'

Robert M. Leven

Larissa V. Levin'

Richard P. Levy

Ming-Liang Li"

Robert P. Liburdy

Frank T. Lindgren

$\operatorname{Jan}$ E. Litton

Francoise Livolant'

Bernhard A. Ludewigt"

John T. Lyman

Marcos F. Mnestre

Androw C. Magyarosy

Noela B. Manloy

Su-Yao Mao

Paul K. Maraden

Manuela Martins-Green

Chester A. Mathis

Mark R. Mc Call

Joyce C. MeCann'

Jean M. Mefferd

Howard C. Mel'

Kathleen L. Mijiier

Stephen M. Moerlein*

Robert K. Mortimer ${ }^{4}$

Willinm W. Moses

Brian R. Moyer

Thomas A. Musliner

Nicola T. Neff

Richard Newmark

Alex V. Nichole'

Masataka Onizuka

William G. Owen'

John C. Owicki'

Charles S. Parkins'

Gordon Parry

Richard Payne'

Achot Petrousian'

Paula L. Petti

Mark H. Phillip:

Theodore L. Phillips"

Dennis E. Prosen

Gian M. Ratto"

Migual T. Robinson

Adrian Rodriguez

Mark S. Roow

Ruth J. Roots

Thornton Sargent, III

David Schild

Walter Schimmerling

John C. Schooley' 
Richard I. Schwarz

J. Philip Seab

Alexander T. Shulgin

Bea Singer

Jerome R. Singer

Thomas H. Slone

Sylvia J. Spengler

Martha R. Stampfer

Henry H. Stauffer

Claudio D. Stern"

Andrew W. Stoker

Thomas Swain

Joseph R. Taylor"

Thomas S. Tenforde

Allan Tischler

Cornelius A. Tobias:

Peter E. Valk

Karen M. Vranizan

John R. Wettorau"

Paul T. Williams

Mervyn Wong

Tracy C. Yang

Yukio Yano

Michael J. Yexzi"

\section{DIVISION SUPPORT STAFF}

Paul Abdul-Malak

Linda D. Abe

Frederick E. Aljrams"

Gerald L. Adamian

Mari Aker

David C. Albarian

Nicholas Alezander

Charles M. Allison

Sharon L. Amacher

Georganne M. Backman"

Kari P. Baken

John R. Baker

Ashley J. Barboza:

Josophine L. Barr

Elizabeth D. Benttie"

Maren Bell

Sindy E. Berger

Kathleen A. Bjornstad

Judith M. Blair

Patricia J. Blanche

Nicolas R. Bolo

S. Kay Bristol

Gerald L. Brools:

Mark A. Brown'

Mary L. Cabbage

Veronica G. Cabras

John L. Cahoon
Mardel M. Carnahan

Dorothy A. Carpenter

Adelle H. Cavanaugh

Rosemarie L. Celli

Polly Y. Chang

Te Ning Chang

Frank Chavez

Li-How Chen

Marica Chen"

Steve Chi-Long Chen

Cheo-Hstung Sheng

Dennis Chin

Amy L. Choi

Frank Chuang

Ling-Fong Chung

Gary M. Cole"

Miguel M. Colina

C. Rabeccu Contopoulou

Vincent E, Cook

Douglas Corley"

Benedict J. Costello"

Laurie M. Craise

Froddie L. Crenshaw, Jr.

Betwoy L. Cullen

Anne M. Cummings

Maria N. Da Costa*

Massood Darvishzaden

Randy J. De Guzman

Darlene J. De Manincor

Kim Des Rochers"

Aridrew M. Dienstfrey"

Uyen Nina Dinh"

Luisa I. Disini

Niedra A Dodson

Neils M. Dua

Michael I. Dunker

Sujay Dutta

Maria K. Dybbro

Suman L. Eisenberg

Dennis M. Fantin

Deborah A. Farson

Myrtle L. Foster

Rochelle I. Frank*

Roscoe Frazier

Samuel W. French

John Frey

Denis L. Fung"

Jennifer C. Fung

Asuof Gebremichael

Sherry I. Gee

Kalle B. Gehring

Christine Giotas

Queen E. Gipson

Brian J. Glassner 
Laura A. Glines

Michael A. Glotzer

Tennessee W.-Y Gock

Elina Golder

Kaarin Keer Goncz

Elaine L. Gong

Edwin H. Goodwin

Sara P. Goolsby

Anders Greenwood

Robert W. Gribben'

Helena B. Hansen"

Steven M. Hanrahan

William A. Hare

Rita Harvey-Tumer

Linda J. Harrison"

Annu R. Hashima

Chri: A. Haskell*

Carroll Hatier

Virginia C. Haven'

Lilian E. Hawkins

Linda G. Hayathi

Marjaneh Hedavet'

Mark D. Hertle

Chrintene S. Ho

Lori L. Hollander"

Elizabeth C. Holloway

Chriatine S. Hong

Sok C. Hons

Laura J. Horn

Midori M. Hosobuchi

Mildred K. Hughes

Jacquelyn J. Iler

Gayla P. Ivery

Heather M. Jackson *

Nylan M. Jeung

Jay A. Johneon"

Reese M. Jones"

Mary Jordan

Jay S. Joseph*

Julian S. Joseph*

James W. Judnick*

Norbert V. Kang

Peter M. Kang

Aaron B. Kantor

Kriatina S. Kavanau

Leah A. Kenaga"

Marc L. Kessler

John Kim

Jeffrey S. King

Chris B. Kingsley

Leslie A. Klein"

Brian L. Knittel

Kenneth J. Knudsen'

Seok-Hwan Kong
Vida W. Kong

Brian S. Korotzer"

Kari L. Koszdin"

Birgetta R. Kullgren

Mary Lou Kurtz

Natalia Kusubov

Mark T. Lasartemay*

Ann Iee

Charles Y. Lee*

Joong W. Lee

Kyung-Dall Lee

Poter P. Lee

Gerri A. Levine

Lynette L. Levy

Rebecca H. Lichtenberg

Eng H. Lo

Loora Lommol'

Janot S. Lowe'

Ryan P. McCormack

Tommy J. McKoy

Ronae I. Magaw"

Eva J. Mah'

Lynn J. Mahlmann

Dimitrios T. Maleas"

Marc S. Mendonca'

Peter L. Miller

Roger L. Millor

Barbara Modlinski

Herbert W. Moise, III

Charles W. Moniak

Alyasa M. Morimoto'

Marshall L. Morningstar

Lenny Mos:"

Stove S. Neben

Tamlyn $\mathbf{K}$. Neben

Robert W. Nordhausen

Virginia I. Obie

Christene Y. Oh'

Lucinda S. Olney

Joseph R. Orr

Lars G. Osterberg

Laura M. Palanck

Annie C. Pang

Srisawai Pattamakom

Eva A. Penzes

Guy A. Perkins

Denise M. Peterson

Patrick G. Pieper"

Huan N. Phan'

Patricia P. Powers-Risius

John C. Prioleau

Tracy G. Ram

Jose A Ramirez

Ross A. Ramos 
Monica H. Reimers

David Reisman

Gerardo C. Rios"

Ellen Saegerbarth

Laureen Sasaki

Karen R. Schenk

Janis S. Scherer

James B. Schmidt

Annelie D. Schumann

Janet F. Selmek-Halsey

Mark Shavers

Michael Sieweke

Mohindar Singh

Karen C. Sitney"

Jonathan Slack

Karen L. Smith*

Margaret M. Snowden'

Michael T. Solis'

Marcia E. Somert

Dorothy S. Sprague

Karen A. Springutoen

Uhea Srinivanan

Audrey D. Stapleton

Daniel Straus

John D. Stubbe

Shirley C. Sution
Herbert C. Szeto"

Annie Tang

Pat Tittiranonda

Jo Ann Trejo*

Sally P. Tubach

Julia A Twitchell

Greg Y. Uramoto

Vadimir Vacata

Janice Valmassoi"

Dresden D. Van Dusen

Paul F. Vanek:

Peter J. Walian

Alex K-Y Wang

Karly S. Wang:

David K. Warland

Chiahon Wei'

David C. Weat

Nancy C. Whito

Monroe Whitney

Eric D. Wieder

Scot W. Wigert

Jennifer A. Wong:

Sam T.S. Wong

Marilyn Yee

Alice Yeh"

Karen L. Zettl 
Committees

DIVISION ADVISORY COMMTTTEE

Paul H. Silverman, Chair

John C. Bartley/Priscilla K. Cooper

Mina J. Bissell

Eleanor A. Blakely

Thomas F. Budinger/Thornton Sargent III

Trudy M. Forte/Bing Jap

Rabert K. Mortimer

Comelius A. Tobiav/Aloke Chatterjec

Igor R. Blake'

Lori E. Ryan'

\section{DIVISION STAFF COMMITTEE}

Tony W. Sargent, Chair

Mina J. Bissell

Aloke Chatterjee

Trudy M. Forte

John T. Lyman

Walter Schimmerling

\section{EQUIPMENT COMMITTEE}

Shìrley N. Ebbbe, Chair

Staphen E. Derenzo

Wiltiven R. Holley

Steven A. Loadon

Marcos F. Maestre

Richard I. Schwarz

Allan W. Longt

\section{SPACE COMMITTEE}

Thomas S. Tenforde, Chair

Priscilla K. Cooper

Kenneth H. Downing

Chestel 1. Mathis

Richard I. Schwarz

Allan W. Long*

\section{SALARY COMMFTTEE}

Paul H. Silvorman, Chair

John C. Bartley

Thomas F. Budinger

Trudy Forte

Cornelius A. Tobias

Igor R. Blaket
DONNER SEMINAR COMMITTEE

Priscilla K. Cooper, Chair

Sheri D. Henderson

Bing Jap

Gordon Parry

HUMAN USE COMMITTEE

Henry H. Stauffer, Chair

J. Michael Collier

Shirley N. Ebobe

Kathleen E. Handron

Mark H. Phillips

Peter E. Valk

Jenice C. DoMoort

RADIOACTIVE DRUG RESEARCH COMMITTEE

Henry H. Stauffor, Chair

Aloke Chatterjee

Patricia W. Durbin

Jacob I. Fabrikant

Paola S. Timiras

Peter E. Valk

Janice C. DoMoort

ANIMAL WELFARE AND RESEARCH COMMITTEE

John C. Bartley, Chair

Hermann Bonasch

Kathleen M. Brennan

Gieole K. Clemons

Janice C. DeMoor

Stove F. Sapontzis

Kent A. Zimmerman

Robert W. Springsteen'

DONNER LIBRARY COMMITTEE

Stanley B. Curtis, Chair

James C. Bartholomew (LCB)

Jacob Bastacky

J. Michael Collier

Junko Hosoda

John C. Owicki

Adrian Rodriguez

Dorothy F. Denney*

Hillis L. Griffin 
SAFETY COMMITTEE

John T. Lyman, Chair Eleanor A Blakely

Kathleen M. Brennan

Deborah A. Farson

Regine Goth-Goldstein
Jacqueline Her

Herbert W. Moise

Robert W. Nordhausen

Patricia Powers-Risius

Robert W. Springsteen

Allan W. Longt 